\title{
Prey preferences of the Persian leopard AND TROPHIC COMPETITION WITH HUMAN HUNTERS IN IRAN
}

\author{
Dissertation \\ for the award of the degree \\ "Doctor of Philosophy" (Ph.D. Division of Mathematics and Natural \\ Sciences) \\ of the Georg-August-Universität Göttingen
}

within the doctoral program: Biodiversity and Ecology

submitted by

M.Sc. \& DIC Arash Ghoddousi

from Tehran (Iran)

Göttingen, 2016 
“Gedruckt bzw. veröffentlicht mit Unterstützung des Deutschen Akademischen Austauschdienstes" 


\section{Thesis Committee}

PD Dr. Matthias Waltert

(Dept. of Animal Ecology | Workgroup on Endangered Species)

Prof. Dr. Michael Mühlenberg

(Dept. of Animal Ecology | Workgroup on Endangered Species)

Prof. Dr. Niko Balkenhol

(Dept. Wildlife Sciences)

\section{Members of the Examination Board}

PD Dr. Matthias Waltert

(Dept. of Animal Ecology | Workgroup on Endangered Species)

Prof. Dr. Michael Mühlenberg

(Dept. of Animal Ecology | Workgroup on Endangered Species)

Prof. Dr. Niko Balkenhol

(Dept. Wildlife Sciences)

Prof. Dr. Erwin Bergmeier

(Dept. of Vegetation and Phytodiversity Analysis)

Prof. Dr. Eckhard W. Heymann

(Dept. Sociobiology/Anthropology)

PD Dr. Sven Bradler

(Dept. of Morphology, Systematic \& Evolution)

Date of the oral examination: 24.08.2016 


\section{Table of contents}

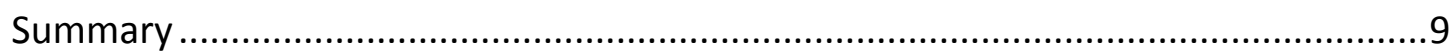

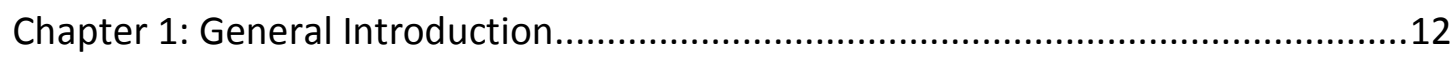

1.1. Poaching as a global threat to biodiversity..........................................13

1.2. Consequences of poaching on large carnivores ......................................14

1.3. Persian leopard as an endangered subspecies .......................................14

1.4. Status of Iranian reserves and wildlife....................................................17

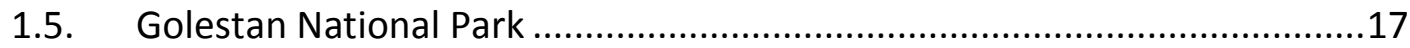

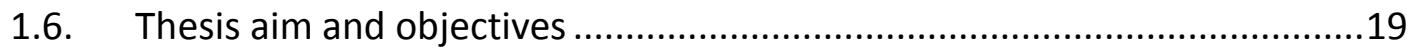

Chapter 2: Re-evaluating models for estimating prey consumption by leopards.......22

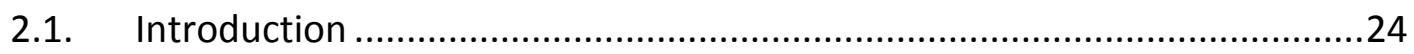

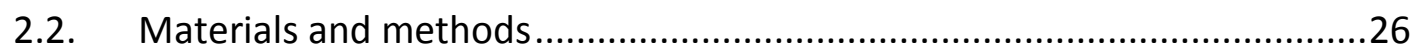

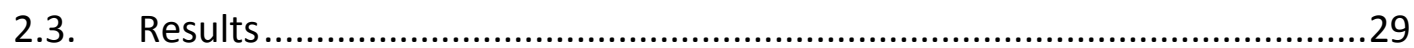

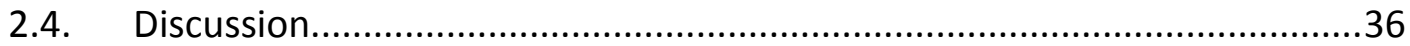

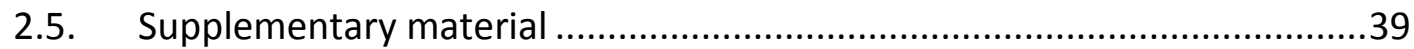

Chapter 3: Effects of ranger stations on predator and prey distribution and

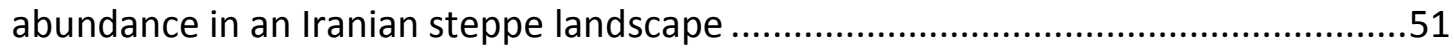

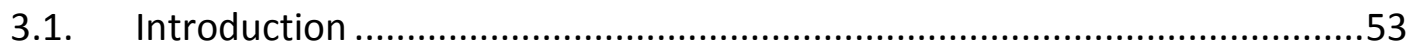

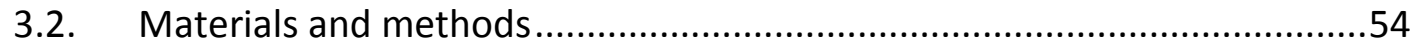

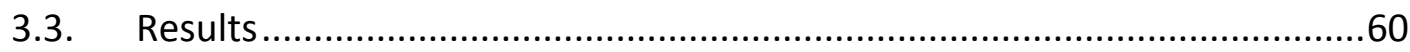

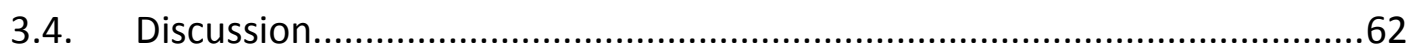

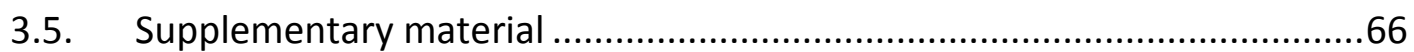


Chapter 4: Precision and reliability of indirect population assessments for the Caspian red deer (Cervus elaphus maral)

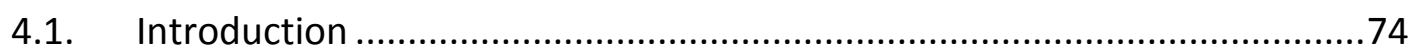

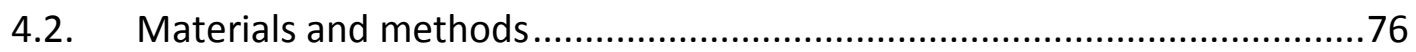

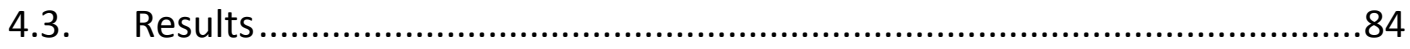

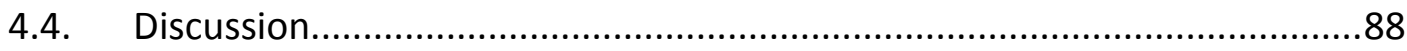

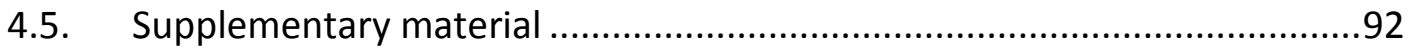

Chapter 5: Decline of ungulate populations calls for urgent actions against poaching

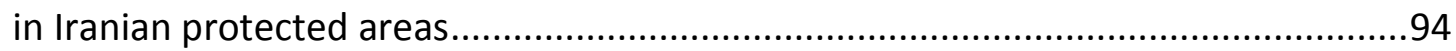

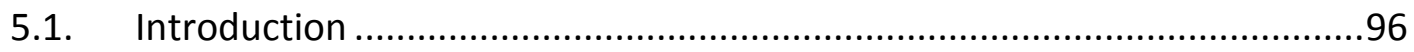

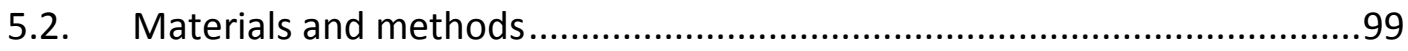

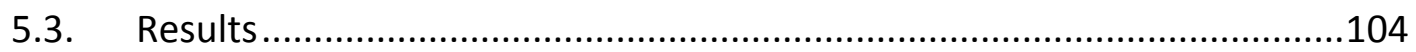

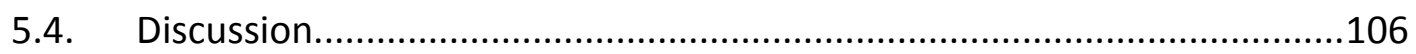

Chapter 6: Assessing the role of livestock in big cat prey choice using spatiotemporal availability patterns

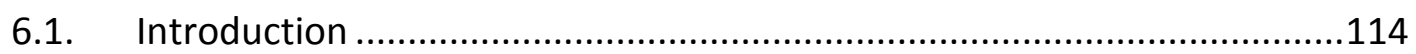

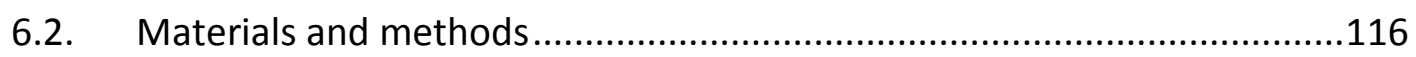

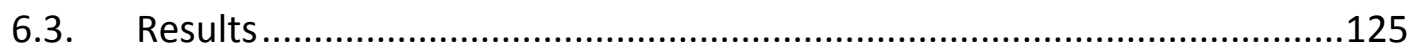

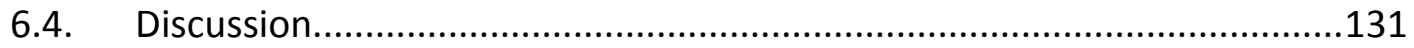

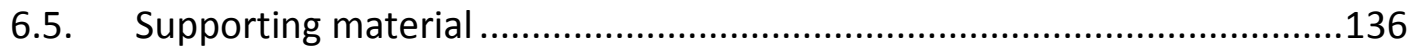

Chapter 7: When pork is not on the menu: assessing trophic competition between

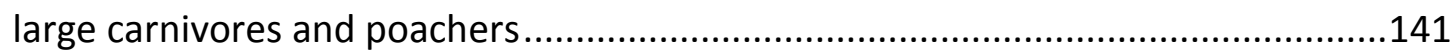

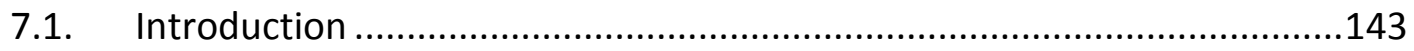


7.3. Results.

7.4. Discussion

Chapter 8: Synthesis

6.6. Objective 1: Development of leopard-specific correction factors and quantification of leopard diet

6.7. Objective 2: Quantification of prey abundance.

6.8. Objective 3: Estimation of prey preferences, dietary niche breadth and dietary competition of Persian leopard and poachers 160

6.9. Overall conclusions 160

Bibliography

Acknowledgements.

Declaration 180 


\section{Summary}

Poaching is a global environmental threat, which drives populations of many species toward extinction. Current levels of poaching are unsustainable, causing substantial impacts on ecosystems and wildlife. By poaching, humans also limit the prey resources of large carnivores. Therefore, human hunters may compete with large carnivores over food resources and threaten their survival. However, the threat to large carnivores from prey depletion has rarely been quantified. In this study, I assessed the trophic competition between the endangered Persian leopard (Panthera pardus saxicolor) and local poachers in Golestan National Park, Iran.

Using data from 36 feeding trials in zoos, I developed novel leopard-specific correction factors (chapter 2 ) for robust estimation of biomass $\left(\mathrm{CF}_{1}\right)$ and number of consumed prey from scat data $\left(\mathrm{CF}_{2}\right)$. I used a new approach in calculation of $\mathrm{CF}_{2}$, limiting the maximum consumption rate to $25 \mathrm{~kg}$ for heavier prey species, which is in accordance with feeding ecology of leopards in the wild. I estimated leopard diet using 77 scat samples from across the park and compared the prey hair remains with available reference collections (chapter 6). Leopard diet consisted of 12 different species, the majority ( $81 \%$ biomass consumed) of which were from wild ungulate species. Wild boar (Sus scrofa) comprised most of the leopard diet (50.2\% biomass consumed) and other important species were bezoar goat (Capra aegagrus) and urial (Ovis vignei). Also, the considerable amount of livestock (sheep, goat and cattle) and dog (17.1\% biomass consumed) included shows existence of an alarming human-leopard conflict in the study area.

I estimated the abundance of four main species hunted by leopard and poachers by line transect sampling (186 km), camera trapping (2777 camera days), doubleobserver point-counts (64 scans) and dung counts (38 km) (chapters 3, 4 and 5). The populations of bezoar goat, red deer (Cervus elaphus) and urial showed a 66-89\% decline in the past decades due to poaching. However, in the absence of poaching pressure due to religious prohibition of pork consumption, the population of wild boar showed an $58 \%$ increase compared to the 1970's estimates. The local poachers' incentives for ungulate poaching (in non-ordinal manner) included 
poverty/subsistence, hunting for meat market/trade, pleasure/love of hunting, tradition/habits, and hunting for revenge/conflict with conservation regulations and bodies (chapter 5). Furthermore, the results of multivariate analyses of urial and leopard distribution (chapter 3) suggested that poaching pressure causes higher concentration of urials around ranger stations where they benefit from higher law enforcement levels.

I compared leopard prey preference with prey offtake by poachers ( 75 poacher seizure records). Persian leopards highly preferred bezoar goat despite its lower abundance. Wild boar and red deer were predated according to their abundance, and urial was avoided by leopards. Moreover, using a novel livestock spatiotemporal availability coefficient, I determined that leopards show high avoidance of small livestock. Local poachers preferred red deer, urial and bezoar goat and strongly avoided wild boar hunting. Interview data from local poachers revealed that the highest stated preference was for hunting urial, followed by red deer and bezoar goat. Both leopard (niche breadth 0.24) and poachers (niche breadth 0.19) showed hunting specialization. Also, both apex predators showed exclusivity (niche overlap 0.31 ) in their dietary/hunting niches, which suggests the lack of exploitative competition.

This pattern likely results from the major role of wild boar in leopard diet and its avoidance by poachers. Considering the general avoidance of Suidae species across the leopard range, depletion of alternative prey species may have resulted in a preyswitching strategy by leopards. In spite of low dietary competition with poachers, limited prey choice may threaten the long-term survival of leopards. In conclusion, conservation should focus on reversing rapidly declining ungulate populations by improving control of current poaching pressure, which affects large carnivores as well. More efficient law enforcement practices and initiatives targeting a combination of economic and non-economic incentives are recommended to avert local people from poaching. 


\section{Chapter 1: General Introduction}

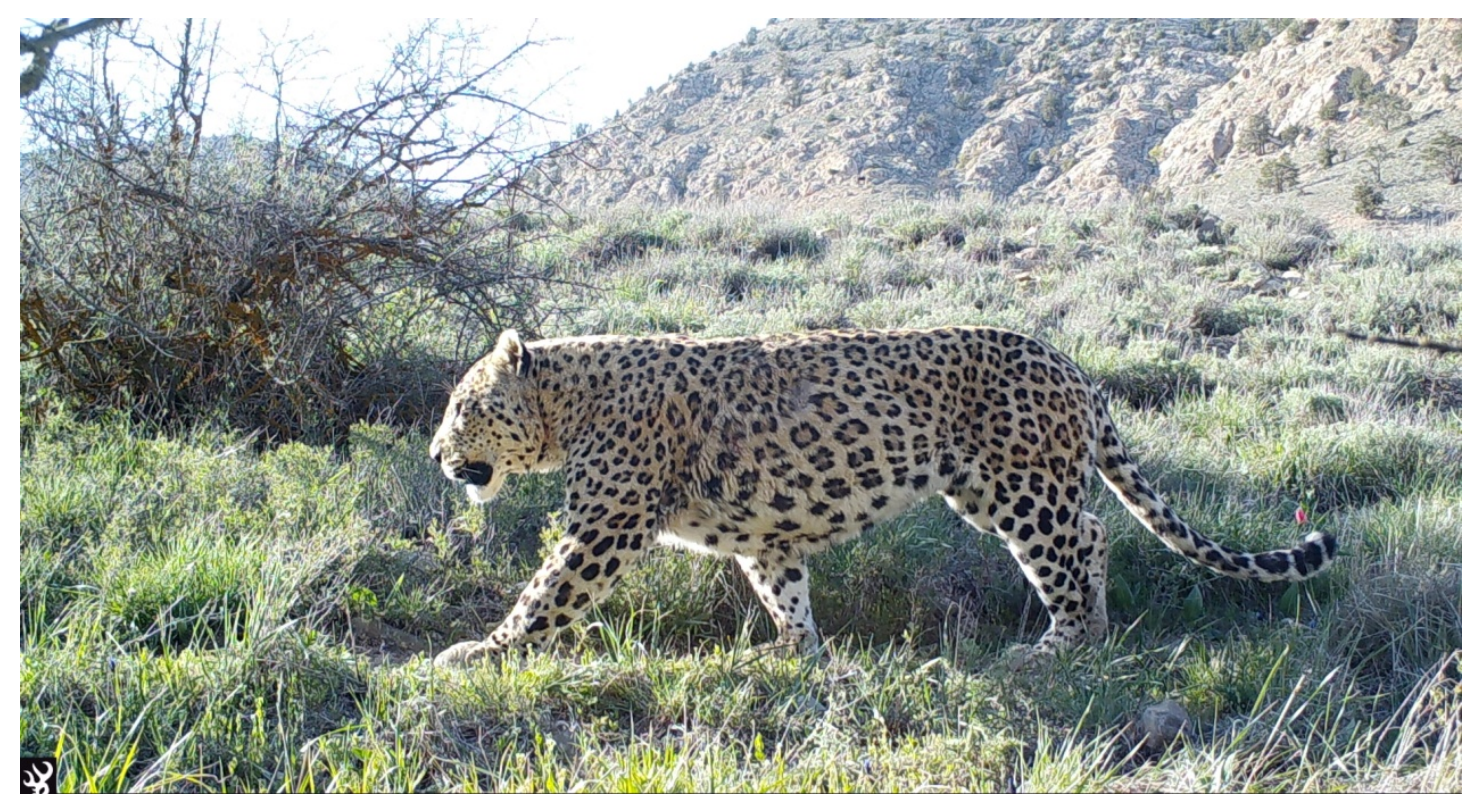

A camera trap photo of Persian leopard in Golestan National Park. Photo:

PWHF/GAUG/Golestan DoE 


\subsection{Poaching as a global threat to biodiversity}

Overexploitation of natural resources is among the most serious environmental challenges threatening biodiversity and ecosystem functioning (Ehrlich \& Pringle 2008; Gavin et al. 2010). For over 6000 years overharvesting has changed species assemblages and continuously caused extinctions around the globe (Lyons et al. 2016). Now, populations of flora and fauna are being eradicated at faster pace due to increasing human population, higher efficiency in exploitation techniques and better access to markets (Sutherland 2000). For example, the global value of environmental crimes has increased by $26 \%$ between 2014 to 2016, having reached an estimated US\$ 91-258 billion (Nellemann et al. 2016). Overexploitation not only affects the viability of natural resources, but also influences ecological interactions and increases threats to the livelihood of people dependent on these resources (Milner-Gulland \& Bennett 2003; Rowcliffe et al. 2003; Darimont et al. 2015).

A key phenomenon in overexploitation of natural resources is poaching, which may occur at variable scales - from subsistence hunting by local communities to generation of income by selling wild meat in markets or as part of international criminal gangs trafficking wildlife or their body parts (Challender \& MacMillan 2014). At subsistence level alone, it is estimated that around 579 million animals are hunted annually in the African Congo basin, in addition to 19 million animals in the Brazilian Amazon region (Fa \& Peres 2001). As a consequence, the wild meat supplies from African forests are expected to reduce by $81 \%$ over the next 50 years (Fa et al. 2003). Unfortunately, protected areas and integrated conservation and development projects (ICDP) across the world have not sufficiently addressed this threat thus far (Watson et al. 2014; Duffy et al. 2016). Current levels of poaching are unsustainable, causing substantial impacts on ecosystems and wildlife, which results in mass extinctions (Darimont et al. 2015). Finding solutions to the poaching problem requires better understanding of the different aspects of this threat and is a key issue in conservation science (Milner-Gulland \& Bennett 2003). It is thus necessary to obtain knowledge on ecological responses of species affected by poaching to enable 
detection of even the most subtle consequences of poaching, which may not have been considered before (Darimont et al. 2015).

\subsection{Consequences of poaching on large carnivores}

Owing to their large space requirements, large carnivores function as structuring agents, biodiversity indicators and act as priority species for conservation due to their charismatic appearance (Sergio et al. 2008; Ripple et al. 2014). Due to their trophic position, large carnivores are restricted to low densities (Ripple et al. 2014) and are sensitive to the density and biomass of their preferred prey (Carbone et al. 2011). By increasing exploitation of wildlife through poaching, humans limit prey resources and affect the survival of large carnivores (Datta et al. 2008; Darimont et al. 2015). Therefore, prey depletion is considered as a key threat to large carnivores worldwide (Ripple et al. 2014) and requires conservation attention (Chapron et al. 2008). However, this threat has been rarely quantified and as yet has attracted little scientific research (Henschel et al. 2011; Darimont et al. 2015; Foster et al. 2016).

As an established pillar in ecological interactions, species compete over food when they share limited resources and therefore, indirectly affect fitness of one another (Sinclair et al. 2006). In such cases, the degree of dietary niche overlap among a guild of species may indicate the levels of competition (Karanth \& Sunquist 2000). When dietary niche overlap between two species increases, they may enter exploitative competition, which results in niche separation or displacement of the disfavored species (Sinclair et al. 2006). Using this concept, the influence of humans as an apex predator on the trophic niche of animal predators can be quantified to assess the threat of prey depletion on these species (Henschel et al. 2011). Such information explains the ecological niche of human and animal predators in a changing world, which is increasingly necessary for 'coexistence' of large carnivores with humans in the future (Chapron \& López-Bao in press).

\subsection{Persian leopard as an endangered subspecies}

Leopard's (Panthera pardus) are one of the most widespread large carnivores in the world, largely owing to their plasticity in habitat and prey choice (Jacobson et al. 
2016). The species has the broadest diet among all big cats with at least 111 prey species recorded (Hayward et al. 2006). Furthermore, it occurs in a diversity of habitats from rainforests to deserts, rugged mountains to savannas, farmlands and even suburban and urban landscapes (Stein et al. 2016). Due to healthy populations of leopard in Sub-Saharan Africa, the species was not considered threatened until recently when it was globally classified as 'Vulnerable' in the IUCN Red List of Threatened Species (Stein et al. 2016). However, the species has a dire status in much of its range out of SubSaharan Africa and is extirpated from around $85 \%$ of its historical range in Asia (Jacobson et al. 2016). Five out of the eight subspecies of leopard, all of which are in Asia, are classified as 'Endangered' or 'Critically Endangered' in the IUCN Red List of Threatened Species (Jacobson et al. 2016). The main threats to the species are anthropogenic, including habitat fragmentation, reduced prey, and conflict with livestock farmers (Stein et al. 2016). Although leopard conservation benefits from extensive scientific studies on habitat fragmentation (Crooks et al. 2011) and humancarnivore conflict (Inskip \& Zimmermann 2009), prey depletion has received little attention so far. Across its entire range, competition between leopard and hunters has only been assessed in Gabon (Henschel et al. 2011), despite being identified as a major driver of leopard range contraction (Jacobson et al. 2016).

The Persian leopard (P. p. saxicolor), which occurs in Southwest Asia, is an 'Endangered' subspecies according to the IUCN Red List of Threatened Species (Khorozyan 2008). It lives mostly in mountains and forested habitats and is known as one of the largest leopards in the world (Fig. 1.1; Kiabi et al. 2002; Khorozyan 2008). The global population is estimated at 871-1290 individuals, of which 550-850 individuals live in Iran (Kiabi et al. 2002; Khorozyan 2008). In recent decades, the Persian leopard has lost $72-84 \%$ of its historical range and is considered extinct in five of its former range countries (Jacobson et al. 2016). Now, over $87 \%$ of its distribution extent is in Iran (Jacobson et al. 2016). Therefore, Iran is known as the stronghold of Persian leopard population worldwide (Khorozyan 2008). 


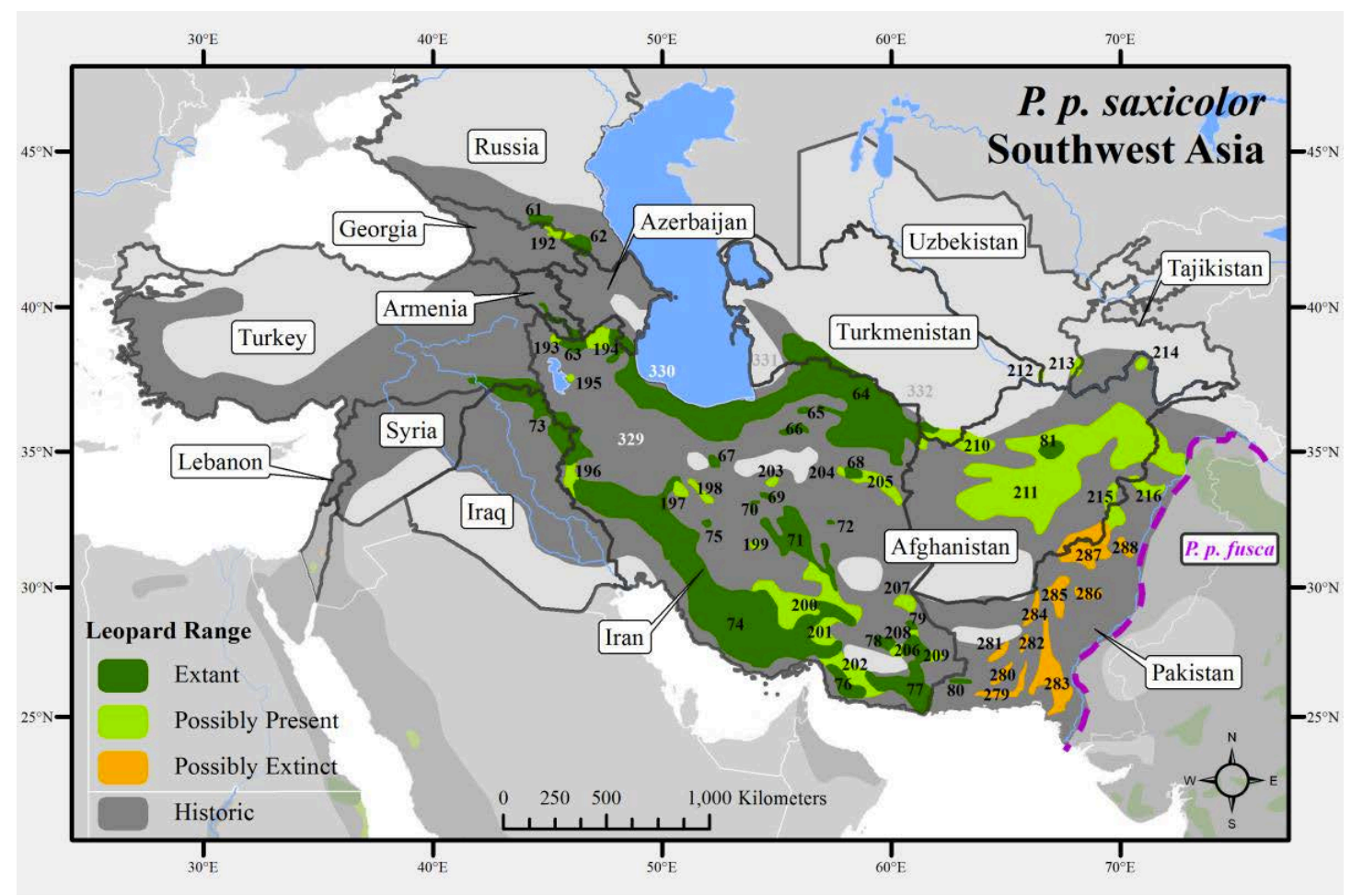

Figure 1.1. Distribution of Persian leopard (Panthera pardus saxicolor) in Southwest Asia (numbers indicate the population patches) (Adopted from Peter Gerngross (2016) Panthera pardus. The IUCN Red List of Threatened Species. Version 2015-4 presented in Jacobson et al. (2016)).

In Iran, leopards are the last remaining member of the Panthera genus after the extinction of Asiatic lion P. leo persica and Caspian tiger P. tigris virgata (Firouz 2005). Leopard is increasingly threatened in Iran due to habitat loss and retaliatory killing as a result of livestock depredation (Kiabi et al. 2002). Despite signs of severe population decline in most ungulate species in Iran due to poaching (Karami et al. 2002; Tatin et al. 2003; Kiabi et al. 2004; Firouz 2005; Shams Esfandabad et al. 2010), the threat of prey depletion has never been considered for Persian leopards. As prey loss may also drive big cats to depredate livestock and therefore, indirectly cause killing of leopards as a consequence, investigation of human-leopard dietary competition is of high priority (Kiabi et al. 2002; Khorozyan et al. 2015a). Therefore, comprehensive understanding of trophic interactions between leopards and human hunters is required for adoption of appropriate conservation measures for the Persian leopard. 


\subsection{Status of Iranian reserves and wildlife}

As a vast country $\left(1,640,000 \mathrm{~km}^{2}\right)$ located in the transition zone between the contrasting Euro-Siberian, Irano-Turanian, Sudanian, and Saharo-Arabian phytogeographical realms, Iran has rich diversity of flora and fauna (Zohary 1973; Firouz 2005). Almost 8000 species of vascular plants and 1674 species of vertebrates are known to exist in Iran (Zehzad et al. 2002; Firouz 2005). However, this country has received little conservation attention in the past decades (Moore 1976; Firouz 2005). Although the network of Iranian protected areas covers around $10 \%$ of the country's landmass, these areas are largely inefficient at tackling overexploitation (Stone 2015). The major constraints toward conservation success in protected areas are lack of trained personnel, equipment and funding, and on-going conflicts with local communities (Kolahi et al. 2012, 2013). The establishment of protected areas in Iran follows a top-down approach and leads to frequent conflicts with local communities (Kaffashi et al. 2012; Valipour et al. 2014; Zendehdel et al. 2010). As a consequence, illegal and unorganized exploitation of natural resources during the past decades has yielded in dramatic consequences for Iran's ecosystems (Stone 2015). Ungulate poaching is one of the most serious conflicts widely observed within Iranian reserves (Tatin et al. 2003; Kiabi et al. 2004; Kolahi et al. 2013). However, due to the lack of robust monitoring methods the severity of this threat and its consequences for large carnivores, such as the critically endangered Asiatic cheetah (Acinonyx jubatus vanaticus) and Persian leopard, is unclear.

\subsection{Golestan National Park}

This study was implemented in Golestan National Park (GNP), located in northeast of Iran. GNP was the first area to be designated as a national park in Iran in 1957. It is uniquely situated in mountainous terrain, spanning from deciduous forest to steppe and arid plains, with mean annual precipitation of 142 and $866 \mathrm{~mm}$ in the east and west, respectively (Fig. 1.2; Akhani 2005). GNP is a UNESCO 'biosphere reserve' comprising an area of $874 \mathrm{~km}^{2}$, which together with its buffer zones holds world's largest protected population of Persian leopard with an estimated 23-42 individuals (Hamidi et al. 2014). 


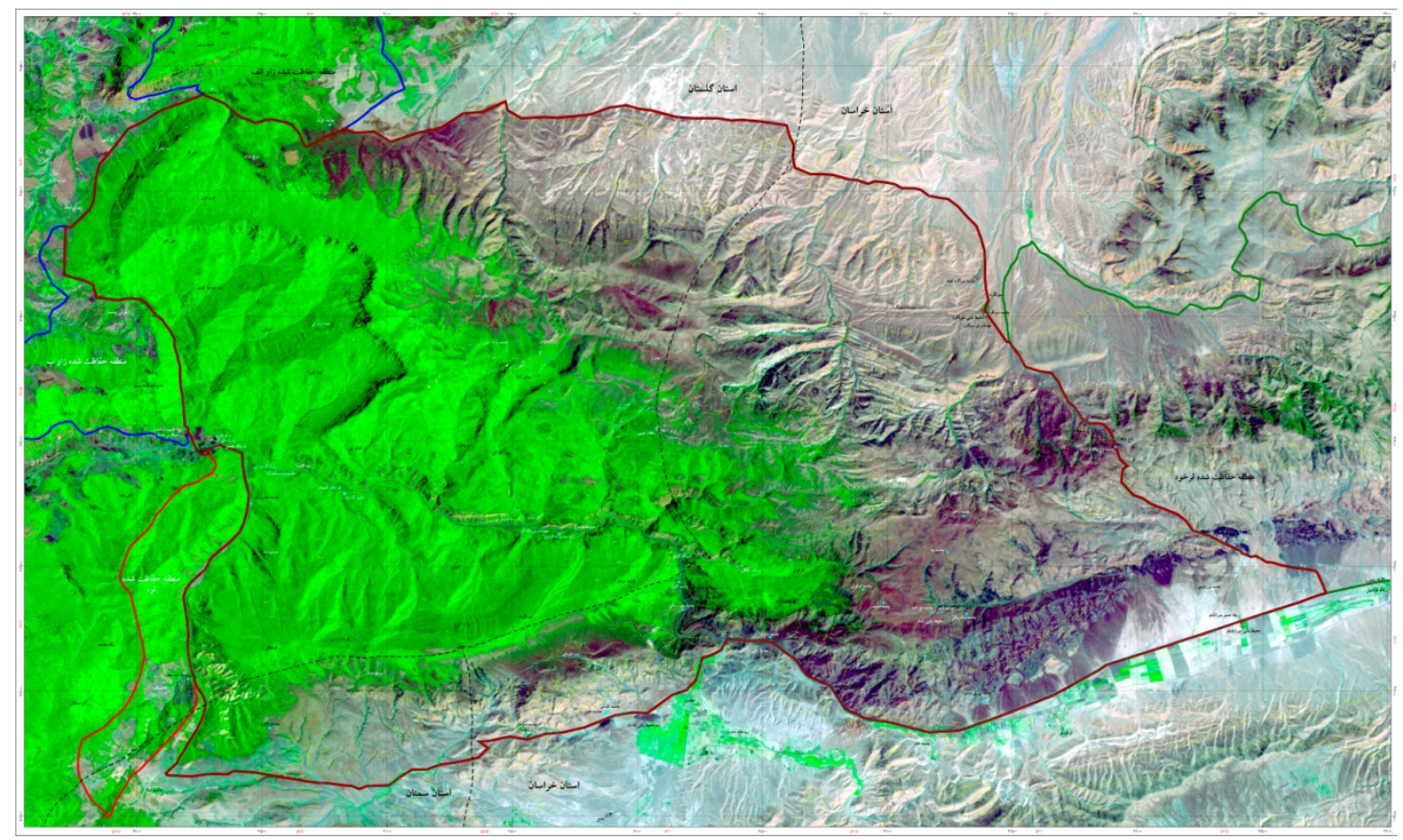

Figure 1.2. Satellite image of Golestan National Park and its surrounding protected areas (courtesy of Iranian Department of Environment).

GNP is famous for its diverse landscapes and vegetation types, resulting in cooccurrence of a range of ungulate species, including the bezoar goat (Capra aegagrus), goitered gazelle (Gazella subgutturosa), red deer (Cervus elaphus), roe deer (Capreolus capreolus), urial (Ovis vignei), and wild boar (Sus scrofa). The sympatric large predators of the park include the brown bear (Ursus arctos), gray wolf (Canis lupus) and striped hyaena (Hyaena hyaena), which seem to be rare and/or have limited dietary overlap with leopard. The Caspian tiger once existed in the park but the last individual of this subspecies was killed in 1958 in GNP (Firouz 2005).

The results of a Persian leopard camera trapping study in GNP, which was conducted prior to this research, signaled an alarming decline in populations of ungulate species (Hamidi et al. 2014). Although road accidents are suggested to be the main threat to leopards in GNP (Kiabi et al. 2002), it can be hypothesized that prey loss may also be important for the survival of Persian leopards in one of its population strongholds. Therefore, I have chosen GNP for this research due to its 
irreplaceability for Persian leopards, long history of conservation and occurrence of diverse ungulate species in combination with the presence of poaching pressure.

\subsection{Thesis aim and objectives}

The overall aim of this study was to analyze the prey preferences of Persian leopards in GNP and to study the dietary competition between the leopards and human hunters. However, the interdisciplinary nature of this research and lack of baseline information made it essential to conduct additional research on leopard-specific biomass models (chapter 2), effects of law enforcement on distribution of exploited species (chapter 3 ) and poachers' incentives (chapter 5). The objectives of this research are as follows:

\section{Development of leopard-specific correction factors and quantification of} leopard diet

Chapter 2: Re-evaluating models for estimating prey consumption by leopards

Chapter 6: Assessing the role of livestock in big cat prey choice using spatiotemporal availability patterns

Due to overestimation of small prey using frequency of occurrences in scat analysis, the use of correction factors (CF) is recommended (Ackerman et al. 1984). In chapter 2, I developed novel leopard-specific CFs for estimation of prey biomass and numbers consumed. However, as our leopard-specific CFs were not published yet, I used existing CFs for tropical big cats (Wachter et al. 2012) in estimation of leopard diet using scat samples in GNP (chapter 6).

\section{Quantification of prey abundance}

Chapter 3: Effects of ranger stations on predator and prey distribution and abundance in an Iranian steppe landscape

Chapter 4: Precision and reliability of indirect population assessments for the Caspian red deer (Cervus elaphus maral)

Chapter 5: Decline of ungulate populations calls for urgent actions against poaching in Iranian protected areas 
Estimation of leopard and poachers' prey/hunting preference requires information on abundance of prey species. Due to the absence of data from robust monitoring methods in GNP, in chapters 3, 4 and 5, I applied a variety of methods (line transects, camera trapping, dung- and point counts) to estimate the populations of bezoar goat, red deer, urial and wild boar. Furthermore, in chapter $3 \mathrm{I}$ assessed the effect of law enforcement on distribution of an exploited species (urial) and leopard. Finally, in chapter 5, I studied poachers' incentives using semi-structured interviews in order to better understand the causes of poaching among local communities.

3. Estimation of prey preferences, dietary niche breadth and dietary competition of Persian leopard and poachers

Chapter 6: Assessing the role of livestock in big cat prey choice using spatiotemporal availability patterns

Chapter 7: When pork is not on the menu: assessing the trophic competition of large carnivores and poachers

To reach the overall aim of this study, in chapter 6 I estimated prey preferences of Persian leopard in GNP by using information from chapters 3 and 5 . Moreover, due to significant contribution of livestock to leopard diet, I used spatiotemporal availability patterns to estimate the role of livestock in leopard prey choice (chapter 6). Also, using leopard prey preference and poachers' seizure records, as well as, results from the interviews, I estimated and compared the dietary niche breadth of leopard and poachers (chapter 7). Finally, I calculated the dietary niche overlap of the two apex predators to quantify the risk of competition between leopard and poachers in GNP (chapter 7). 


\section{Chapter 2: Re-evaluating models for estimating prey consumption by leopards}

Tanja Lumetsberger, Arash Ghoddousi, Angie Appel, Igor Khorozyan, Matthias Waltert, Christian Kiffner

Resubmitted, Journal of Zoology, submission date: $4^{\text {th }}$ October 2015

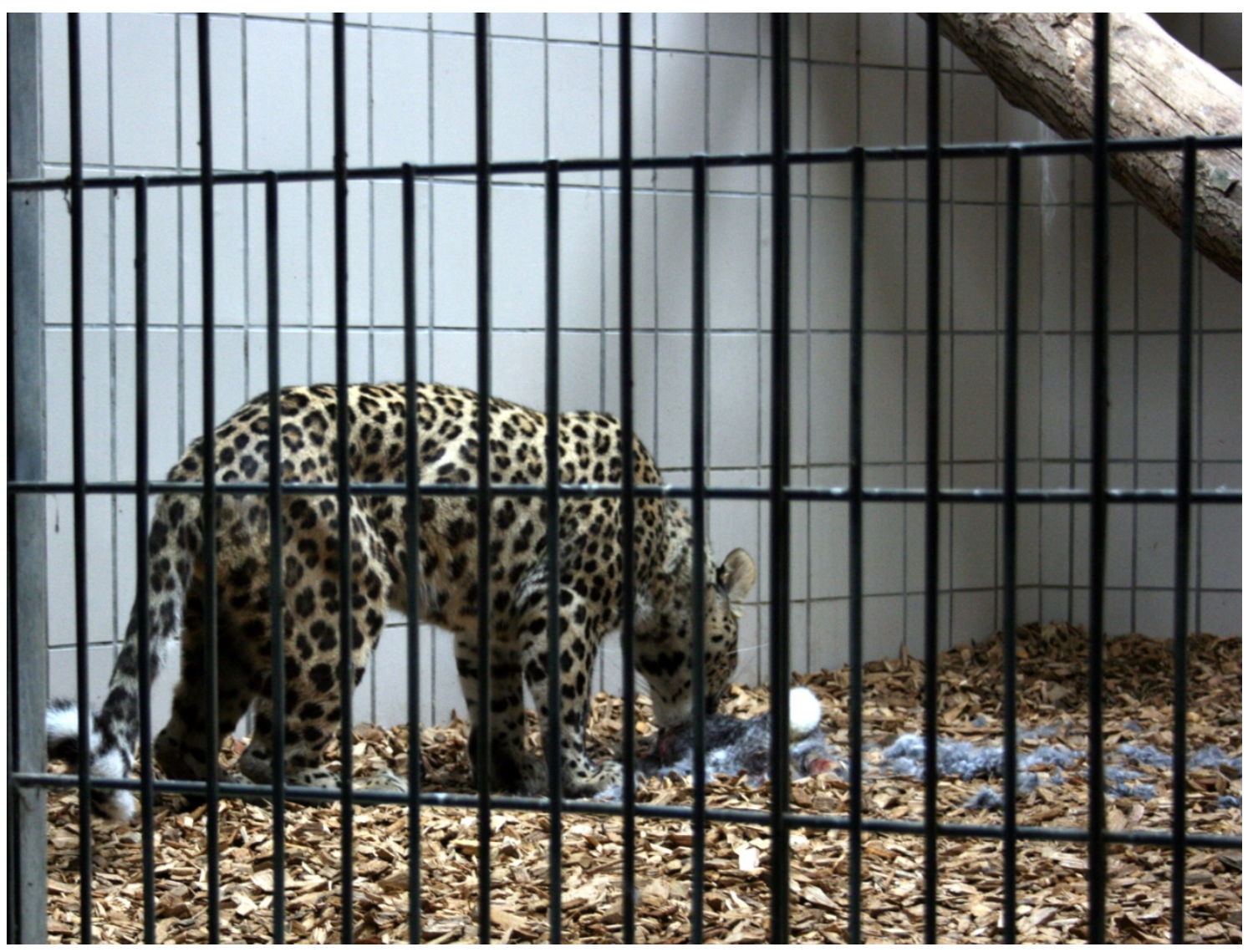

Leopard feeding trial in Allwetter Zoo, Münster, Germany. Photo: A. Ghoddousi 


\begin{abstract}
Biomass regression models and associated correction factors ( $\left.C F^{\prime} s\right)$ derived from feeding trials are essential to convert frequency of prey occurrence from scats into biomass and numbers of prey individuals consumed by carnivores. These dietary analyses form a substantial part of many research projects on predator-prey relationships and human-carnivore conflicts. So far, diet studies of leopard (Panthera pardus) applied the linear biomass model developed for puma (Puma concolor). Recent works, however, suggested that non-linear biomass models are more meaningful for estimating prey biomass and numbers, and presented a generalized model of biomass consumption for all tropical felids. This model accounted for partial consumption of prey, but did not include ecological factors limiting prey consumption by felids. Hence, using 35 feeding trials we developed a leopard specific regression equation by setting a consumption limit for leopard per prey. This new correction factor takes into account inedible proportion of prey and daily food intake rates limiting prey consumption by leopard. Reanalysing prey consumption of leopards from published dietary studies by using our new regression model suggests a significant decrease in estimated numbers of prey individuals consumed. In addition to refining leopard specific biomass models, our study confirmed the non-linear relationship between prey consumption and scat production by large carnivores.
\end{abstract}




\subsection{Introduction}

Assessing the diet of large, terrestrial carnivores is important for ecological research and conservation, but is notoriously difficult given the rarity and cryptic nature of these species (Nilsen et al., 2012). Hence, diet profiles are generated mostly by indirect methods such as identification of undigested prey remains (hair, bones, teeth, hooves and claws) in scats found in the environment (Klare, Kamler \& Macdonald, 2011). Despite the progress in methodologies of prey recognition in scats, reliable estimation of prey biomass from scats remains challenging (Rühe, Ksinsik \& Kiffner, 2008; Klare et al., 2011; Rodgers \& Janečka, 2013).

Although still frequently used in practice, simple frequency of prey occurrence $(F O)$ in scats introduces a considerable bias in prey proportions by over-representing small prey species and underestimating large prey in the diet (Floyd, Mech \& Jordan, 1978; Ackerman, Lindzey \& Hemker, 1984; Klare et al., 2011). This is because (1) the surface-to-volume ratio is inversely related to prey body mass and (2) small prey is often consumed completely while only parts of large-bodied species are ingested by carnivores (Floyd et al., 1978; Wachter et al., 2012). Hence, fur and other indigestible matter is disproportionally represented in ingested smaller prey, leading to larger number of scats when feeding on small vs. large prey species (Floyd et al., 1978; Ackerman et al., 1984; Jethva \& Jhala, 2004). To overcome this bias in estimating the biomass and individuals of consumed prey from scats, several methods are proposed and have been extensively reviewed by Rühe et al. (2008) and Klare et al. (2011). They are usually based on data from feeding trials in which carnivores consume prey species of different body masses and the produced scats are subsequently quantified. Two different approaches can then be used to estimate prey biomass from scats:

(1) Dry mass of indigestible matter is related to fresh matter of the prey individual. This generates a single conversion factor for a given prey species or size class (Webbon et al., 2006; Rühe et al., 2008) or a linear function that can be used to convert dry mass of indigestible scat remainders to prey body mass (Rühe, Burmester \& Ksinsik, 2007).

(2) Prey biomass consumed per excreted scat is related to prey body mass as expressed by linear or non-linear regressions equations, which are known as biomass models or correction factors (CF's; Wachter et al., 2012). 
Biomass models were first developed for wolf (Canis lupus; Floyd et al., 1978) and subsequently for several felid species, e.g. puma (Puma concolor; Ackerman et al., 1984) and cheetah (Acinonyx jubatus; Marker et al., 2003; Wachter et al., 2012), with the equation of Ackerman et al. (1984) still being the most widely applied in felid diet studies (e.g. Selvan et al., 2013; Lyngdoh et al., 2014; Santos et al., 2014; HernándezSaintMartín et al., 2015).

As leopard (Panthera pardus) is known for its diverse mammalian diet, biomass models are preferred over conversion factors because they can deal with the full range of prey species and are less laborious (Ciucci, Tosoni \& Boitani, 2004; Hayward et al., 2006; Klare et al., 2011; Shehzad et al., 2012). Yet, several issues arise when applying these models. The first issue concerns the shape of the biomass model. Previous models assumed a linear relationship between prey biomass consumed per excreted scat $(y)$ and prey body mass (x) (Floyd et al., 1978; Ackerman et al., 1984). However, Wachter et al. (2012) suggested that this relationship should reach an asymptote due to physiological considerations, and indeed, their presented biomass models for cheetah were non-linear. A recent publication validated this non-linear relationship for biomass consumption and introduced a generalized model to calculate biomass consumption for all tropical felids based on feeding trials with lion (Panthera leo), leopard, jungle cat (Felis chaus) and domestic cat (F. catus) (Chakrabarti et al., 2016). The second issue concerns the estimation of numbers of prey individuals consumed. Previous approaches assumed the complete consumption of prey body by simply dividing the biomass consumed $(D)$ by the average prey body mass $(x)$ to obtain the numbers of prey individuals consumed (E) (Floyd et al., 1978; Ackerman et al., 1984; Marker et al., 2003). Yet, carnivores often do not consume a carcass completely for various reasons (Vucetich, Vucetich \& Peterson, 2012). For example, the mean carcass utilisation by cheetah and Eurasian lynx (Lynx lynx) during feeding trials was $69.7 \%$ and 78.0\% respectively, and the portions of inedible matter typically depend on prey body mass (Stander et al., 1997; Marker et al., 2003; Rühe et al., 2007). Therefore, Wachter et al. (2012) developed two CF's, which account for these two biases: correction factor $1\left(C F 1_{w}\right)$ to determine the consumed prey biomass and correction factor 2 (CF2 $\left.w\right)$ to express the number of prey individuals consumed. Though this new approach (CF2 $w$, estimating prey numbers consumed) accounts for partial consumption of prey, duration of single feeding trials does not span the entire time free-ranging leopards 
spend on their kills. The leopard is known to prey for up to five days upon a carcass (Sunquist \& Sunquist, 2009) and was observed to consume on average $4.7 \pm 0.3 \mathrm{~kg}$ of meat per day (Odden \& Wegge, 2009).

So far, studies of leopard diet applied the linear regression equation developed by Ackerman et al. (1984) in spite of novel models by Wachter et al. (2012) and Chakrabarti et al. (2016) (Selvan et al., 2013; Taghdisi et al., 2013; Farhadinia, Moqanaki \& Hosseini-Zavarei, 2014; Sidhu, Raman \& Mudappa, 2015). However, applying potentially inaccurate methods to estimating prey consumption by leopards might be particularly problematic when assessing the extent of human-leopard conflict, e.g. when quantifying livestock depredation rate or the extent of prey overlap with human hunters (Kissui, 2008; Henschel et al., 2011; Shehzad et al., 2014; Athreya et al., 2016). Hence, accurate estimation of prey individuals consumed by leopards is a priority topic for conservation, which could help mitigating drivers of conflict, e.g. by restoring depleted wild prey base and planning reintroduction projects for sympatric carnivores (Hayward et al., 2006; Inskip \& Zimmermann, 2009; Mondal et al., 2012; Kabir et al., 2014). Apart from this, accurate estimates help evaluating the impact of leopards on prey species of conservation concern (Farhadinia et al., 2014).

In this study, we (1) develop leopard specific biomass models from feeding trials to improve the existing biomass models for obtaining more realistic estimates of prey biomass and numbers consumed and (2) apply these models to selected published leopard diet studies in order to reassess and compare these estimates.

\subsection{Materials and methods}

\section{Feeding trials}

We conducted 22 feeding trials with 23 captive leopards between 2012 and 2016 in nine zoos in Germany, Switzerland and Iran (Tables S2.1 \& S2.2). The prey species ranged from $0.87 \mathrm{~kg}$ (rabbit Oryctolagus cuniculus) to $69.45 \mathrm{~kg}$ (domestic sheep Ovis aries) (Table S2.2). All feeding experiments were carried out by zoo personnel following the same protocol and setup of previous studies (Ackerman et al., 1984; Wachter et al., 2012). Prior to feeding, leopards were fasted for at least 48 hours until 
no more scats from previous feedings were produced and all scats from the enclosure were removed. During each feeding experiment, a leopard was provided with one or more intact prey items of the same species of known body mass. If the leopard did not feed on the prey after some time, the abdominal cavity of the prey was opened. In one trial, the prey head was removed for safety reasons. The zoos provided all prey specimens and the feeding events were part of their usual feeding programme. Because of the dependence of scat production on prey body mass, food items were selected to cover the whole prey range of the leopard (Ackerman et al., 1984). Large prey items were left in the enclosure for up to two days. In one case, the prey was left for 65 hours. Small prey items were removed earlier if the leopard showed no signs of feeding behaviour for at least two hours. All prey remains were collected after the end of the feeding, weighed and compared with the initial prey body mass to assess carcass utilisation. After fasting for another 48 hours, all scats produced in the enclosure during the feeding event were collected, counted and weighed individually. The time frame of 48 hours used for fasting and scat collection was based upon the observations by Bothma \& le Riche (1994) and was similar to other studies (Floyd et al., 1978; Ackerman et al., 1984). To increase our sample size, we added 14 feeding trials with leopards from Chakrabarti et al. (2016), which followed the same procedure as Ackerman et al. (1984) and Wachter et al. (2012). The prey species ranged from $1.7 \mathrm{~kg}$ (chicken Gallus sp.) to $151 \mathrm{~kg}$ (water buffalo Bubalus bubalis) (Chakrabarti et al., 2016).

\section{Data analysis}

We obtained the leopard specific correction factors - CF $1_{\text {leopard }}$ to estimate biomass and CF $2_{\text {leopard }}$ to estimate number of individuals consumed - following the method specified by Wachter et al. (2012).

To obtain CF2 $2_{\text {leopard, }}$ we amended Wachter et al.'s (2012) method by extrapolating the excreted scats per leopard and prey (Q4) from the actual consumption of a carcass $(C U)$ in relation to the maximum possible carcass utilisation $\left(S_{i}\right)$ based on field observations and defined as $100 \%$ consumption of prey $<5 \mathrm{~kg}, 95 \%$ of $5-25 \mathrm{~kg}$ prey and $70 \%$ of prey $>25 \mathrm{~kg}$ (Stander et al., 1997). However, as complete consumption of large prey seems unrealistic we added another consumption limit to our CF $2_{\text {leopard }}$ model. Based on average maximum daily food intake of $5 \mathrm{~kg}$ (Odden \& Wegge, 2009) and a maximum of five days spent per kill (Sunquist \& Sunquist, 2009), we set the maximum 
consumption limit to $25 \mathrm{~kg}$ ( $5 \mathrm{~kg}$ per day by five days) of meat per prey larger than $35.7 \mathrm{~kg}(70 \%=25 \mathrm{~kg})$. Hence, for each feeding trial we used the consumption limits mentioned above to predict the amount of scats produced under natural conditions $\left(Q 4_{\text {new }}\right)$. Finally, to test the modified $C F 2_{\text {leopard }}$ method with the previous approach, we also developed a CF2 leopard-w model for leopard strictly following Wachter et al.'s (2012) CF2 w method.

All analyses were carried out in R statistical software (R Development Core Team, 2012). The regression analyses were done using the package "nlme" (Pinheiro et al., 2012) with the function 'nls' (nonlinear least squares) for fitting the linear and nonlinear regression models to data (Tables S2.2 \& S2.3). The final model was chosen based on a combination of the best values of Akaike Information Criterion (Burnham \& Anderson, 2002), residual sum of squares (RSS) and $\mathrm{R}^{2}$ (Table S4).

\section{Recalculation of dietary studies}

From a literature search in the Web of Science by Thomson Reuters, we retrieved all published articles that applied the CF's of Ackerman et al. (1984) or Wachter et al. (2012) to leopard scat data. Because Chakrabarti et al.'s (2016) generalized biomass model for tropical felids was published only recently, no study had applied their correction factor to date. We excluded all studies lacking prey body mass $(x)$ and frequency of prey occurrence in scats $(F O)$. This selection resulted in eight peerreviewed articles - seven applying Ackerman's convention method $\left(C F_{A}\right)$ and one applying Wachter's non-linear models for tropical felids (CF1 ${ }_{W \text {-trop }}$ and CF $2_{W \text {-trop }}$ ) - for which we recalculated biomass $D$ and number of prey individuals $E$ consumed (Khorozyan \& Malkhasyan, 2002; Henschel, Abernethy \& White, 2005; Andheria, Karanth \& Kumar, 2007; Ramesh et al., 2009; Wang \& Macdonald, 2009; Taghdisi et al., 2013; Sidhu et al., 2015; Ghoddousi et al., 2016b). Out of these, only two studies presented the absolute values of $D(\mathrm{~kg})$ and $E(n)$ (Khorozyan \& Malkhasyan, 2002; Ghoddousi et al., 2016b). Based on data from these eight studies, we compared prey numbers estimated using $C F_{A}$ or $C F 1_{W \text {-trop }}$ and $C F 2_{W \text {-trop }}$ vs. our $C F 1_{\text {leopard }}$ and $C F 2_{\text {leopard }}$ models. Furthermore, we compared $C F 2_{\text {leopard }}$ to $C F 2_{\text {leopard-w }}$ by recalculating the same case studies. 
As the regression equations ( $C F 1_{\text {leopard }}, C F 2_{\text {leopard, }} C F 2_{\text {leopard-W }}$ ) were solved for each prey species $(i)$, we estimated the biomass $\left(D_{i}=n_{i}{ }^{*} C F 1_{i}\right)$ and the numbers $\left(E_{i}=\right.$ $n_{i} / C F 2_{i}$ ) of prey consumed, where $n_{i}$ is the number of scats containing the $i$-th prey species. Prey body mass was taken from the corresponding studies. Wilcoxon signedrank test was run to test for differences between the new and published estimates of $D$ and $E$.

\subsection{Results}

\section{Feeding trials}

Each leopard consumed on average ( \pm standard error $S E) 5.02 \pm 0.78 \mathrm{~kg}$ ( $N=21$ trials) and in total 87 scats were collected. With the inclusion of 14 leopard feeding trials from India (Chakrabarti et al., 2016) ( $N=35$ trials), $28.57 \%$ ( $N=10$ trials) of prey used in trials fell within the preferred prey mass range of $10-40 \mathrm{~kg}$ by leopards and $88.57 \%$ ( $N=31$ trials) fell within the accessible (preferred and killed relative to abundance) prey mass range of 1-45 kg (Clements et al., 2014).

\section{Leopard-specific correction factors}

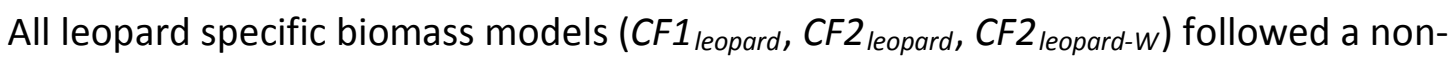
linear pattern. The relationship between prey mass and biomass consumed per scat produced ( $C F 1_{\text {leopard }}$ ) was best described by the Michaelis-Menten model (Fig. 2.1; Table S2.4). In CF1 leopard $=2.242 x /(4.976+x)\left(S E: \mathrm{a}=0.227, \mathrm{~b}=1.701 ; R^{2}=0.54 ; p<\right.$ 0.001), the consumed prey biomass per excreted scat reached a plateau at about $65 \mathrm{~kg}$ of prey body mass with ca. $2 \mathrm{~kg}$ of prey consumed per scat. The relationship between prey mass and number of scats produced per prey individual consumed (CF $2_{\text {leopard }}$ ) was best described by a 3-parameter asymptotic exponential function (Fig. 2.2; Table S2.5). In CF $2_{\text {leopard }}=13.004-11.601 \exp ^{-0.078 x}\left(S E: \mathrm{a}=1.195, \mathrm{~b}=1.417, \mathrm{c}=0.024 ; R^{2}=0.68 ; p<\right.$ 0.001 ) a plateau was reached at about $50 \mathrm{~kg}$ of prey body mass with 12-13 scats excreted. CF $2_{\text {leopard-w }}$ was also best represented by a 3-parameter asymptotic exponential function $C F 2_{\text {leopard- } w}=8.912-6.792 \exp ^{-0.049 x}(S E: \mathrm{a}=1.369, \mathrm{~b}=1.400, \mathrm{c}=$ 0.026; $R^{2}=0.46 ; p<0.001$ ) (Fig. 2.3; Table S2.5). The relationship between the leopard specific CF1 leopard and CF $2_{\text {leopard }}$ to other biomass models is shown in Figs. 2.4-5, 
respectively. The relationship between $C F 2_{\text {leopard }}$ and the conventional $C F 2_{\text {leopard- } W}$ is presented in Fig. 2.6.

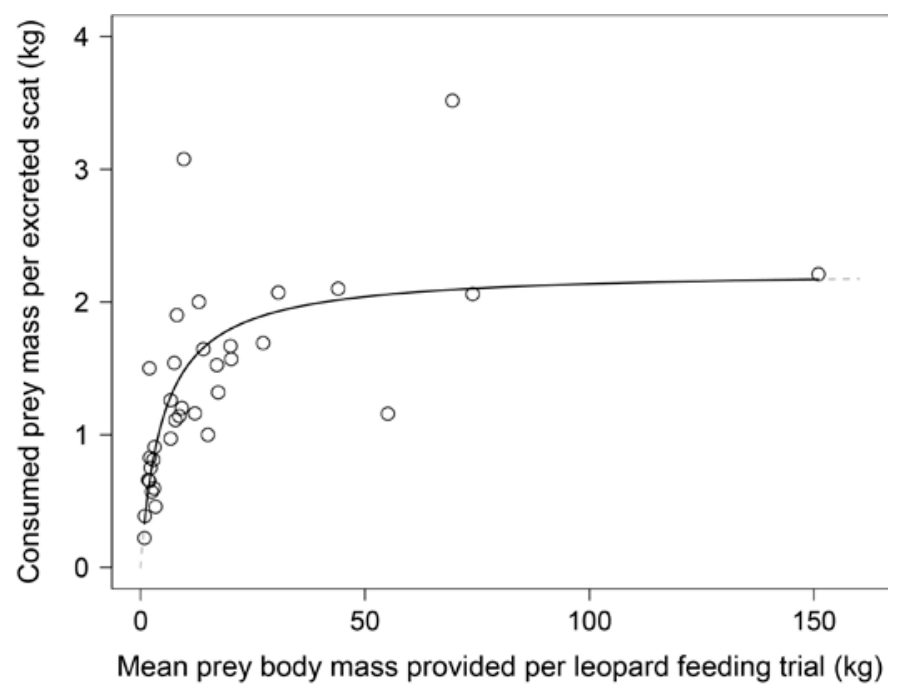

Figure 2.1. Leopard-specific biomass regression model showing the relationship between the prey biomass consumed per excreted scat (Q5) and the mean prey body mass $(x)$ best described by a Michaelis-Menten function $C F 1_{\text {leopard }}=2.242 x /(4.976+x)$.

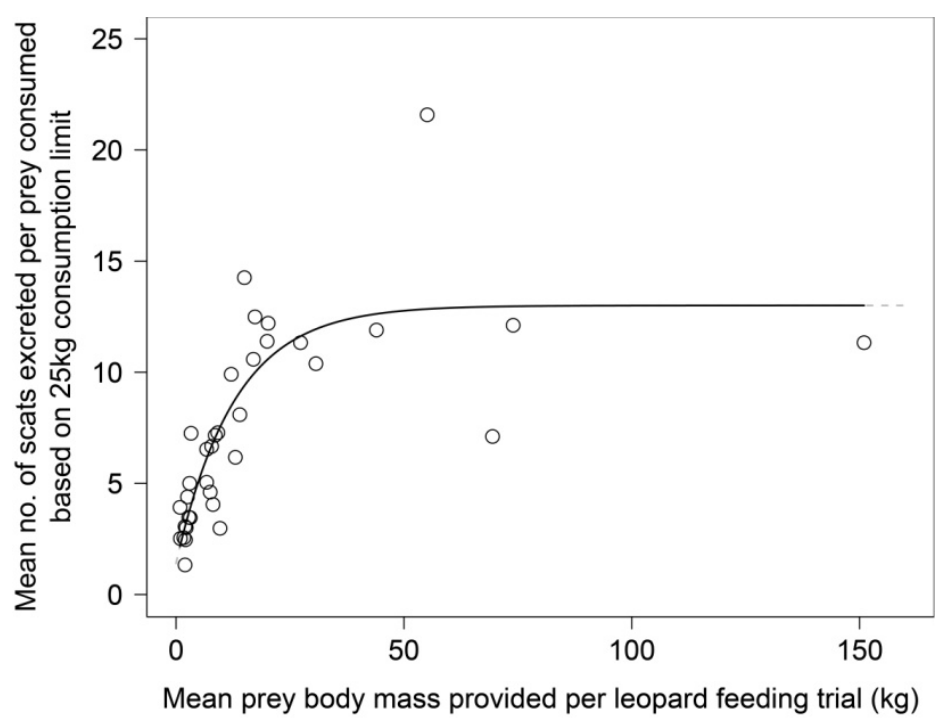

Figure 2.2. Leopard-specific biomass regression model showing the relationship between the mean number of collectable scats excreted per prey consumed (Q4) and the mean prey body mass $(x)$, based on edible carcass proportions (Stander et al. 1997) and a consumption limit of $25 \mathrm{~kg}$ of meat for prey larger than $35.7 \mathrm{~kg}$, best described by a 3-parameter asymptotic exponential function CF2 $2_{\text {leopard }}=13.004-11.601 \mathrm{exp}^{-0.078 x}$. 


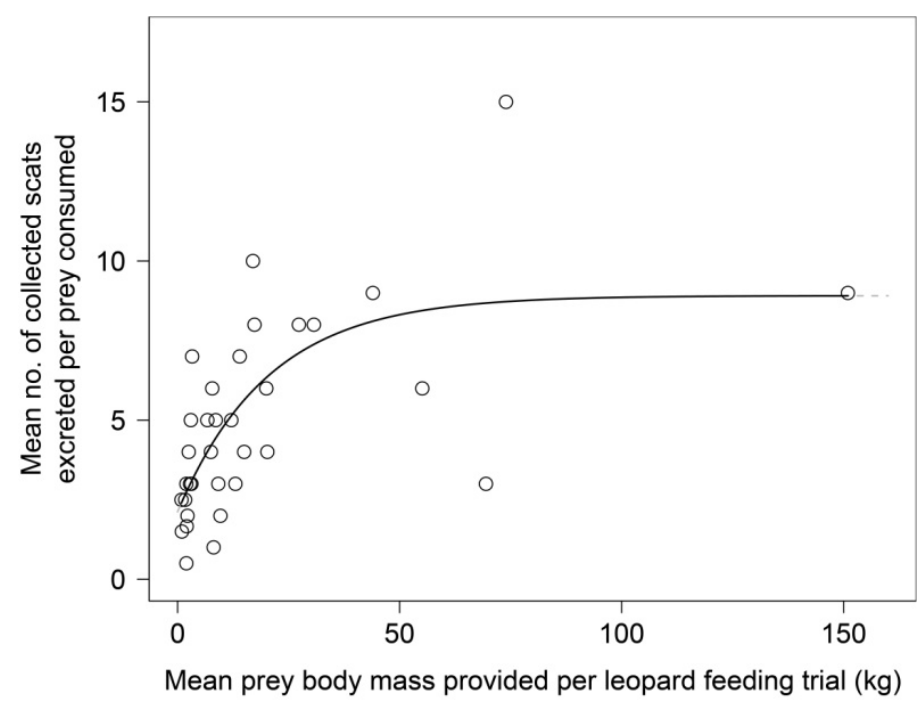

Figure 2.3. Leopard-specific biomass regression model showing the relationship between the mean number of collected scats excreted per prey consumed (Q4) and the mean prey body mass $(x)$, following Wachter et al.'s (2012) proposed method, best described by a 3-parameter asymptotic exponential function CF2 $2_{\text {leopard- } w}=8.912$ $6.792 \exp ^{-0.049 x}$.

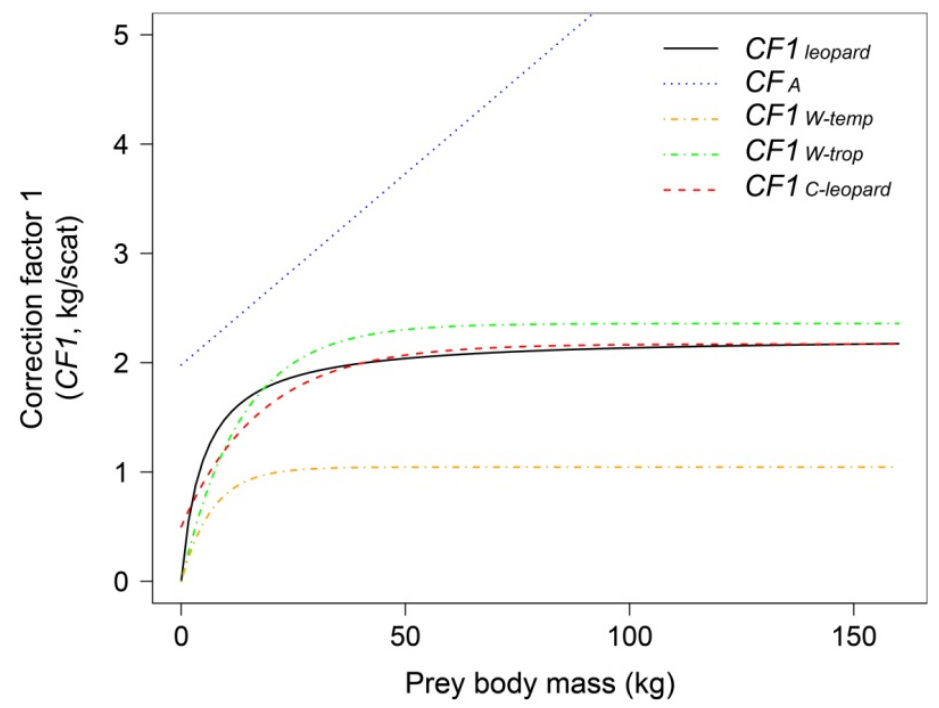

Figure 2.4. Comparison of different biomass regression models used in scat analyses of felids. The relationship between $C F 1_{\text {leopard }}$ (leopard), $C F_{A}$ (puma; Ackerman et al., 1984), CF $1_{W \text {-trop }}$ (cheetah and tropical felids), CF1 ${ }_{W \text {-temp }}$ (lynx and temperate felids; Wachter et al., 2012), and CF1 C-leopard (Indian leopards; Chakrabarti et al., 2016) to estimate prey biomass consumed by carnivores. 


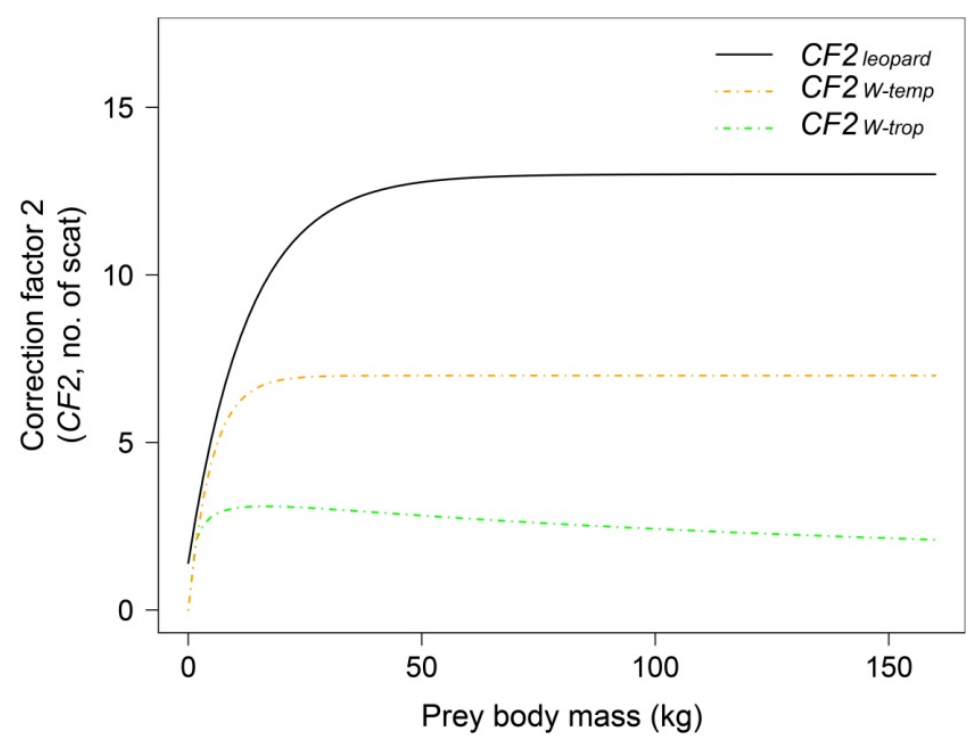

Figure 2.5. Comparison of different biomass regression models used in scat analyses of felids. The relationship between $C F 2_{\text {leopard }}$ (leopard), CF2 ${ }_{W \text {-trop }}$ (cheetah and tropical

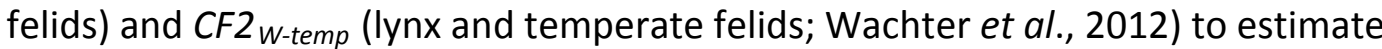
number of prey individuals consumed by carnivores.

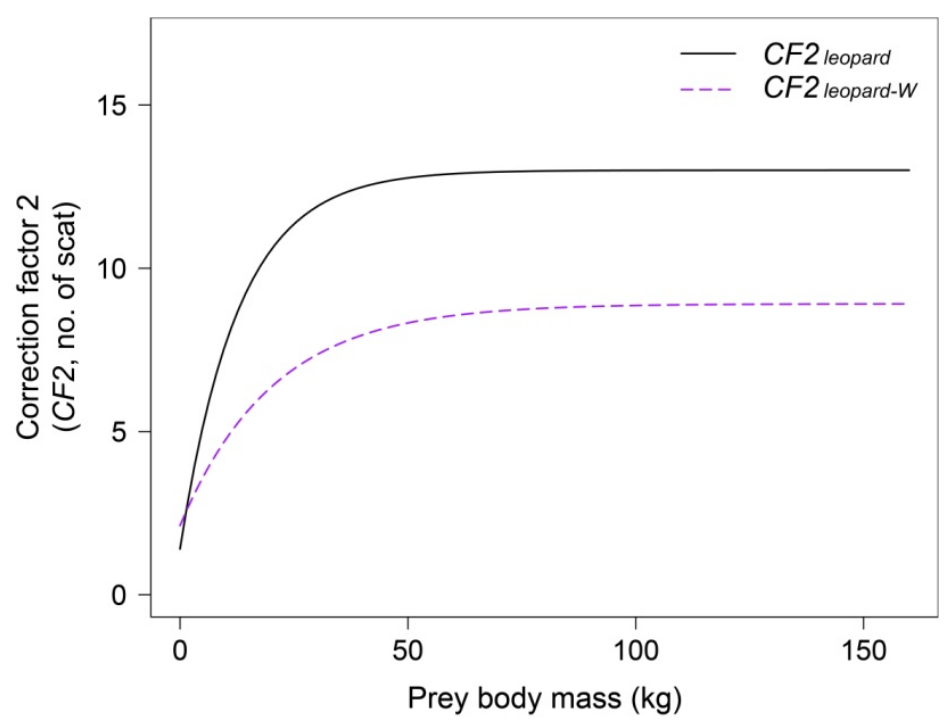

Figure 2.6. Comparison of different biomass regression models used in scat analyses of felids. The relationship between the modified $C F 2_{\text {leopard }}$ and the conventional $C F 2_{\text {leopard- }}$ w following Wachter et al.'s (2012) method to estimate prey individuals consumed by leopards. 


\section{Recalculations of leopard diet}

Recalculation of biomass consumption from the eight selected studies with the leopard specific $C F 1_{\text {leopard }}$ resulted in no significant change in estimates of relative biomass consumed $D(\%)$ compared to $C F_{A}\left(Z=-1.368, p>0.05\right.$; Fig. 2.7a-g) and $C F 1_{W \text {-trop }}(Z=-$ $0.1529, p>0.05$; Fig. 2.7h), and no change in estimates of absolute prey biomass consumed $D(\mathrm{~kg})$ compared to $C F 1_{W \text {-trop }}(Z=-1.6818, p>0.05$; Fig. 2.8h). Relative prey numbers consumed $E$ (\%) obtained by the modified CF $2_{\text {leopard }}$ changed significantly in either direction compared to the $C F_{A}$ estimates $(Z=-2.383, p<0.05 ;$ Fig. 2.7a-g). No significant changes were observed in $E$ (\%) between CF2 leopard and CF2 ${ }_{W \text {-trop }}$ (Z = $0.3568, p>0.05$; Fig. 2.7h). However, absolute prey numbers consumed $E(n)$ were significantly lower when applying $C F 2_{\text {leopard }}$ compared to $C F 2_{W \text {-trop }}(Z=-2.8031, p<$ 0.01 ; Fig. 2.8b). Absolute estimates of prey biomass and numbers of prey individuals consumed were not compared with Khorozyan \& Malkhasyan (2002) due to small sample size $(N=6)$ but Fig. 2.8a shows a decrease in estimates of both $D(\mathrm{~kg})$ and $E(n)$ by using $C F 1_{\text {leopard }}$ and $C F 2_{\text {leopard }}$ compared to $C F_{A}$, respectively.

A comparison of our non-linear modified $C F 2_{\text {leopard }}$ with non-linear $C F 2_{\text {leopard-W }}$ resulted in significant smaller numbers of prey individuals consumed $E(n)(Z=-7.2744$, $p<0.001)$, but had no significant changes in relative prey numbers consumed $E(\%)(Z$ $=-0.1444, p<0.05)$ (Table S2.6a-h). 
(a) Khorozyan \& Malkhasyan (2002) - Armenia
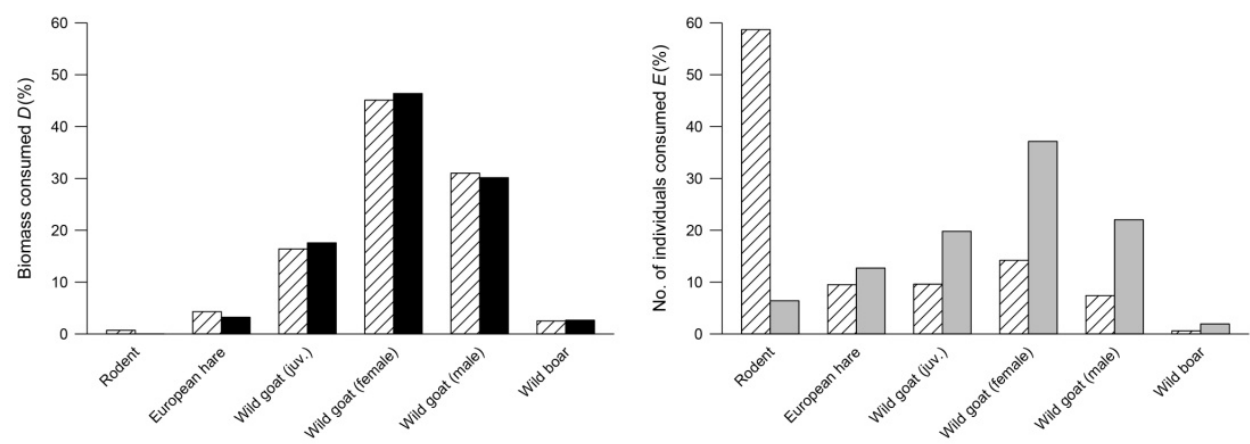

(b) Henschel et al. (2005) - Gabon
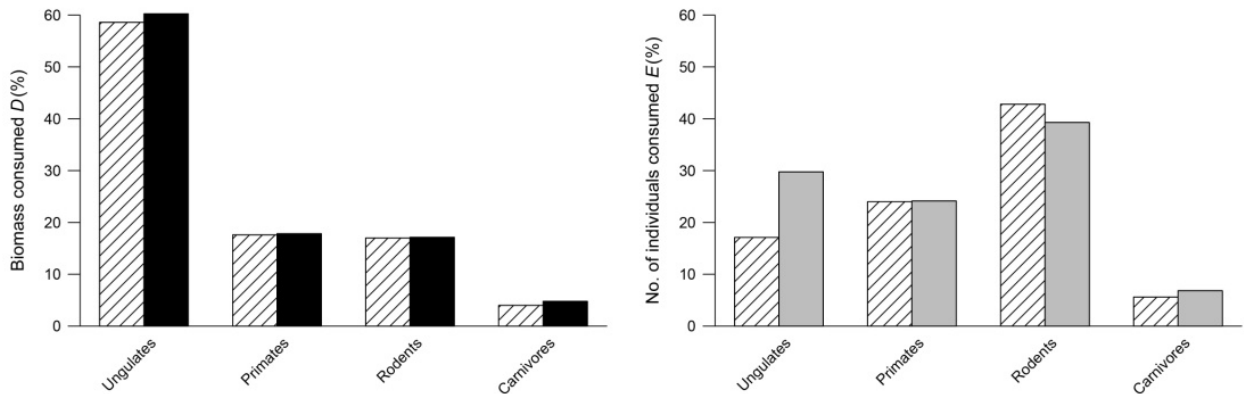

(c) Andheria et al. (2007) - India
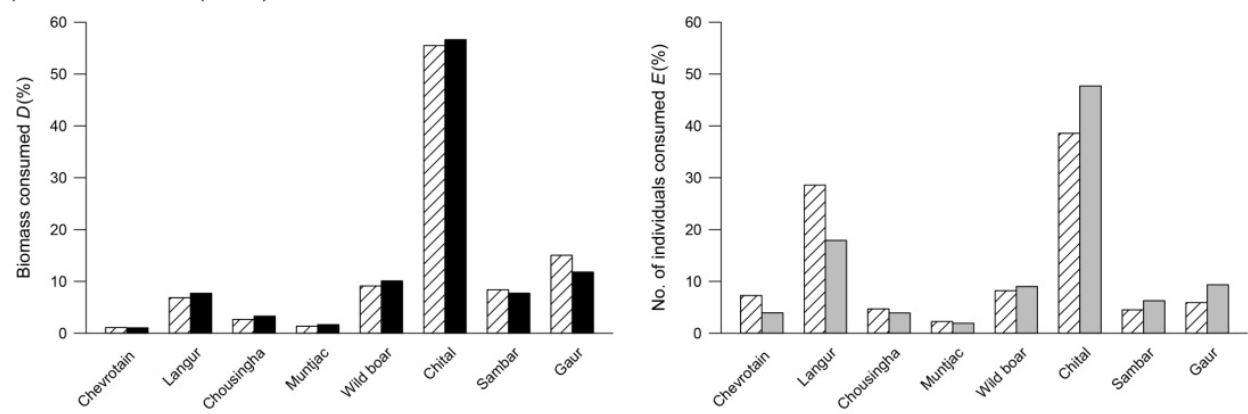

(d) Ramesh et al. (2009) - India
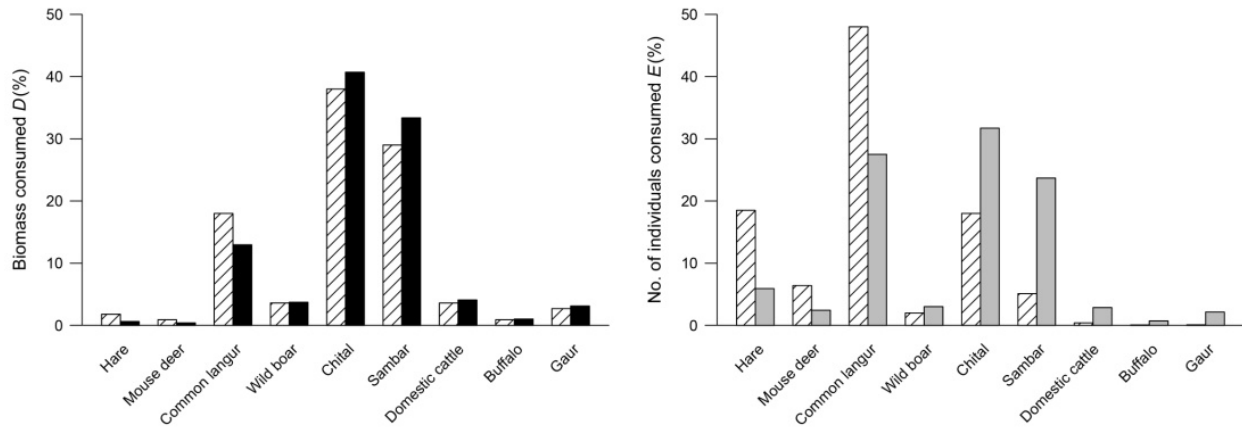

$\square C F_{A}$

- CF1 leopard 
(e) Wang \& Macdonald (2009) - Bhutan
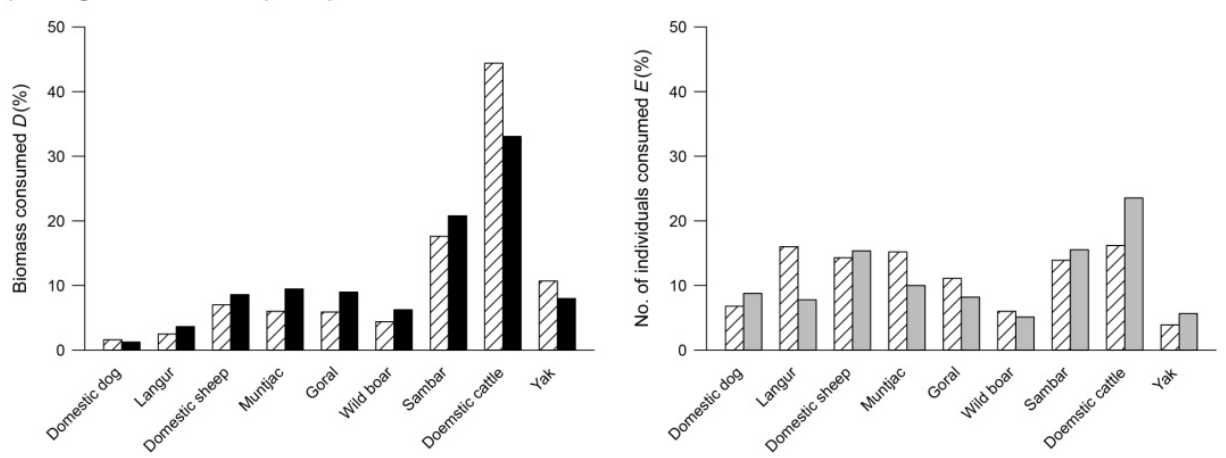

(f) Taghdisi et al. (2013) - Iran
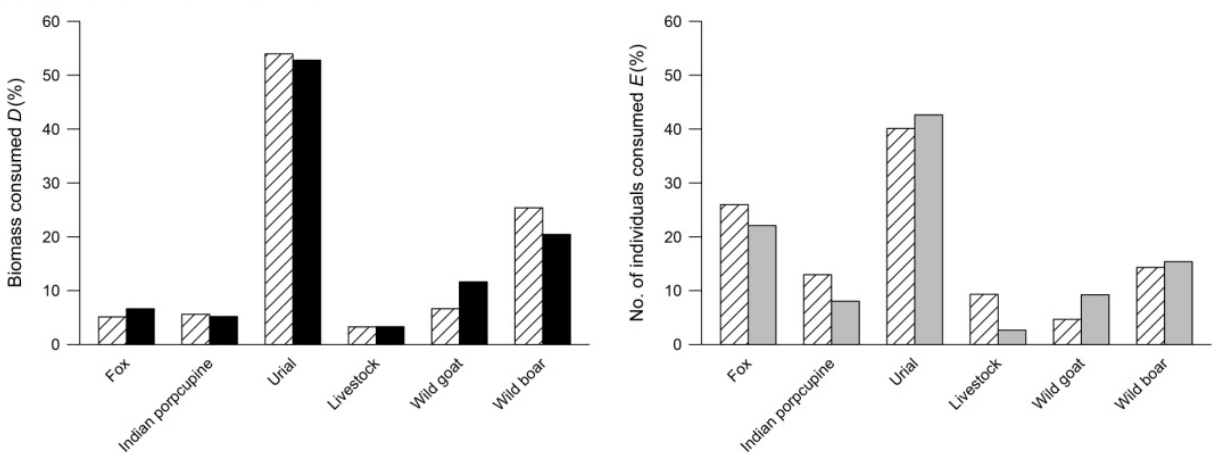

(g) Sidhu et al. (2015) - India
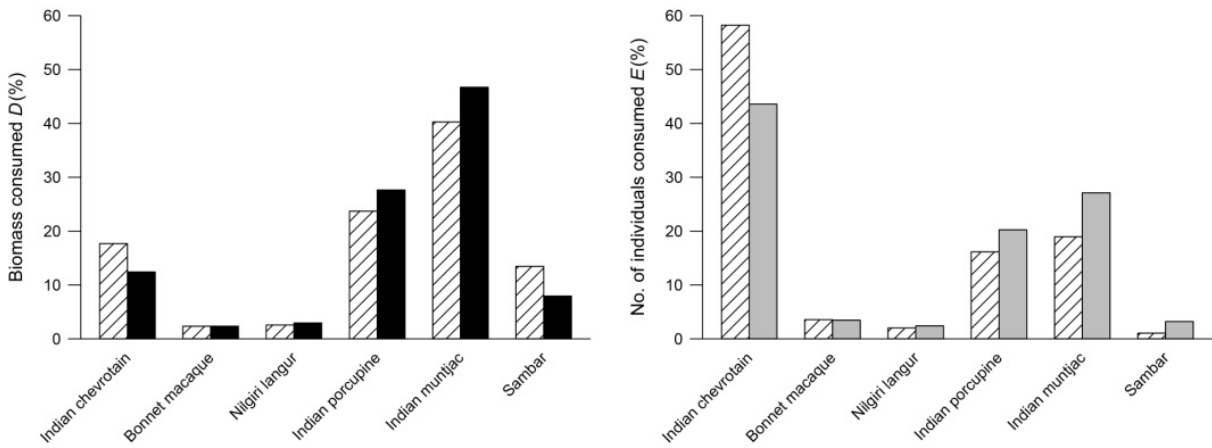

(h) Ghoddousi et al. (2016) - Iran
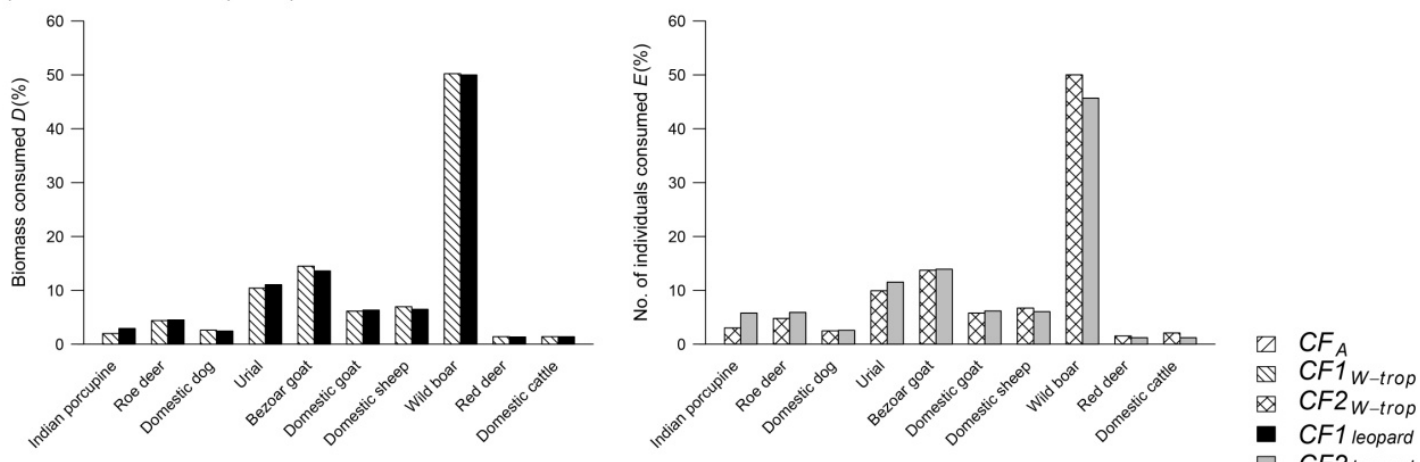

Figure 2.7. Comparisons of relative biomass consumed $D(\%)$ and relative number of individuals consumed $E(\%)$ from selected studies based on $C F_{A}$ (Khorozyan \& Malkhasyan, 2002; Henschel et al., 2005; Andheria et al., 2007; Ramesh et al., 2009; Wang \& Macdonald, 2009; Taghdisi et al., 2013; Sidhu et al., 2015) and CF1 W-trop (Ghoddousi et al., 2016b) with corresponding estimates calculated using CF1 leopard and CF2 $2_{\text {leopard }}$ models respectively. 

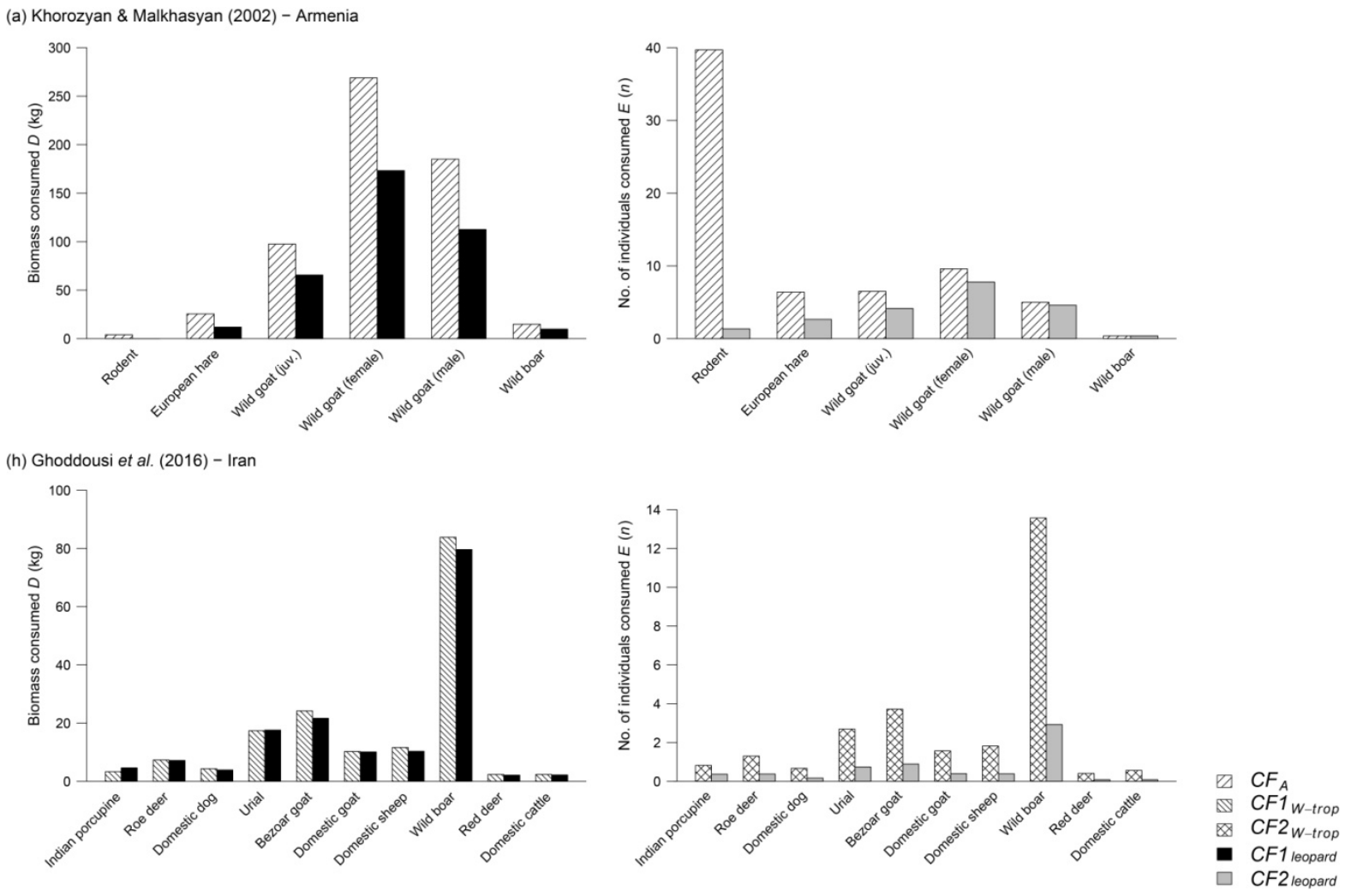

Figure 2.8. Comparisons of biomass $D(\mathrm{~kg})$ and numbers of individuals $E(n)$ consumed

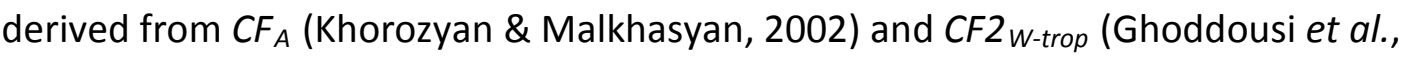
$2016 b)$ with corresponding estimates calculated using CF1 leopard and CF2 leopard models respectively.

\subsection{Discussion}

Our leopard specific biomass models support previous findings that the relationships between prey body mass, biomass consumption and scat production follow an asymptotic curve (Wachter et al., 2012; Chakrabarti et al., 2016) in contrast to earlier models stating a linear relationship (Ackerman et al., 1984; Marker et al., 2003). Although Wachter et al. (2012) considered partial consumption of prey as an important factor in estimating prey numbers consumed, a number of other limitations (e.g. daily food intake, limitations in in-situ experiments) were not considered. Particularly, estimation of prey numbers consumed using CF2 is highly sensitive to carcass utilisation. Considering the proportion of inedible matter of prey at different body mass ranges (Stander et al., 1997), an average maximum daily consumption limit of $5 \mathrm{~kg}$ (Odden \& Wegge, 2009) and a maximum of five days spent feeding on prey (Sunquist \& Sunquist, 2009), we developed a possibly more realistic biomass model 
(CF2 $2_{\text {leopard }}$ ) to estimate the numbers of prey individuals consumed from leopard scat data. However, when estimating actual numbers, application of correction factors is only valid with a regular sampling scheme of scats applied (Wachter et al., 2012).

Application of our modified leopard specific non-linear model to published studies of leopard feeding data resulted in much lower absolute numbers of individuals consumed compared to the estimates derived from conventional non-linear and linear biomass models. Further, it confirmed significant differences between absolute biomass and relative number of individuals consumed as estimated by non-linear vs. linear models. However, no differences were observed in relative prey biomass consumed between the conventional linear and non-linear models and our new model.

As leopard is a top predator with extensive distribution and diverse diet, its feeding ecology received extraordinary attention in the scientific literature (summarised by Hayward et al., 2006 and Balme et al., 2014). These studies clearly defined the leopard as an opportunistic ambush hunter that preferentially preys upon ungulates within 10-40 kg of body mass within an accessible prey mass range of 1$45 \mathrm{~kg}$ (Hayward et al., 2006; Clements et al., 2014). Because of its elusive behaviour, the use of rugged terrain and dense cover, that preclude direct observations, a vast majority of these diet studies were based on scat analyses (e.g. Karanth \& Sunquist, 1995; Andheria et al., 2007; Mondal et al., 2012). Some of these studies used only frequency of occurrence and thus substantially underestimated the contribution of large prey and overestimated small prey (Ott, Kerley \& Boshoff, 2007; Shehzad et al., 2014; Chattha et al., 2015). Multiple studies attempted to correct for size-dependent digestibility of prey using the puma specific linear biomass model of Ackerman et al. (1984) (e.g. Selvan et al., 2013; Taghdisi et al., 2013; Farhadinia et al., 2014). Here, we show that even these leopard prey studies underestimated the relative share of medium and larger prey individuals in the diet despite the overestimation of actual prey numbers consumed (Fig. 2.7a-g). Only one leopard study had applied non-linear biomass models in diet calculations (Ghoddousi et al., 2016b).

Beyond prey body mass and feeding ecology of predators, several ecological parameters are likely to affect the shape of biomass models. As carcass utilisation is important when estimating prey numbers with the CF2 ${ }_{w}$ model, we advocate for the use of more realistic prey consumption rates in biomass models. In this study, we used 
some considerations on maximum prey intake and revisitations to kills using field observations. However, due to interspecific ecological relationships some uncertainties remain, e.g. prey lost to kleptoparasites and the overall abundance of prey may significantly affect the carcass utilisation by leopard (Bailey, 1993; lyengar, 2008; Rühe et al., 2008; Stein, Bourquin \& McNutt, 2015). Also, carcass utilisation be lower in human dominated areas than in undisturbed settings, e.g. due to humans chasing leopards away from kill sites or responding to livestock depredation by removing the carcass (Treves \& Naughton-Treves, 1999; Kissui, 2008). Therefore, we recommend that field researchers measure daily food intake, revisitation rates of leopards to carcasses and the rate of carcass utilisation under different management regimes and predator guilds.

As a major, global analysis of leopard prey preferences was based on diet studies, which used dissimilar data from frequency of prey occurrence in scats, linear biomass models and kill rates, we anticipate that the application of the new leopard specific models may change the preferred prey body mass range of leopard (Hayward et al., 2006). Since our recalculation of leopard case studies shows a much higher contribution of heavier prey compared to linear models (Fig. 2.7a-g), we predict a shift in preferred prey range towards higher body masses. Therefore, our models can be especially important in areas with high actual or potential human-leopard conflicts where accurate estimation of numbers of wild prey and livestock consumed by leopards has a high priority (e.g. Shehzad et al., 2014).

We recommend using the modified non-linear leopard specific biomass regression models in future diet studies of leopard, particularly in human-leopard conflict research. We also call for a recalculation of previously published leopard diets because new estimates of predation rates and livestock losses may seriously affect decisions made in biodiversity conservation and management.

\section{Acknowledgements}

We would like to thank the zoos and their personnel involved in the organization and realization of feeding trials with their leopards. 


\subsection{Supplementary material}

Table S2.1. Name and location of zoos in which leopard feeding trials were conducted.

Name

Allwetterzoo Münster, Germany

No. trials

Tehran Zoo, Eram Park, Tehran, Iran

Tierpark Dählhölzli, Bern, Switzerland

Tierpark Nordhorn, Germany

Zoo Köln, Germany

Zoo Neuwied, Germany

Zoo Wuppertal, Germany

Zoologischer Stadtgarten Karlsruhe, Germany 
Table S2.2. Details of feeding trials with leopards in the zoos of Germany, Switzerland and Iran between 2012 and 2016 . For group size $\geq 2$ the average of the quantities Q1, Q3 and Q4 was taken.

\begin{tabular}{|c|c|c|c|c|c|c|c|c|c|c|c|c|c|c|}
\hline \multirow[b]{2}{*}{ Trial } & \multicolumn{3}{|c|}{ Leopard } & \multicolumn{3}{|c|}{ Prey } & \multicolumn{4}{|c|}{ Prey consumed } & \multicolumn{2}{|c|}{ Scats } & \multirow[b]{2}{*}{$\begin{array}{c}\text { CU } \\
\text { Carcass } \\
\text { utilization }\end{array}$} & \multirow[b]{2}{*}{$\begin{array}{c}\text { Q4 }{ }_{\text {new }}{ }^{d} \\
\text { Scats produced } \\
\text { based on } 25 \mathrm{~kg} \\
\text { consumption } \\
\text { limit }\end{array}$} \\
\hline & $\begin{array}{l}\text { Body } \\
\text { mass }\end{array}$ & $\operatorname{Sex}^{\mathrm{b}}$ & $\begin{array}{l}\text { Group } \\
\text { size }\end{array}$ & Species & No. & $\begin{array}{l}\text { Prey } \\
\text { body } \\
\text { mass }\end{array}$ & $\begin{array}{c}\text { Q1 } \\
\text { Prey } \\
\text { mass per } \\
\text { leopard } \\
\text { \& prey }\end{array}$ & $\begin{array}{l}\text { Prey mass } \\
\text { consumed }\end{array}$ & $\begin{array}{c}\text { Q3 } \\
\text { Consumed } \\
\text { per leopard } \\
\text { \& prey }\end{array}$ & No. & $\begin{array}{c}\text { Q4 } \\
\text { Scats per } \\
\text { leopard } \\
\text { \& prey }\end{array}$ & $\begin{array}{c}Q 5=Q 3 / Q 4 \\
\text { Consumed } \\
\text { per scat }\end{array}$ & & \\
\hline & $\mathrm{kg}$ & & & & & $\mathrm{kg}$ & $\mathrm{kg}$ & $\mathrm{kg}$ & $\mathrm{kg}$ & & & $\mathrm{kg} / \mathrm{scat}$ & $\%$ & \\
\hline 1 & 35 & 0 & 1 & Oryctolagus cuniculus & 2 & 1.74 & $0.87^{\mathrm{a}}$ & 1.11 & 0.55 & 5 & 2.50 & 0.22 & 63.56 & 3.93 \\
\hline 2 & $50-60$ & 1 & 1 & Oryctolagus cuniculus & 2 & 1.95 & $0.98^{\mathrm{a}}$ & 1.16 & 0.58 & 3 & 1.50 & 0.39 & 59.53 & 2.52 \\
\hline 3 & 50 & 0 & 1 & Oryctolagus cuniculus & 2 & 4.00 & $2.00^{\mathrm{a}}$ & 1.50 & 0.75 & 1 & 0.50 & 1.50 & 37.50 & 1.33 \\
\hline 4 & $50-60$ & 1 & 1 & Oryctolagus cuniculus & 3 & 6.13 & $2.04^{\mathrm{a}}$ & 4.14 & 1.38 & 5 & 1.67 & 0.83 & 67.52 & 2.47 \\
\hline 5 & 40 & 0 & 1 & Oryctolagus cuniculus & 1 & 2.25 & 2.25 & 1.50 & 1.50 & 2 & 2.00 & 0.75 & 66.67 & 3.00 \\
\hline 6 & 30 & 0 & 1 & Gallus g. domesticus & 1 & 2.82 & 2.82 & 2.43 & 2.43 & 3 & 3.00 & 0.81 & 86.24 & 3.48 \\
\hline 7 & 50 & 1 & 1 & Oryctolagus cuniculus & 1 & 2.98 & 2.98 & 2.98 & 2.98 & 5 & 5.00 & 0.60 & 100.00 & 5.00 \\
\hline 8 & 45 & 1 & 1 & Gallus g. domesticus & 1 & 3.14 & 3.14 & 2.72 & 2.72 & 3 & 3.00 & 0.91 & 86.72 & 3.46 \\
\hline 9 & 60 & 1 & 1 & Gallus g. domesticus & 1 & 3.32 & 3.32 & 3.20 & 3.20 & 7 & 7.00 & 0.46 & 96.44 & 7.26 \\
\hline
\end{tabular}


Table S2.2. (continued). Details of feeding trials with leopards in the zoos of Germany, Switzerland and Iran between 2012 and 2016. For group size $\geq 2$ the average of the quantities Q1, Q3 and Q4 was taken.

\begin{tabular}{|c|c|c|c|c|c|c|c|c|c|c|c|c|c|c|}
\hline \multirow[b]{2}{*}{ Trial } & \multicolumn{3}{|c|}{ Leopard } & \multicolumn{3}{|c|}{ Prey } & \multicolumn{4}{|c|}{ Prey consumed } & \multicolumn{2}{|c|}{ Scats } & \multirow[b]{2}{*}{$\begin{array}{c}\text { CU } \\
\text { Carcass } \\
\text { utilization }\end{array}$} & \multirow[b]{2}{*}{$\begin{array}{c}\text { Q4 }{ }_{\text {new }}{ }^{d} \\
\text { Scats produced } \\
\text { based on } 25 \mathrm{~kg} \\
\text { consumption } \\
\text { limit }\end{array}$} \\
\hline & $\begin{array}{l}\text { Body } \\
\text { mass }\end{array}$ & Sex ${ }^{b}$ & $\begin{array}{l}\text { Group } \\
\text { size }\end{array}$ & Species & No. & $\begin{array}{l}\text { Prey } \\
\text { body } \\
\text { mass }\end{array}$ & $\begin{array}{c}\text { Q1 } \\
\text { Prey mass } \\
\text { per leopard } \\
\text { \& prey }\end{array}$ & $\begin{array}{l}\text { Prey mass } \\
\text { consumed }\end{array}$ & $\begin{array}{c}\text { Q3 } \\
\text { Consumed } \\
\text { per leopard } \\
\text { \& prey }\end{array}$ & No. & $\begin{array}{c}\text { Q4 } \\
\text { Scats } \\
\text { per } \\
\text { leopard } \\
\text { \& prey }\end{array}$ & $\begin{array}{c}Q 5=Q 3 / Q 4 \\
\text { Consumed } \\
\text { per scat }\end{array}$ & & \\
\hline & $\mathrm{kg}$ & & & & & $\mathrm{kg}$ & $\mathrm{kg}$ & $\mathrm{kg}$ & $\mathrm{kg}$ & & & $\mathrm{kg} / \mathrm{scat}$ & $\%$ & \\
\hline 11 & 35 & 0 & 1 & Capra hircus & 1 & 8.60 & 8.60 & 5.70 & 5.70 & 5 & 5.00 & 1.14 & 66.28 & 7.17 \\
\hline 12 & 45 & 1 & 1 & Capra hircus & 1 & 9.20 & 9.20 & 3.60 & 3.60 & 3 & 3.00 & 1.20 & 39.13 & 7.28 \\
\hline 13 & 100 & 1 & 1 & Dama dama & 1 & 9.65 & 9.65 & 6.15 & 6.15 & 2 & 2.00 & 3.08 & 63.73 & 2.98 \\
\hline 14 & 60 & 1 & 1 & Capra hircus & 1 & 12.10 & 12.10 & 5.80 & 5.80 & 5 & 5.00 & 1.16 & 47.93 & 9.91 \\
\hline 15 & $60 / 35$ & 1,0 & 2 & Capra hircus & 1 & 26.00 & 13.00 & 12.00 & 6.00 & 6 & 3.00 & 2.00 & 46.15 & 6.18 \\
\hline 16 & 60 & 1 & 1 & $\begin{array}{l}\text { Capreolus } \\
\text { capreolus }\end{array}$ & 1 & 14.00 & 14.00 & 11.51 & 11.51 & 7 & 7 & 1.64 & 82.19 & 8.09 \\
\hline 18 & 45 & 0 & 1 & Bos taurus (calf) & 1 & 15.00 & 15.00 & 4.00 & 4.00 & 4 & 4.00 & 1.00 & 26.67 & 14.25 \\
\hline 19 & 60 & 1 & 1 & $\begin{array}{l}\text { Capreolus } \\
\text { capreolus }\end{array}$ & 1 & 17.00 & 17.00 & 15.25 & 15.25 & 10 & 10 & 1.53 & 89.69 & 10.59 \\
\hline 20 & 65 & 1 & 1 & Bos taurus (calf) & 1 & 20.00 & 20.00 & 10.00 & 10.00 & 6 & 6.00 & 1.67 & 50.00 & 11.40 \\
\hline 21 & 35 & 0 & 1 & Ovis aries & 1 & 55.10 & 55.10 & 6.95 & 6.95 & 6 & 6.00 & 1.16 & 12.61 & 21.58 \\
\hline 22 & 58 & 1 & 1 & Ovis aries & 1 & 69.45 & 69.45 & 10.55 & 10.55 & 3 & 3.00 & 3.52 & 15.19 & 7.11 \\
\hline
\end{tabular}

${ }^{\mathrm{a}}$ Average prey mass

b 1 for male; 0 for female 
${ }^{\mathrm{C}}$ Carcass utilisation $C U=\mathrm{Q} 1 / \mathrm{Q} 3 * 100$

${ }^{\mathrm{d}}$ Prey <35.7 kg: $\left.\left.Q 4_{\text {new }}=Q 4 / C U[\%]\right) * S_{i}\right) ;$ prey $>35.7 \mathrm{~kg} Q 4_{\text {new }}=(Q 4 / C U[\%]) *((25 \mathrm{~kg} / Q 1) * 100)$

Table S2.3. Models selected to describe data in this study. Model equations were taken from Crawley (2007), Bolker (2008) and Logan (2010).

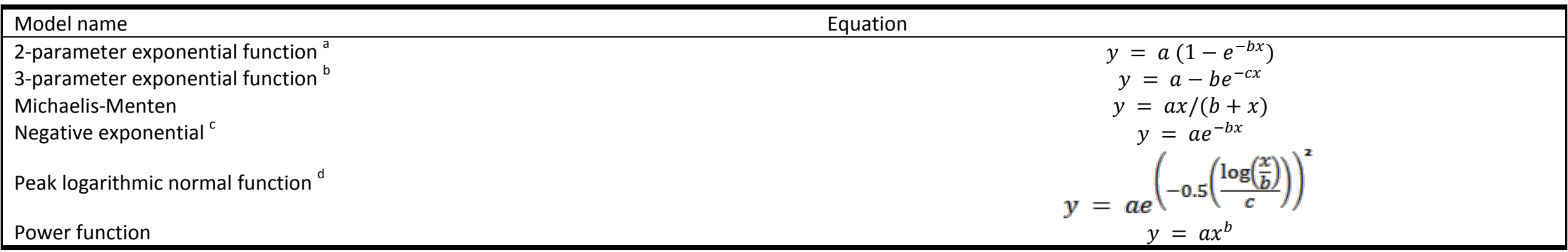

${ }^{a}$ Used by Wachter et al. (2012) to describe CF1 for cheetah.

${ }^{b}$ Used by Chakrabarti et al. (2016) to describe generalized biomass model for felids.

${ }^{\mathrm{C}}$ Used to explain the rate of carcass consumption.

${ }^{d}$ Used by Wachter et al. (2012) to explain CF2 for cheetah. 
Table S2.4. Fitted regression models describing the relationships between CF1 leopard $(y)$ and prey body mass $(x)$ sorted by ascending AIC value. The selected model is marked in bold. Abbreviations: SE - standard error, AIC - Akaike Information Criterion, $\Delta$ - difference between the AIC value of the model and the minimum AIC of the best model, $P$ - significance level, $R^{2}-$ coefficient of determination, RSS - residual sum of squares.

\begin{tabular}{|c|c|c|c|c|c|c|c|c|}
\hline Model & Function & $S E$ & AIC & $\Delta$ & $\begin{array}{c}\text { Log- } \\
\text { Likelihood }\end{array}$ & $P$-value & $R^{2}$ & RSS \\
\hline \multicolumn{9}{|l|}{ CF1 $1_{\text {leopard }}$} \\
\hline Michaelis-Menten & $y=2.242 x /(4.976+x)$ & $\begin{array}{l}a=0.227 \\
b=1.701\end{array}$ & 54.65 & 0 & -24.32 & 0.000009 & 0.54 & 8.23 \\
\hline Power function & $y=0.715 x^{0.270}$ & $\begin{array}{l}a=0.113 \\
b=0.048\end{array}$ & 56.84 & 2.19 & -25.42 & 0.000001 & 0.51 & 8.76 \\
\hline $\begin{array}{l}\text { 2-parameter exponential } \\
\text { function }\end{array}$ & $y=1.918\left(1-\exp ^{-0.175 x}\right)$ & $\begin{array}{l}a=0.164 \\
b=0.047\end{array}$ & 57.63 & 2.98 & -25.81 & 0.000004 & 0.50 & 8.96 \\
\hline $\begin{array}{l}\text { 3-parameter exponential } \\
\text { function }\end{array}$ & $y=2.137-1.673 \exp ^{-0.083 x}$ & $\begin{array}{l}a=0.232 \\
b=0.282 \\
c=0.036\end{array}$ & 57.82 & 3.17 & -24.91 & 0.00001 & 0.52 & 8.51 \\
\hline
\end{tabular}


Table S2.5. Fitted regression models describing the relationships between CF $2_{\text {leopard }}$ / CF $2_{\text {leopard-w }}(y)$ and prey body mass ( $x$ ) sorted by ascending AIC value. The selected models are marked in bold. Abbreviations: SE - standard error, AIC - Akaike Information Criterion, $\Delta$ difference between the AIC value of the model and the minimum AIC of the best model, $P$ - significance level, $R^{2}-$ coefficient of determination, RSS - residual sum of squares.

\begin{tabular}{|c|c|c|c|c|c|c|c|c|}
\hline Model & Function & $S E$ & AIC & $\Delta$ & $\begin{array}{c}\text { Log- } \\
\text { Likelihood }\end{array}$ & P-value & $R^{2}$ & RSS \\
\hline \multicolumn{9}{|l|}{ CF2 $2_{\text {leopard }}$} \\
\hline $\begin{array}{l}\text { 2-parameter } \\
\text { exponential function }\end{array}$ & $y=12.724\left(1-\exp ^{-0.097 x}\right)$ & $\begin{array}{l}a=1.059 \\
b=0.020\end{array}$ & 170.29 & 0 & -82.15 & 0.00001 & 0.66 & 223.98 \\
\hline $\begin{array}{l}\text { 3-parameter } \\
\text { exponential function }\end{array}$ & $y=13.004-11.601 \exp ^{-0.078 x}$ & $\begin{array}{l}a=1.195 \\
b=1.417 \\
c=0.024\end{array}$ & 170.62 & 0.31 & -81.31 & 0.000005 & 0.68 & 213.55 \\
\hline Michaelis-Menten & $y=14.497 x /(8.328+x)$ & $\begin{array}{l}a=1.505 \\
b=2.489\end{array}$ & 171.58 & 1.29 & -82.79 & 0.0000008 & 0.65 & 232.37 \\
\hline $\begin{array}{l}\text { Peak logarithmic normal } \\
\text { function }\end{array}$ & $y=12.88 \exp ^{(-0.5((\log (x / 67.237)) /-1.951)) 2}$ & $\begin{array}{l}a=1.052 \\
b=28.911 \\
c=0.331\end{array}$ & 172.06 & 1.87 & -82.03 & 0.000002 & 0.66 & 222.51 \\
\hline \multicolumn{9}{|l|}{$C F 2_{\text {leopard-W }}$} \\
\hline Power function & $y=2.428 x^{0.295}$ & $\begin{array}{l}a=0.482 \\
b=0.059\end{array}$ & 161.55 & 0 & -77.78 & 0.000002 & 0.44 & 174.49 \\
\hline $\begin{array}{l}\text { 3-parameter } \\
\text { exponential function }\end{array}$ & $y=8.912-6.792 \exp ^{-0.049 x}$ & $\begin{array}{l}a=1.369 \\
b=1.400 \\
c=0.026\end{array}$ & 162.66 & 1.11 & -77.33 & 0.000001 & 0.46 & 170.11 \\
\hline Michaelis-Menten & $y=8.830 x /(6.733+x)$ & $\begin{array}{l}a=1.207 \\
b=2.828\end{array}$ & 162.75 & 1.20 & -78.37 & 0.000007 & 0.42 & 180.55 \\
\hline $\begin{array}{l}\text { Peak logarithmic normal } \\
\text { function }\end{array}$ & $y=11.488 \exp ^{(-0.5((\log (x / 1358.203)) / 3.796)) 2}$ & $\begin{array}{l}a=9.197 \\
b=7609.887 \\
c=2.471\end{array}$ & 162.85 & 1.30 & -77.42 & 0.000007 & 0.45 & 171.01 \\
\hline
\end{tabular}


Table S2.6. Recalculation of selected leopard dietary studies (Khorozyan \& Malkhasyan 2002; Henschel et al. 2005; Andheria et al. 2007;

Ramesh et al. 2009; Wang \& Macdonald 2009; Taghdisi et al. 2013; Sidhu et al. 2015; Ghoddousi et al. 2016b) showing the actual and relative prey biomass consumed $(D)$ and numbers of prey individuals consumed $(E)$ estimated using $C F 1_{\text {leopard, }} C F 2_{\text {leopard }}$ and $C F 2_{\text {leopard-W }}$ accordingly. Prey body mass and frequency of prey occurrence $(F O)$ were taken from the respective studies.

a) Khorozyan \& Malkhasyan (2002).

\begin{tabular}{|c|c|c|c|c|c|c|c|c|}
\hline \multirow[b]{2}{*}{ Prey } & \multirow[b]{2}{*}{ Body mass (kg) } & \multirow[b]{2}{*}{$F O$} & \multicolumn{2}{|c|}{$C F 1_{\text {leopard }}$} & \multicolumn{2}{|c|}{$C F 2_{\text {leopard-W }}$} & \multicolumn{2}{|c|}{ CF2 $2_{\text {leopard }}$} \\
\hline & & & $D(\mathrm{~kg})$ & $D(\%)$ & $E(n)$ & $E(\%)$ & $E(n)$ & $E(\%)$ \\
\hline Wild goat (juv.) & 15.0 & 5 & 65.66 & 17.58 & 6.90 & 21.53 & 4.15 & 19.80 \\
\hline Wild goat (fem.) & 28.0 & 57 & 173.24 & 46.38 & 12.66 & 39.51 & 7.78 & 37.14 \\
\hline Wild goat (male) & 37.0 & 91 & 112.64 & 30.16 & 7.30 & 22.80 & 4.61 & 22.03 \\
\hline Wild boar & 37.0 & 39 & 9.88 & 2.65 & 0.64 & 2.00 & 0.40 & 1.93 \\
\hline European hare & 4.0 & 12 & 11.99 & 3.21 & 3.60 & 11.25 & 2.66 & 12.70 \\
\hline Rodents & 0.1 & 2 & 0.09 & 0.02 & 0.93 & 2.90 & 1.34 & 6.40 \\
\hline
\end{tabular}


b) Henschel et al. (2005).

\begin{tabular}{|c|c|c|c|c|c|c|c|c|}
\hline \multirow[b]{2}{*}{ Prey } & \multirow[b]{2}{*}{ Body mass (kg) } & \multirow[b]{2}{*}{$F O$} & \multicolumn{2}{|c|}{ CF1 leopard } & \multicolumn{2}{|c|}{$C F 2_{\text {leopard-W }}$} & \multicolumn{2}{|c|}{ CF $2_{\text {leopard }}$} \\
\hline & & & $D(\mathrm{~kg})$ & $D(\%)$ & $E(n)$ & $E(\%)$ & $E(n)$ & $E(\%)$ \\
\hline Ungulates & & & & 60.25 & & 33.23 & & 29.75 \\
\hline Blue duiker & 3.9 & 6 & 5.91 & 1.42 & 1.82 & 3.07 & 1.35 & 3.17 \\
\hline Water chevrotain & 10.4 & 8 & 12.13 & 2.92 & 1.66 & 2.80 & 1.02 & 2.39 \\
\hline Red duiker spp. & 15.5 & 38 & 64.49 & 15.54 & 6.63 & 11.20 & 3.98 & 9.35 \\
\hline Yellow-backed duiker & 56.7 & 6 & 12.37 & 2.98 & 0.71 & 1.19 & 0.47 & 1.10 \\
\hline Bushbuck & 38.4 & 17 & 33.74 & 8.13 & 2.16 & 3.65 & 1.37 & 3.21 \\
\hline Sitatunga & 62.8 & 6 & 12.46 & 3.00 & 0.70 & 1.18 & 0.46 & 1.09 \\
\hline Red river hog & 61.9 & 38 & 78.86 & 19.00 & 4.43 & 7.48 & 2.94 & 6.91 \\
\hline African forest buffalo & 118.8 & 14 & 30.13 & 7.26 & 1.57 & 2.66 & 1.08 & 2.53 \\
\hline Primates & & & & 17.84 & & 23.87 & & 24.14 \\
\hline Greater spot-nosed monkey & 3.2 & 16 & 14.04 & 3.38 & 5.15 & 8.71 & 4.03 & 9.47 \\
\hline Crested mona monkey & 2.2 & 2 & 1.37 & 0.33 & 0.71 & 1.20 & 0.62 & 1.45 \\
\hline Moustached guenon & 2 & 3 & 1.93 & 0.46 & 1.09 & 1.84 & 0.97 & 2.29 \\
\hline Grey-cheeked mangabey & 4.1 & 4 & 4.05 & 0.98 & 1.19 & 2.01 & 0.87 & 2.05 \\
\hline Black colobus & 8.4 & 11 & 15.49 & 3.73 & 2.49 & 4.21 & 1.58 & 3.70 \\
\hline Mandrill & 10.2 & 11 & 16.58 & 3.99 & 2.30 & 3.88 & 1.42 & 3.33 \\
\hline Central chimpanzee & 38.7 & 4 & 7.95 & 1.91 & 0.51 & 0.86 & 0.32 & 0.76 \\
\hline Western lowland gorilla & 78.1 & 6 & 12.65 & 3.05 & 0.68 & 1.16 & 0.46 & 1.09 \\
\hline Rodents & & & & 17.13 & & 36.76 & & 39.28 \\
\hline Greater cane rat & 5 & 50 & 56.18 & 13.54 & 13.90 & 23.50 & 9.71 & 22.80 \\
\hline African brush-tailed porcupine & 2.3 & 21 & 14.88 & 3.59 & 7.38 & 12.48 & 6.35 & 14.91 \\
\hline Unknown small rodent & 0.1 & 1 & 0.04 & 0.01 & 0.46 & 0.78 & 0.67 & 1.57 \\
\hline Carnivores & & & & 4.78 & & 6.15 & & 6.83 \\
\hline African palm civet & 2.1 & 4 & 2.66 & 0.64 & 1.44 & 2.43 & 1.27 & 2.98 \\
\hline African civet & 11.3 & 1 & 1.56 & 0.37 & 0.20 & 0.34 & 0.12 & 0.29 \\
\hline African golden cat & 9.8 & 5 & 7.43 & 1.79 & 1.06 & 1.79 & 0.66 & 1.54 \\
\hline Leopard & 40.3 & 4 & 7.98 & 1.92 & 0.50 & 0.85 & 0.32 & 0.75 \\
\hline Unknown small carnivore & 0.5 & 1 & 0.20 & 0.05 & 0.44 & 0.74 & 0.54 & 1.27 \\
\hline
\end{tabular}


c) Andheria et al. (2007).

\begin{tabular}{|c|c|c|c|c|c|c|c|c|}
\hline \multirow[b]{2}{*}{ Prey } & \multirow[b]{2}{*}{ Body mass (kg) } & \multirow[b]{2}{*}{ FO } & \multicolumn{2}{|c|}{$C F 1_{\text {leopard }}$} & \multicolumn{2}{|c|}{$C F 2_{\text {leopard-W }}$} & \multicolumn{2}{|c|}{ CF2 $2_{\text {leopard }}$} \\
\hline & & & $D(\mathrm{~kg})$ & $D(\%)$ & $E(n)$ & $E(\%)$ & $E(n)$ & $E(\%)$ \\
\hline Gaur & 85 & 12 & 25.42 & 11.81 & 1.36 & 8.93 & 0.92 & 9.35 \\
\hline Sambar & 62 & 8 & 16.60 & 7.72 & 0.93 & 6.11 & 0.62 & 6.27 \\
\hline Chital & 48 & 60 & 121.88 & 56.64 & 7.26 & 47.60 & 4.71 & 47.71 \\
\hline Wild boar & 37 & 11 & 21.74 & 10.10 & 1.41 & 9.24 & 0.89 & 9.01 \\
\hline Muntjac & 20 & 2 & 3.59 & 1.67 & 0.31 & 2.06 & 0.19 & 1.92 \\
\hline Chousingha & 19 & 4 & 7.11 & 3.30 & 0.64 & 4.21 & 0.39 & 3.91 \\
\hline Langur & 8 & 12 & 16.59 & 7.71 & 2.78 & 18.20 & 1.77 & 17.90 \\
\hline Chevrotain & 5 & 2 & 2.25 & 1.04 & 0.56 & 3.65 & 0.39 & 3.93 \\
\hline
\end{tabular}

d) Ramesh et al. (2009).

\begin{tabular}{|c|c|c|c|c|c|c|c|c|}
\hline \multirow[b]{2}{*}{ Prey } & \multirow[b]{2}{*}{ Body mass (kg) } & \multirow[b]{2}{*}{ FO } & \multicolumn{2}{|c|}{$C F 1_{\text {leopard }}$} & \multicolumn{2}{|c|}{$C F 2_{\text {leopard-W }}$} & \multicolumn{2}{|c|}{ CF $2_{\text {leopard }}$} \\
\hline & & & $D(\mathrm{~kg})$ & $D(\%)$ & $E(n)$ & $E(\%)$ & $E(n)$ & $E(\%)$ \\
\hline Hare & 2.1 & 2 & 1.33 & 0.62 & 0.72 & 4.47 & 0.63 & 5.92 \\
\hline Mouse deer & 3 & 1 & 0.84 & 0.40 & 0.33 & 2.04 & 0.26 & 2.44 \\
\hline Common langur & 8 & 20 & 27.64 & 12.96 & 4.63 & 28.82 & 2.95 & 27.50 \\
\hline Wild boar & 38 & 4 & 7.93 & 3.72 & 0.51 & 3.17 & 0.32 & 3.01 \\
\hline Chital & 45 & 43 & 86.81 & 40.70 & 5.27 & 32.81 & 3.40 & 31.71 \\
\hline Sambar & 125 & 33 & 71.15 & 33.36 & 3.71 & 23.10 & 2.54 & 23.69 \\
\hline Domestic cattle & 180 & 4 & 8.73 & 4.09 & 0.45 & 2.80 & 0.31 & 2.87 \\
\hline Buffalo & 273 & 1 & 2.20 & 1.03 & 0.11 & 0.70 & 0.08 & 0.72 \\
\hline Gaur & 450 & 3 & 6.65 & 3.12 & 0.34 & 2.10 & 0.23 & 2.15 \\
\hline
\end{tabular}


e) Wang \& Macdonald (2009).

\begin{tabular}{|c|c|c|c|c|c|c|c|c|}
\hline \multirow[b]{2}{*}{ Prey } & \multirow[b]{2}{*}{ Body mass (kg) } & \multirow[b]{2}{*}{$F O$} & \multicolumn{2}{|c|}{$C F 1_{\text {leopard }}$} & \multicolumn{2}{|c|}{$C F 2_{\text {leopard-W }}$} & \multicolumn{2}{|c|}{$C F 2_{\text {leopard }}$} \\
\hline & & & $D(\mathrm{~kg})$ & $D(\%)$ & $E(n)$ & $E(\%)$ & $E(n)$ & $E(\%)$ \\
\hline Sambar & 62.0 & 19 & 39.43 & 20.78 & 2.21 & 15.39 & 1.47 & 15.54 \\
\hline Muntjac & 20.0 & 10 & 17.95 & 9.46 & 1.57 & 10.93 & 0.95 & 9.99 \\
\hline Langur & 8.0 & 5 & 6.91 & 3.64 & 1.16 & 8.04 & 0.74 & 7.78 \\
\hline Goral & 27.0 & 9 & 17.04 & 8.98 & 1.27 & 8.81 & 0.78 & 8.20 \\
\hline Wild boar & 37.0 & 6 & 11.86 & 6.25 & 0.77 & 5.35 & 0.49 & 5.13 \\
\hline Domestic cattle & 140.0 & 29 & 62.79 & 33.08 & 3.26 & 22.65 & 2.23 & 23.54 \\
\hline Yak & 140.0 & 7 & 15.16 & 7.98 & 0.79 & 5.47 & 0.54 & 5.68 \\
\hline Domestic sheep & 9.7 & 11 & 16.30 & 8.59 & 2.35 & 16.31 & 1.46 & 15.36 \\
\hline Domestic dog & 2.7 & 3 & 2.37 & 1.25 & 1.01 & 7.04 & 0.83 & 8.78 \\
\hline
\end{tabular}

f) Taghdisi et al. (2013).

\begin{tabular}{|c|c|c|c|c|c|c|c|c|}
\hline \multirow[b]{2}{*}{ Prey } & \multirow[b]{2}{*}{ Body mass (kg) } & \multirow[b]{2}{*}{$F O$} & \multicolumn{2}{|c|}{ CF1 $1_{\text {leopard }}$} & \multicolumn{2}{|c|}{ CF2 $2_{\text {leopard-W }}$} & \multicolumn{2}{|c|}{ CF2 $2_{\text {leopard }}$} \\
\hline & & & $D(\mathrm{~kg})$ & $D(\%)$ & $E(n)$ & $E(\%)$ & $E(n)$ & $E(\%)$ \\
\hline Urial & 34 & 32 & 62.58 & 52.79 & 4.19 & 43.77 & 2.63 & 42.63 \\
\hline Wild boar & 45 & 12 & 24.23 & 20.43 & 1.47 & 15.34 & 0.95 & 15.39 \\
\hline Wild goat & 36 & 7 & 13.79 & 11.63 & 0.90 & 9.43 & 0.57 & 9.24 \\
\hline Common fox & 5 & 7 & 7.87 & 6.63 & 1.95 & 20.31 & 1.36 & 22.07 \\
\hline Indian porcupine & 11 & 4 & 6.17 & 5.21 & 0.81 & 8.43 & 0.50 & 8.03 \\
\hline Domestic sheep and goat & 35 & 2 & 3.93 & 3.31 & 0.26 & 2.71 & 0.16 & 2.65 \\
\hline
\end{tabular}


g) Sidhu et al. (2015).

\begin{tabular}{|c|c|c|c|c|c|c|c|c|}
\hline \multirow[b]{2}{*}{ Prey } & \multirow[b]{2}{*}{ Body mass (kg) } & \multirow[b]{2}{*}{ FO } & \multicolumn{2}{|c|}{$\overline{C F 1_{\text {leopard }}}$} & \multicolumn{2}{|c|}{$C F 2_{\text {leopard-W }}$} & \multicolumn{2}{|c|}{$C F 2_{\text {leopard }}$} \\
\hline & & & $D(\mathrm{~kg})$ & $D(\%)$ & $E(n)$ & $E(\%)$ & $E(n)$ & $E(\%)$ \\
\hline Indian chevrotain & 3 & 8 & 6.75 & 12.42 & 2.62 & 37.14 & 2.09 & 43.57 \\
\hline Bonnet macaque & 6.5 & 1 & 1.27 & 2.34 & 0.25 & 3.56 & 0.17 & 3.46 \\
\hline Nilgiri langur & 12.5 & 1 & 1.60 & 2.95 & 0.19 & 2.71 & 0.12 & 2.41 \\
\hline Indian porcupine & 14.5 & 9 & 15.02 & 27.65 & 1.61 & 22.85 & 0.97 & 20.24 \\
\hline Indian muntjac & 21 & 14 & 25.38 & 46.71 & 2.16 & 30.56 & 1.30 & 27.12 \\
\hline Sambar & 125 & 2 & 4.31 & 7.94 & 0.22 & 3.18 & 0.15 & 3.20 \\
\hline
\end{tabular}

h) Ghoddousi et al. (2016b).

\begin{tabular}{|c|c|c|c|c|c|c|c|c|}
\hline \multirow[b]{2}{*}{ Prey } & \multirow[b]{2}{*}{ Body mass (kg) } & \multirow[b]{2}{*}{$F O$} & \multicolumn{2}{|c|}{$C F 1_{\text {leopard }}$} & \multicolumn{2}{|c|}{$C F 2_{\text {leopard-W }}$} & \multicolumn{2}{|c|}{ CF $2_{\text {leopard }}$} \\
\hline & & & $D(\mathrm{~kg})$ & $D(\%)$ & $E(n)$ & $E(\%)$ & $E(n)$ & $E(\%)$ \\
\hline Indian porcupine & 11 & 3 & 4.63 & 2.91 & 0.61 & 6.13 & 0.37 & 5.78 \\
\hline Roe deer & 20 & 4 & 7.18 & 4.51 & 0.63 & 6.36 & 0.38 & 5.90 \\
\hline Domestic dog & 32.2 & 2 & 3.88 & 2.44 & 0.27 & 2.69 & 0.17 & 2.58 \\
\hline Urial & 34 & 9 & 17.60 & 11.05 & 1.18 & 11.93 & 0.74 & 11.51 \\
\hline Bezoar goat & 36 & 11 & 21.67 & 13.60 & 1.42 & 14.35 & 0.89 & 13.93 \\
\hline Domestic goat & 44.8 & 5 & 10.09 & 6.33 & 0.61 & 6.20 & 0.40 & 6.16 \\
\hline Domestic sheep & 57.1 & 5 & 10.31 & 6.47 & 0.59 & 5.95 & 0.39 & 6.05 \\
\hline Wild boar & 71.5 & 38 & 79.65 & 49.99 & 4.36 & 44.12 & 2.93 & 45.69 \\
\hline Red deer & 98.8 & 1 & 2.13 & 1.34 & 0.11 & 1.14 & 0.08 & 1.20 \\
\hline Domestic cattle & 250 & 1 & 2.20 & 1.38 & 0.11 & 1.13 & 0.08 & 1.20 \\
\hline
\end{tabular}




\section{Chapter 3: Effects of ranger stations on predator and prey distribution and abundance in an Iranian steppe landscape}

Arash Ghoddousi, Amirhossein Kh. Hamidi, Mahmood Soofi, Igor Khorozyan, Bahram

H. Kiabi, Matthias Waltert

Animal Conservation, 2016, Vol. 19, p. 273-280. DOI: 10.1111/acv.12240

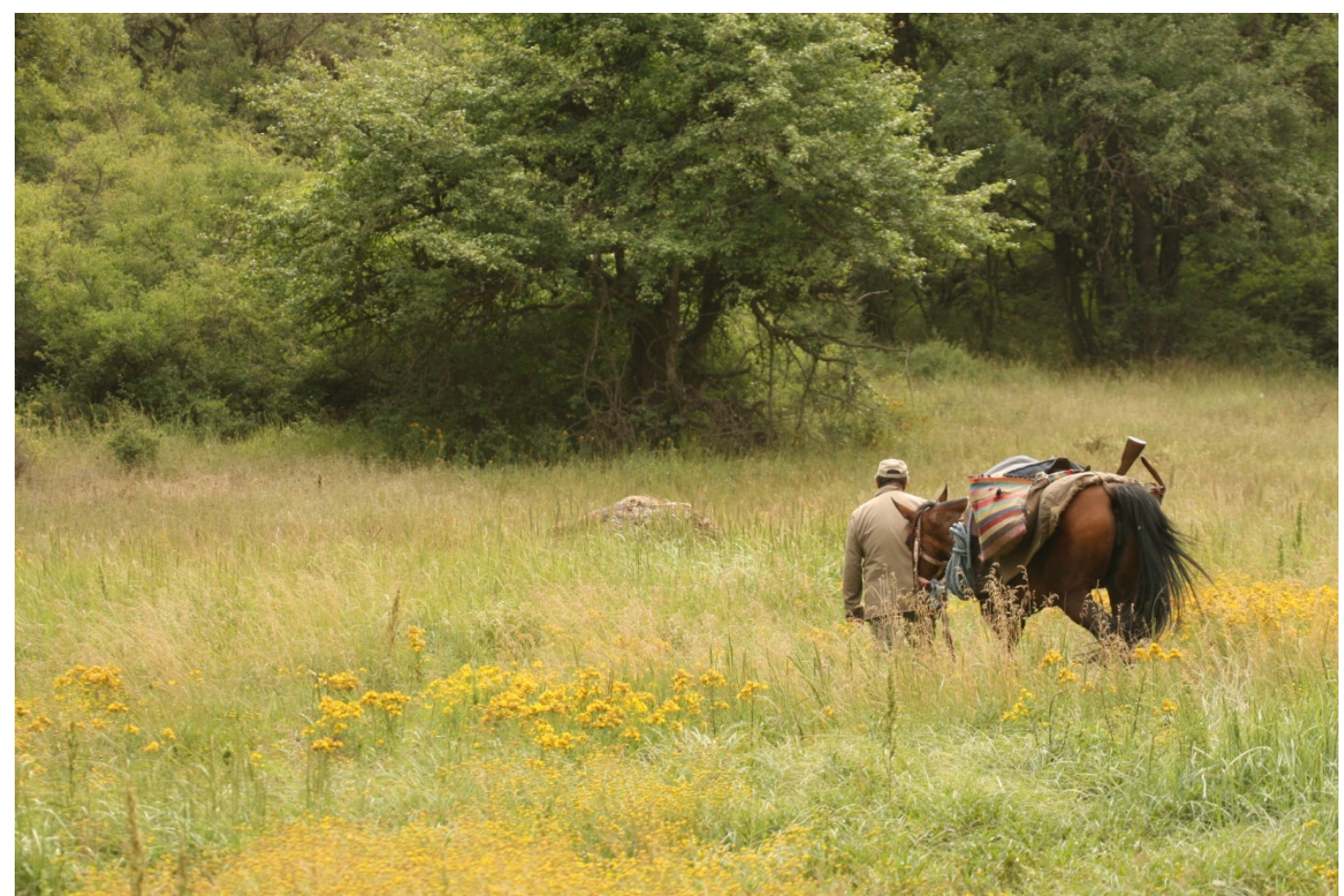

A ranger in Golestan National Park. Photo: A. Kh. Hamidi 


\section{Abstract}

Ranger stations are essential to combat poaching in protected areas and the distance from ranger stations is sometimes used as a proxy for poaching levels and law enforcement intensity. However, the influence of the spatial distribution of ranger stations on wildlife abundance and population structure has rarely been investigated. We evaluated the abundance and distribution of urial sheep (Ovis vignei) and Persian leopard (Panthera pardus saxicolor) in the steppe of Golestan National Park in northeastern Iran. The spatial distribution of these species in regard to anthropogenic (distances to ranger stations, villages and park border) and environmental variables (distance to water resources, average slope and normalized difference vegetation index) was assessed using systematic line transect sampling (186 km) and camera trapping (1150 trap nights). The studied steppe area is divided into three management zones differing in the number of ranger stations and their position with respect to park boundaries. The results of multivariate analyses highlighted that the distance to ranger stations was negatively related to the size and density of urial clusters and the most important variable in explaining urial distribution. Moreover, the distance to park borders influenced urial cluster density. Leopard abundance was positively associated with urial density but was less affected by the other variables tested. We found urial densities in the three management zones to range from $0.15 \pm$ SE 0.09 individuals $/ \mathrm{km}^{2}$ (zone with just one station outside the park) to $21.77 \pm \mathrm{SE} 7.92$ individuals $/ \mathrm{km}^{2}$ (zone with three stations). Taking into account these results and historical data on ungulate abundance and distribution in these management zones, we conclude that law enforcement from ranger stations has shaped current patterns of ungulate distribution. These results confirm that a good coverage (both numbers and locations) of ranger stations is of central importance for the management of protected areas. 


\subsection{Introduction}

Human exploitation can alter density, demography, distribution and behavior of ungulates (Hay et al. 2007; Jachmann 2008; Averbeck et al. 2012) and also affects large carnivores, which are highly dependent on their prey (Kilgo et al. 1998; Karanth et al. 2004). Poaching is one of the most eminent threats to wildlife (Gavin et al. 2010) and rigorous law enforcement is important in tackling poaching pressure (Rowcliffe et al. 2004; Hilborn et al. 2006).

Essential park infrastructures related to law enforcement are ranger stations. Such stations, as well as infrastructure for researchers and tourists, can affect density and distribution of illegally harvested species (Campbell et al. 2011; Jenks et al. 2012; N'Goran et al. 2012). The distance to ranger stations is sometimes used as a proxy for hunting pressure or law enforcement (Hunter \& Cresswell 2015). Such an assumption is due to the fact that most patrolling is done up to a certain distance from patrol posts (Plumptre et al. 2014), resulting into better coverage of effectively patrolled areas near those stations, decreasing gradually with distance from the ranger posts (Hunter \& Cresswell 2015).

The establishment of ranger stations is often linked to logistical considerations or touristic requirements (Campbell et al. 2011). Sometimes ranger posts are created at the border or even outside protected areas and that may leave some parts of the protected area effectively unprotected (Dajun et al. 2006; Jenks et al. 2012). Ideally, ranger stations should be located in places where they can deter illegal activities most effectively and where protection of target species is most required (Plumptre et al. 2014). Therefore, analyses of the relationships between the distributions of ranger posts and those of wildlife abundance or population structure (Dajun et al. 2006; Jenks et al. 2012) should be of interest to conservation management.

In this study, we use data from line transect counts and camera trapping in Golestan National Park (GNP), Iran, to test whether urial sheep (Ovis vignei; also formerly known as O. orientalis; Valdez 2008; Rezaei et al. 2010) and Persian leopard (Panthera pardus saxicolor; Khorozyan 2008) distribution, abundance and demography are associated with the distance to ranger stations in comparison with 
other anthropogenic and environmental variables. Assuming that poaching deterrence is higher near ranger stations, we hypothesized that 1) wildlife abundance and distribution would be negatively related to distance from ranger stations and that 2) differing coverage of ranger stations (both numbers and locations) would result into population responses in harvested species.

\subsection{Materials and methods}

\section{Study area}

Located in northeastern Iran (Fig. 3.1), GNP was the first area to be designated as a national park in Iran in 1957. The park is in a mountainous terrain with landscapes ranging from deciduous forest to steppe and arid plains, which have mean annual precipitation of 142 and $866 \mathrm{~mm}$ in the east and west, respectively (Akhani 2005). This UNESCO Biosphere Reserve comprises an area of $874 \mathrm{~km}^{2}$, with an elevation range of 450 to $2411 \mathrm{~m}$ above sea level (Akhani 2005). GNP is famous for its diverse landscapes and vegetation types and is the reserve holding the largest (sub)population of Persian leopards ( $n=27 \pm$ standard error SE 4.61 individuals; Hamidi et al. 2014). The area is well connected with three buffer protected areas in the east, west and northwest (Fig. 3.1). Urial sheep is the main ungulate species of the steppe region, highly sought after among local poachers and serving as one of the staple prey species of Persian leopard (Decker \& Kowalski 1972; Farhadinia et al. 2014; Hamidi et al. 2014). Despite a ban on hunting in all Iranian national parks, insufficient acceptability among local communities and lack of enough conservation measures have led this park to face dramatic ungulate declines in the past decades (Decker \& Kowalski 1972; Kiabi 1978; Hamidi et al. 2014). The steppe area of the park is divided into three management zones: the zone $A$ has three stations, the highest ranger station density compared to the zones $B$ and $C$ with each having one ranger station (Fig. 3.1). The station in the zone $\mathrm{C}$ is located $5 \mathrm{~km}$ outside of the park borders. Over 22,000 inhabitants live in 34 villages surrounding GNP, which are concentrated mostly in the northwest of the park, near the zone C (Fig. 3.1). 


\section{Survey design}

We applied distance sampling using line transects to estimate the density of urial sheep (Buckland et al. 2001). After classification of the park into forest, steppe, and semi-arid plain landscapes using satellite imagery (Landsat7, 2000) in ArcGIS 10.1 (ESRI, Redlands, CA), the steppe area was stratified for the urial survey (Fig. 3.1). The approximate total sampling area was $340 \mathrm{~km}^{2}$. Superimposing a systematic grid cell of $3 \times 3 \mathrm{~km}$ over the study area using Hawth's Tools in ArcGIS 9.3 (ESRI, Redlands, CA), we randomly selected 22 transects throughout the sampling area. Transects were chosen in the north-south direction, which complies with the general density gradient of the species from the core of the park to its boundaries (Buckland et al. 2001). One transect was later removed from the study as it crossed the rugged areas (slope $>45^{\circ} ; 30 \mathrm{~m}$ digital elevation map DEM) of the park and therefore was inaccessible. We walked or rode on horseback transects by groups of two to five people including the team members (A.G., A.K.H. and M.S.), park rangers, volunteers, and local ex-poachers. To offset high conservation costs and gain local support, in this study we applied line transect counts using a participatory approach (involving local people), which is increasingly adopted in natural resource management (Holmern et al. 2007). All groups were equipped with laser rangefinders, binoculars, compasses and handheld GPS units for optimum urial detection and calculation of distances to the transect line. All observers were trained on the use of field protocols and equipment, and each group consisted of at least one ranger or ex-poacher and one volunteer to minimize the observer bias in detection capabilities. Transects were conducted during winter and summer (as the detection probability of urials does not differ in the steppe habitat throughout the year; this study), for 13 fieldwork days (from 22 January to 19 February 2013, from 15 August to 8 September 2013 and from 21 to 24 February 2014). Total survey effort was $186 \mathrm{~km}$. In total, 31 volunteers, 19 park rangers and nine local expoachers participated. The total number of sampled transects was 17, as four out of the 21 designed transects were not surveyed because of hard accessibility or deep snow cover during winter (Fig. 3.1). Most transects $(n=12)$ were surveyed four times; four transects were surveyed three times, and one transect was surveyed 
twice (Table S3.1). All three management zones are located in suitable urial habitats (Pahlevani 2004) and were almost proportionately populated by this species with the estimates around 10,000-15,000 individuals during the last systematic population surveys conducted in the park in the 1970s (Decker \& Kowalski 1972; Kiabi 1978).

\section{Camera trapping}

We used camera-trapping data from the leopard population assessment project carried out in GNP by Persian Wildlife Heritage Foundation (Hamidi et al. 2014). In the steppe area, 29 passive camera traps (Deercam, Park Falls, WI) with $35 \mathrm{~mm}$ film were installed for 50 consecutive days from January to March 2011 along the main trails and ridge tops of the park, wherever leopard signs were present (Hamidi et al. 2014). One camera trap was installed per station at the height of $40 \mathrm{~cm}$, operating day and night with one-minute delay between consecutive photographs (Hamidi et al. 2014). Nine camera traps were stolen during this period; from six of them data were available only for 25 days and from three cameras no data were retrieved.

\section{Data analysis}

We used Distance 6.0 software (Thomas et al. 2010) for estimation of urial sheep density while accounting for detectability and selected the best model based on the lowest Akaike's Information Criterion (AIC) score (Buckland et al. 2001; Waltert et al. 2008). To reduce potential errors in counting and measuring distances to remote observations, a 5\% right truncation was performed (Buckland et al. 2001; Thomas et al. 2010). This truncation resulted in omitting observations farther than $587 \mathrm{~m}$ distance.

We used the urial cluster density $\left(C D\right.$, number of clusters $\left./ \mathrm{km}^{2}\right)$ as the metric of urial abundance (Muchaal \& Ngandjui 1999). We defined the cluster as a group of urials encountered together in a site. The CD was estimated in Distance, using transect-specific encounter rate (ER; number of cluster observations per kilometer of transect surveyed) and a global detection probability estimate. The best-fitting detection function was derived from a half-normal key with transect effective strip width of $344.43 \mathrm{~m}$. Since the numbers of urial observations on each transect were 
not sufficient to fit transect-specific detection functions, the global detection probability estimate was also used for estimation of $C D$ at transect level. We also used the cluster size (CS, individuals) to assess the effects of different variables on the urial demography (Manor \& Saltz 2003; Averbeck et al. 2012). On each transect, we calculated the median of CS and its 95\% confidence interval ( $\mathrm{Cl}$ ) based on 2000 bootstrap replicates in Flocker 1.1 software (Reiczigel et al. 2008).

Leopards were recognized individually from their unique coat pattern on flanks and limbs (Ghoddousi et al. 2010). Because of using one camera per station, only photos from either flank (left or right) with the highest numbers of identified individuals were used (Hamidi et al. 2014). We used the rounded mean number of leopard individuals identified from camera traps in the radius of $3 \mathrm{~km}$ from the central point of each transect as the metric of leopard abundance. Data from between zero to four camera traps were used for each transect to estimate leopard abundance. No camera traps were available near two transects (ID 14 and 16; Fig. 3.1) and therefore these transects were removed from the leopard analysis.

We used the population metrics of urial CD, CS and leopard abundance as the response variables to analyze effects of different variables (Muchaal \& Ngandjui 1999; Urquiza-Hass et al. 2011; Vanthomme et al. 2013). In order to assess the edge effect (Woodroffe \& Ginsberg 1998) and the impacts of ranger station distribution (Dajun et al. 2006) and human population (Jachmann 2008; Metzger et al. 2010) on response variables, we considered three anthropogenic predictor variables (closest distances from park border, ranger stations, and villages). Additionally, we considered three environmental predictor variables (closest distance to water resources, normalized difference vegetation index (NDVI) and slope) to assess the effects of habitat features on response variables (Ransom et al. 2012). We measured the distance predictor variables (distances to park border, ranger stations, villages and water resources) from the transect center points and the average NDVI and slopes in the $1.5 \mathrm{~km}$ radius of each transect center point in ArcGIS 10.1. When GNP borders adjoined the neighboring protected areas (Fig. 3.1), we measured the nearest distance to the borders with unprotected areas. We measured slopes from the $30 \mathrm{~m}$ DEM map of GNP. We obtained NDVI data from a Moderate Resolution 
Imaging Spectroradiometer (MODIS) scene available from the National Aeronautics and Space Administration, NASA (http://modis.gsfc.nasa.gov/data). We tested the relationship between leopard abundance and urial density (interaction of transectspecific urial $\mathrm{CD}$ and $\mathrm{CS}$ ) on transects.

As two to three rangers per shift (7-10 days) were based in each ranger station of GNP during our research, patrolling intensity was not biased by numbers of rangers. Rangers normally do few daily patrols per shift by vehicle, horse or walking to detect poachers and return to their stations, rarely staying in the field overnight. Despite an effort to widely spread the patrols in each management zone, almost all patrolling trips begin from the stations and the areas around them are the most intensively patrolled. Rangers' patrolling intensity, efficiency and motivations can be variable, but difficult to measure. Due to the lack of spatial records of the patrolling routes, we were not able to measure patrolling intensity and efficiency (Linkie et al. 2015) and therefore they were assumed to be equally distributed between all the stations. Usually, rangers in GNP rotate their positions between shifts and stations every few months, which mitigates potential biases due to variations in team performance.

We tested multicollinearity of predictor variables using the collinearity diagnostics test (Variance Inflation Factor; VIF) (Kutner et al. 2004). We identified the influential data points of outliers by regressing the Cook's distance against the centered leverage values for each transect. We visually identified the data points far from the regression line with high Cook's distance and centered leverage values and excluded them from the analysis (Fig. S3.1, S3.2 and S3.3). We used two-tailed $Z$ test for comparison of differences in seasonal ER. For assessing the combined effects of environmental and anthropogenic variables, we tested the relationship between the response variables (urial CD and CS and leopard abundance) and all possible combinations of all predictor variables using the generalized linear modeling (GLM) framework. We acknowledge that in the GLM analysis estimates of variance in our response variables (urial CD, CS and leopard abundance) are not taken into account. 
As all villages are located outside the GNP borders, we assumed that a potential interaction between the distance from park border and the distance from villages might exist. Therefore, we included the interaction of these two variables as an additional predictor. We used Tweedie distribution and log link function, which is a highly flexible family of distributions (Jorgensen 1987). The Tweedie distributions have been only recently used in ecological studies and are applicable for monitoring data, as they account for non-negative data with the spike at zero (Swallow et al. 2016). We used Poisson distribution for the leopard abundance GLM analysis. Because of small sample size, we chose the best model based on second-order corrected AIC $\left(\mathrm{AIC}_{\mathrm{c}}\right)$ values and their differences $(\Delta)$ using the multi-model inference R package 'MuMIn' (Barton 2009; Burnham \& Anderson 2002) (Table S3.2). The best models with $\Delta<2$ were chosen to explain the relationships between the response and predictor variables (Burnham \& Anderson 2002) (Table S3.2). We applied the Akaike weights to rank models (Burnham \& Anderson 2002) (Table S3.2). We conducted the analyses using R statistical software 2.15.1 (R Development Core Team, 2012) and SPSS 17.0 (SPSS, 2008).

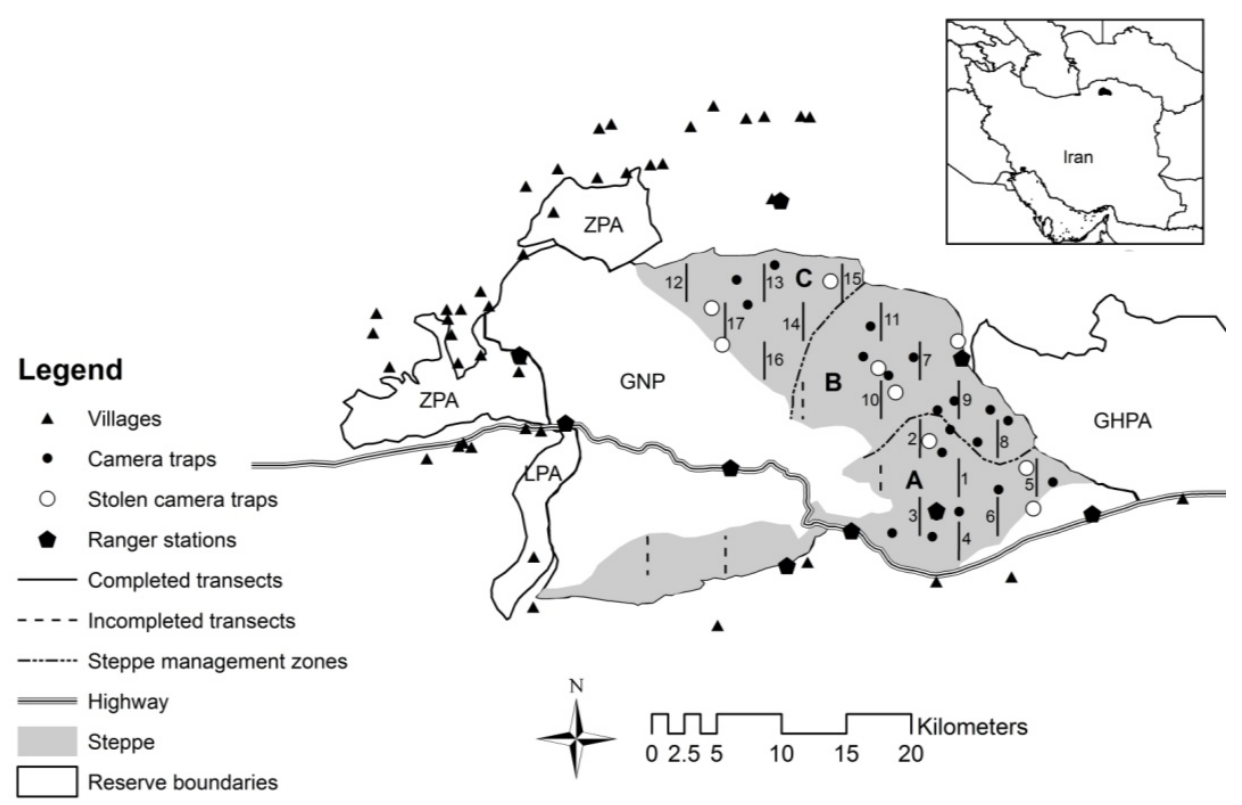

Figure 3.1. Location of Golestan National Park in the northeast of Iran (black area; inset map) and distribution of line transects (with ID number), camera traps and management zones ( $\mathrm{A}, \mathrm{B}$ and $\mathrm{C}$ ) in the steppe area, as well as villages and ranger stations of the park (GNP: Golestan National Park, GHPA: Ghorkhod Protected Area, LPA: Loveh Protected Area, ZPA: Zav Protected Area). 


\subsection{Results}

During the line transect counts, we observed 1981 urials in 70 groups and found no difference in ER between the seasons $(Z=1.18, P=0.23)$. The average ER was 0.37 groups $/ \mathrm{km}$ (coefficient of variation $\mathrm{CV} \%=30.80$ ). Urial clusters varied from one to 191 individuals. The global mean CS after truncation was $29.06 \pm$ SE 3.98 animals/cluster in 66 observations. The global density of urials was estimated at 12.57 individuals $/ \mathrm{km}^{2}(\mathrm{CV} \%=35.51 ; 95 \% \mathrm{Cl}=6.22-25.38)$ and the population size was estimated at 4275 individuals $(95 \% \mathrm{Cl}=2117-8632)$. By incorporating an effort of 1150 camera trap-nights, we took 35 leopard captures and identified nine leopard individuals based on left flank pictures.

There was no multicollinearity of predictor variables (VIF < 10), but one outlier transect was removed from the urial CD and CS analyses (ID 3; Fig. 3.1) due to high Cook's distance and centered leverage values. This transect is located in a different habitat than the rest of the study area on the only high plateau of the park in the transition area between the forest and steppe landscapes. This area was not occupied by urials during our study, possibly due to heavy winds and far distances from available shelters. For urial CD and CS, we used the Tweedie distribution, which revealed that the compound Poisson-Gamma distribution (power $=1.5$ ) best fitted our continuous non-integer non-negative zero-inflated data. Model ranking based on the lowest $\mathrm{AIC}_{\mathrm{c}}$ values showed a negative relationship between the distance to ranger stations and urial CD in the top models (see above; Table 3.1). In the two top models, the distance to ranger stations was significantly inverse to urial $C D$, while the distance to borders showed a positive relationship only in one of these models (Table 3.1). A similar influence of the distance to ranger stations was observed in the models of urial CS and other predictor variables (see above; Table 3.1). The distance to ranger stations was the single best predictor in explaining urial CS. Among the leopard models, urial density was the most influential predictor of its abundance, whereas other predictor variables were not presented among the best models (see above; Table 3.1). 
On average, transect-specific urial density was 145.13 times higher in the zone A with three ranger stations $\left(21.77 \pm\right.$ SE 7.92 individuals $\left./ \mathrm{km}^{2}\right)$ than in the zone $C$ with one station outside of the park $\left(0.15 \pm\right.$ SE 0.09 individuals $\left./ \mathrm{km}^{2}\right)$. The zone $B$ with one station at the boundary of the park (6.90 \pm SE 2.97 individuals $\left./ \mathrm{km}^{2}\right)$ had 46 times higher average urial density than the zone $\mathrm{C}$.

Table 3.1. Summary of the top four generalized linear models (GLM) for urial cluster density, urial cluster size and leopard abundance in Golestan National Park (GNP), Iran.

\begin{tabular}{|c|c|c|c|c|c|c|c|c|c|c|}
\hline Rank & $\begin{array}{c}\text { Model } \\
\text { covariates }^{a}\end{array}$ & \multicolumn{4}{|c|}{ Parameter $^{\mathrm{b}}$} & \multicolumn{5}{|c|}{ Coefficient ( \pm standard error) } \\
\hline \multicolumn{11}{|c|}{ Urial cluster density (after exclusion of one outlier transect) } \\
\hline & & $\mathrm{K}$ & $\mathrm{AIC}_{\mathrm{c}}$ & $\Delta$ & $\begin{array}{c}\mathrm{AIC}_{\mathrm{w}} \\
(\%)\end{array}$ & Intercept & RSt & Bor & NDVI & \\
\hline 1 & RSt & 3 & 38.33 & $0.00^{c}$ & 22.32 & $1.51 \pm 0.69$ & $-0.40 \pm 0.12$ & & & \\
\hline 2 & RSt + Bor & 4 & 39.22 & $0.89^{c}$ & 14.32 & $0.50 \pm 0.76$ & $-0.44 \pm 0.11$ & $0.27 \pm 0.13$ & & \\
\hline 3 & NDVI & 3 & 40.95 & 2.62 & 6.03 & $0.66 \pm 0.56$ & & & $-0.06 \pm 0.02$ & \\
\hline 4 & RSt + NDVI & 4 & 41.19 & 2.86 & 5.35 & $1.67 \pm 0.75$ & $-0.33 \pm 0.14$ & & $-0.02 \pm 0.03$ & \\
\hline \multicolumn{11}{|c|}{ Urial cluster size (after exclusion of one outlier transect) } \\
\hline & & $\mathrm{K}$ & $\mathrm{AIC}_{\mathrm{c}}$ & $\Delta$ & $\begin{array}{c}\mathrm{AIC}_{\mathrm{w}} \\
(\%)\end{array}$ & Intercept & RSt & Bor & Wat & Vil \\
\hline 1 & RSt & 3 & 97.68 & $0.00^{\mathrm{c}}$ & 31.94 & $4.40 \pm 0.60$ & $-0.38 \pm 0.10$ & & & \\
\hline 2 & $\mathrm{RSt}+\mathrm{Bor}$ & 4 & 100.66 & 2.98 & 7.19 & $4.03 \pm 0.77$ & $-0.40 \pm 0.11$ & $0.11 \pm 0.13$ & & \\
\hline 3 & RSt + Wat & 4 & 100.68 & 3.00 & 7.14 & $4.20 \pm 0.69$ & $-0.41 \pm 0.11$ & & $0.18 \pm 0.22$ & \\
\hline 4 & RSt + Vil & 4 & 100.75 & 3.07 & 6.88 & $4.82 \pm 0.79$ & $-0.38 \pm 0.10$ & & & $-0.04 \pm 0.06$ \\
\hline \multicolumn{11}{|c|}{ Leopard abundance } \\
\hline & & $\mathrm{K}$ & $\mathrm{AIC}_{\mathrm{c}}$ & $\Delta$ & $\begin{array}{c}\mathrm{AIC}_{\mathrm{w}} \\
(\%)\end{array}$ & Intercept & $\mathrm{D}$ & Bor & Wat & Vil \\
\hline 1 & D & 3 & 42.97 & $0.00^{c}$ & 25.43 & $-0.24 \pm 0.33$ & $0.03 \pm 0.01$ & & & \\
\hline 2 & $D+V i l$ & 4 & 45.15 & 2.17 & 8.55 & $-0.96 \pm 0.82$ & $0.03 \pm 0.01$ & & & $0.06 \pm 0.06$ \\
\hline 3 & $D+$ Wat & 4 & 45.56 & 2.58 & 6.98 & $-0.65 \pm 0.65$ & $0.03 \pm 0.01$ & & $0.20 \pm 0.25$ & \\
\hline 4 & $D+$ Bor & 4 & 45.98 & 3.01 & 5.68 & $-0.05 \pm 0.58$ & $0.03 \pm 0.01$ & $-0.06 \pm 0.15$ & & \\
\hline
\end{tabular}

${ }^{a}$ Abbreviation of covariates: RSt, shortest distance from transect center points to ranger stations $(\mathrm{km})$; Bor, shortest distance from transect center points to GNP borders with unprotected areas $(\mathrm{km})$; NDVI, normalized difference vegetation index in a $1.5 \mathrm{~km}$ radius of transect center points; Wat, shortest distance from transect center points to water resources $(\mathrm{km})$; Vil, shortest distance from transect center points to villages; D, urial density on transects (cluster size CS $\times$ cluster density CD, individuals $/ \mathrm{km}^{2}$ ).

${ }^{b}$ Abbreviation of parameters: K, number of model parameters; $\mathrm{AIC}_{\mathrm{c}}$, second-order corrected Akaike's Information Criterion; $\Delta$, difference in $\mathrm{AIC}_{\mathrm{c}}$ scores between a given model and the best model; $\mathrm{AIC}_{\mathrm{w}}$, Akaike weight (\%)

${ }^{\mathrm{c}}$ Best fitting models with $\Delta<2$ (Burnham \& Anderson 2002) 


\subsection{Discussion}

Several regional studies show that large mammal populations can respond positively to law enforcement over time (Hilborn et al. 2006; Jachmann 2008), but the role of ranger stations and associated patrolling effort in shaping the spatial distribution and population structure of species in predator-prey complexes has been rarely documented (Dajun et al. 2006; Jenks et al. 2012). A few studies show that high hunting pressure can force sought-after species to move to safer areas (Kilgo et al. 1998; Jenks et al. 2012), such as conservation stations, monitoring, or tourism centers (Dajun et al. 2006; N'Goran et al. 2012). Here, we also documented a spatial relationship between the distribution of ungulates and conservation infrastructure. Given the secondary importance of environmental variables in our dataset, we are inclined to relate the distribution and density difference of urials to an increased deterrence of poachers in the stations' vicinity. Urials in GNP live in an open homogenous habitat, mainly consisting of juniper woodland and steppe (Stipa, Artemisia and Artemisia-Stipa steppes), with constant accessibility to perennial water resources (Decker \& Kowalski 1972; Pahlevani 2004; Akhani 2005). Therefore, a lack of an influence of water availability and vegetation cover on urial distribution is plausible.

According to suggested levels of enforcement to control illegal activities (staff ratio of one ranger per $23.8 \mathrm{~km}^{2}$ in savanna woodland of southern Africa; Jachmann \& Billiouw 1997), GNP's steppe area has relatively sufficient law enforcement personnel (one ranger per $28.3 \mathrm{~km}^{2}$ in every shift). However, the recent urial population (4275 individuals, $95 \% \mathrm{Cl}=2117-8632 ; 2013-2014$ ) is $57.3-71.5 \%$ lower in comparison to the earlier estimates in the 1970s in GNP (but see different methodologies used by Decker \& Kowalski 1972; Kiabi 1978). These, in combination with our recent data, suggest that the spatial arrangement of ranger stations might have resulted into different levels of poacher deterrence, with the management zone C (Fig. 3.1) without ranger station inside the park experiencing an especially sharp decline in urial numbers. This suggests that placing ranger stations in or near villages may not reduce poaching from these villages in a significant way (Dajun et al. 2006). In contrast, establishing ranger stations in villages can expose ranger's 
patrolling efforts to local poachers. The establishment of ranger stations should happen primarily inside protected areas in order to be able to detect noncompliance directly. The decision on the exact location should be based upon considerations of patrolling efficiency, poaching levels or concentrations of most threatened conservation targets (Campbell et al. 2011; Plumptre et al. 2014).

Mapping the distribution of effective law enforcement (e.g., patrol routes and poacher detentions/unit of effort) is beneficial for the identification of patrolling gaps. For a robust assessment of law enforcement distribution, it is recommended to record patrolling routes and intensity, as well as conservation non-compliance and wildlife encounters (Plumptre et al. 2014; Linkie et al. 2015).

Cluster size and sex/age composition of ungulates have been suggested as metrics of human nuisance assessment (Averbeck et al. 2012). The cluster size of ungulates may indicate poaching pressure when robust population estimates cannot be obtained and is believed to detect subtle human disturbances even before changes in abundance occur (Averbeck et al. 2012). Being a simple demography metric, which can be easily collected by rangers, cluster size may be monitored for such purposes. Also in our study area, the social organization of urials may have varied with hunting pressure as exemplified by the low cluster sizes in areas far from stations. Unfortunately, sex/age ratio monitoring was not possible in our study site as the urial sheep clusters are timid and the differentiation of young males from adult females in remote distances may be affected by observer skills.

In contrast to other studies (Holmern et al. 2007; Jachmann 2008; Metzger et al. 2010; N'Goran et al. 2012), which found effects of villages (as sources of poaching) on game species abundance, we found little influence of distance to villages on urial abundance and demography. Urial cluster density, however, was affected by the distance to park borders, which positively contributed to the second best GLM model. We suspect that the lack of a strong relationship with distances to villages and borders is due to the relatively small size of GNP and an ease of access to its core areas by poachers. 
We found a strong evidence for the dependence of leopard abundance on urial densities, but we could not detect a direct relationship between leopard abundance and the location of ranger stations. Herbivore abundance is known to be the main determinant of large carnivore distribution at a broad scale, although at a finer scale prey 'catchability' may be a more important predictor (Hopcraft et al. 2005; Balme et al. 2007). Being affected by lack of prey (Henschel et al. 2011), the spatial distribution of carnivores may rely on prey distribution at a spatial scale different than those of poaching and law enforcement (Karanth et al. 2004; Jenks et al. 2012). Studying leopard distribution at a finer scale may reveal other patterns between leopard, prey and poaching in our study area.

With this research we show that distance to ranger stations may serve as a valuable variable in distribution and abundance of harvested species in steppe areas of northeastern Iran. It also shows that the coverage (both numbers and locations) of ranger stations is of special importance for management planning. In addition, the study shows that the use of population metrics such as cluster size may help to uncover otherwise cryptic illegal behavior and effects of law enforcement on wildlife.

\section{Acknowledgements}

German Academic Exchange Service (DAAD) and Panthera's Kaplan Graduate Award funded the PhD research of A.G. Erasmus Mundus and Alexander von Humboldt Foundation funded M.S. and I.K., respectively. We are grateful for the support by Iranian Department of Environment, Golestan provincial office of Department of Environment, and Golestan National Park management for collaborating with us at every stage of this study. We thank Persian Wildlife Heritage Foundation for securing access to their camera trapping data and logistical support during the fieldwork. Turkmen Ecolodge provided generous logistical support throughout this project, which we sincerely appreciate. This work would have not been possible without the support from Golestan National Park's rangers, as well as all the local guides and volunteers who participated in this project. We thank them all. We would like to 
thank E. J. Milner-Gulland and three anonymous reviewers for their useful comments on the earlier version of the manuscript. 
3.5. Supplementary material

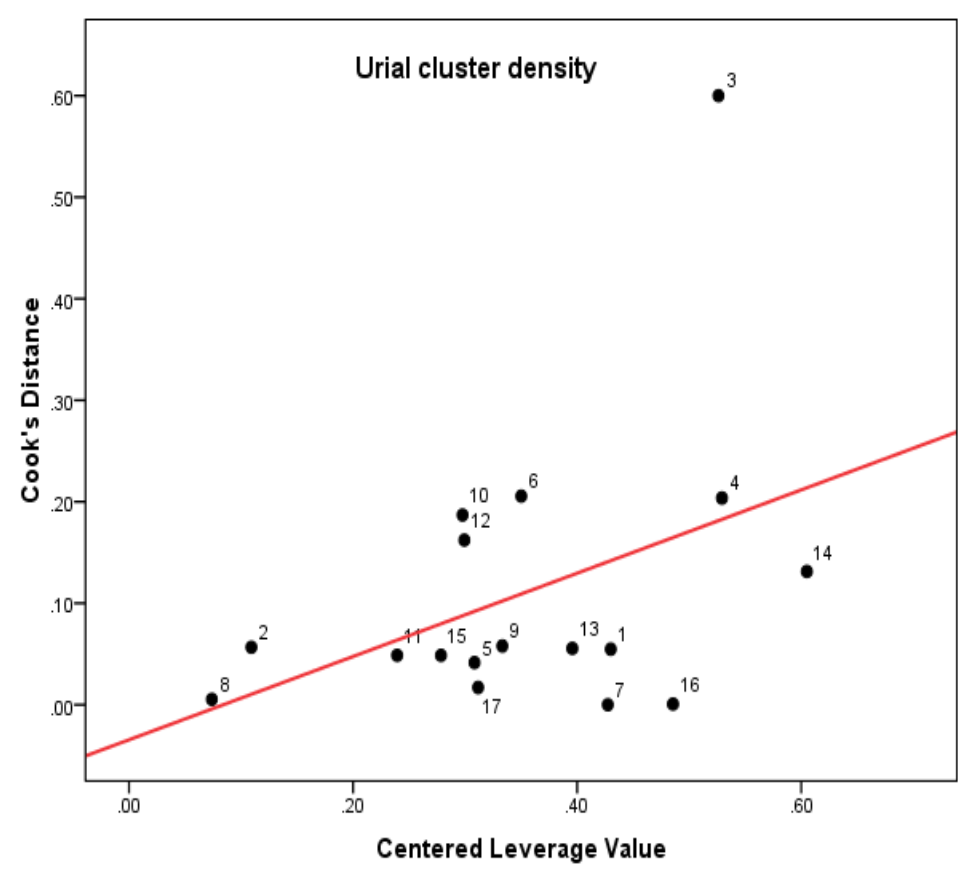

Figure S3.1. The Cook's distance and leverage values of transect-specific urial cluster density and its regression line.

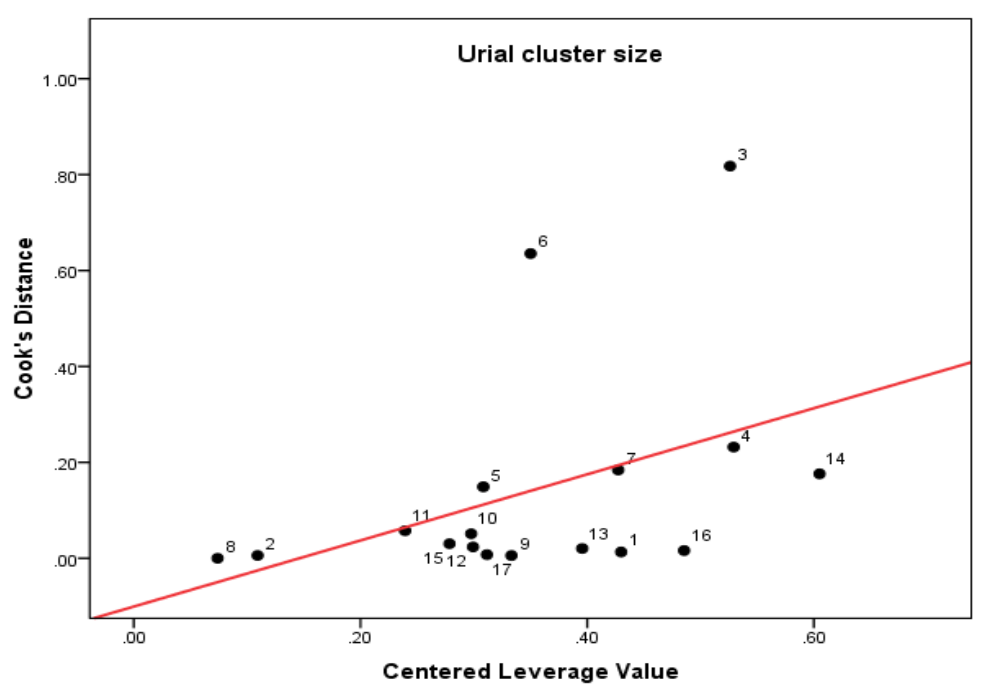

Figure S3.2. The Cook's distance and leverage values of transect-specific urial cluster size and its regression line. 


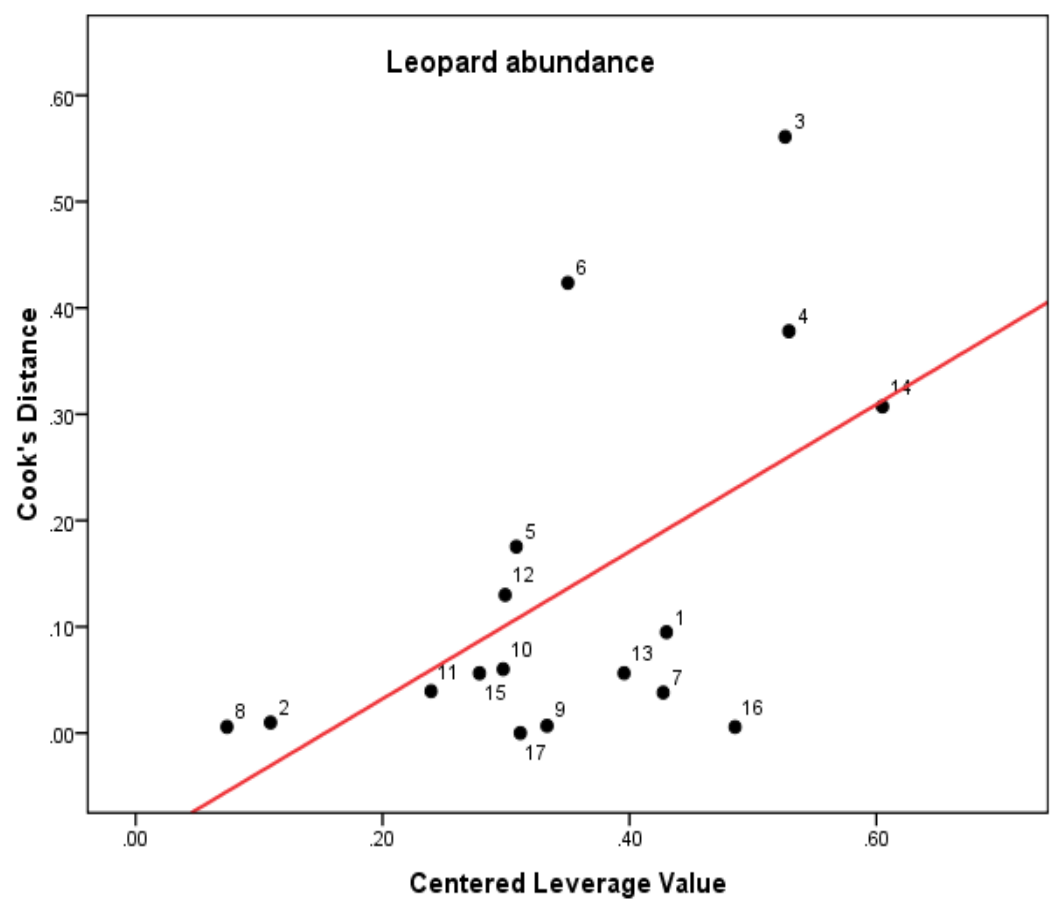

Figure S3.3. The Cook's distance and leverage values of transect-specific leopard abundance and its regression line.

We used Cook's distance in combination with leverage values to understand the influence of each data point. We plotted these two factors and visually identified the data points with influential high Cook's distance (Fig. S3.1, S3.2 and S3.3). In the urial analyses, we only removed the transect \#3 with the Cook's distance 0.6-0.8 and the leverage values $\sim 0.5$ (Fig. S3.1 and S3.2). We earlier suspected that this transect might be irrelevant as it is located in a different setting than other transects. This transect is located in the only high plateau of the park, which is affected by heavy winds and has no shelters. There are no recent records of urials in this area. Therefore, we believe that the exclusion of only one transect from the analyses due to statistical and empirical reasons is not biased toward any preconceptions and our results are valid. We used all 15 transects to explore the relationship between leopard abundance and the response variables, as no influential transect with high Cook's distance value was observed (Fig. S3.3). 
Table S3.1. Summary of data on each transect regarding urial population metrics (CD and CS) and leopard abundance and the related anthropogenic and environmental variables.

\begin{tabular}{|c|c|c|c|c|c|c|c|c|c|c|c|c|c|c|}
\hline \multicolumn{2}{|c|}{ Transect } & \multicolumn{6}{|c|}{ Urial } & \multirow{2}{*}{$\begin{array}{c}\text { Leopard } \\
\text { Abundance }^{d}\end{array}$} & \multicolumn{6}{|c|}{ Anthropogenic variables } \\
\hline ID & $(\mathrm{km})$ & Observations & $\begin{array}{c}\mathrm{CD}^{\mathrm{a}} \\
\text { (clusters } / \mathrm{km}^{2} \text { ) }\end{array}$ & $\mathrm{Cl}^{\mathrm{a}}$ & $\mathrm{CS}^{\mathrm{b}}$ & $\mathrm{Cl}^{\mathrm{b}}$ & $\begin{array}{c}\mathrm{D}^{\mathrm{c}} \text { (individuals } / \mathrm{k} \\
\mathrm{m}^{2} \text { ) }\end{array}$ & & $\begin{array}{l}\mathrm{RSt}^{\mathrm{e}} \\
(\mathrm{km})\end{array}$ & $\begin{array}{l}\text { Bor }^{f} \\
(\mathrm{~km}) \\
\end{array}$ & $N D V I^{g}$ & $\begin{array}{l}\text { Wat } \\
(\mathrm{km})\end{array}$ & $\begin{array}{c}\text { Slop } \\
\left(^{\circ}\right)\end{array}$ & $\begin{array}{r}\mathrm{Vil}^{\mathrm{j}} \\
(\mathrm{km}) \\
\end{array}$ \\
\hline 1 & 12 & 17 & 1.84 & $1.56-2.16$ & 25 & $15.00-44.00$ & 46 & 2 & 3.15 & 6.75 & 8 & 1.48 & 7.35 & 8.18 \\
\hline 2 & 6 & 6 & 1.3 & $1.10-1.53$ & 16 & $4.00-81.00$ & 20.8 & 3 & 5.99 & 6.56 & 30 & 1.36 & 8.98 & 11.04 \\
\hline $3^{*}$ & 12 & 0 & 0 & 0 & 0 & 0 & 0 & 0 & 1.35 & 4.15 & 19 & 1.04 & 5.89 & 5.18 \\
\hline 4 & 9 & 3 & 0.43 & $0.36-0.51$ & 7 & $4.00-25.41$ & 3.01 & 0 & 2.78 & 2.17 & 28 & 0.34 & 12.4 & 3.57 \\
\hline 5 & 12 & 14 & 1.51 & $1.28-1.78$ & 28.5 & $5.00-43.00$ & 43.04 & 4 & 5.48 & 4.32 & 9 & 1.78 & 6.85 & 7.81 \\
\hline 6 & 12 & 5 & 0.54 & $0.46-0.63$ & 33 & $33.00-33.00 * *$ & 17.82 & 2 & 4.69 & 2.67 & 34 & 2.28 & 9.07 & 4.71 \\
\hline 7 & 12 & 6 & 0.65 & $0.55-0.76$ & 23 & $5.00-109.00$ & 14.95 & 2 & 3.25 & 3.25 & 12 & 2.61 & 6.91 & 16.94 \\
\hline 8 & 12 & 9 & 0.97 & $0.82-1.14$ & 10 & $4.00-42.00$ & 9.7 & 1 & 6.75 & 5.4 & 27 & 1.1 & 9.12 & 10.65 \\
\hline 9 & 12 & 8 & 0.86 & $0.73-1.02$ & 11.5 & $4.00-50.00$ & 9.89 & 2 & 3.21 & 2.36 & 20 & 2.57 & 9.97 & 14.12 \\
\hline 10 & 12 & 0 & 0 & 0 & 0 & 0 & 0 & 1 & 7.05 & 7.05 & 42 & 0.57 & 12.58 & 14.64 \\
\hline 11 & 12 & 0 & 0 & 0 & 0 & 0 & 0 & 0 & 6.82 & 2.73 & 14 & 4.23 & 4.99 & 12.69 \\
\hline 12 & 9 & 1 & 0.14 & $0.12-0.17$ & 3 & $3.00-3.00 * *$ & 0.42 & 0 & 9.26 & 1.72 & 35 & 2.08 & 6.82 & 9.26 \\
\hline 13 & 12 & 0 & 0 & 0 & 0 & 0 & 0 & 1 & 6.55 & 2.33 & 17 & 0.7 & 3.62 & 6.55 \\
\hline 14 & 12 & 1 & 0.1 & $0.09-0.12$ & 5 & $5.00-5.00 * *$ & 0.5 & $N A^{* * *}$ & 9.79 & 5.1 & 35 & 5.26 & 9.63 & 9.79 \\
\hline 15 & 12 & 0 & 0 & 0 & 0 & 0 & 0 & 2 & 8.47 & 1.94 & 15 & 3.37 & 4.56 & 8.47 \\
\hline 16 & 9 & 0 & 0 & 0 & 0 & 0 & 0 & $N A^{* * *}$ & 12.54 & 8.36 & 53 & 1.33 & 9.55 & 12.54 \\
\hline 17 & 9 & 0 & 0 & 0 & 0 & 0 & 0 & 0 & 10.17 & 5.15 & 50 & 1.46 & 13.44 & 10.17 \\
\hline
\end{tabular}

${ }^{\mathrm{a}}$ Urial cluster density (CD) (clusters $/ \mathrm{km}^{2}$ ) calculated by transect-specific encounter rate and global detection function and the related $95 \%$ confidence intervals $(\mathrm{Cl})$ in the

\section{Distance software}

${ }^{b}$ Urial cluster size calculated as the median of groups observed on each transect and the related $95 \%$ confidence intervals (Cl) with 2000 bootstrap replications in Flocker 1.1 software

${ }^{\mathrm{C}}$ Urial density (D) calculated as the interaction of urial cluster density (CD) and cluster size (CS) (individuals/ $\mathrm{km}^{2}$ )

${ }^{\mathrm{d}}$ Leopard abundance based on rounded mean identified individuals in camera traps in $3 \mathrm{~km}$ radius distance from the transect centre points. 
e Shortest distance from transect center points to ranger stations (RSt) (km)

${ }^{\mathrm{f}}$ Shortest distance from transect center points to GNP borders with unprotected areas (Bor) (km)

${ }^{\mathrm{g}}$ Normalized difference vegetation index (NDVI) in a $1.5 \mathrm{~km}$ radius of transect center points

${ }^{\mathrm{h}}$ Shortest distance from transect center points to water resources (Wat) (km)

'Average slope in a $1.5 \mathrm{~km}$ radius of transect center points based on digital elevation map (DEM)

${ }^{j}$ Shortest distance from transect center points to villages (Vil) ( $\mathrm{km}$ )

* Removed from urial analysis after being identified as outlier

** Due to low number of cluster observations, calculation of $\mathrm{Cl}$ was not possible for these transects.

*** Two transects had no camera traps in their vicinity (NA) and removed from leopard analysis. 
Table S3.2. Detail of top five generalized linear models (GLM) of urial cluster density, urial cluster size and leopard abundance in Golestan National Park (GNP), Iran.

\begin{tabular}{|c|c|c|c|c|c|c|c|c|c|c|c|c|c|}
\hline Rank & Intercept & $\begin{array}{c}\text { Distance } \\
\text { to } \\
\text { border }\end{array}$ & $\begin{array}{c}\text { Distance to } \\
\text { ranger } \\
\text { stations }\end{array}$ & $\begin{array}{c}\text { Distance } \\
\text { to villages }\end{array}$ & $\begin{array}{c}\text { Distance to } \\
\text { water } \\
\text { resources }\end{array}$ & NDVI & Slope & $\begin{array}{l}\text { Distance to } \\
\text { border } \mathrm{x} \\
\text { Distance to } \\
\text { villages }\end{array}$ & $\begin{array}{c}\text { Urial } \\
\text { density }\end{array}$ & $\begin{array}{l}\text { Degree of } \\
\text { freedom }\end{array}$ & $\mathrm{AlCc}$ & $\begin{array}{l}\text { AICc } \\
\text { Delta }\end{array}$ & $\begin{array}{c}\text { AICc } \\
\text { Weight } \\
(\%)\end{array}$ \\
\hline \multicolumn{14}{|c|}{ Urial cluster density } \\
\hline 1 & 1.506 & NA & -0.396 & NA & NA & NA & NA & $\mathrm{NA}$ & NA & 2 & 38.330 & 0.000 & 22.321 \\
\hline 2 & 0.499 & 0.275 & -0.435 & NA & NA & NA & NA & NA & NA & 3 & 39.218 & 0.888 & 14.316 \\
\hline 3 & 0.658 & NA & NA & NA & NA & -0.059 & NA & NA & NA & 2 & 40.949 & 2.619 & 6.026 \\
\hline 4 & 1.672 & NA & -0.325 & NA & NA & -0.025 & NA & NA & NA & 3 & 41.187 & 2.857 & 5.350 \\
\hline 5 & 1.697 & NA & -0.380 & NA & -0.152 & NA & NA & NA & $\mathrm{NA}$ & 3 & 41.478 & 3.148 & 4.624 \\
\hline \multicolumn{14}{|c|}{ Urial cluster size } \\
\hline 1 & 4.408 & NA & -0.383 & NA & NA & NA & NA & NA & NA & 2 & 97.680 & 0.000 & 31.949 \\
\hline 2 & 4.031 & 0.113 & -0.401 & NA & NA & NA & NA & NA & NA & 3 & 100.660 & 2.980 & 7.199 \\
\hline 3 & 4.202 & NA & -0.415 & NA & 0.187 & NA & NA & NA & NA & 3 & 100.680 & 3.000 & 7.143 \\
\hline 4 & 4.830 & NA & -0.382 & -0.045 & NA & NA & NA & NA & NA & 3 & 100.750 & 3.070 & 6.887 \\
\hline 5 & 4.862 & NA & -0.386 & NA & NA & NA & -0.052 & NA & NA & 3 & 100.930 & 3.250 & 6.288 \\
\hline \multicolumn{14}{|c|}{ Leopard abundance } \\
\hline 1 & -0.248 & NA & NA & NA & NA & NA & NA & NA & 0.034 & 2 & 42.975 & 0.000 & 25.437 \\
\hline 2 & -0.965 & NA & NA & 0.067 & NA & NA & NA & NA & 0.038 & 3 & 45.154 & 2.179 & 8.556 \\
\hline 3 & -0.651 & NA & NA & NA & 0.201 & NA & NA & NA & 0.036 & 3 & 45.561 & 2.586 & 6.981 \\
\hline 4 & -0.050 & -0.062 & NA & NA & NA & NA & NA & NA & 0.038 & 3 & 45.989 & 3.013 & 5.638 \\
\hline 5 & 0.067 & NA & NA & NA & NA & $\mathrm{NA}$ & -0.038 & NA & 0.033 & 3 & 46.009 & 3.034 & 5.580 \\
\hline
\end{tabular}




\section{Chapter 4: Precision and reliability of indirect population assessments for the Caspian red deer (Cervus elaphus maral)}

Mahmood Soofi, Arash Ghoddousi, Amirhossein Kh. Hamidi, Banjamin Ghasemi, Lukas Egli, Ana-Johanna Voinopol-Sassu, Bahram H. Kiabi, Niko Balkenhol, Igor Khorozyan, Matthias Waltert

Resubmitted, Wildlife Biology, submission date: $14^{\text {th }}$ January 2016

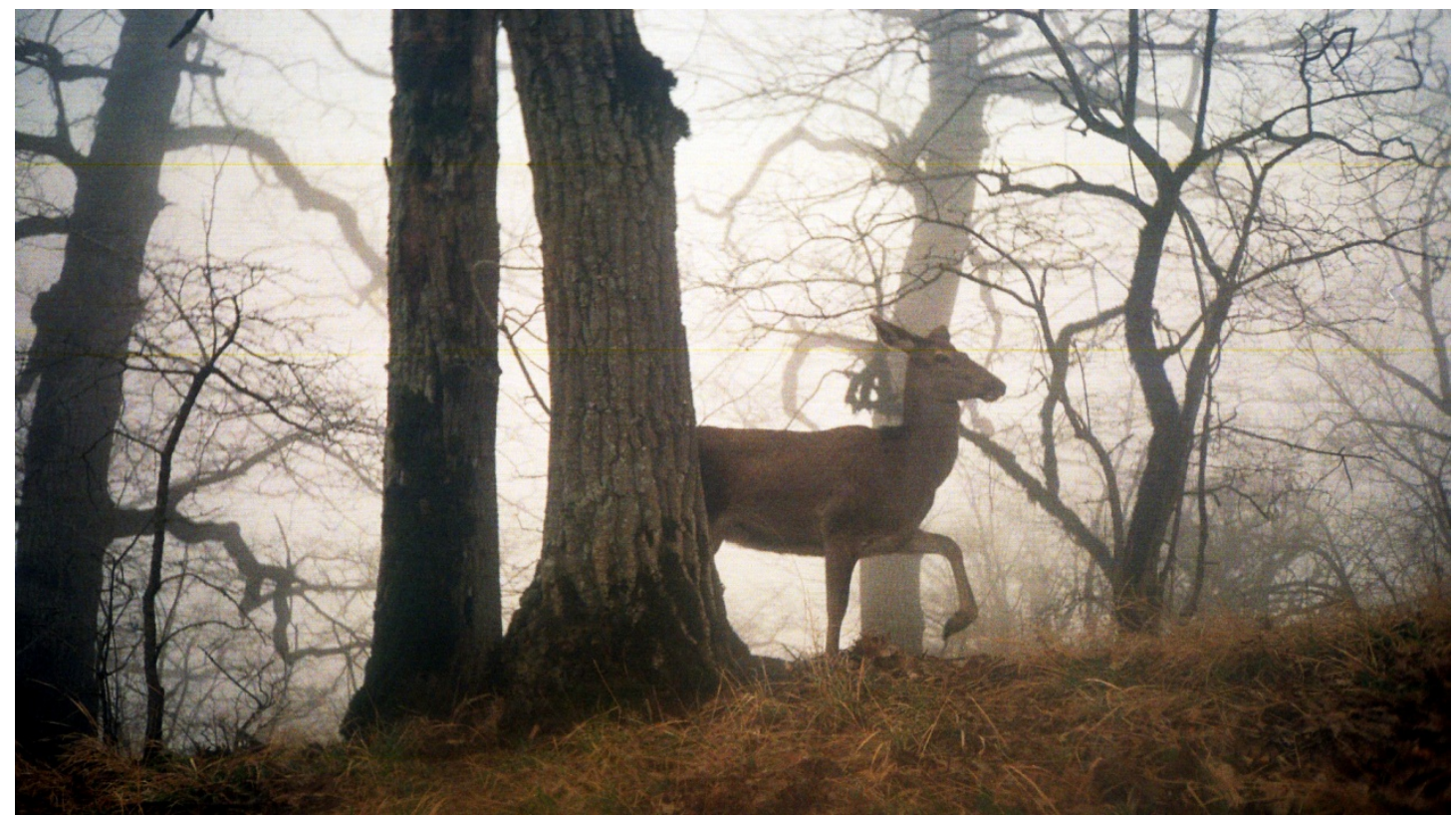

A camera trap photo of red deer in Golestan National Park. Photo: PWHF/GAUG/Panthera/Golestan DoE 


\section{Abstract}

The elusive Caspian red deer (Cervus elaphus maral) lives at low densities in rugged forest habitats of the Caucasus and the South Caspian region, and its declining population requires urgent attention. We here address the precision and reliability of dung counts (Fecal Standing Crop approach FSC) and camera trapping (Random Encounter Model REM) for estimating its population size. We surveyed $36 \mathrm{~km}$ of strip transects arranged in systematic random design and applied 1585 camera trap nights of effort in the mountainous forest habitats of Golestan National Park, Iran. We also conducted a dung decay analysis of 80 samples. Dung decay rates were not habitat-specific and the mean time to decay was $141.8 \pm 15.1$ days, i.e. only ca. $52 \%$ of the most reliable estimate available for red deer dung. Estimated deer population size and density from dung counts was lower (194 \pm 46 individuals, $0.46 \pm 0.11$ individuals $/ \mathrm{km}^{2}, 2012-2013$ ) than from REM (257 \pm 84 individuals, $0.61 \pm 0.20$ individuals $/ \mathrm{km}^{2}, 2011$ ), but this difference was insignificant. Both these estimates confirm a sharp decline of the population from an estimated 2096 animals in the 1970 's. Density estimates reached a stable level and were most precise at a sampling effort of 15 transects (FSC) and 1345 camera trap-days (REM). Our results confirm that FSC and REM can both be reliable for assessing populations of Cervidae. 


\subsection{Introduction}

Knowledge of population size is crucial for the development of effective wildlife management strategies (Laing et al. 2003). In many cases, traditional total counts of large ungulates do not provide reliable and precise density estimates because of logistical constraints, unrealistic assumptions or poor theoretical background (Buckland et al. 2001). Several techniques of population estimation are well developed, but the selection of monitoring methods is often an intricate process depending on available logistics and time, species biology, budget, purposes and habitat physiognomies (Campbell et al. 2004; Waltert et al. 2008; Alves et al. 2013). In case of cryptic species living in mosaics of open and closed vegetation such as deer (Cervus spp.), specific survey approaches are required (Buckland et al. 2001).

Direct counts such as distance sampling are among the most popular techniques for density estimation of large herbivores (Buckland et al. 2001). For deer, these counts are applicable in open areas where animals are most visible (Smart et al. 2004). However, in closed habitats such as forests and dense scrublands direct counts are difficult to apply and in most cases this method fails to produce reliable results (Marques et al. 2001). Counts become even more problematic in small populations and/or naturally cryptic species, in which detection probabilities are low (Zero et al. 2013). Under these circumstances, indirect monitoring techniques such as dung counts and camera trapping can provide valuable alternatives (Burton et al. 2015).

In contrast to direct counts, indirect dung counts estimate an average abundance over several months and not only for the day of the survey, thus leading to higher accuracy (Marques et al. 2001; Tsaparis et al. 2009). As a disadvantage, they cannot account for the sex/age structure of the population (Buckland et al. 2001). Furthermore, dung counts on strip transects may underestimate density because of litter and grass cover affecting detection probability and encounter rate (Hemami \& Dolman 2005).

Dung count techniques are well described and are among the most preferable survey methods for deer monitoring (Buckland et al. 2001; Tsaparis et al. 2009). Two 
approaches to dung counts have been developed: (1) Fecal Standing Crop (FSC) estimation of animal density as a function of the number of recorded dung samples, decay rate as the probability of dung presence/absence and the defecation rate and (2) the Fecal Accumulation Rate (FAR) method, which is based on counts of pellet groups in previously cleared sampling units and substituting time to disappearance by the period of time between two visits (Hemami \& Dolman 2005). The latter has a substantial advantage over FSC by not requiring an estimate of decay rate. Thus, abundance can be estimated relatively quickly, without the need to monitor dung samples over a lengthy period of time (Alves et al. 2013). However, FAR also has several limitations, such as highly variable decay rates which demand for quite short periods between visits (counts of pellet groups) during which dung samples do not decay and can be sampled (Laing et al. 2003). Laing et al. (2003) suggested that at least six pellets per dung sample should persist during subsequent visits, otherwise the sample is considered as decayed. FSC has recently been shown to be more precise than FAR (Alves et al. 2013) and it can be conducted using both line and strip transects. Like FAR, FSC depends on the knowledge of defecation rates, which can be estimated in controlled (semi)captive conditions (Hemami \& Dolman 2005; Buckland et al. 2001). Overall, the most cost-efficient and effective method for estimating deer number via dung counts is FSC, particularly in small populations (Laing et al. 2003; Alves et al. 2013).

Camera trapping is another important technique to estimate animal population size and density (Burton et al. 2015). The use of camera traps is especially encouraging in studies of activity patterns and behavior of elusive species in forests (Cusack et al. 2015b). The most common analytical approach for capture-recapture data relies on individual recognition of camera-trapped animals, but this is difficult to do in most ungulates, which do not have natural markings (Foster \& Harmsen 2012; Anile et al. 2014). To overcome this limitation, Rowcliffe et al. (2008) have suggested an alternative approach, the Random Encounter Model (hereafter, REM), which is based on the ideal gas model. This model, developed originally in physics to describe the collision between gas molecules, was adapted by ecologists to characterize encounters between animals and observers (Hutchinson \& Waser 
2007). Thereafter, Rowcliffe et al. (2008) modified that theory in REM, which similarly describes contact rates between camera traps and animals. The REM technique has already been successfully applied to rare ungulate species (Rovero \& Marshall 2009; Zero et al. 2013). As REM is a relatively new technique, its application is still uncommon and not tested in many regions, including the Middle East.

In this study, we estimate abundance and density of the Caspian red deer ( $C$. elaphus maral) in montane forests of Iran by analyzing data from FSC and REM and discuss the precision and reliability of these two techniques for population estimation. The main threats to Caspian red deer are poaching, competition with livestock, and habitat loss. While livestock encroachment to natural habitats is certainly on the rise, poaching for meat and trophy antlers appears to be the most important cause of the rapid decline of this large herbivore (Kiabi et al. 2004).

\subsection{Materials and methods}

\section{Study area}

We conducted this research in Golestan National Park (GNP) located in northeastern Iran (Fig. 4.1). GNP is the first Iranian protected area, which was designated as a national park in 1957 and became a UNESCO biosphere reserve in 1977 (Zehzad et al. 2002). The park is located in the mountainous terrain and represents a transitional zone between humid Caspian deciduous forest and dry steppe, with mean annual precipitation of 142 and $866 \mathrm{~mm}$ in the east and west, respectively. The GNP comprises a total area of $874 \mathrm{~km}^{2}$ with an elevation range of 450 to $2411 \mathrm{~m}$ a.s.I. The forested part, where this study was conducted, covers approximately 422 $\mathrm{km}^{2}$ in the western part of GNP (Fig. 4.1, Akhani 2005).

GNP has been considered as one of the last refuges for large mammals in Iran (Ghoddousi et al. 2016a,b). The red deer shares its habitat with the Persian leopard (Panthera pardus saxicolor), urial (Ovis vignei), bezoar goat (Capra aegagrus), wild boar (Sus scrofa), roe deer (Capreolus capreolus), brown bear (Ursus arctos), gray wolf (Canis lupus), jungle cat (Felis chaus) and wild cat (Felis silvestris) (Kiabi et al. 
2004). In the past decades, maral distribution in the Caspian forest was significantly reduced and many populations were locally extirpated, mainly due to poaching; now, several surviving populations are restricted to protected areas (Kiabi et al. 2004). In GNP, red deer suffers from intensive poaching and ineffective law enforcement (Kiabi et al. 2004; Ghoddousi et al. 2016a). The red deer is officially protected in Iran (Kiabi et al. 2004).

\section{Dung decay surveys}

One of the key components in the sampling design is to ensure adequate and spatially standardized sampling to cover the study area (Sutherland 2006). The red deer range in GNP was stratified into closed forest (CF, 58\% of the range), closed scrubland (CS, 24\%) and open scrubland (OS, 18\%) using ArcGIS 9.1 (ESRI Inc. USA) and Google Earth 7.1.5 (Fig. 4.1, Table S4.1). Mean time to decay was estimated by monitoring the status of fresh dung samples $(n=80)$ recorded from deer resting places between December 2011 and November 2012, roughly once every four weeks. Each dung sample represented a group of pellets produced in a single act of defecation. Samples were identified as being fresh based on their size, moisture content, texture, shiny and wet surface, smell and lack of decomposition signs (Laing et al. 2003). Any dung samples, which could be confused with co-existing roe deer, were excluded. Thus, all dung samples used in this study were assumed to be fresh and 0-2 days old. For better visibility during subsequent visits, each recorded sample was marked by staining trees nearby. Dung samples that were covered by leaves, scattered as a result of animal trampling, washed away by precipitation or removed by invertebrates were all considered as decayed or disappeared (Laing et al. 2003; Tsaparis et al. 2009). Decay was recorded if $\leq 6$ pellets were re-found in a dung sample during subsequent visits (Laing et al. 2003).

Twelve visits were undertaken across three habitats in order to record fresh dung samples for the decay experiment (Tsaparis et al. 2009). During each visit, at least two samples per habitat were recorded due to very low deer population density and detection probability of fresh deer dung. 


\section{Estimation of defecation rate}

Defecation rate was estimated in December 2015 in a 2 ha enclosure with 20 deer individuals located in Ghorogh, $125 \mathrm{~km}$ away from GNP. The area is covered by native Quercus castaneifolia, Zelcova carpinifolia, Parrotia persica, Carpinus betulus and Celtis caucasia. We cleared the area carefully of any dung and chose an 8-days period for estimation of defecation rate, considering that the decay rate in GNP is more than two weeks. We fed red deer with plants collected from GNP: Poa mazandaranica, Vicia variabilis, Heracleum gorganicum, Hypericum perfratum, Phlomis cancellata, Asperula gorganica, Saponaria bodeana, Centaurea golestanica, Poa bulbosa, Physocaulis nodosus, Arabidopsis thaliana and Hordeum bulbosum. Overall, 1676 dung samples were counted by four observers moving $1 \mathrm{~m}$ apart at the end of the 8-day period.

\section{Dung count surveys}

Originally, 26 strip transects were randomly selected using a $2 \times 2 \mathrm{~km}$ grid (systematic random sampling) in ArcGIS 9.1 (ESRI Inc. USA) and Hawth's Tools (Beyer 2004), of which eight transects were inaccessible. Of the 18 remaining transects, eight were located randomly in CF, four in CS and six in OS. For logistical reasons, we used strip transect sampling, which is accurate and comparable with the line transect method (Alves et al. 2013). The survey was conducted in January-February 2013. All transects were oriented in the south-north direction as it complies with the general density gradient from the core of the park to the boundaries (Buckland et al. 2001; Fig. 4.1). Each strip transect of 2-km length and 2-m width was surveyed by two observers, one on either side of the strip to minimize the chance of double counts (Buckland et al. 2001). We assumed detection probability of deer dung to equal 1 (Alves et al. 2013) as transects in our study area were narrow and $2 \mathrm{~m}$ of transect width minimized the probability of non-detections. These observers were sufficiently skilled to recognize red deer dung based on size and general appearance. Any dung samples of doubtful origin were discarded from the study. To investigate the optimum number of transects and dung samples, we used the standard error (SE) of dung samples as a measure of precision (Alves et al. 2013). 


\section{Camera trapping}

We used the camera trapping database of the Persian leopard population assessment project in GNP, which was conducted during May-December 2011 (Hamidi et al. 2014). We mounted 53 passive 35-mm film camera traps (Deercam TM, Park Falls WI, USA) in the forested area at a height of $\sim 40 \mathrm{~cm}$ for $42.83 \pm$ SE 0.02 consecutive camera days in each station along the trails and ridge tops, whenever leopard signs were present (Hamidi et al. 2014; Ghoddousi et al. 2016a). The minimum distance between camera traps was $2 \mathrm{~km}$ (Ghoddousi et al. 2016b). Since 16 camera traps were stolen during the study period (Hamidi et al. 2014; Fig. 4.1), we used data from 37 camera traps. Although camera traps were set up for leopard captures, we assume that they were placed randomly in relation to red deer movements (Rowcliffe et al. 2013; Ghoddousi et al. 2016b). Camera traps were programmed to take pictures at $1 \mathrm{~min}$ delay, operate $24 \mathrm{~h} /$ day and stamp date and time on pictures.

\section{Data analysis}

\section{Decay rate}

To estimate dung decay, each $i$-th marked dung sample $(i=1, \ldots, 80)$ was assigned 1 if present during subsequent visits or 0 if absent (decayed). The period between the time of defecation and the time of the visit was denoted as age ( $t$, days) and the habitat was denoted as $H$. Binary logistic regression was used to analyze the effect of $t$ and $H$ on dung presence or absence during re-visits (Laing et al. 2003; Tsaparis et al. 2009; Amos et al. 2014).

We tested four candidate models (Table 1 ): $\operatorname{model} f_{0}$ was the null model without covariates, model $f_{1}$ incorporated dung age $(t), f_{2}$ described the additive effect of the covariates habitat $(H)$ and age $(t)$ and $f_{3}$ addressed the interaction between $H$ and $t$ (Laing et al. 2003; Tsaparis et al. 2009). The Akaike Information Criterion corrected for small sample size $\left(\mathrm{AIC}_{\mathrm{c}}\right), \mathrm{AIC}_{\mathrm{c}}$ weights $\left(w_{\mathrm{i}}\right)$ and delta $\Delta_{\mathrm{i}}$ (difference between a given model's $\mathrm{AlC}_{\mathrm{c}}$ and the best model's minimum $\mathrm{AIC}_{c}$ ) were used for model selection. The best models were defined as those with $\Delta_{i}<2$ (Burnham \& Anderson 
2002). The mean time to decay ( $T_{\text {decay }}$ ) was computed from dung age $t$ using equation 1 (Laing et al. 2003):

$$
T_{\text {decay }}=\int_{0}^{\infty} \frac{-\beta_{1} t\left[1+\exp \left(-\beta_{0}\right)\right] \exp \left[-\left(\beta_{0}+\beta_{1} t\right)\right]}{\left[1+\exp \left(-\left(\beta_{0}+\beta_{1} t\right)\right)\right]^{2}} d t
$$

where the intercept $B_{0}$ and the slope $B_{1}$ of age $t$ were obtained from logistic regression (Laing et al. 2003). The SE and the $95 \%$ confidence interval $(95 \% \mathrm{Cl})$ of $T_{\text {decay }}$ were estimated by means of bias-corrected and accelerated bootstrapping with 10000 iterations (Efron \& Tibshirani 1993). The predictive power of the logistic model was tested with the area under the curve (AUC) of Receiver Operating Characteristic (ROC). The score AUC $=0.5$ means that the model has no discriminatory ability and $A U C=1$ means that models are perfectly discriminated (Stephanie et al. 2001). Chi-square test was performed to test for difference of density estimates between habitats.

\section{Defecation rate}

We estimated defecation rate as 10.48 dung samples per individual and day using equation 2 from Buckland et al. (2001):

$$
P=\frac{N_{\text {dung }}}{N_{\text {deer }} \times N_{\text {days }}}
$$

where $N_{\text {dung }}$ is the number of dung samples counted, $N_{\text {deer }}$ is the number of deer in the enclosure and $N_{\text {days }}$ is the number of days during which dung had been accumulated. It was not possible to estimate the SE because defecation rates of individual deer were unknown. The precision of $N_{\text {dung }}$ was expressed as the coefficient of variation CV\% $=(\mathrm{SE} /$ mean $) * 100$ (Plumptre 2000).

Density estimation: FSC

Deer density (individuals/km2) in GNP was calculated as in equation 3 (Laing et al. 2003):

$$
D_{\text {FSC }}=\frac{N_{\text {dung }}}{T_{\text {decay }} \times P} \times A
$$


where $D_{F S C}$ is the estimated deer density (individuals $\left./ \mathrm{km}^{2}\right), N_{\text {dung }}$ is the estimated dung density (dung samples $/ \mathrm{km}^{2}$ ), $T_{\text {decay }}$ is the estimated mean time to decay (days), $P$ is the estimated defecation rate (dung samples/individual and day) and $A$ is the study area $\left(\mathrm{km}^{2}\right)$. The precision of FSC was measured by the delta method of equation 4 proposed by Laing et al. (2003):

$$
\left[C V_{\text {total }}\left(D_{F S C}\right)\right]^{2} \approx\left[c v\left(N_{\text {dung }}\right)\right]^{2}+\left[c v\left(T_{\text {decay }}\right)\right]^{2}+[(p)]^{2}
$$

where $C V_{\text {total }}$ is the total coefficient of variation.

Density estimation: REM

REM was used to estimate deer density from photo-captures as in equation 5 (Rowcliffe et al. 2008):

$$
D_{R E M}=\frac{y}{t} \frac{\pi}{\operatorname{vr}(2+\theta)} \times g
$$

where $D_{R E M}$ is the animal group density (groups $/ \mathrm{km}^{2}$ ), y is the number of independent photo-captures per camera station, $t$ is the sampling effort (camera days) per camera station, $v$ is the animal daily distance walked ( $\mathrm{km} /$ day), $r$ is the camera trap detection distance (meters), $\vartheta$ is the camera trap angle and $g$ is the average animal group size (individuals/group) (Rowcliffe et al. 2008). The mean group size was estimated as $2.78 \pm$ SE 0.26 individuals/group from $n=57$ group observations by GNP rangers. These observations came from daily patrolling records, which covered the camera trapping period across the red deer habitats in 2012 (Table 4.1). The values of $\vartheta(0.175$ radians $)$ and $r(0.012 \mathrm{~km})$ were taken from Rowcliffe et al. (2008) who used the same model of camera traps as we did. 
Table 4.1. The parameters required for estimating red deer density from cameratrapping rates using the Random Encounter Model. CV = coefficient of variation, $\mathrm{SE}=$ standard error.

\begin{tabular}{|lccl|}
\hline Parameters & Mean \pm SE & CV\% & \multicolumn{1}{c|}{ Reference } \\
\hline $\begin{array}{l}\text { Photo-captures/camera station } \\
(\mathrm{y})\end{array}$ & $0.27 \pm 0.09$ & 33.34 & Hamidi et al. (2014) \\
Camera days/camera station $(t)$ & $42.83 \pm 0.02$ & 0.04 & Hamidi et al. (2014) \\
Daily distance walked $(v, \mathrm{~km} /$ day) & $3.36 \pm 0.23$ & 6.84 & $\begin{array}{l}\text { Pepin et al. (2004, 2008, } \\
\text { 2009), Carranza et al. (1991) }\end{array}$ \\
Detection distance $(r, \mathrm{~km})$ & 0.012 & & Rowcliffe et al. (2008) \\
Detection angle $(\theta$, radians) & 0.175 & & Rowcliffe et al. (2008) \\
Group size $(g$, individuals/group) & $2.78 \pm 0.26$ & 9.35 & $\begin{array}{l}\text { Golestan National Park, } \\
\text { unpublished data (2011-2012) }\end{array}$ \\
\hline Total CV & & & \\
\hline
\end{tabular}

We extracted the range of daily distances walked $v$ from the literature on red deer radio-telemetry: 3.85, 2.78 and 3.2 km/day in France (Pepin et al. 2004, 2008, 2009) and $3.62 \mathrm{~km} /$ day in Portugal (Carranza et al. 1991). From these estimates, we calculated the average daily distance walked as $3.36 \pm$ SE $0.23 \mathrm{~km} /$ day. This average estimate was used in REM density calculations using equation 5 , whereas the extreme estimates were taken for fixing the simulation and sensitivity analysis. The overall CV of the REM density was computed using the delta method (Rowcliffe et al. 2008). A threshold value of 10 photo-captures which is a minimum number of captures to achieve from expected trap rates was used to estimate the deer density as indicated by Rowcliffe et al. (2008). The $95 \% \mathrm{Cl}$ of REM density was calculated as the mean $\pm 1.96 *$ SE (Zero et al. 2013).

\section{Sensitivity analysis}

To evaluate the sensitivity of our population estimates to potential violations of the underlying methodical assumptions, we conducted two types of sensitivity analyses. First, we simulated dung encounter rates and camera trapping data to account for non-random distribution of deer and non-random placement of camera traps based on Rowcliffe et al. (2008). Random dung and trapping data was simulated for each transect and camera trap, respectively, using a negative binominal distribution. The 
mean was calculated as the expected number of samples (dung or photos) per sampling unit (transect or camera) from field-collected samples and the variance was calculated as the observed variance of encounter rate (Rowcliffe et al. 2008). We then recalculated population estimates based on the methods described above (equations 3 and 5, respectively), resampling for 10000 times each. We extracted the $95 \% \mathrm{Cl}$ as the mean $\pm 1.96 * \mathrm{SE}$ of population estimates. Second, we used the extreme ranges of the model parameters to account for their variability. For FSC, we used the lower and upper $95 \% \mathrm{Cl}$ of decay rate (114.57 and 173.65) and recalculated population size. For REM, we used the lowest and highest observed mean group sizes per season (2.42 and 3.58 individuals/group) and the most extreme daily movement estimates ( 2.78 and $3.85 \mathrm{~km} /$ day) and recalculated population size based on all four combinations. For both methods, we reported the full range of the population estimates.

Finally, we performed the Z-test in order to evaluate the difference of population estimates between FSC and REM (Buckland et al. 2001). All statistical analyses were done in R statistical software v. 3.2.3 (2015). 


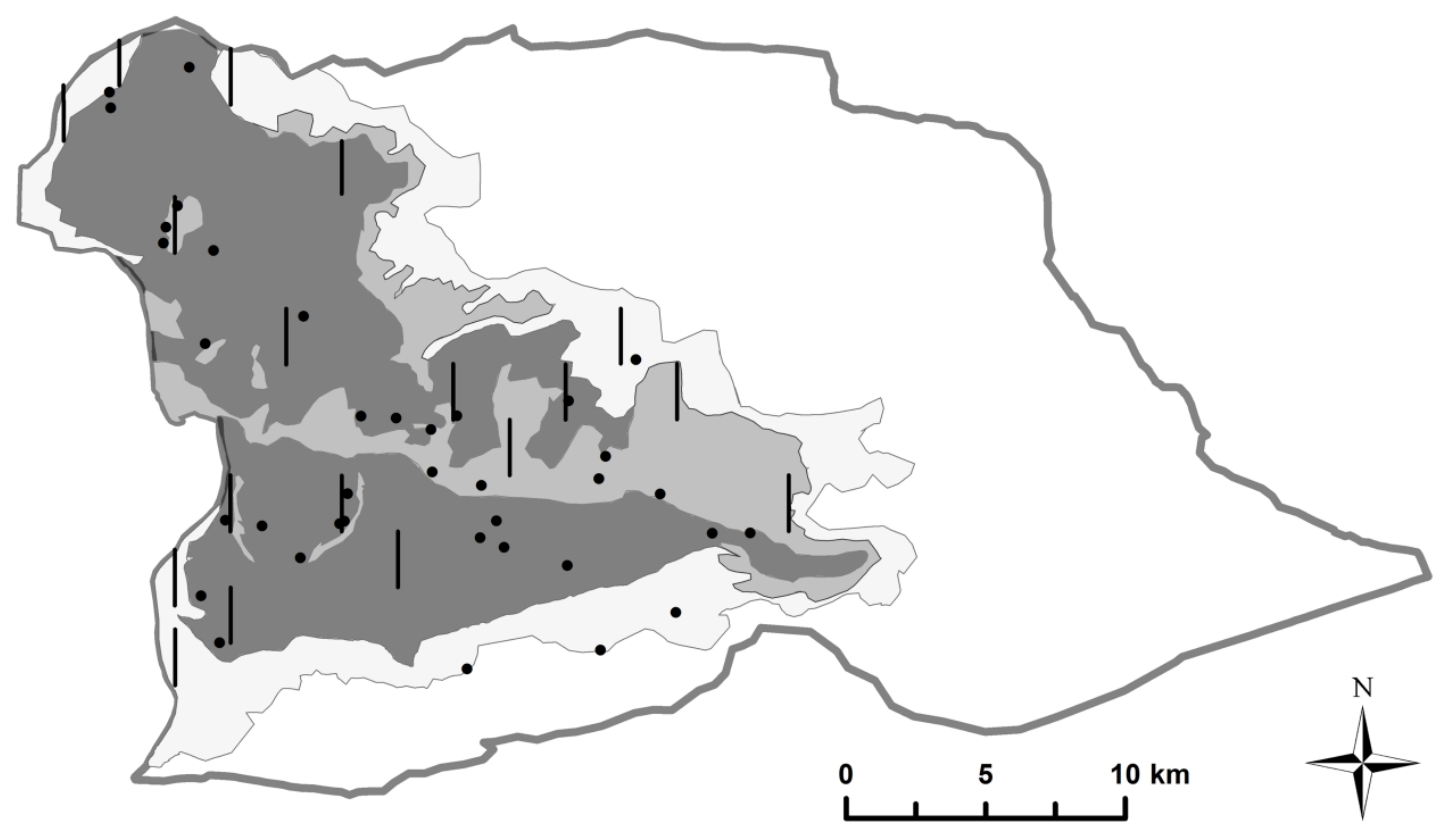

\section{Legend}

- Camera traps
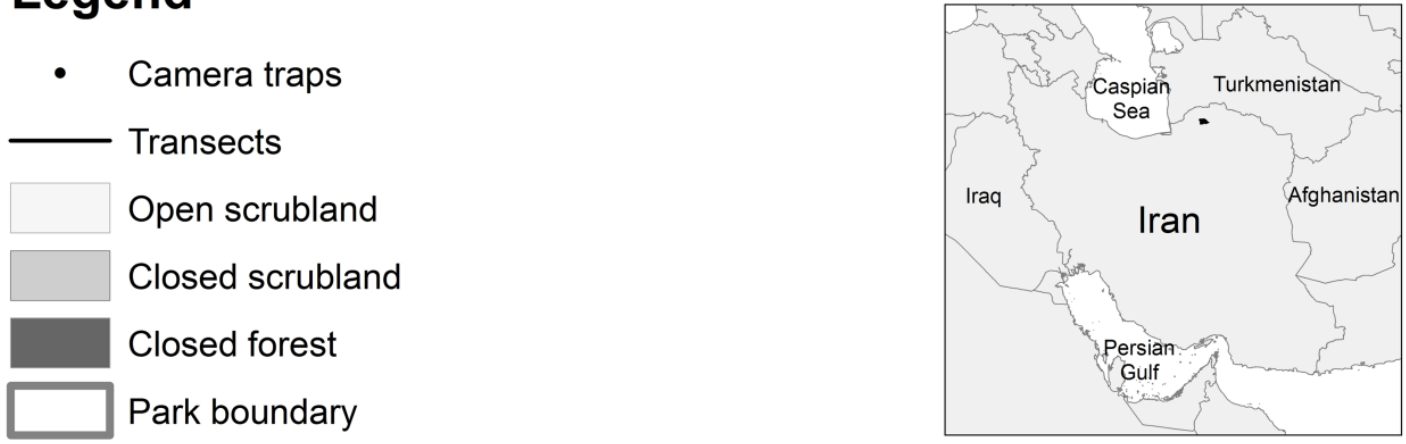

Figure 4.1. The study area, habitats and location of transects and camera-trap stations in Golestan National Park, Iran.

\subsection{Results}

Using FSC, we estimated deer population size as $194 \pm$ SE 46 individuals (overall CV\% $=28.44$ ) and density as $0.46 \pm$ SE 0.11 individuals $/ \mathrm{km}^{2}$. With the increasing numbers of dung samples $\left(N_{\text {dung }}=50\right)$ and transects surveyed, precision increased (Figs. 4.2a and b) and leveled off at approximately 15 transects (Fig. 4.2b). Although we monitored dung samples only once every four weeks, pooling dung records from all three habitats provided a smooth dung decay curve (Fig. 4.2c). Deer density was higher in closed scrubland than in other habitat types (Fig. 4.2d, Table S4.2), but this difference was non-significant $\left(\chi^{2}=0.875, P=0.831\right)$. For estimating the mean time 
to dung decay, we sampled 80 fresh dung samples, of which 28 were in CF, 26 in CS and 26 in OS. Of the logistic models of dung decay rates, the age-based model $f_{1}$ was the best with $\Delta_{i}<2$ (Fig. 4.2, Table 1). The habitat-based models received less support and the null model was not supported (Table 1). The fitted logistic regression curve of the model $f_{1}$ (Fig. 4.2) had high predictive power (AUC $=0.87 \pm$ SE 0.04, $\mathrm{P}_{\mathrm{AUC}}<0.001, \%$ correct classification $\left.=81.3 \%\right)$. The mean $T_{\text {decay }}$ was estimated as $141.81 \pm$ SE 15.07 days $(95 \% \mathrm{Cl}=114.57-173.65)$.

Table 4.2. The logistic models of red deer dung decay rates in Golestan National Park

\begin{tabular}{|ccccccc|}
\hline Model & Covariates & Residual deviance & $d f$ & $\mathrm{AlC}_{\mathrm{c}}$ & $\Delta_{\mathrm{i}}$ & $w_{\mathrm{i}}$ \\
\hline$f_{1}$ & $t$ & 59.46 & 78 & 63.62 & 0.00 & 0.77 \\
$f_{2}$ & $H+t$ & 58.17 & 76 & 66.70 & 3.09 & 0.16 \\
$f_{3}$ & $H^{\star} t$ & 55.40 & 74 & 68.56 & 4.94 & 0.07 \\
$f_{0}$ & Null & 85.30 & 79 & 87.36 & 23.74 & 0.00 \\
\hline
\end{tabular}

$\mathrm{AlC}_{\mathrm{c}}=$ Akaike Information Criterion corrected for small sample size; $d f=$ degree of freedom; $H=$ habitat; $t=$ dung age (days); $w_{\mathrm{i}}=$ AIC weight; $\Delta_{\mathrm{i}}=$ delta of the model. 

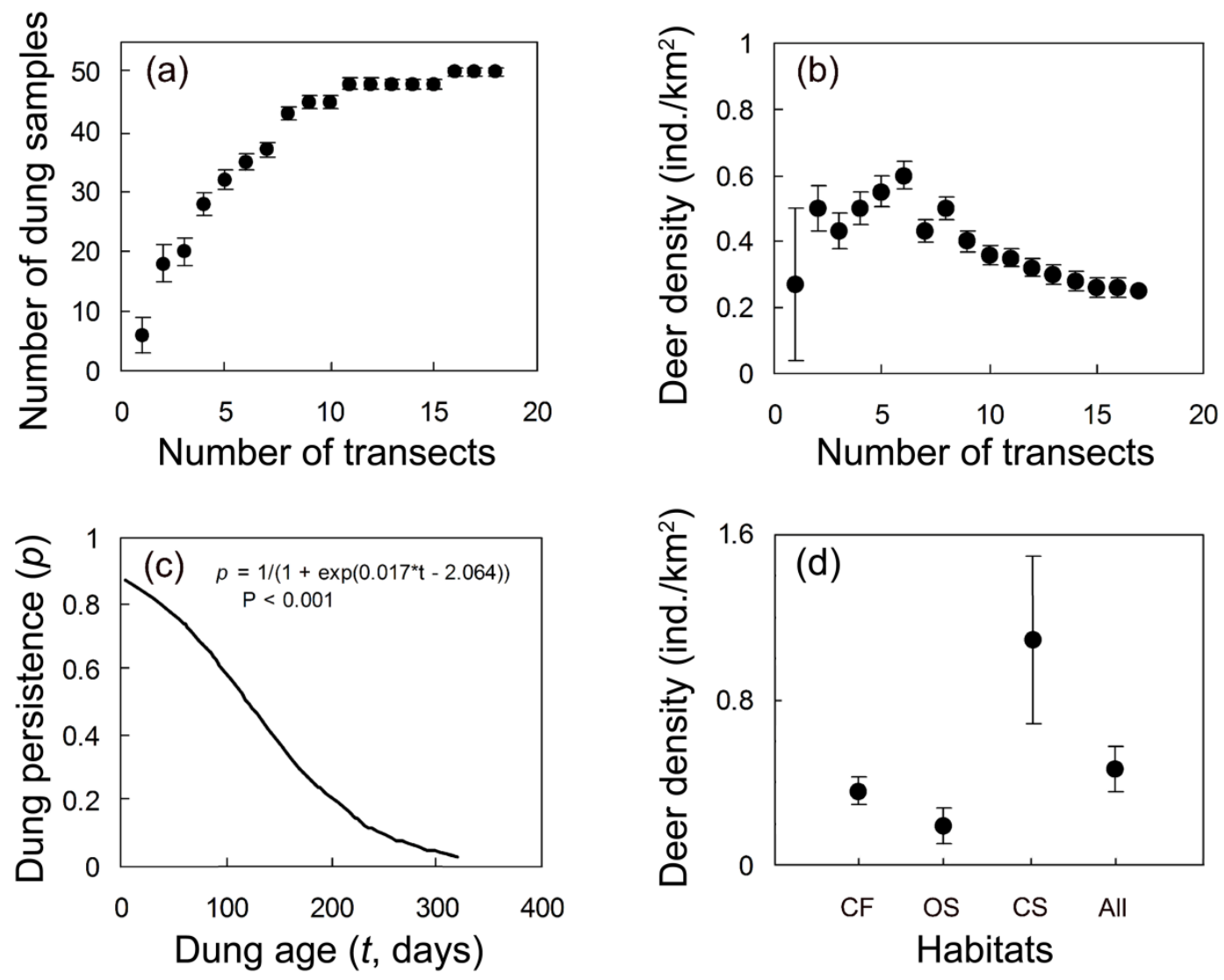

Figure 4.2. The number of dung samples (a) and red deer (Cervus elaphus maral) density estimates (b) in relation to the number of transects, the logistic regression curve of the probability of dung persistence over time (c) and the distribution of FSC deer density estimates across (CF, OS,CS) (d). The standard errors are displayed by bars.

A total of 1585 camera days was accumulated over 37 camera trap stations and 10 photo-captures of red deer were obtained. Using REM, we estimated the population size as $257 \pm$ SE 84 individuals (overall CV\% $=35.30$ ) and density as $0.61 \pm$ SE 0.20 individuals $/ \mathrm{km}^{2}$. REM precision leveled off at 31 camera traps and 1345 camera days.

The difference between the estimates of the population size and density obtained by FSC and REM was insignificant (Table 3 ). The $95 \% \mathrm{Cls}$ of sensitivity analysis were similar to those of original FSC and REM estimates. The FSC simulation yielded a $95 \% \mathrm{Cl}$ of $135-257$ individuals compared to the original $\mathrm{FSC} 95 \% \mathrm{Cl}$ of $102-$ 285 individuals. The REM simulation analysis estimated a $95 \% \mathrm{Cl}$ of $77-440$ 
individuals compared to the original REM $95 \% \mathrm{Cl}$ of $91-423$ individuals. Also, the sensitivity analyses using the extreme values of each parameter resulted in similar population estimates. They ranged from 237 to 486 individuals for REM (compared to the original estimate of 257 individuals) and from 163 to 248 individuals for FSC (compared to the original estimate of 194 individuals).

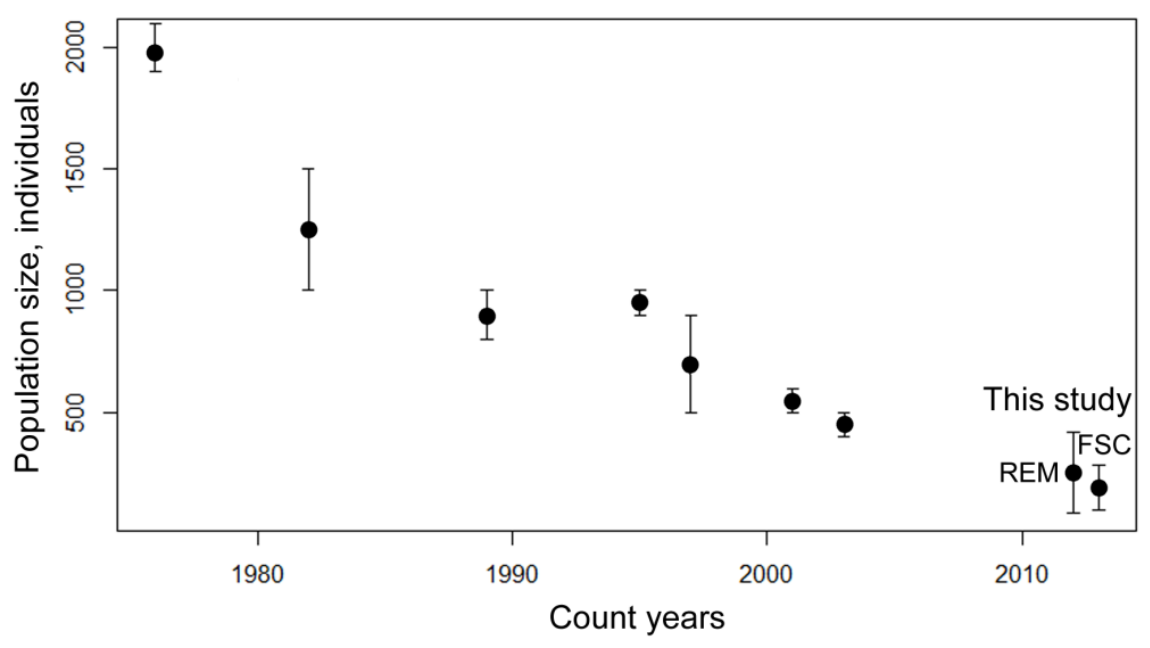

Figure 4.3. The estimates of red deer population size in Golestan National Park according to dung counts in 1976-1977 and total counts during the rutting season in 1978-2003 (Kiabi et al. 2004). Our REM (2011) and FSC (2012-2013) estimates are given for a comparison. The error bars show the limits of total counts (1976-2003) and $95 \%$ confidence intervals (present study).

Table 4.3. Comparison of red deer density estimates from Fecal Standing Crop (FSC) and Random Encounter Model (REM) methods. $\mathrm{Cl}=$ confidence interval, $\mathrm{SE}=$ standard error.

\begin{tabular}{|lcc|}
\hline Estimated parameters & FSC & REM \\
\hline Density, individuals $/ \mathrm{km}^{2} \pm \mathrm{SE}$ & $0.46 \pm 0.11$ & $0.61 \pm 0.20$ \\
$95 \% \mathrm{Cl}$ of density & $0.25-0.67$ & $0.22-1.08$ \\
Population size, individuals & $194.12 \pm 46.57$ & $257.42 \pm 84.55$ \\
$95 \% \mathrm{Cl}$ of population size & $102-285$ & $91-423$ \\
\hline
\end{tabular}




\subsection{Discussion}

Monitoring red deer is challenging throughout its global range (Marques et al. 2001). This research is the first attempt to fill a gap in empirical knowledge on red deer population size and density by applying two independent count techniques in a montane forest ecosystem. Although direct observation methods are methodologically well developed, they are difficult to apply in places where this species is rare or less habituated to human presence (Tsaparis et al. 2009), and in hardly accessible rugged landscapes (Singh \& Milner-Gulland 2011).

Dung counts are often applied as an alternative method to count deer species (Alves et al. 2013; Amos et al. 2014). In this study, we successfully estimated population size and density of red deer in Golestan from dung counts (Table 3). In contrast to the study by Tsaparis et al. (2009), we did not find variation in decay rates between habitats. However, the mean time to decay was $52 \%$ shorter than elsewhere (141.81 \pm SE 15.07 vs. $275 \pm$ SE 42 days; Laing et al. 2003). The high rate of dung decay in our study area could result from high diversity of dung beetles and intensive wildlife movements, which potentially accelerate dung decomposition (Bahrami et al. 2011). An accurate density estimate via pellet counts relies mainly on accurate estimation of dung encounter and decay rates (Alves et al. 2013). Although we attempted to minimize variation of dung counts by obtaining local estimates of dung decay and defecation rates, still many transects contained no dung, which reduced the overall precision of FSC estimates of deer number and density. Further progress in counting deer in Golestan could be reached with the application of a stratified random survey design and species distribution modeling, for which independent historical data on population trends could serve as a reliable baseline (Kiabi et al. 2004; Hemami et al. 2007; Tsaparis et al. 2009; Alves et al. 2013).

Our results also suggest that red deer numbers and density can be reliably estimated by REM from camera-trap records without the need for individual recognition of animals (Rowcliffe et al. 2008). An allometric diagram of species densities and distances walked provided by Rowcliffe et al. (2008) shows that at least 1000 camera-days are required to obtain 10 photographs of rare ungulates. We reached this threshold at a similar camera trapping effort of 1345 camera days. As 
camera trapping rates are intuitively linked with animal abundance, encounter rates between individuals and camera traps are expected to increase with population density (Rowcliffe et al. 2008; Rovero \& Marshall 2009). This relationship between camera trapping rates and population density is strong and can be linear, as in forest ungulates of Tanzania (Rovero \& Marshall 2009). According to Rowcliffe et al. (2008), the number of camera trap stations and the amount of effort in our study were adequate and could not affect deer capture rates. Therefore, low capture rates of red deer in Golestan are most likely caused by low densities of this ungulate.

Nevertheless, there are some limitations involved in study design and methodology, which might have influenced our results. Our camera trapping data comes from a study focused on leopards and this could have affected red deer capture rates. Although the predator-prey relationship between leopard and red deer may have affected the capture rates, we assume that the movement pattern of red deer is independent from leopard movements and therefore is spatially unbiased. Moreover, a recent study (Cusack et al. 2015a) revealed that herbivore capture rates are insensitive to placement of camera traps. Additional biases may arise from the application of non-local daily distance estimates and seasonal variation of group size, but the sensitivity analysis showed that our results are sufficiently reliable. As daily distances moved by red deer were unavailable for our study area, we had to borrow them from the Mediterranean region in France and Portugal (Carranza et al. 1991; Pepin et al. 2004, 2008, 2009). We strongly encourage researchers who apply REM to use local data, in particular on the most influential population parameters such as group size and animal movements. Another source of uncertainty is that the defecation rate may differ between captive and free-living animals and also depend on seasons, forage intake, sex and age (Buckland et al. 2001). We attempted to minimize such potential bias by feeding animals with natural vegetation. Other studies also found that defecation rates are less variable than other parameters used in density estimation from dung counts (Neff 1968; Buckland et al. 2001; Marques et al. 2001). We also acknowledge that our camera trapping and dung count data were collected in distinct years (2011 and 2013), which also might affect the results. However, we have no ground to surmise that the 
population of red deer experienced any significant changes during this short period. Finally, our results could be affected by theft of 16 out of 53 camera traps by poachers, which reduced sample size and habitat coverage (Rovero \& Marshall 2009).

Both FSC and REM have clearly shown the rarity of red deer in Golestan. A comparison of our estimates with historical records suggests that the local deer population may have dropped by 90\% from ca. 2096 (dung count, 1976-1977), 1897 (transects, 1976-1978), 900-1500 (rutting counts, 1982-1995) and 400-900 (rutting counts, 1995-2003) individuals to only 194-257 individuals now (Fig. 4.3, Table 3; Kiabi et al. 2004). The other indicators of population decline are smaller group size (2.8 vs. 4.6 individuals/group in Kiabi et al. 2004) and heavy impact of poaching pressure on large mammals in Golestan in general (Ghoddousi et al. 2016a).

Most of red deer poaching occurs during the rutting season (SeptemberOctober) when stags are easily attracted by call imitation. In order to control poaching, the Iranian Department of Environment (DoE) implements constant patrolling throughout the red deer habitat in Golestan. Despite this, the scales of deer poaching are alarming. According to Kiabi et al. (2004), the main threat to red deer in Golestan is a combination of poaching and habitat degradation. This is indirectly confirmed by our study as deer were detected mainly in safe core zones rather than in ecotones along the forest edge. Thus, in line with Kiabi et al. (2004) we also emphasize the necessity to protect areas close to reserve borders similar to those within the core zone of the park. Moreover, getting more knowledge on poachers' incentives may help in reversing the population decline of red deer in Golestan (Kiabi et al. 2004).

Overall, we concluded that FSC and REM could serve as the practical techniques to count and monitor red deer populations living at low densities in montane forests. We strongly recommend to carefully consider opportunities and limitations of these methods and to use locally obtained variables of population size and density. We further confirm the plight of the red deer population in Golestan and appeal for urgent, targeted and practical evidence-based conservation actions. It is advised to 
conduct socio-economically oriented studies to unveil the potential reasons for poaching and decrease their incentives.

\section{Acknowledgements}

The field study was financially supported by Persian Wildlife Heritage Foundation and Competence Center of Environment, Water and Nature Conservation of Carinthia, Austria. Currently, M.S. is supported by Erasmus Mundus/Action2-SALAM and Rufford Small Grant Programme. Other donors for this project included DAAD, Panthera (A.G.) and Alexander von Humboldt Foundation (I.K.). We thank all volunteers who helped us during the fieldwork. This research would not have been possible without the sincere support and collaboration of R.A. Rostaghi, former director of Golestan National Park, and park rangers. We would also like to thank the Golestan provincial office of the Department of Environment for study permits. We acknowledge improvements by three anonymous reviewers to the earlier version of the manuscript. 


\subsection{Supplementary material}

Table S4.1. Red deer (Cervus elaphus maral) habitats in Golestan National Park surveyed in this study (Akhani 2005).

\begin{tabular}{|ll|}
\hline Habitat & Description of species composition \\
\hline Closed forest (CF) & Mainly Quercus castaneifolia, Carpinus betulus, Acer velutinum, Cerasus \\
& avium, Sorbus torminalis, Fraxinus excelsior, Alnus glutinosa, Acer \\
& capadocium, and Ilex spinigera. Understory is covered by grasses and \\
& herbs, e.g. Danea racemosa, Euphorbia amygdaloides, Brachypodium \\
& sylvaticum, Parietaria officinalis, Carex sylvatica, Festuca gigantea and \\
& Poa nemoralis. \\
& Covered predominantly by invasive fern Pteridium aquilinum and also by \\
Closed scrubland (CS) & divaricata, Paliurus spina-christi, Mespilus germanica, Thalictrum minus, \\
& Euonymus latifolia, Vicia variabilis, Lathyrus pratensis, Brachypodium \\
& sylvaticum, Dactylis glomerata, Rubus dolicocarpus and Rosa canina. \\
& Assorted by scattered scrub layers comprising Quercus macranthera, \\
Carpinus orientalis, Acer monspsselanum, Malus orientalis, Crataegus \\
microphylla, Pyrus boissieriana, Lonicera floribunda, Rubus sanctus, \\
Prunus divaricata, Rahmnus pallasi, Cerasus microcarpa, Hypericum \\
perforatum, Agrimonia eupatoria, Dactylis glomereta, Heteropapus \\
altaicus, Botrichloa ischaemum and Rosa canina.
\end{tabular}

Table 4.2. Deer density estimates and their confidence intervals in different habitats.

\begin{tabular}{|llll|}
\hline Habitat & Density, ind $/ \mathrm{km}^{2} \pm \mathrm{SE}$ & $95 \% \mathrm{Cl}$ of density & Habitat size, $\mathrm{km}^{2}$ \\
\hline Closed forest & $0.35 \pm 0.07$ & $0.22-0.48$ & 247.58 \\
Open scrubland & $0.19 \pm 0.08$ & $0.04-0.34$ & 98.44 \\
Closed scrubland & $1.09 \pm 0.41$ & $0.29-1.89$ & 75.75 \\
\hline All deer range & $0.46 \pm 0.11$ & $0.25-0.67$ & 421.77 \\
\hline
\end{tabular}

$\mathrm{Cl}$ - confidence interval, SE - standard error 


\section{Chapter 5: Decline of ungulate populations calls for urgent actions against poaching in Iranian protected areas}

Arash Ghoddousi, Mahmood Soofi, Amirhossein Kh. Hamidi, Sheyda Ashayeri, Lukas Egli, Siavash Ghoddousi, Julian Speicher, Igor Khorozyan, Bahram H. Kiabi, Matthias Waltert

In review, Oryx, submitted: $22^{\text {nd }}$ June 2016

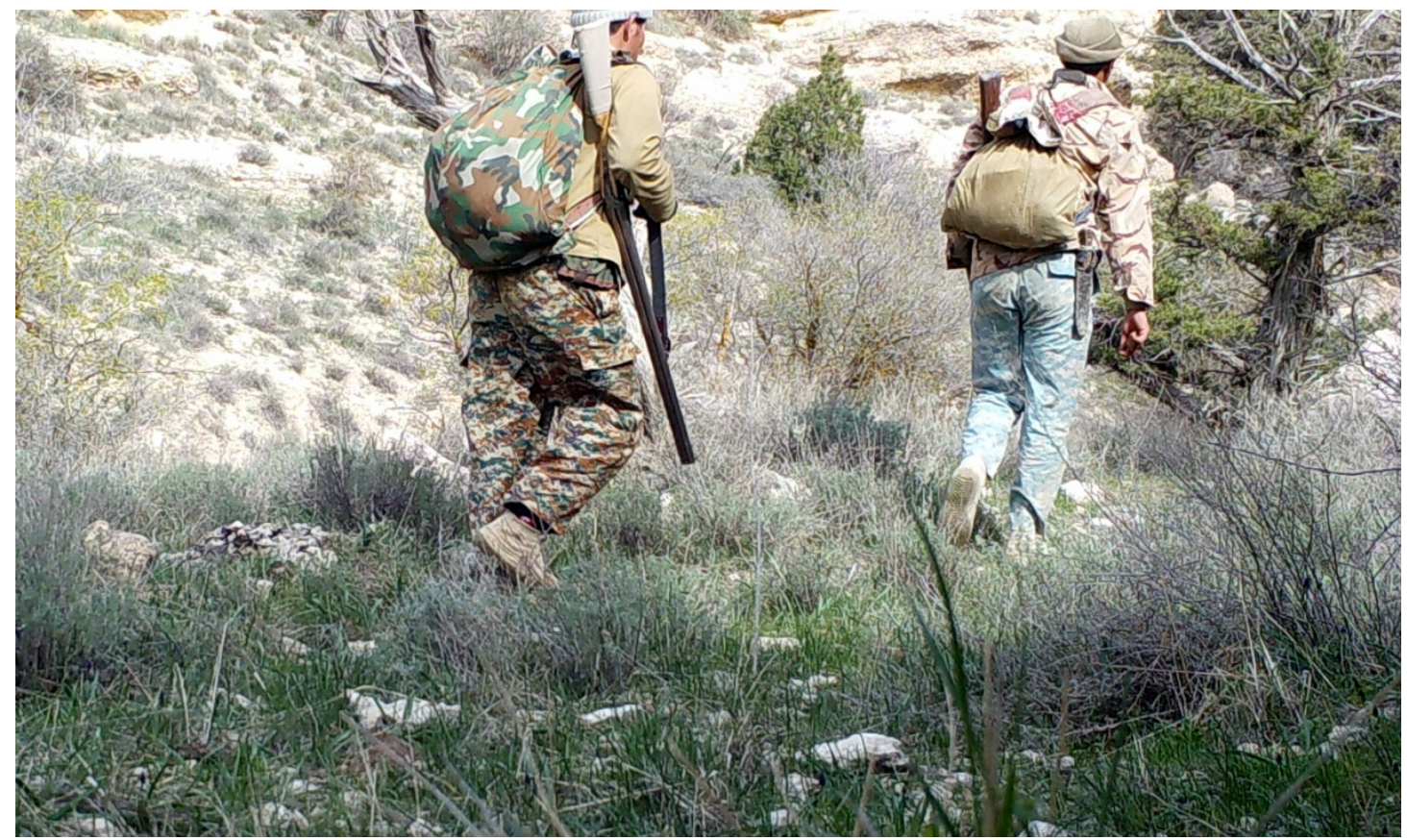

A camera trap photo of two poachers in Golestan National Park. Photo:

PWHF/GAUG/Golestan DoE 


\section{Abstract}

Poaching is cryptically but rapidly driving many species toward extinction in many parts of the world. Knowledge on population trends of exploited species and poaching incentives is necessary for adoption of appropriate conservation measures. In this study, we estimated the abundance of four ungulate species, using line transect sampling (186 km), camera trapping (2777 camera-nights), point counts (64 scans) and dung counts (38 km) in Golestan National Park, Iran, and compared them with those from earlier records. We also analyzed incentives of local poachers using a semi-structured interview survey. Population estimates from 2011-2014 indicated a 66-89\% decline in three ungulate species compared to 1970-1978. Only wild boar showed a population increase by $58 \%$ during the same period, possibly due to religious restrictions regarding the consumption of this species. Local poachers' incentives were categorized (in a non-ordinal manner) as subsistence, pleasure, tradition, trade of wild meat, and conflict with conservation regulations and bodies. The alarming declines in hunted ungulates in Iran's oldest national park call for urgent conservation actions in the study area and also other reserves of the country. The country requires adoption of participatory conservation strategies, improvement of law enforcement practices and cooperation of international expertise in resolving its poaching problem. Taking into account poachers' incentives, a combination of economic and non-economic strategies should be considered. 


\subsection{Introduction}

Overexploitation of natural resources is among the most serious environmental challenges threatening biodiversity richness and ecosystem functioning (Gavin et al. 2010). A key phenomenon in overexploitation is poaching, which drives many species toward extinction in different parts of the world (Milner-Gulland \& Bennett 2003). Poaching may occur due to different incentives and at variable scales, from subsistence hunting by local communities to income generation by selling wild meat in urban markets and international trafficking of wildlife or their body parts (Sutherland 2000). Due to the illegal and cryptic nature of poaching, and lack of systematic wildlife monitoring schemes, detection of population declines from poaching is challenging (Singh \& Milner-Gulland 2011; Nuno et al. 2013). Lack of information on wildlife trends may hamper timely conservation responses against poaching (Milner-Gulland \& Bennett 2003).

A range of practices has been applied against poaching, depending on its scale and poachers' incentives. Enforcement measures, awareness-raising and creation of alternative livelihoods are among the most common approaches apart from conservation laws (Challender \& MacMillan 2014). Enforcement measures are probably most widely practiced and recent studies demonstrate a positive response of wildlife to their intensification (Hilborn et al. 2006; Ghoddousi et al. 2016a). However, enforcement requires social acceptability and proper sanctions to be effective (Milner-Gulland \& Rowcliffe 2007). Therefore, integrated conservation and development projects (ICDP) may be influential in reduction of poaching by targeting economic or non-economic incentives (Duffy et al. 2016). Nevertheless, ICDPs may also fail to address poaching if targeting wrong agential incentives (Winkler 2011; Duffy et al. 2016). Therefore, knowledge on poaching incentives at local level is necessary to choose appropriate conservation measures for reducing poaching pressure (South \& Wyatt 2011; Nuno et al. 2013; Challender \& MacMillan 2014).

Hunting has a long history in the livelihood and culture of people of Iran (Firouz 2005). Historical records of royal hunting trips and description of hunting grounds are frequent in the Persian literature (see Tajbakhsh \& Jamali 1995; Firouz 2005). 
However, despite widespread hunting, it appears that limited accessibility and lack of efficient hunting tools prevented overexploitation of wildlife. The onset of the $20^{\text {th }}$ century brought off-road vehicles and better firearms to the public, which led to wildlife massacres across Iran (Firouz 2005). The Caspian tiger Panthera tigris virgata and Asiatic lion $P$. leo persica have gone extinct in Iran during this period and the Persian fallow deer Dama mesopotamica was considered extinct until its rediscovery in 1957 (Firouz 2005). This trend severely declined wildlife numbers in most areas until the first efforts of modern hunting control were introduced in the 1950's (Moore 1976; Firouz 2005).

Regulation of hunting in Iran began in 1956 with the establishment of Game Council of Iran, which was renamed and expanded to Department of Environment (DoE) in 1974, and creation of the first network of reserves. These efforts initiated recovery of wildlife in some areas of the country (Moore 1976; Firouz 2005). Since then, DoE kept on continuously increasing the number of its reserves and now the area under its protection covers over $10 \%$ of the country's land (Kolahi et al. 2012). However, political turbulences since 1979, lack of acceptability of conservation laws by local communities and insufficient resources of DoE resulted in widespread poaching in most Iranian reserves (Tatin et al. 2003; Kiabi et al. 2004; Ghoddousi et al. 2016a).

Ungulates are a major target of hunting in Iran (Tajbakhsh \& Jamali 1995; Firouz 2005). Currently, they represent a diverse range of species including the bezoar or wild goat Capra aegagrus, chinkara or jebeer Gazella bennettii, goitered gazelle Gazella subgutturosa, mouflon or wild sheep Ovis orientalis, urial O. vignei, onager Equus hemionus onager, Persian fallow deer, red deer Cervus elaphus, roe deer Capreolus capreolus and wild boar Sus scrofa. Six of these species are threatened at global scale according to the IUCN Red List of Threatened Species and two species (Persian fallow deer and onager) are currently native only to Iran (Mallon 2008; Valdez 2008; Weinberg et al. 2008; Hemami et al. 2015; Werner et al. 2015; note synonymity of urial and mouflon according to the IUCN, but new classification according to Rezaei et al. 2010). Apart from Persian fallow deer, which lives in semicaptive conditions, and wild boar whose consumption is religiously prohibited, all 
other ungulate species are threatened by poaching and experience population declines in recent decades (Karami et al. 2002; Tatin et al. 2003; Kiabi et al. 2004; Shams Esfandabad et al. 2010; Ghoddousi et al. 2016a; Soofi et al. submitted).

Ungulate poaching in Iran appears to be local and unrelated to international wildlife trade (Ashayeri \& Newing 2012), but smuggling of ungulates from southern Iran to the neighboring countries has been reported (own data, unpublished). Despite widespread poaching, the dimension of population decline in Iranian reserves is yet unknown, as robust ungulate monitoring techniques are largely lacking. Also, the knowledge on poachers' incentives is yet limited in the country. Subsistence, monetary profit, traditional values and conflict with DoE are the main incentives for ungulate poaching in Bamu National Park (Ashayeri \& Newing 2012), but whether they hold true in other reserves of Iran is unclear.

In this study, we measured ungulate population trends in Golestan National Park (GNP) where ungulate abundance data are available from the 1970's (Decker \& Kowalski 1972; Kiabi 1978; Kiabi et al. 2004). We assessed the populations of four ungulate species (bezoar goat, red deer, urial and wild boar) and compared them with their earlier status. There is no information on large-scale migrations, diseases or other environmental conditions which might have considerably affected the populations of these four species in this period in GNP (Ghoddousi et al. 2016b). There is no competition with livestock in this area as grazing is banned inside GNP and illegal grazing occurs only at limited scale along the periphery of the park (Ghoddousi et al. 2016b). Moreover, no major habitat destruction or development projects have reduced wildlife habitats in the park in the recent decades. However, poaching has been widely reported as one of the main threats to ungulate species in the park (Kiabi et al. 2004; Hamidi et al. 2014; Ghoddousi et al. 2016a; Soofi et al. submitted). Therefore, we assume that any remarkable declines in the abundance of GNP ungulates are due to poaching pressure.

The severity of penalties, probability of capture by rangers and incentives are the most important factors in poaching decisions (Milner-Gulland \& Leader-Williams 1992). Hunting is illegal in GNP and fines or imprisonment applies to non-compliers. 
Also, GNP has a sufficient number of rangers in the steppe zone to control illegal activities according to international recommendations (Jachmann \& Billiouw 1997; Ghoddousi et al. 2016a). As understanding incentives may help managers find solutions against poaching (Milner-Gulland \& Leader-Williams 1992), in this study we also evaluated the incentives of local poachers for hunting ungulates in context of existing disincentives.

\subsection{Materials and methods}

Study area

GNP was established in 1957 in north-eastern Iran (Fig. 5.1). It encompasses Hyrcanian montane forests, steppes and arid plains in an area of $874 \mathrm{~km}^{2}$ (Akhani 2005). From west to east, elevations range from 450 and $2411 \mathrm{~m}$ above sea level and mean annual precipitation is 866 and $142 \mathrm{~mm}$, thus creating a variety of habitats (Akhani 2005). The park holds six species of ungulates, therewith it represents one of the Iranian protected areas with highest ungulate richness (Ghoddousi et al. 2016b). Urial is distributed in steppes of the park to the east and north, and roe deer and red deer inhabit forests in western and central parts of the park. Wild boar is present all around GNP with higher densities in forests. The population of goitered gazelle lives in narrow plains in the east and north of the park. Bezoar goat occurs in cliffs across the park. There are no villages inside GNP, but 15 villages inhabited by around 8660 inhabitants are located at less than $2 \mathrm{~km}$ from the park borders. The communities mainly rely on crop and livestock farming.

\section{Estimation of ungulate populations}

We used a variety of population estimation methods due to different detection probabilities and habitat characteristics of the studied ungulate species in GNP (Ghoddousi et al. 2016b). We excluded goitered gazelle and roe deer from our study. Goitered gazelle has limited distribution in GNP and roe deer data was insufficient to allow population estimates. The abundance estimates from 2011-2014 were compared to the reported accounts from 1970-1978, which used comparable 
systematic monitoring methods (Decker \& Kowalski 1972; Kiabi 1978; Kiabi et al. 2004). We are not aware of any other studies on populations of these ungulates species in this time frame. When more than one estimate for a given species for each period was available or if a population range was given, the arithmetic mean of the two figures was calculated.

\section{Bezoar goat}

We used double observer point-count to estimate bezoar goat abundance in GNP (Suryawanshi et al. 2012). We identified $53.6 \mathrm{~km}^{2}$ of rugged landscapes as bezoar goat habitat and chose 20 random sampling points within this area with a minimum distance of $3 \mathrm{~km}$ between two points. Bezoar goat groups were counted from vantage points 200-500 m away from sampling points using two observers from November to December 2014. The data was analyzed using DOBSERV software (Nichols et al. 2000). The sampled area was calculated as the overlap of observable areas from vantage points and the identified bezoar goat habitat using the viewshed function in ArcGIS 10.1. A detailed description of our sampling and modeling approaches is provided elsewhere (Ghoddousi et al. 2016b). The earlier population estimate of bezoar goat was based on full-day observations in sample areas in 19761978 (Kiabi 1978), which estimated 4000-4500 bezoar goat individuals for the park (Kiabi 1978).

\section{Red deer}

To estimate red deer population size, we used dung counts by faecal standing crop approach (FSC) and camera-trap data by randomized encounter model (REM) in 422 $\mathrm{km}^{2}$ of GNP forests and grasslands (Buckland et al. 2001; Rowcliffe et al. 2008). For FSC method, we estimated red deer defecation rates by observing 20 red deer in a $0.02 \mathrm{~km}^{2}$ enclosure with a habitat comparable to GNP during eight days. Also, we estimated dung decay rate by monitoring 80 fresh dung samples across red deer habitats in GNP and using binary logistic regression to assess the influence of time and habitat types in survival of dung samples. Further, we allocated 26 strip transects of $2 \mathrm{~km}$ length and $2 \mathrm{~m}$ width for search of dung across red deer habitats from January to February 2013. For REM, we used data from an earlier study using 
37 camera traps during May-December 2011 (Hamidi et al. 2014). An average size of red deer groups was calculated from observations of 57 groups by GNP rangers during the period of camera trapping. Due to the lack of red deer movement data from GNP or Iran, we used an average of daily range estimates from other studies as $3.36 \pm$ standard error SE $0.23 \mathrm{~km}$.day ${ }^{-1}$ (Soofi et al. submitted). The camera-related parameters required by REM were retrieved from a previous study, which used a similar brand of camera traps (Deercam DC300; Non Typical Inc., Wisconsin, USA) (Rowcliffe et al. 2008). Details on sampling and application of both methods are provided elsewhere (Soofi et al. submitted). The red deer abundance from 19761978 period was estimated by Hahn's census method through line transect surveys, and dung counts (Kiabi et al. 2004). The red deer population size estimated by Hahn's method and dung counts was 1897 and 2096 individuals, respectively (Kiabi et al. 2004).

\section{Urial}

We used line transects to estimate urial population size in $340 \mathrm{~km}^{2}$ of steppes in the east and north of GNP (Buckland et al. 2001). We designed 21 transects of $3 \mathrm{~km}$ length and surveyed them in January to February 2013, August to September 2013 and in February 2014. We used Distance 6.0 to analyze data (Thomas et al. 2010). A detailed description of our methodology used to estimate the urial population is provided elsewhere (Ghoddousi et al. 2016a). The urial population in 1970 was estimated by total counts in 12 sampling units and the extrapolation of obtained densities over GNP steppes (Decker \& Kowalski 1972). The estimated abundance was around 15000 individuals (Decker \& Kowalski 1972). During a separate effort that used direct counts on line transects, 10000-11000 urials were estimated between 1976 and 1978 (Kiabi 1978).

Wild boar

We estimated wild boar abundance using REM approach from camera trapping surveys conducted between January and December 2011 (Rowcliffe et al. 2008; Hamidi et al. 2014). We used data from 67 camera traps installed throughout GNP (Hamidi et al. 2014). The average group size of wild boars was estimated from 
observations of this species on line transects in 2013-2014 (see above). Due to the lack of information on daily range of this species from the study site, we used an estimate of $6.8 \pm$ SE $0.57 \mathrm{~km}_{\text {.day }}{ }^{-1}$ from a study with similar habitat conditions (Podgórski et al. 2013). Detail on our study design and analysis is published elsewhere (Hamidi et al. 2014; Ghoddousi et al. 2016b). As a reference, we used an earlier estimate of wild boar abundance from line transect surveys as $2500-3000$ individuals in 1976-1978 (Kiabi 1978).

\section{Sensitivity analysis}

To assess the effects of uncertainty in population estimates, we conducted sensitivity analysis using different combinations of $95 \%$ confidence intervals $(95 \% \mathrm{Cl})$ (2011-2014) and population ranges (1970-1978) for each species.

\section{Interview survey}

Due to sensitivity of poaching as an illegal activity, we collected data on poaching incentives among locals using semi-structured interviews (Newing 2011). We identified poachers in villages in vicinity of GNP through a process of chain referral (Newing 2011). Local poachers agreed to participate in this study after we collaborated in joint wildlife monitoring programs (Hamidi et al. 2014; Ghoddousi et al. 2016a), built mutual trust and explained them the purpose of this study. Not being affiliated to any governmental organizations also facilitated the process of data gathering and communicating with local poachers. We asked each poacher to name the main reasons for poaching ungulates in GNP amongst other questions (Ashayeri \& Newing 2012). In some cases, we asked for further explanations from each interviewee to reliably evaluate and categorize incentives. We encoded and classified incentives into different categories based on similar elements in responses (Ashayeri \& Newing 2012). We ensured interviewees that their data would remain anonymous. Interviewees gave their verbal consent for attending the survey. We avoided acquiring written consent from participants as it might affect their trust and, consequently, reduce data quality. Interviews were not recorded and we documented information by note-taking only (Ashayeri \& Newing 2012). A focus group meeting with participation of five poachers was held on December 2012 to get 
information on the incentives of poacher. Moreover, we used findings of an earlier social study on GNP poachers (Ashayeri 2014). Information on incentives of 15 poachers was gathered using informal qualitative interviews from June 2013 to February 2014. Interviews were continued until data reached the level of saturation, meaning that no further information could be extracted from new interviews (Newing 2011). Detail on interview procedure and analytical approaches of that study can be found in a technical report (Ashayeri 2014). The interviewees in both studies were all men, between 29 and 66 years old, from 10 villages around GNP (Fig. 5.1).

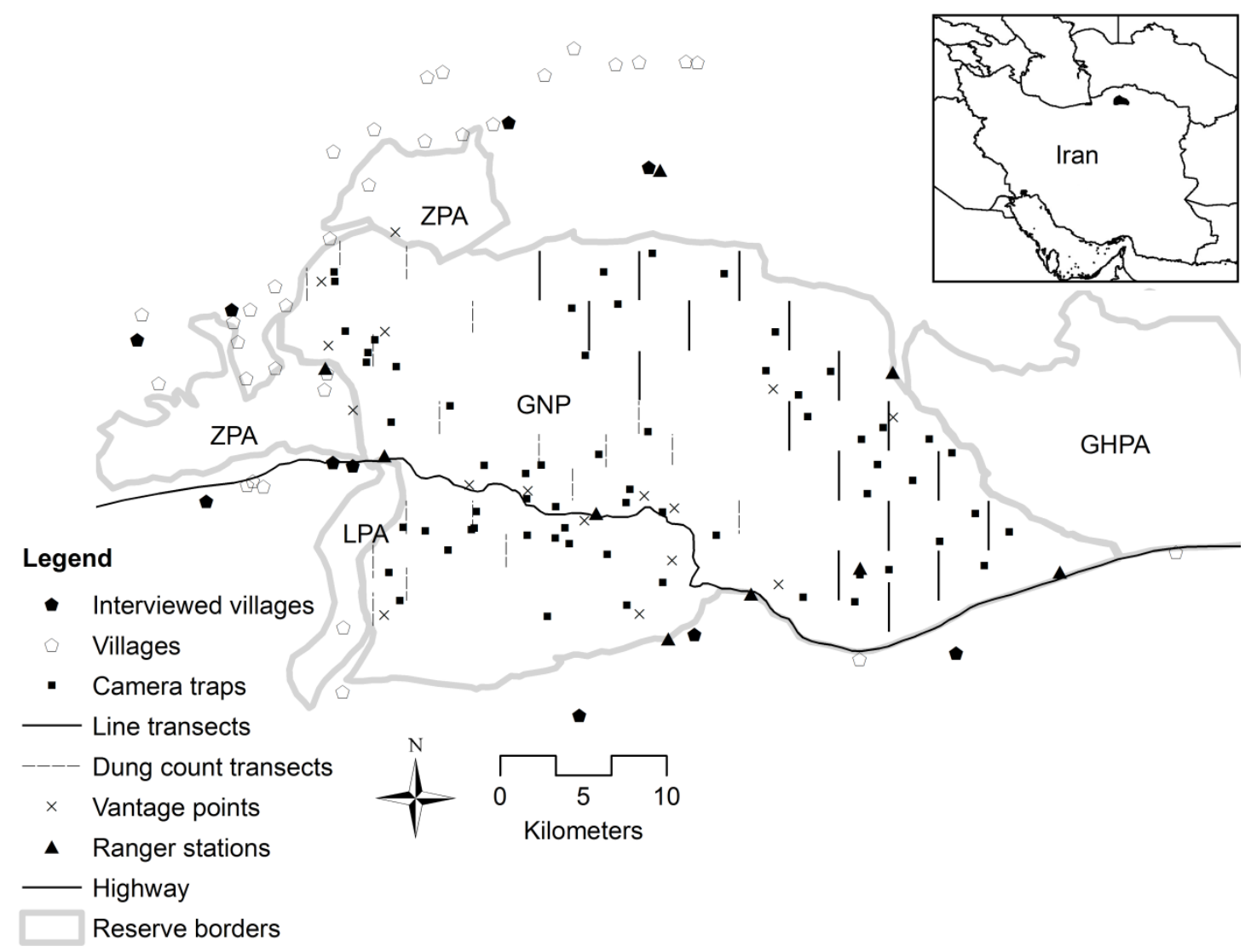

Figure 5.1. Map of Golestan National Park and the location line transects, dung count transects, camera traps, vantage points, ranger stations, as well as interviewed villages and neighboring reserves (LPA: Loveh Protected Area; ZPA: Zav Protected Area; GHPA: Ghorkhod Protected Area). 


\subsection{Results}

Ungulate population estimation

Bezoar goat

We surveyed 16 sampling points from the nearby vantage points using two observers (Fig. 5.1). During 64 scans of 15 minutes each, we observed 39 bezoar goats in seven groups. The model with equal detection probability between the observers estimated an abundance of 519 individuals (confidence interval CV = $31.3 \% ; 95 \% \mathrm{Cl}=201-807 ;$ Table 5.1). A comparison of recent estimates with the mean population size from 1976-1978 indicates an 88\% decline of the bezoar goat population. The results of sensitivity analysis showed a decline of 79 to $96 \%$ during this period (Table 5.1).

Red deer

With 1676 dung samples, the red deer defecation rate was estimated as 10.5 dung piles per individual and day. Due to lack of knowledge on variation of defecation rates among red deer individuals, calculation of SE was not possible. The age-based model estimated dung decay rate for red deer in GNP as $142 \pm$ SE 15 days. The survey effort of $36 \mathrm{~km}$ on 18 transects yielded the detection of 50 red deer dung samples (Fig. 5.1). The FSC method estimated red deer abundance as 194 individuals (CV $=28.4 \% ; 95 \% \mathrm{Cl}=103-285 ;$ Table 5.1). We captured 10 photos of red deer from 1585 camera-nights of effort in forests and grasslands of GNP (Fig. 5.1). Using REM approach, we estimated red deer population in GNP as 257 individuals (CV $=35.3 \%$; $95 \% \mathrm{Cl}=91-423$; Table 5.1). The mean red deer population from 2011-2013 shows an $89 \%$ decline compared to the mean of population estimates from $1976-1978$. We used the wider $95 \% \mathrm{Cl}$ from REM for red deer sensitivity analysis and the results showed a decline rate of 78 to $96 \%$ compared to the $1976-1978$ (Table 5.1).

Urial

The total effort of $186 \mathrm{~km}$ on 17 transects yielded the observation of 1981 urials in 70 groups (Fig. 5.1). The half-normal key detection function of Distance 6.0 
estimated urial population size as 4275 individuals $(C V=35.5 \% ; 95 \% \mathrm{Cl}=2117-8632$;

Table 5.1). The comparison between 2013-2014 abundance estimates and the average of the two estimates from 1970 and 1976-1978 shows a 66\% decline in urial abundance. The results of sensitivity analysis showed a 14 to $86 \%$ decline in urial population (Table 5.1).

Wild boar

By observing 38 groups of wild boar on line transects, we estimated the average group size of $3.1 \pm$ SE 0.9 individuals for this species. We captured 386 wild boar photos during 2777 trap-nights of efforts across GNP (Fig. 5.1) and estimated wild boar abundance using REM approach as 6478 individuals ( $\mathrm{CV}=27.0 \% ; 95 \% \mathrm{Cl}=$ 3050-9906; Table 5.1). In comparison with 1976-1978, the wild boar population increased by $58 \%$. The results of sensitivity analysis ranged from 2 to $75 \%$ growth of the population (Table 5.1).

Table 5.1. Abundance and its change in populations of four ungulate species in Golestan National Park, Iran in 1970-1978 and 2011-2014.

\begin{tabular}{|lccccc|}
\hline Species & \multicolumn{2}{c}{$1970-1978$} & \multicolumn{2}{c|}{$2011-2014$} & Population change \\
& Abundance & Range & Abundance & $95 \% \mathrm{Cl}$ & (sensitivity range) \\
\hline Bezoar goat & $4250^{1}$ & $4000-4500^{2}$ & 519 & $201-837^{5}$ & $-88 \%(-79$ to $-96 \%) \downarrow$ \\
Red deer & $1997^{1}$ & $1897-2096^{3}$ & $226^{1}$ & $91-423^{6}$ & $-89 \%(-78$ to $-96 \%) \downarrow$ \\
Urial & $12,500^{1}$ & $10,000-15,000^{2,4}$ & 4275 & $2117-8632^{7}$ & $-66 \%(-14$ to $-86 \%) \downarrow$ \\
Wild boar & $2750^{1}$ & $2500-3000^{2}$ & 6478 & $3050-9906^{5}$ & $58 \%(2$ to $75 \%) \uparrow$ \\
\hline
\end{tabular}

${ }^{1}$ Arithmetic mean of two population estimates/ranges

${ }^{2}$ Kiabi (1978)

${ }^{3}$ Kiabi et al. (2004)

${ }^{4}$ Decker \& Kowalski (1972)

${ }^{5}$ Ghoddousi et al. (2016b)

${ }^{6}$ Soofi et al. (submitted) from random encounter models

${ }^{7}$ Ghoddousi et al. (2016a)

\section{Poaching incentives}

While the results of our interview surveys and the earlier study (Ashayeri 2014) revealed five main categories of poaching incentives, we concluded that a 
combination of incentives plays a major role for each poacher to go on a hunting trip. Reported incentives were poverty/to fulfill survival needs, hunting for meat market/trade, pleasure/love of hunting, tradition/habits, and hunting for revenge/conflict with the conservation regulations and bodies. Our approach did not allow ordinal ranking of incentives based on their importance but showed a mixture of social, economic and policy-related motivations for poaching in GNP.

\subsection{Discussion}

In this study, we report a $66-89 \%$ population decline of three ungulate species in Golestan National Park since the 1970's. Such a trend in the absence of any reported migrations or mass mortalities may represent the effects of poaching in the oldest national park of Iran. The fact that the wild boar population, whose meat consumption is prohibited by Islam, has increased by $58 \%$ during the same time frame further supports our claim. Our results demonstrate that conservation laws and practiced enforcement measures have failed in stopping poaching in the past four decades and require reconsideration. We identified a combination of economic and non-economic incentives for ungulate poaching in the park, which may help conservationists choose appropriate anti-poaching schemes.

We reported the highest declines in bezoar goat (88\%) and red deer (89\%) populations. Bezoar goat habitat is restricted to patches of cliffs within the park, where they are easily exposed to poachers. Bezoar goat is considered as a highly preferred prey for endangered Persian leopard P. pardus saxicolor, and possible extinction of bezoar goat in the park may threaten the survival of the largest protected population of Persian leopards as well (Hamidi et al. 2014; Ghoddousi et al. 2016b). Golestan National Park also holds one of the last population strongholds of red deer in the Caspian forests (Kiabi et al. 2004). Despite dense vegetation and elusive behavior of red deer in the park, this species is highly vulnerable to poaching, especially during the rutting season (own data, unpublished). In September and October each year, poachers imitate stag calls and attract them to the shooting range. Despite efforts in increasing ranger numbers and setting mobile camps during 
this period, red deer poaching is widespread. Without immediate conservation actions, both of these species may go extinct in Golestan National Park in the near future. Urial population also showed a decline (66\%) of population in the recent decades. This species is highly preferred among local poachers (Ghoddousi et al. submitted) and is almost extirpated from some of its former range in the park (Decker \& Kowalski 1972; Ghoddousi et al. 2016b). However, urials still occur in higher densities in the vicinity of the ranger stations (Ghoddousi et al. 2016a). It appears that the lack of regular systematic monitoring schemes coupled with low detection probability of some species may have created an "illusion of plenty" among park managers (Erisman et al. 2011) who may underestimate the drastic decline in population of hunted ungulates.

In Golestan National Park and other Iranian reserves species living in open landscapes have been routinely monitored by annual direct total counts. Total counts do not follow a systematic sampling approach and the assumption of observation of all individuals in large areas can be rarely met (Buckland et al. 2001). Moreover, this method does not provide a measure of variance, which is necessary for assessing population trends over time (Yoccoz et al. 2001; Suryawanshi et al. 2012). Therefore, it is required to adopt monitoring methods, which are suitable for rugged landscapes and robust to detect trends in exploited populations living at low densities (Singh \& Milner-Gulland 2011). In this study, we were able to successfully conduct a variety of monitoring methods and DoE should initiate capacity-building programs for rangers and invest into necessary equipment to conduct similar surveys on a regular basis.

Although our results provide a clear evidence of population changes in Golestan National Park since the 1970 's, we are aware of some study limitations, which might affect our inferences. The dissimilar monitoring methods used in this study in comparison with historic data may be a source of bias. However, we are not aware of any other systematic surveys of these species since the establishment of the park (Decker \& Kowalski 1972; Kiabi 1978; Kiabi et al. 2004). Although our camera trapping design was targeted on leopard (Hamidi et al. 2014), we assume that it did not produce a major bias as movement patterns of herbivores are independent from 
those of carnivores (Cusack et al. 2015a). Moreover, REM analyses of red deer and wild boar data produced comparable results to other tested methods (Ghoddousi et al. 2016b; Soofi et al. submitted).

In our study, presence of different incentives among poachers shows that single policies are unlikely to succeed in deterring poachers and a combination of approaches is required (Duffy et al. 2016). Poverty and existence of meat market can be grouped as economic incentives. Due to existence of fines and law enforcement, we assume that poachers with monetary incentives are responsible for more frequent hunting trips and maximum number of animals killed in each trip compared to poachers with non-economic incentives. Therefore, we consider economic incentives as a priority to be addressed. However, as the link between poverty and poaching requires further investigations (Milner-Gulland et al. 2014; Duffy et al. 2016), future conservation initiatives should conduct in-depth research of this issue in the local context. Creating alternative livelihoods for local communities is among usual approaches in battling poaching (Duffy et al. 2016). As subsistence poachers normally lack skills, education and cultural capacities required for employment in many sectors (Robinson \& Bennett 2002; Nuno et al. 2013), alternative livelihood schemes may fail to correctly target poachers. However, local ecological knowledge of poachers is of high value in conservation and initiatives, which may efficiently increase their employment opportunities in conservation and other nature-related sectors (Lindsey et al. 2013). ICDPs may explore livelihood opportunities in developing ecotourism or facilitating the establishment of community-based reserves, which are underperforming in Iran (Lindsey et al. 2013; Ghoddousi et al. submitted). Also, awareness-raising campaigns against wild meat consumption in urban areas may be suggested to target demand (Challender \& MacMillan 2014). Moreover, the distribution and efficiency of law enforcement efforts in Golestan National Park should be improved (Ghoddousi et al. 2016a). Finally, since 2015 there has been a sharp increase in DoE fines for poaching bezoar goat (82\%; USD \$ 2900), red deer (91\%; USD \$10,000) and urial (82\%; USD \$ 2900) in an attempt to stop poaching. However, the effects of such rather unrealistic fines in deterring poachers with economic incentives require investigations. 
The existence of incentives related to tradition and pleasure of hunting may indicate that alternative livelihood programs alone may fail to address the poaching problem (Waylen et al. 2009). As an example, community outreach programs aiming at building trust, awareness, motivation, and opportunities are proven to be influential in controlling poaching in Southeast Asia (Steinmetz et al. 2014). Moreover, it appears that the limited number of hunting permits issued annually by DoE is not sufficient to satisfy interest in hunting. Establishing community-based reserves may provide legal hunting opportunity for local communities, which is currently unavailable in their surrounding areas. ICDPs may further investigate opportunities for creating such reserves in the future. Finally, like in a previous study in Iran (Ashayeri \& Newing 2012) conflict with conservation bodies and regulations was stated as a poaching incentive. The non-participatory and top-down approach to protected area management in Iran (Zendehdel et al. 2010), coupled with hostile encounters between rangers and local communities, cause conflicts between the two parties. Additionally, DoE has increased the minimum educational requirements for employment of rangers and, therefore, locals living in the vicinity of Golestan National Park have lower opportunities to occupy these positions. Hiring non-local rangers may neglect local ecological knowledge, leave local communities out of decision-making processes in the park, and finally produce conflicts between local communities and conservation authorities. Nevertheless, we suppose that conflict may exacerbate poaching, but not create it.

In this study, we did not use indirect methods to acquire sensitive data (Nuno \& St John 2015). However, as we asked poachers about their incentives and not their poaching rates, we are confident that the issue of underreporting to sensitive questions did not affect our results (Gavin et al. 2010). Also, in this study we did not interview non-local poachers because ICDPs and conservation managers can hardly influence non-local poachers, except for applying law enforcement measures. Poacher seizure records from 2007-2014 in Golestan National Park show that $27.4 \%$ of seizures were from non-local poachers (own data, unpublished).

The alarming decline of hunted ungulate populations in Golestan National Park may also reflect their inadequate status in other reserves of Iran, which generally 
receive less conservation attention and law enforcement resources. With the business-as-usual approach observed in reserves across the country, the fate of hunted species in face of rampant poaching is worryingly unclear. Therefore, DoE should adopt participatory conservation strategies, improve law enforcement practices and cooperate with international expertise in resolving poaching problem nationwide. ICDPs should target poverty, offer alternative livelihoods and engage local communities in decision-making processes. As for poaching deterrents, we recommend strengthening law enforcement, training and motivating rangers, and using modern technologies in detection of poachers. Finally, raising awareness to reduce demand for wild meat and ungulate trophies is required. This initiative requires long-term national commitment and sustainable outreach programs.

\section{Acknowledgements}

We acknowledge support of Iranian Department of Environment, Golestan provincial office of Department of Environment and Golestan National Park management for provision of permits for this study. We appreciate cooperation of Persian Wildlife Heritage Foundation in granting access to their camera trapping and social survey data, as well as logistical support. This study was not possible without collaboration of rangers, local guides and volunteers. German Academic Exchange Service (DAAD) and Panthera's Kaplan Graduate Award funded AG and Erasmus Mundus/SALAM funded MS during their PhD projects. We acknowledge Turkmen Ecolodge for hosting the focus group meeting with local poachers. We also thank K. Seyed Emami for feedbacks on the earlier version of the manuscript. 


\section{Chapter 6: Assessing the role of livestock in big cat prey choice using spatiotemporal availability patterns}

Arash Ghoddousi, Mahmood Soofi, Amirhossein Kh. Hamidi, Tanja Lumetsberger, Lukas Egli, Igor Khorozyan, Bahram H. Kiabi, Matthias Waltert

PLoS ONE, 2016, 11(4): e0153439. DOI: 10.1371/journal.pone.0153439

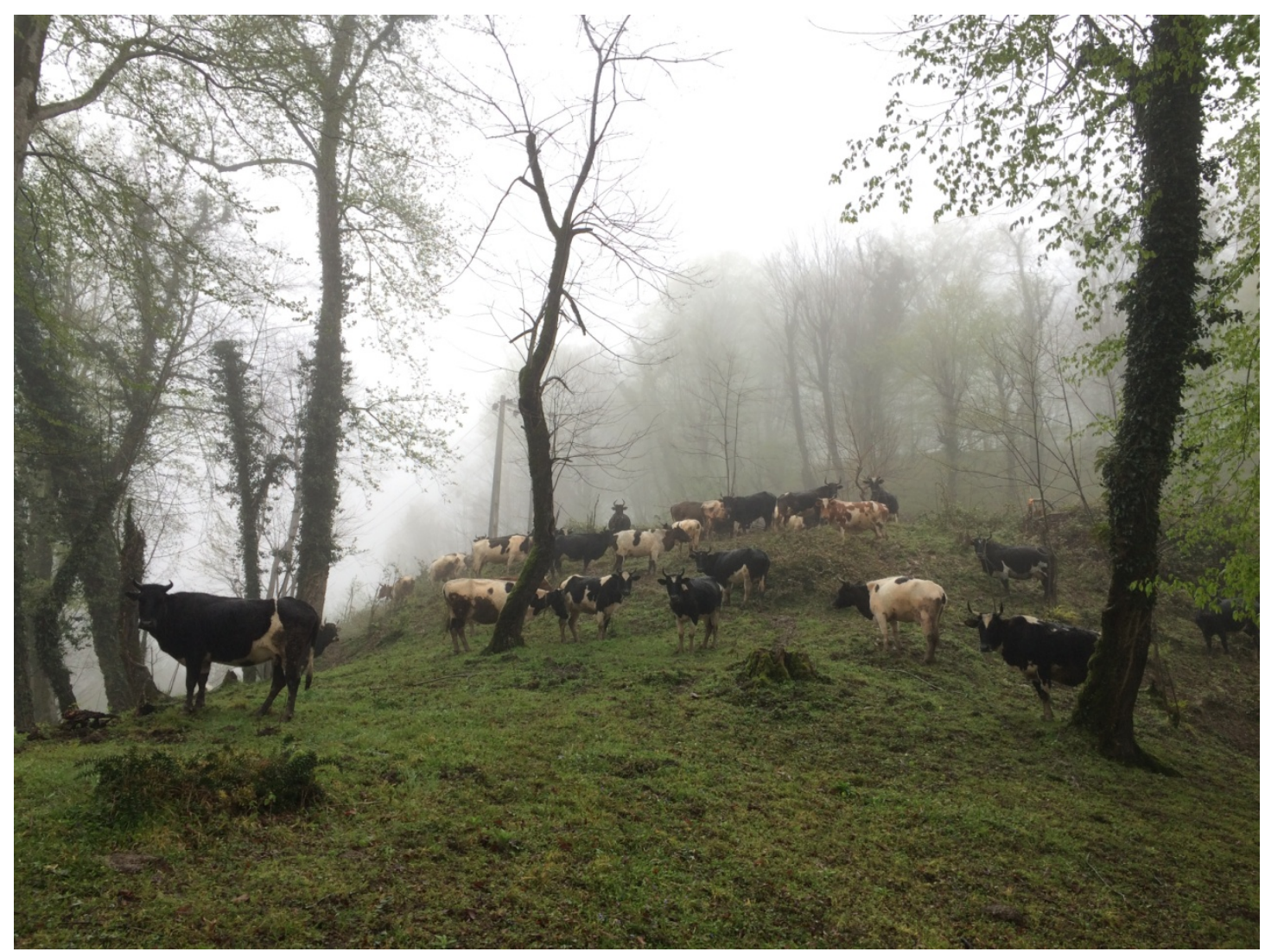

Unattended cattle grazing in Hyrcanian forests. Photo: M. Soofi 


\section{Abstract}

Livestock is represented in big cat diets throughout the world. Husbandry approaches aim to reduce depredation, which may influence patterns of prey choice, but whether felids have a preference for livestock or not often remains unclear as most studies ignore livestock availability. We assessed prey choice of the endangered Persian leopard (Panthera pardus saxicolor) in Golestan National Park, Iran, where conflict over livestock depredation occurs. We analyzed leopard diet (77 scats) and assessed wild and domestic prey abundance by line transect sampling (186 km), camera-trapping (2777 camera days), double-observer point-counts (64 scans) and questionnaire surveys (136 respondents). Based on interviews with 18 shepherds, we estimated monthly grazing time outside six villages with 96 conflict cases to obtain a small livestock (domestic sheep and goat) availability coefficient. Using this coefficient, which ranged between 0.40 and 0.63 for different villages, we estimated the numbers of sheep and goats available to leopard depredation. Leopard diet consisted mainly of wild boar (Sus scrofa) (50.2\% biomass consumed), but bezoar goat (Capra aegagrus) was the most preferred prey species $\left(I_{j}=0.73\right)$, whereas sheep and goats were avoided $\left(I_{j}=-0.54\right)$. When absolute sheep and goat numbers ( 11250) were used instead of the corrected ones ( 6392), avoidance of small livestock appeared to be even stronger $\left(I_{j}=-0.71\right)$. We suggest that future assessments of livestock choice by felids should incorporate such case-specific corrections for spatiotemporal patterns of availability, which may vary with husbandry methods. Such an approach increases our understanding of human-felid conflict dynamics and the role of livestock in felid diets. 


\subsection{Introduction}

As part of the wide diet spectrum of felids, livestock has been depredated throughout the world (Inskip \& Zimmermann 2009). Livestock depredation causes serious damage to local economies and creates or reinforces negative attitudes toward conservation initiatives and felids (Inskip \& Zimmermann 2009). Moreover, conflicts may result in the application of lethal control of felids of high conservation value (Inskip \& Zimmermann 2009). Despite different efforts of husbandry (e.g. night corrals, shepherds and guarding dogs) practiced to minimize losses, livestock still constitutes a considerable proportion to felid diets in some parts of the world (Sangay \& Vernes 2008; Gervasi et al. 2014; Johansson et al. 2015). Therefore, understanding the livestock choice by felids in the world constantly changing due to anthropogenic modifications is of high importance for conservation (Inskip \& Zimmermann 2009; Mukherjee \& Heithaus 2013). Prey choice is a complex trophic relationship defined as the disproportional use of a resource given its availability, relative to all other resources with factors such as prey abundance, body mass, group size and injury threat, as well as habitat features playing important roles (Stephens \& Krebs 1986; Mukherjee \& Heithaus 2013). Decline of natural prey abundance, lax husbandry methods, and individual predator behavior have all been suggested as the important factors in felid depredation on livestock (Linnell et al. 1999; Wang \& Macdonald 2006; Odden et al. 2008; Gervasi et al. 2014; Khorozyan et al. 2015a).

Due to the domestication process, livestock may have lost their agility to predator attacks and are easier targets for predators compared to wild prey (Linnell et al. 1999). However, humans provide livestock with different means of protection, potentially minimizing the predator's chance for depredation and threatening predators themselves (Woodroffe et al. 2007). Nevertheless, preference or avoidance of livestock in felid diet in comparison with wild prey has been rarely quantified (Moa et al. 2006; Mondal et al. 2011; Athreya et al. 2016). The exclusion of livestock from most felid prey choice analyses may originate from the lack of information on their numbers or husbandry practices (Loveridge et al. 2010). As livestock predation risks may vary depending on different husbandry methods 
(Woodroffe et al. 2007; Sangay \& Vernes 2008; Mondal et al. 2011; Gervasi et al. 2014; Johansson et al. 2015; Athreya et al. 2016), absolute livestock numbers may be inadequate to assess the role of livestock in felid prey choice (Loveridge et al. 2010). Therefore, we argue that using spatiotemporal livestock availability stemming from different husbandry methods may result in meaningful incorporation of livestock into prey choice studies. Such spatiotemporal corrections may provide more realistic information on preference of domestic prey by felids and the efficiency of husbandry methods. In this study, for the first time to our knowledge, we incorporate the spatiotemporal livestock availability into a felid prey choice study to better understand the dynamics of a human-felid conflict.

The leopard (Panthera pardus) is known as a predator preying on at least 111 wild species throughout its range (Hayward et al. 2006). This diversity of prey species and the habitats they inhabit shows the flexibility of this species in tolerating different conditions (Hayward et al. 2006). However, leopards are known to prefer preying on medium-sized ungulates within a weight range of 1-45 kg, which occur in small herds, pose a minimal risk of injury and live in habitats with moderate cover for hunting (Hayward et al. 2006; Balme et al. 2007; Pitman et al. 2013; Clements et al. 2014). Leopards are also responsible for livestock depredation in much of their range, but their preference/avoidance of livestock is unknown (Sangay \& Vernes 2008; Shehzad et al. 2014; Minnie et al. 2015).

We assessed the prey choice of the Persian leopard ( $P$. pardus saxicolor) in Golestan National Park (GNP), Iran, where the conflict with humans is of great concern for the conservation of this globally endangered subspecies (Khorozyan et al. 2015b). We used scat sampling for dietary analysis and wild and domestic prey population assessment by means of distance sampling, camera trapping, pointcounts and questionnaire surveys. Using a livestock availability coefficient based on the spatiotemporal patterns of livestock grazing outside conflict villages, we aimed to assess the availability of livestock vs. wild prey in a more informed way than by using crude livestock numbers. This application may assist conservation managers by providing a better understanding of big cat preferences of wild and domestic prey and by improving the effectiveness of husbandry methods in mitigating conflicts. 


\subsection{Materials and methods}

\section{Study area}

GNP is located in northeastern Iran from $37^{\circ} 16^{\prime} 43^{\prime \prime} \mathrm{N}$ and $37^{\circ} 31^{\prime} 35^{\prime \prime} \mathrm{N}$ to $55^{\circ} 43^{\prime} 25^{\prime \prime} \mathrm{E}$ to $56^{\circ} 17^{\prime} 48^{\prime \prime} \mathrm{E}$ (Fig. 6.1), with an area of $874 \mathrm{~km}^{2}$. GNP elevation ranges from 450 to $2411 \mathrm{~m}$ a.s.I. (Akhani 2005). The dissimilar mean annual precipitation of 142 and 866 $\mathrm{mm}$ in the east and west, respectively, results in varied vegetation types from deciduous forest to steppe and semi-desert (Akhani 2005). GNP is known to hold the largest global population of the endangered Persian leopard (27 indiv., 95\% confidence interval $\mathrm{Cl}=23-42$ ) and to be among the richest Iranian reserves in ungulates (six species) (Hamidi et al. 2014). However, extensive poaching in GNP due to insufficient acceptance of conservation laws among local communities and lack of appropriate enforcement measures has caused a drastic decline in the ungulate populations in recent decades (Hamidi et al. 2014; Ghoddousi et al. 2016a). Around 8815 inhabitants live in 16 villages within less than $2.5 \mathrm{~km}$ distance from GNP boundaries (Fig. 6.1) (Khorozyan et al. 2015b). No villages exist inside GNP boundaries. The main occupation of people in these villages is crop cultivation and livestock rearing, with frequent but illegal grazing of livestock inside the park (Khorozyan et al. 2015b). When grazing in pastures outside villages, domestic goat (Capra aegagrus hircus) and sheep (Ovis aries) herds are mostly guarded by shepherds and dogs (Canis familiaris). Otherwise, they are kept in pens inside the villages. As domestic goats and sheep graze in mixed herds in the region, we hereafter consider them as a single prey species available to leopard predation and refer to them as 'small livestock' (Khorozyan et al. 2015b). Although domestic sheep and goats may have different movement patterns and their predation risk can be different, such variations are unknown to us and were considered as constant. High quality cattle (Bos taurus) are kept in pens and other cattle roam freely in pastures and forests outside villages, normally without protection (Khorozyan et al. 2015b). Depredation of livestock by leopards occurs in villages around GNP and in many cases, local people do not tolerate such losses and may illegally kill leopards by poisoning the remaining livestock carcasses or shooting (Firouz 2005). 


\section{Leopard diet analysis}

We used scat analysis for identification of leopard diet in GNP (Klare et al. 2011). Leopards defecate several times from one predation event and use their scats as a territorial sign, which provides valuable dietary information (Klare et al. 2011). Faecal sampling of leopards provides comparable results to inspection of kill sites from GPS-collared animals, while the latter approach is more costly and may underrepresent small species (Pitman et al. 2014; Johansson et al. 2015). As leopards have been recorded all around GNP (Hamidi et al. 2014), we collected their scats on an irregular basis throughout the park alongside the main trails or near scrapes (Athreya et al. 2016). To avoid autocorrelation, we avoided collection of multiple scats from the same location likely originating from the same predation event. Also, we distributed our scat sampling surveys as widely as possible, so that our diet analysis would represent all leopards of GNP (Fig. 6.1). Moreover, leopard diet did not differ between wet and dry seasons, therefore the temporal variation in diet was not considered (Sharbafi 2011). The team members (AG, MS \& AKH) and park rangers collected leopard scats between 2011 and 2014 and distinguished them from other carnivore scats by their diameter $(2-4 \mathrm{~cm}$; mean $=2.85 \mathrm{~cm}$; standard deviation $S D=0.51$ ), cylindrical shape and segmentation into several lobes with pointed ends (Sharbafi 2011). The park holds no other big cats after extinction of tiger (P. tigris) in 1953 (Firouz 2005); hence, we are confident that our scat sampling was restricted to leopards. The scats were air-dried after collection and stored separately in labeled paper bags at room temperature. The undigested prey remains were cleaned with $70 \%$ ethanol and rinsed with distilled water (Klare et al. 2011). Ten random hairs were examined macroscopically and microscopically from each scat sample and identified using the previously compiled hair reference catalogue from the study area (Lumetsberger 2014) and other references (Oli 1993; De Marinis \& Aspea 2006). Frequency of occurrence (FO) and percent of occurrence $(P O)$ of prey remains in scats were calculated from the number of scats containing a certain $i$-th prey species $\left(n_{i}\right)$ by using equations (Klare et al. 2011):

$$
F O_{i}(\%)=\left(n_{i} / N_{\text {scat }}\right) \times 100
$$




$$
P O_{i}(\%)=\left(n_{i} / N_{i t e m}\right) \times 100
$$

To account for more than one prey species per scat, a corrected FO (CFO) was obtained by allocating equal fractions of the scat to the prey species (Karanth \& Sunquist 2000). To overcome the overrepresentation of smaller prey items in the diet, we used a non-linear biomass correction factor for calculation of prey biomass consumed by leopards (Wachter et al. 2012):

$$
C F_{1 ; i}=2.358(1-\exp (-0.075 x))
$$

where $C F_{1}$ is the biomass of the $i$-th consumed prey species per scat against the average body mass of the species $x(\mathrm{~kg})$. For estimation of prey numbers consumed by leopards, we used another non-linear correction factor:

$$
C F_{2 ; i}=3.094 \exp \left(-0.5((\ln (x / 16.370)) / 2.584)^{2}\right)
$$

where $C F_{2}$ is the number of the $i$-th consumed prey species per scat against the average body mass of the species $x(\mathrm{~kg})$. Average body mass of prey species was extracted from the literature as $3 / 4$ of average female body mass to account for predation on juvenile and sub-adult individuals (Goshtasb 2001; Lumetsberger 2014). To check whether our scat samples were sufficient to accurately portray leopard diet diversity in GNP, the accumulation curve was computed in EstimateS 9.1 based on the Shannon diversity index (Colwell 2013). Possible changes in leopard diet profile with higher sample size were assessed by comparing our scat data $(\mathrm{n}=$ 77) with the pooled data from this study and an earlier research in GNP $(n=115)$ using similar methodology (Sharbafi 2011). Differences in the prey species CFOs between the pooled and original data were tested using the two-way Z-test.

\section{Prey population estimation}

We conducted prey population surveys of the top four prey species: wild boar (SUS scrofa), bezoar goat (C. aegagrus), urial (O. vignei) and small livestock, which contributed over $85 \%$ of $P O$ in leopard diet (see above). There was insufficient data on abundance of other potential prey species, which occur seldom in leopard diet in 
our study area. Because of variations in detection probability of prey due to different habitat structure or species ecology, we applied different population estimation methods for each species (see below). We used a stratified random sampling approach for estimation of wild prey abundance.

As there is no reported seasonal migration of wild prey to or from GNP, temporal availability of wild prey was considered as constant. There is no significant difference in the overall diet of leopards between steppe and forest parts of the park (Sharbafi 2011) and the ranging pattern of leopards in GNP is not restricted to a specific habitat (Hamidi et al. 2014). Therefore, variations in spatial availability of wild prey were not considered as well. However, we acknowledge that there are subtle variations in spatiotemporal availability of wild prey within ranges of different leopard individuals, which we were unable to measure. On the other hand, as domestic prey is available to leopard predation only when grazing outside villages and conflict cases are spatially explicit (Miller 2015), we considered the spatiotemporal availability of livestock (see below).

Line transects

We applied Distance sampling using line transects to estimate the density of urial in GNP (Buckland et al. 2001). A detailed description of the urial line transect sampling design and modeling is provided elsewhere (Ghoddousi et al. 2016a). We sampled a $340 \mathrm{~km}^{2}$ steppe area of the park as the main urial habitat by surveying 17 transects

(Fig. 6.1). We used Distance 6.0 software (Thomas et al. 2010) for estimation of urial abundance.

\section{Camera trapping}

We used the random encounter model (REM) for estimation of wild boar abundance (Rowcliffe et al. 2008), using camera-trapping data from January to December 2011 provided by the Persian Wildlife Heritage Foundation (Hamidi et al. 2014). As we attempted to set up camera traps with a minimum distance of $2 \mathrm{~km}$ apart in areas favored by leopards across the park (i.e. wherever leopard signs such as scrapes or scats were detected), we assumed that these locations are random to wild boar 
movements (Cusack et al. 2015b). Our camera trapping procedure has been described in the literature before (Hamidi et al. 2014). Estimation of wild boar density using the REM method incorporates the number of independent photographic events of the species $(y)$, total camera trapping effort $(t)$, average daily movement of the species when active $(v)$ and average group size $(g)$, as well as camera trap-related parameters such as detection distance $(r)$ and angle $(\vartheta)$ using the following equation (Rowcliffe et al. 2008):

$$
D=\frac{y}{t} \frac{\pi}{\operatorname{Vr}(2+\theta)} \times g
$$

We retrieved $r$ and $\vartheta$ values from the published literature (Rowcliffe et al. 2008) that used the same brand of camera traps (Deercam DC300; Non Typical Inc., Wisconsin, USA) at $12 \mathrm{~m}$ and 0.175 radians, respectively. Since wild boars are considered large animals (50-300 kg in GNP) (Goshtasb 2001), there is little difficulty in their detection by camera traps and classical approaches in estimation of camera trap parameters seem sufficient (Rowcliffe et al. 2011). Daily movement of wild boars $(v)$ was extracted from a radio-tracking study in a primeval temperate forest, which is ecologically comparable to GNP, as $6.8 \pm$ standard error (SE) $0.57 \mathrm{~km}_{\mathrm{day}}{ }^{-1}$ (Podgórski et al. 2013). Average group size of wild boars $(g)$ was calculated through the encounters of this species on line transects in GNP (Table S6.1). We estimated the variance of density using the delta method, as the squared variance of each independently estimated REM parameter added to the squared variance of bootstrapped wild boar encounter rate $(y / t)$ [40]. We conducted bootstrapping by resampling camera locations 10,000 times with replacement (Rowcliffe et al. 2008).

Double observer point-count

To assess the abundance of bezoar goats, which inhabit hardly accessible rocky terrain, we applied a double-observer point-count approach based on markrecapture theory (Nichols et al. 2000; Suryawanshi et al. 2012). We followed habitat descriptions in the literature to identify the rugged habitat of bezoar goats in GNP (Shams Esfandabad et al. 2010; Speicher 2013). Namely, we used a threshold of 0.03 for the ruggedness index (Sappington et al. 2005) and $40^{\circ}$ for slope using the digital 
elevation model (DEM) in ArcGIS 10.1 (ESRI, Redlands, CA). Moreover, we added a buffer of $200 \mathrm{~m}$ as bezoar goats graze in areas near cliffs as well (Speicher 2013). We excluded isolated habitat patches of less than $3.5 \mathrm{~km}^{2}$, where we did not expect any animals to exist. Thereby, in the remaining $53.6 \mathrm{~km}^{2}$ of bezoar goat habitat we selected 20 random sampling points with a minimum distance of $3 \mathrm{~km}$ (Fig. 6.1). We selected vantage points at 200-500 m away from the hardly accessible bezoar goat habitat using the viewshed function in ArcGIS 10.1 for scanning the sampling points. Each vantage point was visited once by two trained observers (usually one park ranger and one team member: $A G, A K H, M S$ or $L E)$, each equipped with a rangefinder, binoculars and compass. Each observer conducted four alternating independent scans of 15 minutes and recorded sightings up to a maximum distance of $1000 \mathrm{~m}$ to equalize detection changes for both observers (Nichols et al. 2000). For each sighting, observers mapped the location and recorded the number of animals (cluster size) and the distance to the center of the cluster. After finishing the survey, both observers compared their data sheets to identify 'captures' (clusters detected by one observer) and 'recaptures' (clusters detected by both observers). Due to the relatively low density of the target species, it was unproblematic to distinguish groups and avoid double counting. Point counts were conducted during six fieldwork days (17-19 November and 2-4 December 2014). Due to bad weather conditions and difficult accessibility, we omitted surveying four points. We used the program DOBSERV (Nichols et al. 2000) to model detection probability of bezoar goat clusters based on two capture-recapture models: equal or unequal detection probability between the observers. Methodological details underlying the program are described elsewhere (Nichols et al. 2000). We used the Akaike information criterion corrected for small sample sizes $\left(\mathrm{AIC}_{\mathrm{c}}\right)$ to find the most parsimonious model(s) and selected the best models as those having $\Delta \mathrm{AlC}_{\mathrm{c}} \leq 2$ (Burnham \& Anderson 2002). To translate this number into density, we multiplied it by the average group size and divided by the sampling area. The sampling area was calculated from the overlap of areas visible from vantage points and the identified bezoar goat habitat using the viewshed function in ArcGIS 10.1. The density was then extrapolated to the total bezoar goat habitat to calculate the abundance. 
Interview survey

We conducted structured questionnaire surveys in March and May 2013 among 136 council members and village heads from 34 villages within the GNP watershed to obtain data on small livestock depredation by leopards (Khorozyan et al. 2015b). Although leopard depredation on small livestock has been reported in 12 out of 34 studied villages, we considered only villages $<2.5 \mathrm{~km}$ away from GNP boundaries (spatial availability). This was done to include only villages with the highest likelihood of attacks by leopards from GNP, according to the earlier results on Persian leopard movements (Ghoddousi et al. 2010) and the highest intensity of conflicts in the vicinity of reserves (Khorozyan et al. 2015b; Kuiper et al. 2015; Minnie et al. 2015). Details on our interview survey procedure have been provided elsewhere (Khorozyan et al. 2015b). As spatial characteristics of carnivore attacks on livestock may play an important role in the conflict (Hayward et al. 2011; Johansson et al. 2015; Minnie et al. 2015), we used only small livestock data from villages with confirmed leopard attacks in our analysis (spatial availability). In GNP, small livestock are available to leopard predation only during free grazing or corralling at night in the pastures and are not killed while in pens inside villages (Sangay \& Vernes 2008; Gervasi et al. 2014; Khorozyan et al. 2015b; Kuiper et al. 2015). Having interviewed 18 shepherds, we developed a small livestock availability coefficient $(C)$ as the proportion of the average number of grazing days to the number of all days in a month (temporal availability). So, $C$ ranged from 0 to 1 per month, where 0 means that small livestock do not graze outside and stay only in village pens and 1 means staying overnight in the fields away from villages all month. When small livestock were grazed during the day and returned to village pens in the evening, we considered $C$ as 0.5 . Livestock numbers in each conflict village were corrected by multiplying by their corresponding value of $C$. We acknowledge that this is a simplification of predation risk, which can be affected by other husbandry factors as well (Woodroffe et al. 2007). However, as small livestock are within the leopard's preferred prey body mass range (Clements et al. 2014), cause no injury threat to leopards, and graze mostly inside GNP or its surroundings, we believe their predation probability is determined by availability (Gervasi et al. 2014; Kuiper et al. 
2015). Cattle predation by leopards also occurs in the villages around GNP (Khorozyan et al. 2015b). However, as cattle grazing outside pens and consequently predation by leopard depends on cattle age and breed (Sangay \& Vernes 2008; Khorozyan et al. 2015b; Athreya et al. 2016), we were unable to incorporate its availability and excluded cattle from this study.

\section{Leopard prey preferences}

We used Jacob's index to indicate leopard prey preference $I_{i}$ (Hayward et al. 2006; Hayward et al. 2011):

$$
I_{j}=\frac{r_{i}-p_{i}}{r_{i}+p_{i}-2 r_{i} p_{i}}
$$

where $r_{i}$ is the proportion of the number of individuals of the $i$-th consumed prey species to all consumed individuals and $p_{i}$ is the proportion of the abundance of the $i$-th species to the abundance of all prey species. We estimated the numbers of prey individuals consumed by using $\mathrm{CF}_{2}$. Also, we used abundance estimates of wild prey and small livestock (using $C$ ) for calculation of $p_{i}$. In calculations of $r_{i}$ and $p_{i}$, we used only top four prey species described above and corrected the proportion of prey individuals consumed accordingly. The index ranges from -1 to +1 , where +1 indicates maximum preference and -1 indicates maximum avoidance. We considered the prey species as preferred if their Jacob's index was $>0.3$ and as avoided if it was $<-0.3$, with the index between these values indicating predation based on abundance (Clements et al. 2014). Differences in leopard prey preference with and without small livestock as a prey species were tested using paired $t$-test. To assess the influence of uncertainty of prey abundance estimates on leopard prey preferences, we ran sensitivity analysis using all different combinations of the $95 \% \mathrm{Cl}$ limits of the abundance of wild prey and small livestock (corrected and uncorrected estimates). We compared the results of sensitivity analysis with the original prey preference. Sensitivity analysis was conducted using R statistical software 3.2.2 (R Foundation for Statistical Computing, 2015). 


\section{Ethics statement}

The field surveys including collection of leopard scats, use of camera traps and implementation of ungulate surveys and interviews with local communities in GNP (a state-governed national park) were made possible due to the written approval of the Iranian Department of Environment (DoE) and Golestan provincial office of DoE. Persian Wildlife Heritage Foundation conducted the camera trapping survey (Hamidi et al. 2014), with permits obtained from Golestan provincial office of DoE, and granted the use of its data in this research. The interviews in villages surrounding GNP were conducted within a project approved by the DoE and Golestan provincial office of DoE (Khorozyan et al. 2015b). The interviewees gave their verbal consent as getting written consent could have changed the participants' perceptions of the purpose of this research and consequently could affect the data quality. By filling up the questionnaire forms, one per participant, the participants gave their consent to take part in this study. Interviewees were informed about the purpose of this study and ascertained about the anonymity and security of their data. The interview survey was in accordance to the ethical guidance of Georg-August-Universität Göttingen. The review boards of DoE and Golestan provincial office of DoE approved the interview procedure of this study. No animal handling was conducted in this research. 


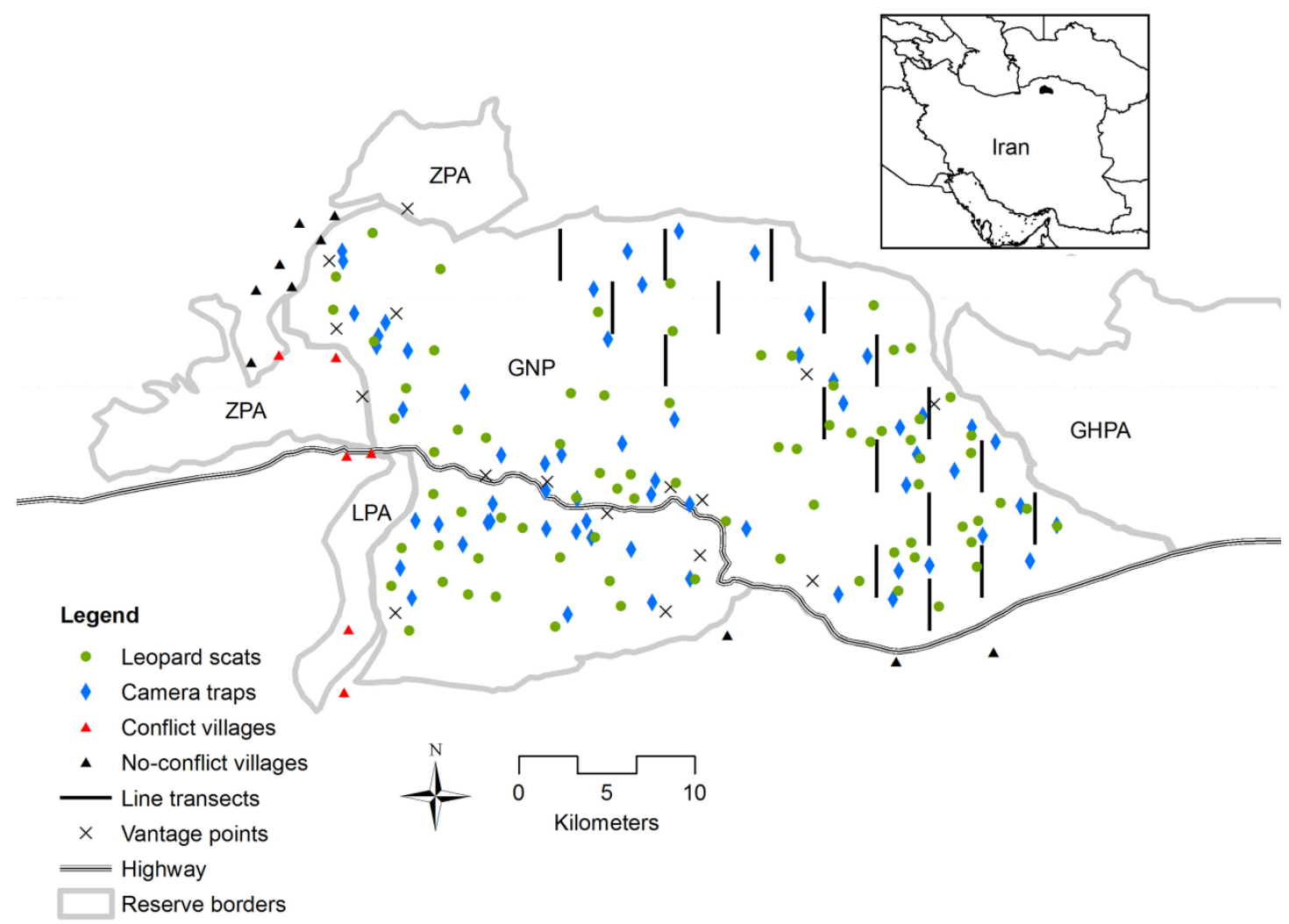

Figure 6.1. Map of Golestan National Park and the location of scat samples, line transects, camera trap stations and vantage points, as well as the conflict and noconflict villages and neighboring reserves (LPA: Loveh Protected Area; ZPA: Zav Protected Area; GHPA: Ghorkhod Protected Area).

\subsection{Results}

\section{Leopard diet analysis}

In total, we collected 77 scats containing 12 different prey species and one scat of unknown remains; therefore, we used 76 scats in dietary analysis (Table 6.1). The majority of leopard diet in GNP consisted of wild boar ( $F O=50.0 \%$; $P O=46.3 \%)$, followed by bezoar goat $(F O=14.5 \% ; P O=13.4 \%)$, urial $(F O=11.8 \% ; P O=13.4 \%)$ and small livestock ( $F O=13.2 \% ; P O=12.2 \%)$. The accumulation curve of the Shannon diversity index leveled-off at approximately 20 samples and reached an asymptote at approximately 50-60 samples, indicating that 76 samples were enough to portray the prey diversity in diet (Fig. S6.1). A comparison of our sample with the pooled sample ( $n=191$; Table S6.2) did not reveal a significant difference in the CFO 
of the top four prey species $\left(P>0.05 ; Z_{\text {wild boar }}=0.46 ; Z_{\text {bezoar goat }}=0.93 ; Z_{\text {urial }}=-1.08\right.$;

$Z_{\text {livestock }}=0.71$ ). Therefore, we are confident that our sample size was sufficient and reliable to show the diversity and the role of each prey species in leopard diet in GNP. We used the leopard diet data only from our study in the prey preference analyses.

Table 6.1. Results of Persian leopard diet analysis in Golestan National Park, Iran.

\begin{tabular}{|c|c|c|c|c|c|c|c|}
\hline \multirow[t]{2}{*}{ Species } & \multirow{2}{*}{$\begin{array}{c}\text { Body } \\
\text { mass }^{a} \\
(\mathrm{~kg})\end{array}$} & \multirow{2}{*}{$\begin{array}{l}\text { No. in leopard } \\
\text { scats } \\
(n)\end{array}$} & \multirow{2}{*}{$\frac{C F O^{d}}{(\%)}$} & \multicolumn{2}{|c|}{$\begin{array}{l}\text { Biomass } \\
\text { consumed }^{\mathrm{e}}\end{array}$} & \multicolumn{2}{|c|}{$\begin{array}{l}\text { Individuals } \\
\text { consumed }^{\mathrm{f}}\end{array}$} \\
\hline & & & & $(\mathrm{kg})$ & $(\%)$ & (n) & (\%) \\
\hline Wild boar Sus scrofa & $71.5^{b}$ & 38 & 47.8 & 83.9 & 50.2 & 13.6 & 50.0 \\
\hline $\begin{array}{l}\text { Bezoar goat Capra } \\
\text { aegagrus }\end{array}$ & $36^{\mathrm{c}}$ & 11 & 14.7 & 24.2 & 14.5 & 3.7 & 13.7 \\
\hline Urial Ovis vignei & $34^{c}$ & 9 & 10.7 & 17.4 & 10.4 & 2.7 & 9.9 \\
\hline Domestic goat C. $a$. hircus & $44.8^{c}$ & 5 & 6.0 & 10.2 & 6.1 & 1.6 & 5.8 \\
\hline Domestic sheep $O$. aries & $57.1^{c}$ & 5 & 6.7 & 11.6 & 7.0 & 1.8 & 6.7 \\
\hline $\begin{array}{l}\text { Roe deer Capreolus } \\
\text { capreolus }\end{array}$ & $20^{c}$ & 4 & 5.4 & 7.3 & 4.4 & 1.3 & 4.8 \\
\hline $\begin{array}{l}\text { Indian crested porcupine } \\
\text { Hystrix indica }\end{array}$ & $11^{\mathrm{c}}$ & 3 & 3.4 & 3.3 & 2.0 & 0.8 & 3.0 \\
\hline $\begin{array}{l}\text { Domestic dog Canis } \\
\text { familiaris }\end{array}$ & $32.2^{\mathrm{c}}$ & 2 & 2.7 & 4.3 & 2.6 & 0.7 & 2.5 \\
\hline $\begin{array}{l}\text { Domestic cattle Bos } \\
\text { taurus }\end{array}$ & $250^{c}$ & 1 & 1.3 & 2.4 & 1.4 & 0.6 & 2.1 \\
\hline Red deer Cervus elaphus & $98.8^{c}$ & 1 & 1.3 & 2.4 & 1.4 & 0.4 & 1.5 \\
\hline Rodents & - & 1 & - & - & - & - & - \\
\hline Birds & - & 1 & - & - & - & - & - \\
\hline Unknown & - & 1 & - & - & - & - & - \\
\hline Total & - & 82 & 100 & 167.0 & 100 & $\sim 27$ & 100 \\
\hline \multicolumn{8}{|c|}{ a $3 / 4$ of mean adult female body mass } \\
\hline \multicolumn{8}{|l|}{ b (Goshtasb 2001) } \\
\hline \multicolumn{8}{|c|}{${ }^{c}$ from various references cited in (Lumetsberger 2014) } \\
\hline \multicolumn{8}{|c|}{${ }^{d}$ corrected frequency of occurrence } \\
\hline \multicolumn{8}{|c|}{${ }^{\mathrm{e}}$ based on $C F_{1 ; i}=2.358(1-\exp (-0.075 x))($ Wachter et al. 2012) } \\
\hline${ }^{\mathrm{f}}$ based on $C F_{2 ; i}=3.094 \mathrm{c}$ & $(-0.5$ & $(x / 16.370)$ & 2.58 & (W & $\mathrm{e}$ & 012) & \\
\hline
\end{tabular}




\section{Prey population estimation}

Urial

With the total survey effort of $186 \mathrm{~km}, 1981$ urials in 70 clusters were detected. The best-fitting detection function derived from a half-normal key resulted into an estimated density of 12.6 indiv. $/ \mathrm{km}^{2}$ (coefficient of variation $\mathrm{CV}=35.5 \% ; 95 \% \mathrm{Cl}=$ 6.2-25.4). The urial population was estimated as 4275 individuals $(95 \% \mathrm{Cl}=2117$ 8632).

Wild boar

A total of 2777 trap-nights resulted in 386 wild boar photos. In total, 38 observed groups of wild boar on line transects yielded an average group size of $3.10 \pm$ SE 0.85 individuals. Wild boar density was estimated as 7.4 indiv. $/ \mathrm{km}^{2}$ ( $\mathrm{CV}=27.0 \% ; 95 \% \mathrm{Cl}=$ 3.5-11.3) and the population size as 6478 individuals $(95 \% \mathrm{Cl}=3050-9906)$.

\section{Bezoar goat}

We observed 39 bezoar goats in seven clusters during 64 scans of the surveyed vantage points. The model with equal detection probability was the best model ( $\Delta$ $\left.A I C_{c}=0\right)$, while the second model had $\Delta A_{C} C_{c}>2$. The best model estimated a detection probability of $0.97(\mathrm{SE}=0.04)$. This revealed a density estimate of 9.7 indiv. $/ \mathrm{km}^{2}$ ( $\left.\mathrm{CV}=31.3 \% ; 95 \% \mathrm{Cl}=3.7-15.6\right)$ and an abundance of 519 individuals (95\% $\mathrm{Cl}=201-837)$.

Small livestock

From the interview surveys, small livestock depredation by leopard was reported in 96 cases in six villages $<2.5 \mathrm{~km}$ away from GNP (Table S6.3), comprising $80.7 \%$ of all cases reported in the prior year (March 2012 to 2013). The total number of small livestock was reported as $\sim 11,250$ individuals in the six conflict villages (Table S6.3). Interviewees did not report any surplus killing by leopards. The annual average small livestock availability coefficient $(C)$ for the six conflict villages ranged between 0.40 and 0.63 (Fig. 6.2; Table S6.4). In the village with the highest small livestock availability coefficient $(C=0.63)$, most of depredation cases were reported $(41.7 \%)$. 
The total number of small livestock corrected for their availability was 6392 individuals (Table S6.4). This means that small livestock were by almost half (43.2\%) less available than if we took the total stock of 11250 individuals as an indicator of availability. The average small livestock loss in conflict villages was around $1.7 \% \pm$ SE $0.01(0.2-6.0 \%$ per village) of the total population.

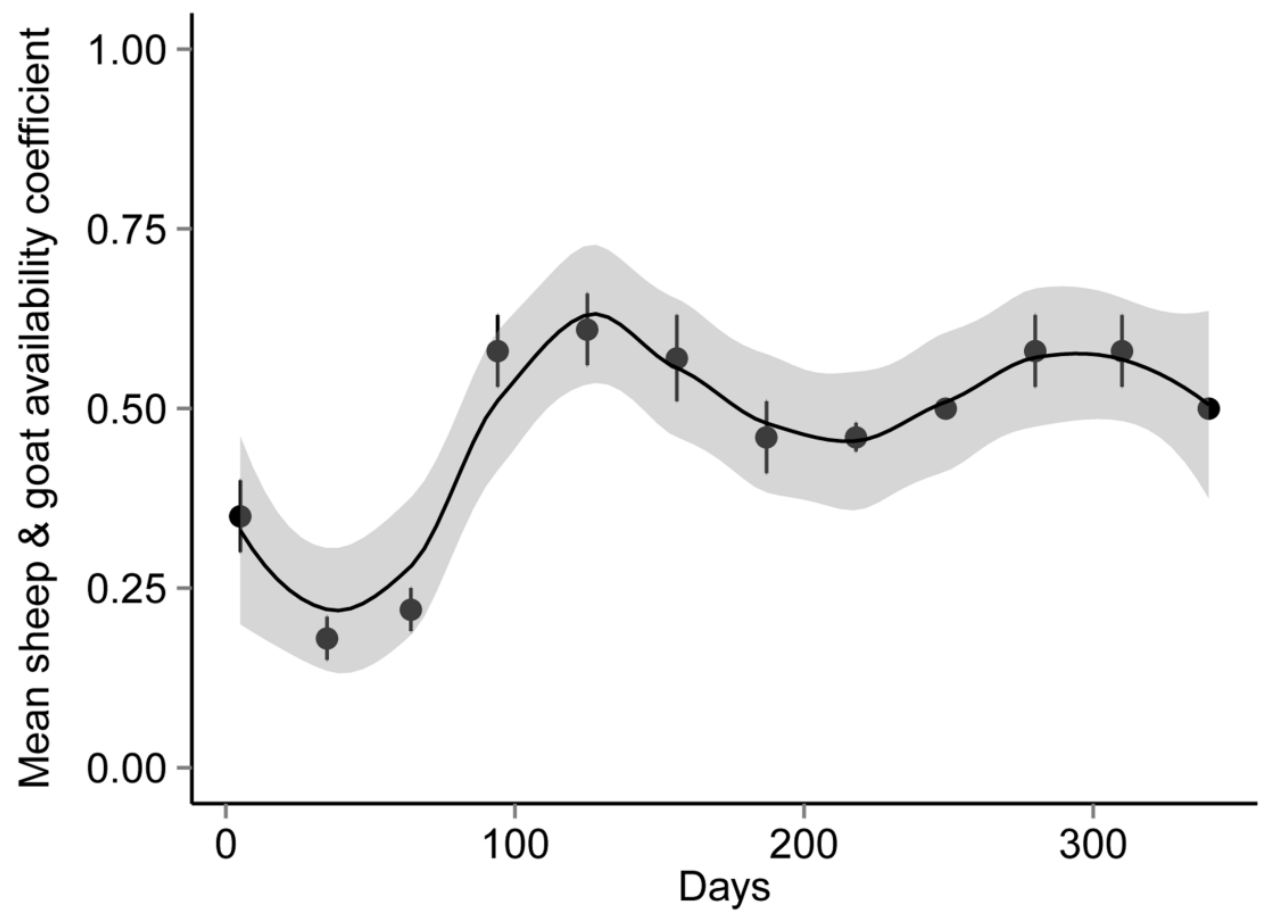

Figure 6.2. Temporal variation (with confidence intervals) in average monthly grazing of sheep and goats outside conflict villages of Golestan National Park.

Leopard prey preferences

In our study, wild boar was marginally preferred $\left(I_{j}=0.41\right.$; Table $6.2 ;$ Fig. 6.3$)$.

However, bezoar goat was the most preferred species although it was the rarest $\left(I_{j}=\right.$ 0.73; Fig. 6.3). Urial $\left(I_{j}=-0.42 ;\right.$ Table 6.2; Fig. 6.3) and small livestock $\left(I_{j}=-0.54 ;\right.$ Table 6.2; Fig. 6.3) were avoided. When small livestock were excluded from our study (as in most previous studies), bezoar goat was still preferred $\left(l_{j}=0.59\right)$ and urial avoided $\left(I_{j}=-0.65\right)$. However, wild boar predation was estimated to be according to its abundance $\left(I_{j}=0.01\right)$. Moreover, when the absolute small livestock number 
$(\sim 11,250)$ was used instead of the corrected one ( 6392$)$, leopards strongly avoided small livestock $\left(I_{j}=-0.71\right)$. The results of the sensitivity analysis show that even using extreme variations in the prey abundance estimates, leopard preference for bezoar goat and avoidance of urial and small livestock remains unchanged. However, the role of wild boar in leopard diet under different prey abundance scenarios was different (Fig. 6.4).

Table 6.2. The prey selectivity and numbers of prey individuals consumed by Persian leopard in Golestan National Park, Iran, in relation to abundance of the top four prey species.

\begin{tabular}{|c|c|c|c|c|}
\hline Species & $\begin{array}{c}\text { Corrected } \\
\text { individuals } \\
\text { consumed }^{\mathrm{a}}(\%)\end{array}$ & $\begin{array}{l}\text { Abundance }(95 \% \\
\left.\qquad \mathrm{Cl}^{\mathrm{b}}\right)\end{array}$ & Abundance (\%) & $\begin{array}{l}\text { Jacob's } \\
\text { index }\end{array}$ \\
\hline Wild boar Sus scrofa & 58.1 & 6478 (3050-9906) & 36.7 & 0.41 \\
\hline Bezoar goat Capra aegagrus & 15.8 & $519(201-838)$ & 2.9 & 0.73 \\
\hline Urial Ovis vignei & 11.5 & $4275(2117-8632)$ & 24.2 & -0.42 \\
\hline $\begin{array}{l}\text { Domestic goat } C \text {. } a \text {. hircus }+ \\
\text { domestic sheep Ovis aries }\end{array}$ & 14.5 & 6392 & 36.2 & -0.54 \\
\hline Total & $\sim 100.0$ & 17,664 & 100 & - \\
\hline${ }^{\mathrm{a}}$ based on $C F_{2 ; i}=3.094 \exp ($ & $-0.5((\ln (x / 16.3$ & $\left.0)(2.584)^{2}\right)$ & chter et al. 2012) & \\
\hline
\end{tabular}




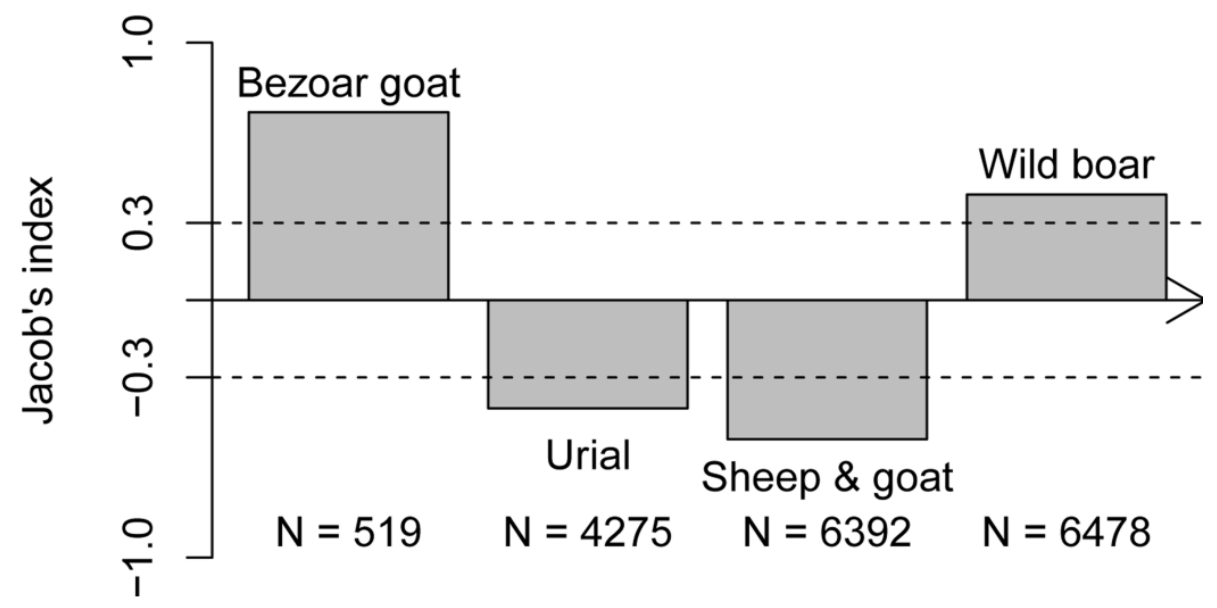

Figure 6.3. Persian leopard prey preference in Golestan National Park based on Jacob's index (in the order of increasing abundance N). Jacob's index $>0.3$ was considered as preferred and $<-0.3$ as avoided, with the index between these values indicating predation proportional to abundance (Clements et al. 2014).

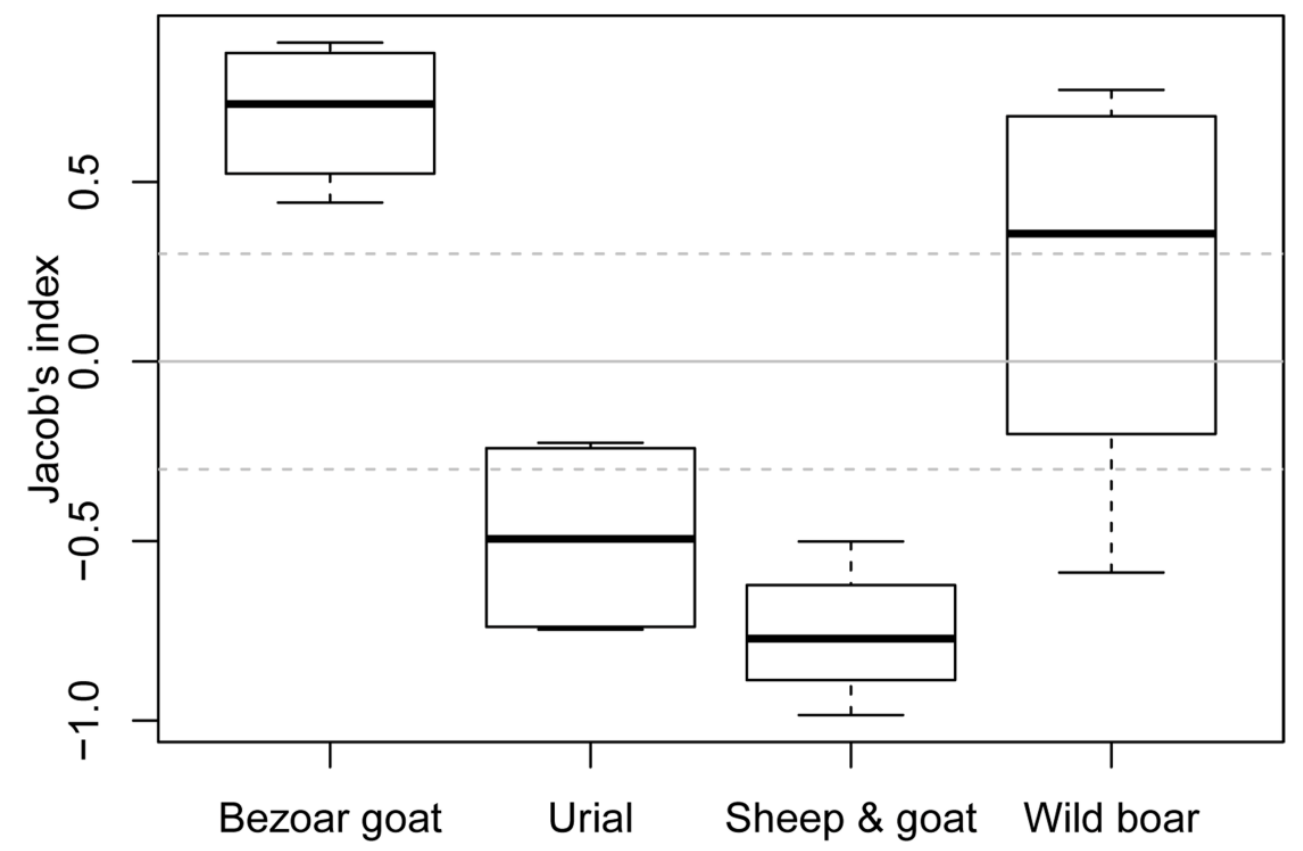

Figure 6.4. Results of sensitivity analysis of Persian leopard prey preference in Golestan National Park based on different combinations of the prey abundance $95 \%$ confidence intervals and corrected and uncorrected small livestock numbers. 


\subsection{Discussion}

Our current understanding of the role of livestock in leopard diet is still limited. The most comprehensive review of leopard prey preference (Hayward et al. 2006) ignores the role of livestock despite its presence in leopard diet in many parts of the world. Two recent studies (Mondal et al. 2011; Athreya et al. 2016), which considered livestock in their calculations, used only crude livestock numbers. Both these studies show that livestock is being avoided by leopards. In this study, we identified variation in sheep and goat availability to leopard depredation based on husbandry methods practiced across the conflict villages, which may affect the choice of this type of prey. When sheep and goat numbers are corrected for their availability outside villages, the leopard appears to still avoid them. Sheep and goats usually graze in large flocks and benefit from anti-predator protection, which possibly makes risks affiliated with this predation high (Woodroffe et al. 2007; Mukherjee \& Heithaus 2013). Preying on sheep and goats accompanied by shepherds and dogs may require a relatively longer time to ambush, capture and subdue, increasing the costs of hunting (Mukherjee \& Heithaus 2013). Moreover, livestock is only temporarily available within leopard habitats, what makes them a less reliable prey (Moa et al. 2006). It suggests that leopards exhibit low preference for sheep and goats compared to other prey species in GNP, hinting that current husbandry methods can be effective in controlling depredation losses, but not in minimizing them (Woodroffe et al. 2007; Odden et al. 2008; Tortato et al. 2015). We encourage the inclusion of livestock availability using such case-specific spatiotemporal corrections in assessing the role of livestock in felid diets and measuring the effectiveness of different husbandry practices in conflict sites.

Despite the avoidance of sheep and goats by leopards in GNP, depredation still occurs and causes considerable financial losses to local livelihoods. Therefore, current levels of conflict may arise from other factors that the results of this study may help conservation managers in better understanding them. Lack of sufficient prey is proposed as the major driver of big cat depredation on livestock (Khorozyan et al. 2015a). The biomass of bezoar goat, wild boar and urial, which make $75 \%$ of total biomass consumed by leopards, in GNP is estimated as $717.09 \mathrm{~kg} / \mathrm{km}^{2}$, which is 
above the minimum prey biomass threshold that drives sheep and goat depredation $\left(544.57 \pm 1.19 \mathrm{~kg} / \mathrm{km}^{2}\right)$ (Khorozyan et al. 2015a). However, we found that local leopards avoided the urial, a steppe-dwelling species, despite its higher availability and appropriate body mass (Clements et al. 2014). In other parts of the world, leopards also avoid open landscapes as a hunting habitat (Balme et al. 2007; Pitman et al. 2013). When excluding urial biomass, the prey biomass falls at the threshold of high sheep and goat predation $\left(550.79 \mathrm{~kg} / \mathrm{km}^{2}\right)$. This may suggest that leopards in GNP are under pressure from insufficiency of natural preferred prey due to rampant ungulate poaching and are forced to take risky prey such as small livestock (Clements et al. 2014; Shehzad et al. 2014; Ghoddousi et al. 2016a). The apparent avoidance of urial suggested by our analysis should be an important aspect in the conservation of Persian leopards throughout its range. This prey (along with mouflon O. orientalis) occurs in many habitats of Persian leopard and is usually considered as one of its main prey species. However, it is likely that the role of this species in leopard diet was overestimated in the past.

Sheep and goat body mass falls within the preferred prey range of leopard and this prey is docile (Linnell et al. 1999; Clements et al. 2014). Although sheep and goats are kept on average $37-60 \%$ of a year within the studied villages, we have no reports of leopard attacks inside village pens. Therefore, it appears that penning has been an efficient tool to curb depredation, but herding practices and the use of guarding dogs during free grazing should be improved (Kuiper et al. 2015). Incidents of leopard depredation on livestock may be related to the periods of lax herding (e.g. harvest season) or straggling livestock individuals (Wang \& Macdonald 2006; Sangay \& Vernes 2008; Johansson et al. 2015). The role of veterinary services in humanleopard conflict is also important in GNP (Khorozyan et al. 2015b). Poor health condition may cause livestock to straggle and make them an easy prey for leopard, especially when they are unattended. The presence of conflict only in certain villages in our study may be related to vegetation cover, ruggedness of pastures (Miller 2015) or occasionally straggling livestock (Khorozyan et al. 2015b). Satisfaction with veterinary services in the conflict villages was $17 \%$ compared to $80 \%$ in non-conflict villages (Table S6.3) (Khorozyan et al. 2015b). Therefore, further investigations of 
livestock diseases in the area, as well as case-specific inspection of depredation site covariates are required to better understand conflict dynamics in the area. We also recorded cases of leopard attacks on sheep and goats in presence of shepherds and dogs. Such a readiness to take the risk of attacking livestock may be driven by individual characteristics such as body condition, experience and other behavioral factors (Mukherjee \& Heithaus 2013). A previous study (Linnell et al. 1999) has shown that some carnivore individuals may display different patterns in daring livestock depredation, which may be linked to the individual's sex and age. High depredation rate in some conflict villages (e.g. $6 \%$ loss of total livestock population in one village) may be due to behavior of certain culprit leopards (Table S6.3). Future genetic analysis for the identification of individuals responsible for depredation of livestock may clarify this pattern.

Unlike earlier assumptions (Hayward et al. 2006; Pitman et al. 2013) that leopards may use rocky outcrops only as refuges from larger predators and not for foraging, in GNP leopards prefer to hunt bezoar goats, which live in rocky areas. Leopards may have preferred bezoar goats because of suitability of rocky habitats for ambush hunting. However, the bezoar goat population in GNP suffers from an over $80 \%$ decline since the 1970 's and is extirpated by poachers from much of its former range (Kiabi 1978). We suppose that scarcity of bezoar goats is one of the main, if not the key factors contributing to leopard depredation on livestock in villages near GNP. Conservation actions to avert the bezoar goat population from further decline should become a top priority to reduce human-leopard conflict. In this study, wild boar represented most of prey biomass in leopard diet, but was only slightly preferred. Leopards avoid preying on members of the family Suidae throughout their range, possibly due to large body mass and aggressive behavior (Hayward et al. 2006; Mondal et al. 2011; Clements et al. 2014). We cannot confirm whether high predation on wild boars in GNP is due to higher body mass of Persian leopards, a shift from bezoar goat toward a less preferred prey, or lack of competition with other large carnivores (Clements et al. 2014).

We acknowledge some limitations in our study design and data analyses, which might affect the interpretation of results. Our scat sampling was conducted over 
three years and the data on sheep and goat depredation by leopards and prey abundance were collected only in one or two of these years. However, we have no ground to surmise that leopard diet or prey abundances experienced any significant changes during this period. We also acknowledge the levels of uncertainty in our prey abundance data. However, this is of less importance as our sensitivity analysis showed that the main conclusions regarding preference or avoidance of prey are mostly valid under different abundance scenarios. In this study, we did not consider the spatial availability of wild prey. Wild prey is not equally distributed in the park, but leopard movements are not restricted to specific habitats and finding scats containing species not inhabiting the surrounding areas is frequent. Therefore, consideration of spatial variation in wild prey availability may not change our conclusions. There can be a potential bias from non-random camera placement in our wild boar abundance estimation because camera traps were set to capture leopards. Although leopard movement patterns may differ from those of wild boars, due to their predator-prey relationships, a correlation between the distribution and movements of these two species may exist. However, random encounter models yielded a very similar estimate of wild boar abundance ( 4890 indiv., $95 \% \mathrm{Cl}=4188$ 5592 ) to line transects (4869 indiv., 95\% Cl = 2453-9664; Table S6.1) in GNP forests. Nevertheless, a potential bias arising from the difference in species daily movements in our and the reference study (Podgórski et al. 2013) remains unaccounted for. We also recognize the small sample size of our bezoar goat data, but the population estimate of this species in GNP is comparable with an earlier study, which used a different methodology (759 indiv., 95\% Cl = 583-935) (Speicher 2013).

Rearing sheep and goat in Iran and generally in Southwest Asia in presence of large carnivores has a long history and normally involves attendance of shepherds and dogs when herding outside villages. These practices may reduce the preference of domestic prey by leopards, but the situation can be different in other cases. Thus, prey preference studies may help conservationists in identification of preferred wild prey in felid diets and the estimation of prey availability, which may drive livestock depredation (Khorozyan et al. 2015a). 


\section{Conclusion}

We assessed livestock availability and identified domestic prey choice by leopards using spatiotemporal patterns of conflict distribution and husbandry methods. We conclude that leopards avoid sheep and goat depredation, which may suggest that in our case study, husbandry methods can be efficient in controlling the humanleopard conflict. Therefore, the cases of leopard depredation on livestock in our study area may be due to low abundance of preferred prey, (occasional) failures in herding practices, or characteristics of individual leopards. We suggest that future prey choice studies in conflict sites should pay attention to livestock availability in a way that incorporates the husbandry methods practiced.

\section{Acknowledgements}

We appreciate collaboration of Iranian Department of Environment, Golestan provincial office of Department of Environment, and Golestan National Park management with us in this study. We thank Persian Wildlife Heritage Foundation's cooperation in sharing their camera trapping data and logistic support. We are indebted to Golestan National Park rangers, especially J. Hassanzadeh, for their support during the fieldwork, as well as to all the local guides and volunteers who participated in this project. We appreciate constructive comments by Sh. Kachel, J. Kamler and one anonymous reviewer on the earlier version of the manuscript. 


\subsection{Supporting material}

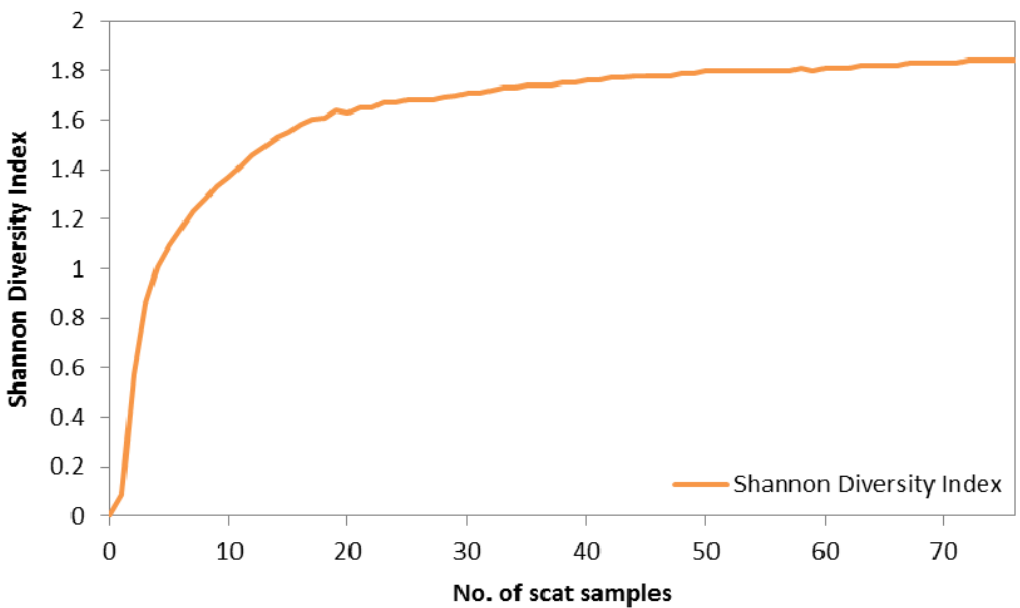

Shannon Diversity Index accumulation curve for the number of prey species in leopard diet in relation to scat numbers in Golestan National Park

Figure S6.1. Accumulation curve of prey species diversity in leopard scat samples. 
Table S6.1. Line transect sampling data in forests of Golestan National Park.

\begin{tabular}{|c|c|c|c|c|c|}
\hline ID & Length $(\mathrm{km})$ & Species & Cluster size & Distance $(\mathrm{m})$ & Angle $\left({ }^{\circ}\right)$ \\
\hline 1 & 6 & - & - & - & - \\
\hline 2 & 6 & - & - & - & - \\
\hline 3 & 2 & - & - & - & - \\
\hline \multirow[t]{5}{*}{4} & 8 & Wild boar & 1 & 45 & 32 \\
\hline & & Wild boar & 1 & 10 & 0 \\
\hline & & Wild boar & 3 & 185 & 38 \\
\hline & & Wild boar & 4 & 355 & 45 \\
\hline & & Red deer & 1 & 175 & 37 \\
\hline 5 & 8 & - & - & - & - \\
\hline 6 & 8 & Wild boar & 1 & 60 & 0 \\
\hline 7 & 6 & Wild boar & 4 & 40 & 20 \\
\hline \multirow[t]{3}{*}{8} & 8 & Wild boar & 1 & 65 & 69 \\
\hline & & Wild boar & 1 & 23 & 90 \\
\hline & & Wild boar & 1 & 120 & 0 \\
\hline \multirow[t]{3}{*}{9} & 12 & Wild boar & 1 & 55 & 70 \\
\hline & & Wild boar & 1 & 64 & 40 \\
\hline & & Red deer & 12 & 146 & 30 \\
\hline \multirow[t]{2}{*}{10} & 9 & Wild boar & 1 & 40 & 30 \\
\hline & & Wild boar & 1 & 13 & 22 \\
\hline 11 & 2 & - & - & - & - \\
\hline \multirow[t]{2}{*}{12} & 8 & Wild boar & 1 & 79 & 20 \\
\hline & & Wild boar & 1 & 355 & 0 \\
\hline \multirow[t]{4}{*}{13} & 8 & Wild boar & 1 & 18 & 40 \\
\hline & & Wild boar & 1 & 63 & 17 \\
\hline & & Wild boar & 1 & 230 & 80 \\
\hline & & Wild boar & 15 & 15 & 0 \\
\hline 14 & 6 & Wild boar & 2 & 110 & 10 \\
\hline \multirow[t]{8}{*}{15} & 6 & Wild boar & 4 & 29 & 44 \\
\hline & & Wild boar & 1 & 22 & 47 \\
\hline & & Roe deer & 1 & 73 & 18 \\
\hline & & Wild boar & 1 & 51 & 65 \\
\hline & & Wild boar & 1 & 12 & 47 \\
\hline & & Wild boar & 1 & 34 & 50 \\
\hline & & Wild boar & 2 & 104 & 38 \\
\hline & & Wild boar & 12 & 294 & 8 \\
\hline 16 & 2 & - & - & - & - \\
\hline 17 & 4 & - & - & - & - \\
\hline 18 & 2 & - & - & - & - \\
\hline 19 & 3 & - & - & - & - \\
\hline \multirow[t]{3}{*}{20} & 4 & Wild boar & 13 & 55 & 32 \\
\hline & & Wild boar & 1 & 18 & 40 \\
\hline & & Wild boar & 4 & 29 & 58 \\
\hline 21 & 4 & Wild boar & 10 & 14 & 0 \\
\hline \multirow[t]{2}{*}{22} & 4 & Wild boar & 1 & 8 & 90 \\
\hline & & Wild boar & 3 & 73 & 78 \\
\hline 23 & 4 & Wild boar & 1 & 5 & 40 \\
\hline 24 & 1 & Wild boar & 1 & 360 & 67 \\
\hline 25 & 1 & - & - & - & - \\
\hline 26 & 2 & - & - & - & - \\
\hline \multirow[t]{2}{*}{27} & 2 & Wild boar & 14 & 50 & 80 \\
\hline & & Wild boar & 1 & 20 & 90 \\
\hline 28 & 2 & Wild boar & 4 & 27 & 34 \\
\hline
\end{tabular}


Table S6.2. Top four prey species of leopard from scat sampling (Sharbafi 2011) and the pooled data with this study.

\begin{tabular}{|lccc|}
\hline Species & $\begin{array}{c}\text { Sharbafi (2011) data } \\
\text { Number of scats }\end{array}$ & $\begin{array}{c}\text { Pooled data } \\
\text { Number of scats }\end{array}$ & CFO \\
\hline Wild boar & 57 & 95 & 0.56 \\
Urial & 11 & 32 & 0.19 \\
Bezoar goat & 23 & 22 & 0.13 \\
Livestock & 11 & 21 & 0.12 \\
\hline Total & 102 & & 170 \\
\hline
\end{tabular}

Table S6.3. Domestic sheep and goat numbers, reported killed numbers by leopard and satisfaction with veterinary services in the villages $<2.5 \mathrm{~km}$ from Golestan National Park borders.

\begin{tabular}{|lccccc|}
\hline Village name & $\begin{array}{c}\text { Sheep and } \\
\text { goat killed }\end{array}$ & $\begin{array}{c}\text { Sheep and } \\
\text { goat numbers }\end{array}$ & $\begin{array}{c}\text { Distance to } \\
\text { Park }\end{array}$ & $\begin{array}{c}\text { Predation } \\
\text { rate }\end{array}$ & $\begin{array}{c}\text { Satisfaction with } \\
\text { veterinary services }\end{array}$ \\
\hline Zav Paiin & 0 & 120 & 0.21 & 0.000 & 0 \\
Cheshmeh Khan & 0 & 3500 & 0.24 & 0.000 & 1 \\
Tutli Tamak & 0 & 200 & 0.36 & 0.000 & 1 \\
Tangerah & 27 & 450 & 0.37 & 0.060 & 0 \\
Ghoshcheshmeh & 7 & 600 & 0.49 & 0.012 & 0 \\
Dasht & 0 & 4000 & 0.72 & 0.000 & 1 \\
Zav Bala & 0 & 500 & 0.74 & 0.000 & 0 \\
Dasht Shad & 40 & 7500 & 0.96 & 0.005 & 0 \\
Souar Bala & 19 & 1000 & 1.37 & 0.019 & 0 \\
Terjenli & 1 & 500 & 1.69 & 0.002 & 1 \\
Armadloo & 0 & 1150 & 1.71 & 0.000 & 1 \\
Gorganduz & 0 & 80 & 1.71 & 0.000 & 1 \\
Khojeh Yapaghi & 0 & 500 & 1.75 & 0.000 & 1 \\
Kondoskouh & 2 & 1200 & 1.82 & 0.002 & 0 \\
Korlar & 0 & 400 & 1.84 & 0.000 & 1 \\
Souar Vasat & 0 & 400 & 2.35 & 0.000 & 1 \\
\hline Total & 96 & 22100 & - & - & - \\
\hline
\end{tabular}


Table S6.4. Interview surveys with shepherds in conflict villages.

\begin{tabular}{|c|c|c|c|c|c|c|c|c|c|c|c|c|c|c|c|}
\hline \multirow[t]{2}{*}{ Village names } & \multicolumn{12}{|c|}{ Julian days } & \multirow{2}{*}{$\begin{array}{c}\text { Annual } \\
\text { average } \\
\text { coefficient }\end{array}$} & \multirow{2}{*}{$\begin{array}{c}\text { Absolute } \\
\text { shoat } \\
\text { numbers }\end{array}$} & \multirow{2}{*}{$\begin{array}{c}\text { Corrected } \\
\text { shoat } \\
\text { numbers }\end{array}$} \\
\hline & 5 & 35 & 64 & 94 & 125 & 156 & 187 & 218 & 249 & 280 & 310 & 340 & & & \\
\hline Dasht Shad & 1 & 1 & 1 & 1 & 0.5 & 0.5 & 1 & 1 & 0.5 & 0 & 0 & 0.5 & 0.63 & 7500 & 4740 \\
\hline Dasht Shad & 1 & 1 & 1 & 0.5 & 0.5 & 0.5 & 1 & 1 & 0.5 & 0 & 0 & 0.5 & & & \\
\hline Dasht Shad & 1 & 1 & 1 & 0.5 & 0.5 & 0.5 & 1 & 1 & 0.5 & 0 & 0 & 0.25 & & & \\
\hline Ghoshcheshmeh & 0.5 & 0.5 & 0.5 & 0.5 & 0.5 & 0.5 & 0.5 & 0.5 & 0.5 & 0.5 & 0 & 0.25 & 0.44 & 600 & 267 \\
\hline Ghoshcheshmeh & 0.5 & 0.5 & 0.5 & 0.5 & 0.5 & 0.5 & 0.5 & 0.5 & 0.5 & 0.5 & 0 & 0.25 & & & \\
\hline Ghoshcheshmeh & 0.5 & 0.5 & 0.5 & 0.5 & 0.5 & 0.5 & 0.5 & 0.5 & 0.5 & 0.5 & 0.25 & 0.25 & & & \\
\hline Tangerah & 0.5 & 0.5 & 0.25 & 0 & 0.25 & 0.5 & 0.5 & 0.5 & 0.5 & 0.5 & 0.25 & 0.25 & 0.40 & 450 & 178 \\
\hline Tangerah & 0.5 & 0.5 & 0.25 & 0.25 & 0.5 & 0.5 & 0.5 & 0.5 & 0.5 & 0.5 & 0.25 & 0 & & & \\
\hline Tangerah & 0.5 & 0.5 & 0.25 & 0 & 0.5 & 0.5 & 0.5 & 0.5 & 0.5 & 0.5 & 0.5 & 0.25 & & & \\
\hline Kondoskouh & 0.5 & 0.5 & 0.5 & 0.5 & 0.25 & 0.5 & 0.5 & 0.5 & 0.5 & 0.5 & 0.25 & 0.25 & 0.47 & 1200 & 558 \\
\hline Kondoskouh & 0.5 & 1 & 1 & 0.5 & 0.25 & 0.5 & 0.5 & 0.5 & 0.5 & 0.5 & 0.25 & 0 & & & \\
\hline Kondoskouh & 0.5 & 0.5 & 0.5 & 0.5 & 0.5 & 0.5 & 0.5 & 0.5 & 0.5 & 0.5 & 0.25 & 0.25 & & & \\
\hline Souar Bala & 0.5 & 0.5 & 0.5 & 0.5 & 0.5 & 0.5 & 0.5 & 0.5 & 0.5 & 0.5 & 0.25 & 0.25 & 0.44 & 1000 & 438 \\
\hline Souar Bala & 0.5 & 0.5 & 0.5 & 0.5 & 0.5 & 0.5 & 0.5 & 0.5 & 0.5 & 0.25 & 0 & 0 & & & \\
\hline Souar Bala & 0.5 & 0.5 & 0.5 & 0.5 & 0.5 & 0.5 & 0.5 & 0.5 & 0.5 & 0.5 & 0.25 & 0.25 & & & \\
\hline Terjenli & 0.5 & 0.5 & 0.5 & 0.5 & 0.5 & 0.5 & 0.5 & 0.5 & 0.5 & 0.25 & 0.25 & 0 & 0.42 & 500 & 212 \\
\hline Terjenli & 0.5 & 0.5 & 0.5 & 0.5 & 0.5 & 0.5 & 0.5 & 0.5 & 0.5 & 0.25 & 0.25 & 0.25 & & & \\
\hline Terjenli & 0.5 & 0.5 & 0.5 & 0.5 & 0.5 & 0.5 & 0.5 & 0.5 & 0.5 & 0 & 0.25 & 0.25 & & & \\
\hline Monthly average & 0.58 & 0.61 & 0.57 & 0.46 & 0.46 & 0.5 & 0.58 & 0.58 & 0.5 & 0.35 & 0.18 & 0.22 & & & \\
\hline Standard deviation & 0.05 & 0.05 & 0.06 & 0.05 & 0.02 & 0 & 0.05 & 0.05 & 0 & 0.05 & 0.03 & 0.03 & & & \\
\hline Total & & & & & & & & & & & & & & 11250 & 6392 \\
\hline
\end{tabular}




\section{Chapter 7: When pork is not on the menu: assessing trophic competition between large carnivores and poachers}

Arash Ghoddousi, Mahmood Soofi, Amirhossein Kh. Hamidi, Tanja Lumetsberger, Lukas Egli, Sheyda Ashayeri, Igor Khorozyan, Bahram H. Kiabi \& Matthias Waltert In review, Biological Conservation, submitted: $11^{\text {th }}$ July 2016

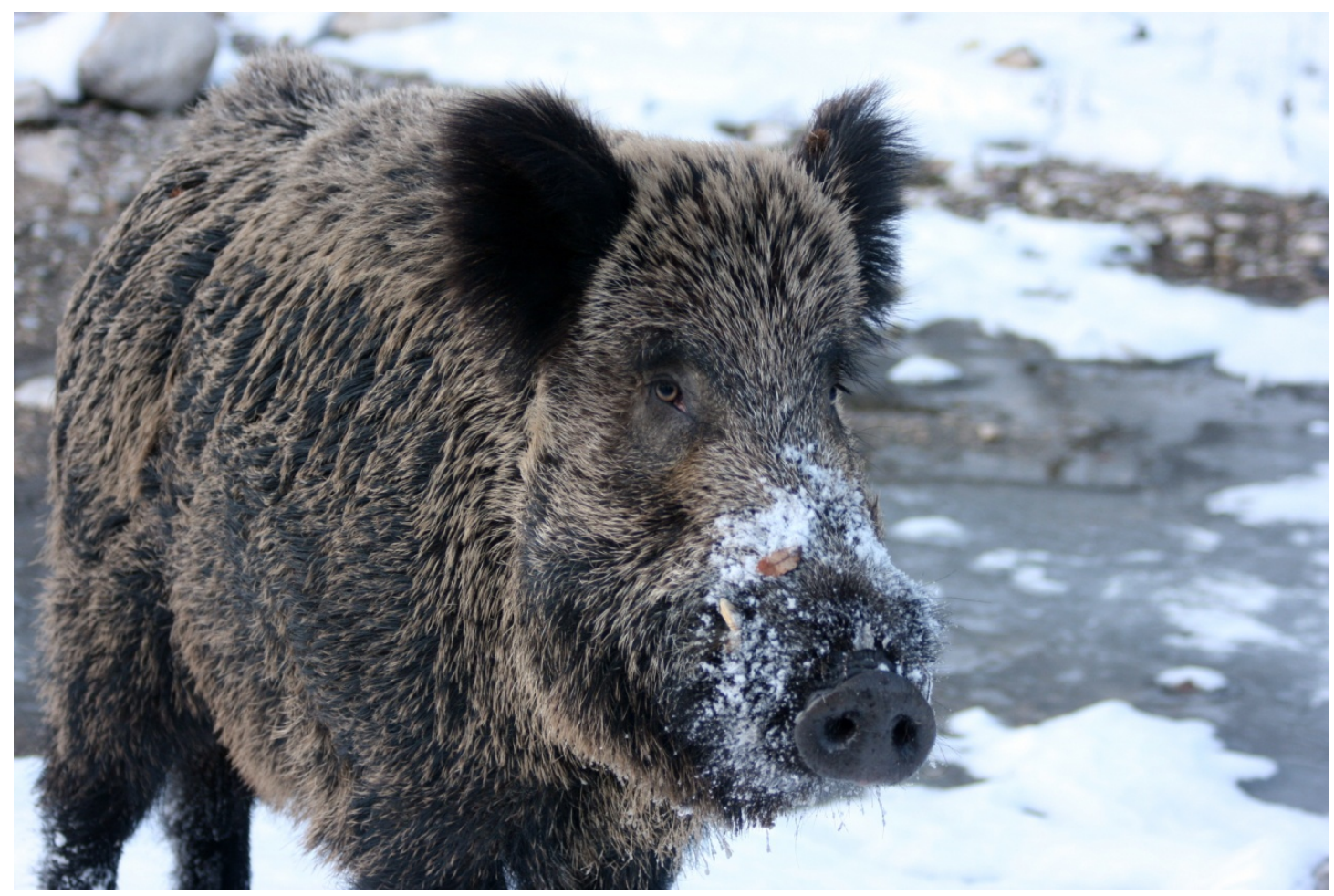

Wild boar in Golestan National Park. Photo: A. Ghoddousi 


\section{Abstract}

Overexploitation of wildlife for meat is a widespread phenomenon, which drives populations of many species toward extinction and may in turn affect large carnivores. Therefore, human hunters may compete with large carnivores over food resources and threaten their survival. In this study, we assessed the trophic competition of endangered Persian leopard with local poachers in Golestan National Park, Iran, where poaching has depleted populations of three ungulate species by $66-89 \%$ in the past decades. We compared leopard diet (77 scats) with prey offtake by poachers ( 75 poacher seizure records). In addition, we estimated prey abundance by line transect sampling (186 km), camera trapping (2777 camera days), doubleobserver point-counts (64 scans) and dung counts (38 km). Using interview surveys with local poachers, we also quantified their stated hunting preference. We documented a narrow hunting specialization of leopard (niche breadth 0.24 ) and poachers (niche breadth 0.19), and exclusivity (niche overlap 0.31) of their dietary/hunting niches, which suggest no exploitative competition between these two apex predators. This pattern likely results from the major role of wild boar in leopard diet. Due to religious beliefs, poachers avoid hunting this species and its population has increased in contrast to other ungulates. Considering the general avoidance of Suidae species across leopard range, depletion of alternative prey species may have resulted in a prey-switching strategy by leopard. In spite of low dietary competition with poachers, limited prey choice may threaten the long-term survival of leopards and their conservation should focus on reversing rapidly declining ungulate populations. 


\subsection{Introduction}

Overexploitation of wildlife for meat is a widespread phenomenon, which drives populations of many species toward extinction (Milner-Gulland \& Bennett 2003). This pattern in form of pursuit hunting or trapping is known to also affect natural food webs (Rowcliffe et al. 2003) as species targeted by humans may play important roles in the diet of large carnivores (Henschel et al. 2011). A recent study revealed that humans exploit shared prey at 1.9 times higher rates than all other predators combined within the human-predator-prey communities studied (Darimont et al. 2015). Therefore, human hunters may compete with carnivores over food resources, acting as an unsustainable "super predator" (Darimont et al. 2015).

Large carnivores are especially vulnerable to low density and biomass of their preferred prey (Carbone et al. 2011) and depletion of prey is one of their major threats worldwide (Ripple et al. 2014). When prey is scarce, large carnivores may expand their hunting effort by increasing home ranges or changing activity patterns (Schmidt 2008). However, if competition reaches exploitative levels, switching to other prey species or extermination from habitats may be observed (Henschel et al. 2011; Rosenblatt et al. 2016). Additionally, prey depletion may force carnivores, such as big cats, to shift toward livestock depredation and trigger retaliatory persecution by humans (Khorozyan, Ghoddousi, et al. 2015). Therefore, prey depletion is a vitally important factor for the survival of large carnivores, which requires further attention by conservationists (Chapron et al. 2008).

Dietary competition between different carnivores is well-studied in ecology (see Caro \& Stoner 2003). Within the large carnivore guilds, species exploit different resources if sufficient prey is available or compete when prey is limited (Karanth \& Sunquist 2000; Odden et al. 2010; Harihar et al. 2011; Jumabay-Uulu et al. 2014). The degree of dietary niche overlap may indicate exploitative competition among predators (Caro \& Stoner 2003). However, the role of humans as an apex predator on the trophic niche of animal predators has been rarely studied (Henschel et al. 2011; Darimont et al. 2015; Foster et al. 2016). Conservation of large carnivores in a changing world requires 'coexistence' of human and animal predators, and 
understanding differences in their ecological niche in local context is increasingly necessary (Chapron \& López-Bao in press).

All these aspects are relevant to preservation of big cats, such as the globally endangered Persian leopard (Panthera pardus saxicolor). The largest protected population of this felid (23-42 individuals) is known to exist in Golestan National Park (GNP), Iran (Hamidi et al. 2014). The main threat to leopards in GNP is thought to be road kills (Kiabi et al. 2002). However, the rapid population decline of at least three ungulate species in GNP since the 1970's may indicate that poaching of prey species is another important threat (Ghoddousi et al. submitted). Such hunting pressure is targeted on ungulates, but not on leopards (Ghoddousi et al. 2016a). Understanding responses of leopards to declining prey species may help to develop appropriate conservation measures for this endangered large carnivore (Lovari et al. 2013). In this study we thus quantified the dietary niche overlap of leopard and poachers to assess the threat of prey depletion to leopard.

We analyzed leopard diet by scat analysis and prey offtake by poachers from GNP law enforcement records and interview surveys. We estimated leopard and poachers' prey preferences, estimated abundance of main prey species, and evaluated the dietary competition and niche breadth of the two apex predators.

\subsection{Materials and methods}

\section{Study area}

GNP is located in northeastern Iran covering an area of $874 \mathrm{~km}^{2}$ (Fig. 7.1). The gradients of elevation from 450 to $2411 \mathrm{~m}$ above sea level and precipitation from 866 to $142 \mathrm{~mm}$ from west to east, respectively, create a variety of different habitats (Akhani 2005). The park has a mountainous terrain covered by sub-humid Hyrcanian forests in the west, and steppes and semi-deserts to the east (Akhani 2005). GNP is the oldest national park of Iran, established in 1957, and a UNESCO Biosphere Reserve. GNP is home to six species of ungulates, most of which are affected by poaching (Ghoddousi et al. submitted). Despite a long history of protection and 
sufficient law enforcement resources (Ghoddousi et al. 2016a), lack of acceptability of conservation laws, poverty and inefficient enforcement practices have resulted in rampant poaching in the park (Ghoddousi et al. submitted). No villages exist within GNP, however, around 8660 inhabitants from different ethnicities including Turkmens, Persians, Balochs and Kurds live in 15 villages less than $2 \mathrm{~km}$ away from its boundaries. The main occupation of local communities is farming crops or livestock.

\section{Leopard diet analysis}

We collected leopard scats from all around GNP from 2011 to 2014 and analyzed prey hair remains for assessment of leopard dietary profile (Klare et al. 2011). We estimated consumed prey numbers using the non-linear correction factor $\mathrm{CF}_{2}$ (Wachter et al. 2012):

$$
C F_{2 ; i}=3.094 \exp \left(-0.5((\ln (x / 16.370)) / 2.584)^{2}\right)
$$

where $C F_{2 ; i}$ is the number of scats produced from consuming an individual of the $i$-th prey species against the average body mass of the species $x(\mathrm{~kg})$. Therefore, the number of individuals of the $i$-th consumed prey was equal to the number of leopard scats containing the $i$-th prey divided by $C F_{2 ; i}$ (Wachter et al. 2012). The average body masses of each prey species were extracted from literature as $3 / 4$ of average female body mass to account for predation on sub-adult individuals (Lumetsberger 2014). Detail on methodologies is provided elsewhere (Ghoddousi et al. 2016b).

\section{Poacher seizure data}

We used GNP poacher seizure records from 2007 to 2014 to obtain an index on the frequency of hunted species by poachers. We used only cases when hunted animals were present and omitted cases of captures before successful hunts. We calculated the proportion of each hunted species to the total number of hunted species. There is a potential variation in detection probability of poachers within different habitats (Keane et al. 2011). In GNP, poaching is practiced solely in form of pursuit hunting with guns and rangers normally use a sit-and-wait or tip-off from local informants to 
detect poachers (own data, unpublished). Therefore, we believe that seizure data represents a robust distribution of hunted species in GNP.

\section{Prey abundance estimation}

We assessed the abundance of main prey species consumed by both leopards and poachers, which were identified from scat analysis and law enforcement records (see above). We used different methodologies for abundance estimation of prey species due to different detection probabilities and habitat characteristics (Ghoddousi et al. 2016b). We estimated bezoar goat Capra aegagrus abundance using a double-observer point-count approach in $53.6 \mathrm{~km}^{2}$ of rugged landscapes of GNP (Suryawanshi et al. 2012). Two independent observers conducted counts at 16 sampling points (Fig. 7.1) and the data was later analyzed using DOBSERV software (Nichols et al. 2000). We estimated urial Ovis vignei population size using line transects in $340 \mathrm{~km}^{2}$ of steppes in eastern GNP (Buckland et al. 2001). We surveyed 17 3-km transects (Fig. 7.1) and the data was analyzed using Distance 6.0 software (Thomas et al. 2010). For assessing the abundance of wild boar Sus scrofa, we applied the random encounter model (REM) using camera traps (Rowcliffe et al. 2008). Data from 67 camera traps deployed across GNP (Fig. 7.1) in 2011 was used

for this purpose (Hamidi et al. 2014). Finally, red deer Cervus elaphus population size was estimated with a combination of REM using camera traps, and dung counts using fecal standing crop (FSC) approach (Buckland et al. 2001; Rowcliffe et al. 2008). Data from 40 camera traps (REM) and 18 2-km transects (FSC) were gathered in 422 $\mathrm{km}^{2}$ of forests in western parts of GNP (Fig. 7.1). Details on methodologies and modeling approaches related to prey abundance estimation by us are provided in other publications (Hamidi et al. 2014; Ghoddousi et al. 2016a,b; Soofi et al. submitted).

\section{Preference indices}

We used Jacob's index $l_{j}$ to calculate leopard and poachers' prey preference (Jacobs 1974):

$$
I_{j}=\frac{r_{i}-p_{i}}{r_{i}+p_{i}-2 r_{i} p_{i}}
$$


where $r_{i}$ is the proportion of the number of individuals of the $i$-th consumed/hunted prey species to all consumed/hunted individuals and $p_{i}$ is the proportion of the abundance of the $i$-th species to the abundance of all prey species. $l_{j}$ ranges from -1 (maximum avoidance) to +1 (maximum preference), with $l_{j}>0.3$ indicating preferred prey species and $I_{j}<-0.3$ as avoided prey. The index between these values suggests predation according to prey abundance (Clements et al. 2014). We calculated the proportion of prey individuals consumed/hunted using the total abundance of the four prey species described above.

\section{Interview survey}

As an independent measure of poaching preference, we used interview surveys to obtain data on self-reported preference of hunted species by local poachers (Gavin et al. 2010; Martin et al. 2012). Although different poachers may have different poaching preferences, we assumed that by interviewing a representative number of poachers we could identify the typical hunting preference of local poachers. As we initiated participatory monitoring schemes with cooperation of local communities in GNP (Hamidi et al. 2014; Ghoddousi et al. 2016a), a number of local poachers were identified through a chain referral approach (Newing 2011). As we worked as a nongovernmental group of researchers and informed local poachers about the purpose of this study, poachers agreed to attend the interview survey. On December 2012, a focus group meeting with participation of five poachers was organized and we collected data on preferred hunted species (up to three entries) using semistructured interviews (Newing 2011; Martin et al. 2012). We also used data on poachers' preferred hunted species from a previous social study (Ashayeri 2014), using individual qualitative interviews from eight participants from June 2013 to February 2014 (Newing 2011). The 13 participants were from eight different villages adjacent to GNP. The respondents' age ranged from 29 to 66 years, and all were males. Based on investigations by former GNP manager (J. Selyari pers. comm.), local informants ( $n=2$; own data, unpublished) and other poachers ( $n=4$; own data, unpublished), we calculated the total number of active hunters in villages around GNP (Martin et al. 2012). The interviewees were ensured about the anonymity and security of their identity would not be recorded nor disclosed to Department of 
Environment (DoE). Interviewees gave their verbal consent on the use of their data, as written consent was not possible and could affect data quality.

Niche breadth and overlap

By incorporating leopard diet and poacher seizure records data, Levin's dietary niche breadth index was calculated (Levins 1968) to assess the degree of dietary/hunting specialization of leopard and poachers. We calculated a standardized dietary niche breadth $\left(B_{\text {sta }}\right)$, as the number of prey species differed between poachers and leopard (Henschel et al. 2011):

$$
B_{\text {sa }}=\left(1 / \sum p_{i}^{2}-1\right) /\left(B_{\max }-1\right)
$$

where $p$ is the proportion of each prey species consumed/hunted (i) and $B_{\max }$ is the total number of prey species consumed/hunted. $B_{\text {sta }}$ ranges between 0 (specialist hunter) and 1 (generalist hunter). Moreover, the dietary/hunting niche overlap between leopard and poachers was calculated using Pianka's index $\left(O_{p l}\right)$, which ranges from 0 (hunting exclusivity) to 1 (hunting overlap) (Pianka 1973):

$$
O_{p l}=\sum_{i}^{n} P_{i p} P_{i I} /\left(\sum P_{i p}^{2} \sum P_{i I}^{2}\right)^{1 / 2}
$$

where $P_{i}$ is the proportion of prey item " $i$ " in the diet/hunting of species " $p$ " (poachers) and "l" (leopard). 


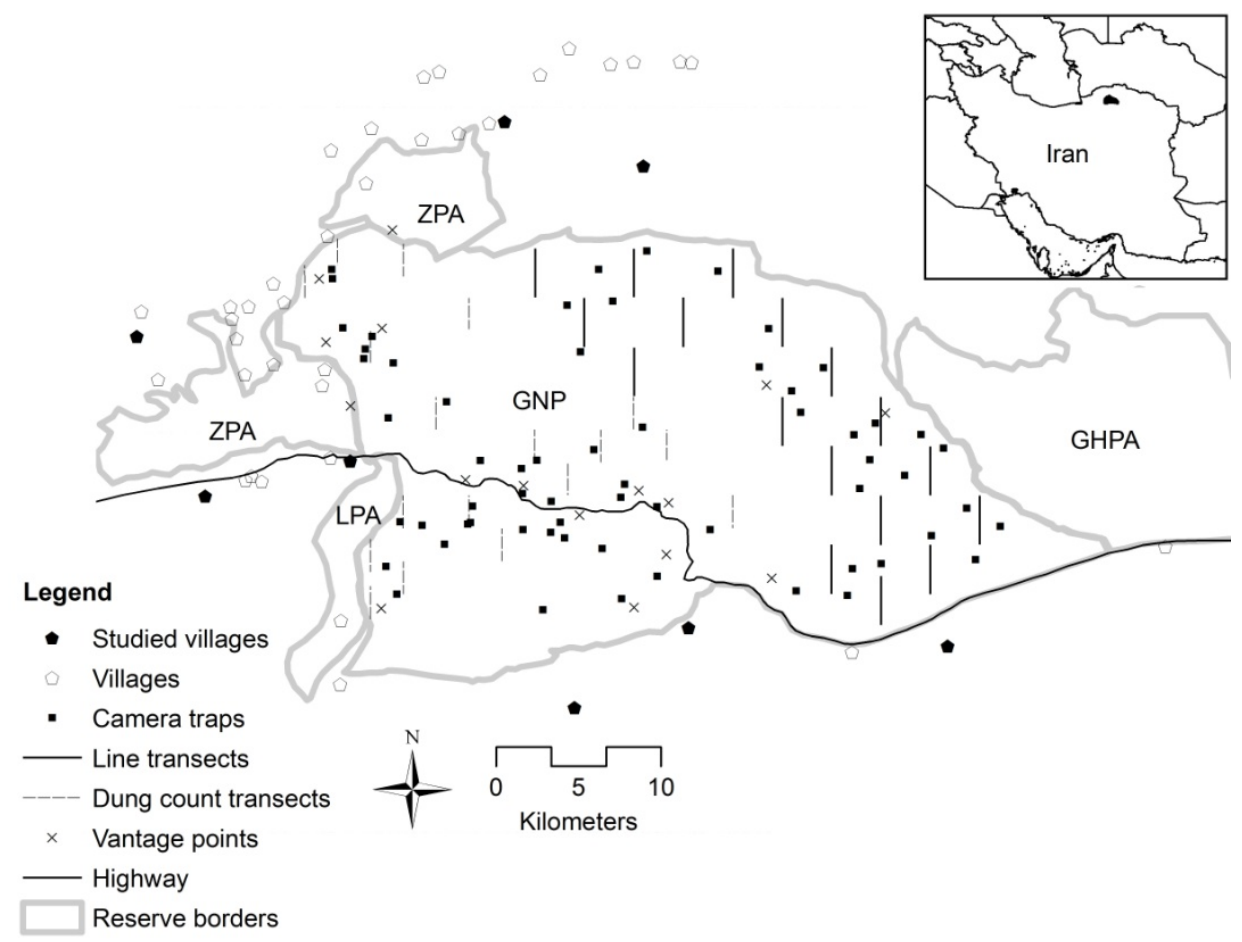

Figure 7.1. Map of Golestan National Park showing the location of line transects, camera traps, vantage points, studied villages and neighboring reserves (LPA: Loveh Protected Area; ZPA: Zav Protected Area; GHPA: Ghorkhod Protected Area).

\subsection{Results}

\section{Leopard diet analysis}

We collected 77 leopard scats containing 12 prey species (Fig. 7.2). The corrected proportions of prey individuals consumed showed the main contribution of wild boar (66.67\%), followed by bezoar goat (18.14\%), urial (13.24\%) and red deer (1.97\%) (Table 7.1).

\section{Poacher seizure}

We collected data on 75 cases of poacher seizures in GNP, reporting on 113 killed animals of eight species (Fig. 7.2). The corrected proportion of hunted species by poachers was highest for urial (68.75\%), followed by red deer (13.54\%), bezoar goat (10.42\%), and wild boar (7.29\%) (Table 7.1). 


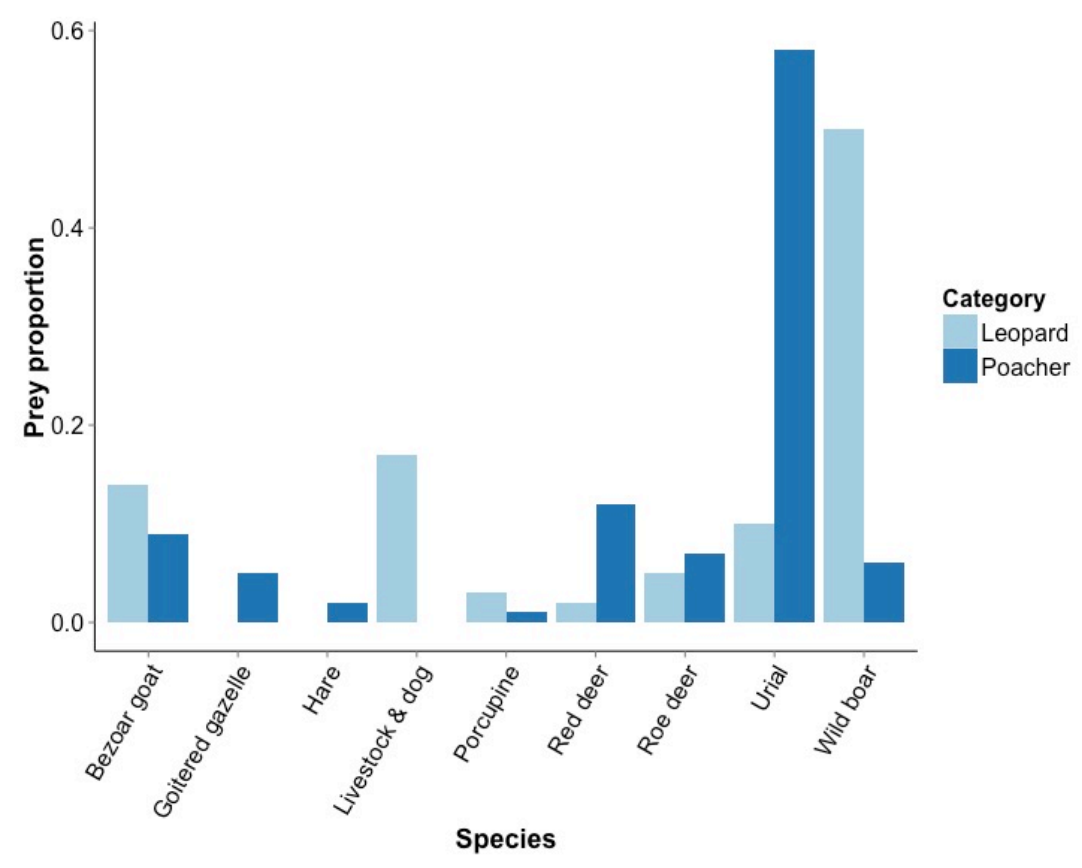

Figure 7.2. Proportions of different prey species in Persian leopard diet and poacher seizure records in Golestan National Park.

\section{Prey abundance estimation}

During 64 scans, we observed 39 bezoar goats in seven groups. The estimated abundance was 519 individuals (coefficient of variation $\mathrm{CV}=31.3 \% ; 95 \% \mathrm{Cl}=201$ 807). From 50 pellet groups, the FSC method estimated red deer abundance as 194 individuals ( $\mathrm{CV}=28.4 \% ; 95 \% \mathrm{Cl}=103-285)$. Also, we captured 10 photos of red deer from 1345 camera days of effort in GNP. Using REM approach, the estimated red deer population in GNP was 257 individuals $(C V=35.3 \%$; $95 \% \mathrm{Cl}=91-423)$. We calculated red deer abundance as 226 individuals, which is the arithmetic mean of the REM and FSC estimates. By a total survey effort of $186 \mathrm{~km}$, we observed 1981 urials in 70 groups and estimated their abundance as 4275 individuals (CV $=35.5 \%$; $95 \% \mathrm{Cl}=2117-8632$ ). Finally, we captured 386 wild boar photos during 2777 camera days of effort across GNP and estimated wild boar abundance as 6478 individuals (CV = 27.0\%; 95\% Cl = 3050-9906). 
Prey preferences

Leopard showed the highest preference for bezoar goat $\left(I_{j}=0.62\right)$ among the studied species (Fig. 7.3). Predation on wild boar $\left(l_{j}=0.23\right)$ and red deer $\left(l_{j}=0.00\right)$ was according to their abundance (Fig. 7.3). Urial $\left(I_{j}=-0.60\right)$ was avoided by leopard in GNP (Fig. 7.3). The poachers' hunting preference using seizure records indicated red deer $\left(I_{j}=0.80\right)$, urial $\left(I_{j}=0.58\right)$ and bezoar goat $\left(I_{j}=0.38\right)$ as the preferred species. Wild boar $\left(I_{j}=-0.72\right)$ was highly avoided by poachers in GNP (Fig. 7.3).

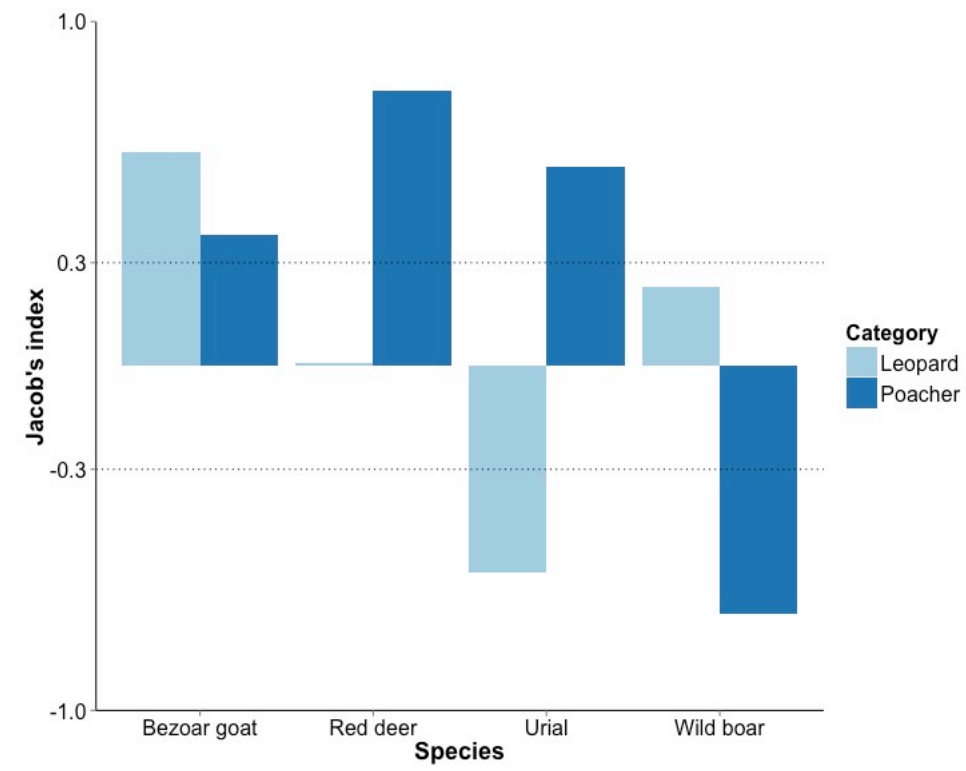

Figure 7.3. Hunting preferences of Persian leopard and poachers in Golestan National Park as estimated by Jacob's index (Jacob's index $>0.3$ was considered as preferred and $<-0.3$ as avoided, with the index between these values indicating predation/hunting proportional to the abundance of prey). 
Table 7.1. Hunting preferences of poachers and Persian leopard in Golestan National Park in relation to abundance of four studied prey species.

\begin{tabular}{|lcccccc|}
\hline & \multicolumn{2}{c}{ Prey abundance } & Leopard diet & $\begin{array}{c}\text { Poacher seizure } \\
\text { data }\end{array}$ & Hunting preference \\
& $\begin{array}{c}\text { No. } \\
\text { individuals }\end{array}$ & $(\%)$ & $\begin{array}{c}\text { Corrected } \\
\text { individuals } \\
\text { consumed (\%) }\end{array}$ & $\begin{array}{c}\text { Corrected } \\
\text { individuals hunted } \\
(\%)\end{array}$ & $\begin{array}{c}\text { Leopard } \\
\text { Jacob's index }\left(I_{j}\right)\end{array}$ \\
\hline Bezoar goat & 519 & 4.51 & 18.14 & 10.42 & 0.62 & 0.38 \\
Red deer & 226 & 1.97 & 1.96 & 13.54 & 0.00 & 0.80 \\
Urial & 4275 & 37.18 & 13.24 & 68.75 & -0.60 & 0.58 \\
Wild boar & 6478 & 56.34 & 66.67 & 7.29 & 0.23 & -0.72 \\
\hline Total & 11,498 & 100 & $\sim 100$ & 100 & & \\
\hline
\end{tabular}

Interview survey

Poachers reported their highest preference for killing urial ( $46.4 \%$ of all records). The other species frequently mentioned as being preferred were red deer (35.7\%) and bezoar goat (17.8\%) (Table 7.2). No poachers from our sampled population stated preference for wild boar hunting. The average number of local poachers around GNP was estimated as $80 \pm$ SE 24 individuals. Therefore, our sample size represents around $16.3 \%$ of GNP poachers.

Table 7.2. Reported hunting preferences of poachers from interview survey and seizure records in Golestan National Park.

\begin{tabular}{|lccc|}
\hline Species & $\begin{array}{c}\text { Reported } \\
\text { preference (\% of all } \\
\text { mentions) }\end{array}$ & $\begin{array}{c}\text { Proportion of } \\
\text { hunted (\%) }\end{array}$ & $\begin{array}{c}\text { Proportion of } \\
\text { hunted minus } \\
\text { reported } \\
\text { preference }\end{array}$ \\
\hline Bezoar goat & 17.86 & 10.42 & -7.44 \\
Red deer & 35.71 & 13.54 & -22.17 \\
Urial & 46.43 & 68.75 & 22.32 \\
Wild boar & 0.00 & 7.29 & 7.29 \\
\hline Total & 100 & 100 & - \\
\hline
\end{tabular}

Niche breadth

The dietary/hunting niche breadth of leopard $\left(B_{\text {sta }}=0.24\right)$ and poachers $\left(B_{\text {sta }}=0.19\right)$ confirms specialization of both predators in prey choice. Also, the dietary/hunting 
niche overlap of poachers and leopard $(O=0.31)$ shows exclusivity of hunted species.

\subsection{Discussion}

In this study, we documented hunting specialization of Persian leopard and local poachers in Golestan National Park. According to our results, the dietary niche overlap of leopards and poachers is low, which suggest no exploitative competition between these two apex predators. Such pattern is likely due to the role of wild boar, which is the major prey of leopard in the national park (Ghoddousi et al. 2016b), but is widely avoided by the poachers (Fig. 7.3). Due to the prohibition of pork consumption by Islam, this species is experiencing low poaching pressure inside the Iranian protected areas (Ghoddousi et al. submitted). Therefore, it appears that religious beliefs are working indirectly in favor of leopards despite rampant poaching of other ungulate species (Ghoddousi et al. submitted).

Religious beliefs and taboos about members of the Suidae family are influential in hunting patterns of local communities in different parts of the world (Randrianandrianina et al. 2010). Under such conditions, the wild boar population has increased by $58 \%$ in the past four decades in Golestan National Park (Ghoddousi et al. submitted). Although abundant wild boar population and low dietary niche overlap with poachers may indicate low trophic competition in the park, our results suggest that wild boar is not a preferred prey for leopards and is only predated upon according to its abundance. Throughout its range, the leopard is known to avoid hunting suids due to their aggressive behavior, group living and heavy body mass exceeding the leopard's preferred prey range (1-45 kg; Hayward et al. 2006; Clements et al. 2014). However, large carnivores are able to adopt to human interventions in other parts of the world as well (Carter \& Linnell in press). Therefore, we hypothesize that a considerable share of wild boar predation in leopard diet in Golestan National Park may be a result of a prey-switching strategy (Garrott et al. 2007), caused by a drastic decline of other ungulate species (Ghoddousi et al. submitted). 
Limited resource availability may influence the diet of carnivores (Lovari et al. 2013), and specialization on different prey species is one of the main strategies to avoid competition in different carnivore guilds (Karanth \& Sunquist 2000; Harihar et al. 2011). Such alteration may lead to dietary niche separation (Pianka 1973). Current levels of ungulate over-hunting and the increasing wild boar population (Ghoddousi et al. submitted) suggests that the dependence of Persian leopards on wild boars would increase in Iran. Lack of alternative prey may be compensated by high densities of wild boars in Iranian forests. However, in arid parts of the country wild boar densities are low and other ungulates constitute a majority of the leopard diet (Taghdisi et al. 2013). Limited dietary niche breadth of leopard may therefore risk survival of Persian leopards in the future, especially in arid areas. Moreover, given the intrinsic risks of injury and energetic costs from wild boar predation to leopards (Qi et al. 2015), it remains unclear how the dependence on this species would affect the long-term viability of Persian leopards.

An earlier study by Henschel et al. (2011) indicated the exploitative competition between leopards and snare-using bushmeat hunters in the Congo basin. Apparently, no such a relationship exists in our study area where poachers practice only pursuit hunting and, therefore, their preference directly affects populations of exploited species (Rowcliffe et al. 2003). Apart from wild boar, we recorded trophic niche separation between leopard and poachers in another two prey species studied. High preference for red deer may be driven by the quantity of meat provided by this largest ungulate of the park for selling in illegal markets (Martin et al. 2012). However, seizure records indicate that poachers kill less red deer than they report (Table 7.2). The sharp decline of the red deer population by $89 \%$ in the past four decades and the low detection probability of this species may have reduced the hunting success rate of this species (Ghoddousi et al. submitted). This species constitutes a minor proportion of leopard diet and was predated upon according to its abundance. In contrast, urial experiences higher poaching pressure than it was claimed by respondents. Despite higher availability, living in open landscapes may limit the success rate of urial hunting by leopards (Balme et al. 2007). Therefore, avoidance of urial by leopards in Golestan National Park is plausible. The only 
studied prey species preferred by both poachers and leopard was bezoar goat. This species has experienced around $88 \%$ decline due to poaching since the 1970 's (Ghoddousi et al. submitted). Despite its rarity, bezoar goat made a remarkable share in poachers' hunts and leopard diet, and was highly preferred by leopard. Enforcement of protection of the last population patches of this species in rocky habitats is essential to secure leopard survival in the park and should be considered a conservation priority.

We are aware of some limitations of this study, which might affect our inferences. Due to lack of data, we did not consider two species hunted by leopard or poachers in Golestan National Park, namely roe deer Capreolus capreolus and goitered gazelle Gazella subgutturosa. However, they play a minor role compared to the four studied prey species, which constitute $75 \%$ of leopard diet and $85 \%$ of poachers' successful hunts. Therefore, we believe that our conclusions on hunting preferences of leopard and poachers are representative for their prey choice. Another limitation was that the camera trapping data used for red deer and wild boar abundance estimation came from a study that targeted leopard (Hamidi et al. 2014). However, as movement patterns of herbivores are independent from those of carnivores (Cusack, Dickman, et al. 2015), this design should not violate the assumptions of random encounter models (Rowcliffe et al. 2008). The application of random encounter model to red deer and wild boar populations in Golestan National Park produced abundance estimates similar to other tested methods (Ghoddousi et al. 2016b; Soofi et al. submitted). Finally, due to sensitivity of illegal hunting, we were not able to include more poachers in our survey. However, we attempted to spatially distribute our interviews in villages around the national park to minimize the potential bias.

\section{Conclusions}

Conservation of threatened carnivores requires careful consideration of their dietary requirements and solutions to alleviate depletion of their prey (Ripple et al. 2014). In this study, leopard and poachers showed exclusivity in their dietary/hunting niches in Golestan National Park despite rampant ungulate poaching. This is likely due to 
the major role of wild boar in leopard diet, which is not preferred nor extensively hunted by poachers due to religious beliefs. Considering the general avoidance of Suidae species across its range, depletion of other prey species may have resulted in a prey-switching strategy by the leopard. We demonstrated that poachers prefer hunting prey with higher body mass (red deer), but are most successful in hunting abundant species (urial). Although in our study leopard and poachers had a low trophic niche overlap, the reduction of dietary niche breadth may threaten the longterm survival of leopard (Hayward \& Kerley 2008). Therefore, conservation initiatives should target poachers' economic and non-economic incentives to reverse alarming population declines of ungulates (Ghoddousi et al. submitted).

\section{Acknowledgements}

Iranian Department of Environment, Golestan provincial office of Department of Environment and administration of Golestan National Park provided permits for this study. We would like to thank Persian Wildlife Heritage Foundation for sharing their camera trapping and social survey data, as well as logistical support. Our gratitude goes to all rangers, local guides and volunteers who participated in this research. German Academic Exchange Service (DAAD) and Panthera's Kaplan Graduate Award funded AG and Erasmus Mundus/SALAM funded MS during this research. 


\section{Chapter 8: Synthesis}

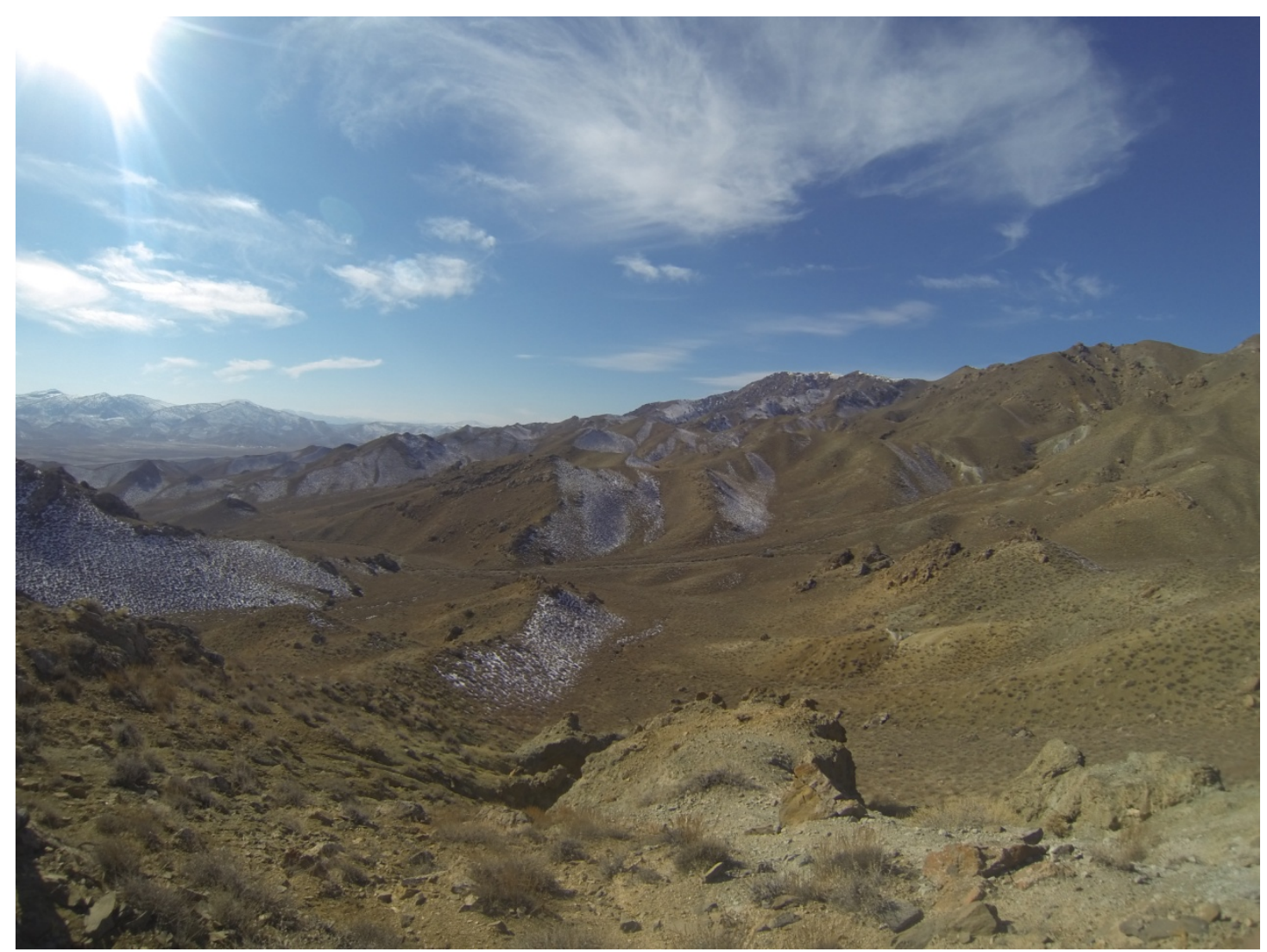

A typical steppe landscape of eastern Golestan National Park. Photo: A. Ghoddousi 


\subsection{Objective 1: Development of leopard-specific correction factors and quantification of leopard diet}

I developed leopard-specific non-linear correction factors (CF) for robust estimation of biomass and number of consumed prey from scat data (chapter 2) and estimated leopard diet in Golestan National Park (GNP) (chapter 6). I developed $\mathrm{CF}_{1}$ to estimate the proportion of consumed prey biomass and $\mathrm{CF}_{2}$ to estimate the numbers of prey individuals consumed by leopards. I used a novel approach in calculation of $\mathrm{CF}_{2}$ by incorporating inedible matter in consumption rates (Stander et al. 1997) and limiting the maximum consumption to $25 \mathrm{~kg}$ for prey species heavier than $36 \mathrm{~kg}$. This was based on maximum daily food intake of $5 \mathrm{~kg}$ (Odden \& Wegge 2009) and a maximum of 5 days of revisiting killed prey in the wild (Sunquist \& Sunquist 2009). The results of re-analysis of previous leopard diet studies (including this study) using the leopard-specific CFs showed marked differences in the estimated absolute number of prey individuals consumed compared to the previous non-linear model. Also, the estimates of biomass and number of individuals consumed from leopard-specific model were significantly different from the linear models. These results call for a recalculation of leopard studies and application of the CFs developed in this study in the future. The use of leopard-specific non-linear models is particularly important for estimation of livestock contribution to leopard diet wherever conservation efforts are focused on resolving human-leopard conflict.

I estimated leopard diet using scat samples from GNP and compared the prey hair remains with available reference collections. As the CFs developed in chapter 2 are not yet published, I was unable to use the leopard-specific regression models and used the non-linear CFs for big cats in tropical areas (Wachter et al. 2012). However, the re-analysis of leopard diet using CFs developed in chapter 2 showed only minor changes in the biomass and number of individuals consumed. Leopard diet in GNP consisted of 12 different species, with major contributions from ungulate species. Wild boar constituted around half of the leopard diet in GNP. Other important species were bezoar goat and urial. The considerable share of livestock (sheep, goat and cattle) and dog (17.1\% biomass consumed) shows the existence of an alarming human-leopard conflict in the villages around GNP. 


\subsection{Objective 2: Quantification of prey abundance}

In chapters 3, 4 and 5, I estimated the abundance of the four main species hunted by leopard and poachers in GNP. I assessed the population of bezoar goat using doubleobserver point-counts as 201-807 individuals, which shows a $79-96 \%$ decline compared to 1970's records. The abundance of red deer was estimated by faecal standing crop using dung counts (103-285 individuals), and random encounter model using camera trapping data (91-423 individuals), which showed a $78-96 \%$ decline in red deer population compared to the 1970's figures. I estimated urial abundance by Distance sampling using line transects as $2117-8632$ individuals. These results show a $14-86 \%$ decline in population of urial compared to estimates from the 1970 's. Finally, the population of wild boar was assessed by random encounter model using camera trapping data as 3050-9906 individuals. Wild boar was the only studied ungulate species to show a population increase $(2-75 \%)$ compared to historical estimates. In the absence of other threats, a severe population decline of the studied species is linked with rampant poaching in the park. Conversely, prohibition pork consumption due to religious beliefs has resulted in low poaching pressure on wild boar and led to the growth of its population. The results of chapter 5 indicate the following incentives of local poachers for ungulate poaching (in non-ordinal manner): poverty/subsistence, hunting for meat market/trade, pleasure/love of hunting, tradition/habits, and hunting for revenge/conflict with conservation regulations and bodies. Moreover, in chapter $3 \mathrm{I}$ conducted a multivariate analysis of urial and leopard distribution in regard to anthropogenic and environmental variables. The results showed that the distance to ranger stations was negatively related to the size and density of urial herds and was the most important predictor of urial distribution. Meantime, leopard distribution was best explained by urial density. These results suggest that poaching pressure causes concentration of urials around ranger stations where they benefit from higher law enforcement levels. 


\subsection{Objective 3: Estimation of prey preferences, dietary niche breadth and dietary competition of Persian leopard and poachers}

In chapters 6 and 7, I assessed the prey preferences of leopard and poachers. Persian leopards highly prefer bezoar goat despite its lower abundance. Wild boar and red deer were predated according to their abundances and urial was avoided by leopards. Avoidance of urial by leopards despite its higher abundance is likely related to living in open steppes, which is not favorable for ambush hunters like leopard. Moreover, I developed a novel livestock spatiotemporal availability coefficient and assessed the role of small livestock (sheep and goat) in leopard diet. Leopards strongly avoided small livestock, which suggests human-leopard conflict might occur due to depletion of preferred natural prey (bezoar goat), failures in herding practices, or characteristics of individual leopards.

Based on seizure records, poachers preferred to hunt red deer, urial and bezoar goat and strongly avoided wild boar hunting. Data from interviews with local poachers determined that they most preferred to hunt urial, followed by red deer and bezoar goat. A comparison of stated preferences and seizure records shows that the abundant urial is being hunted more than stated whereas rare red deer is being hunted less than what poachers prefer. Poachers' high preference for red deer may be related to quantity of meat supplied by the deer, which is the largest ungulate of the park, for selling in illegal markets. Due to religious beliefs, poachers avoided hunting wild boar in GNP. Both leopard and poachers showed hunting specialization due to a narrow dietary/hunting niche breadth. Also, both apex predators showed exclusivity in their dietary/hunting niches, which suggests the lack of exploitative competition.

\subsection{Overall conclusions}

This thesis shows that despite decades of traditional law enforcement measures in Iran's oldest national park, poaching pressure is still severely influencing the populations of exploited ungulate species and consequently the dietary niche of large carnivores. However, it appears that avoidance of hunting wild boar by poachers due to religious beliefs and a considerable share of this species in leopard 
diet separate dietary niches of the two apex predators and exclude exploitative competition between them. Across their range, leopards avoid hunting members of Suidae family due to their body mass exceeding the leopard's preferred prey range, living in large groups and aggressive behavior. Therefore, a substantial share of wild boar in leopard diet in GNP coupled with a severe decline of the populations of other ungulates may indicate signs of prey-switching strategy by this species. However, the viability of such strategy for survival of Persian leopards is unclear. Additionally, decreasing niche breadth of leopard due to poaching may threaten the survival of this species in the future. In this research, I also documented other consequences of poaching, such as higher abundance and distribution of urial in areas with lower poaching pressure. Moreover, reduction of the leopard's preferred prey biomass to the threshold for sheep and goat depredation is likely to trigger high human-leopard conflict in the area, which may result in retaliatory killing of leopards.

Based on poachers' incentives in GNP, conservation initiatives should focus on alternative livelihood programs, which increase local employment opportunities in conservation and other nature-related sectors such as ecotourism and communitybased reserves. Furthermore, community outreach programs aiming at building trust, awareness, motivation, and opportunities among local communities are recommended to change the traditional non-participatory and top-down approach in protected area management in Iran. Finally, the distribution and efficiency of law enforcement efforts should be improved.

In conclusion, long-term survival of large carnivores and their prey species requires control of current poaching pressure by introducing more efficient law enforcement practices in protected areas and conservation initiatives targeting a combination of economic and non-economic incentives. 


\section{Bibliography}

Ackerman, B.B., Lindzey, F.G. \& Hemker, T.P., 1984. Cougar food habits in southern Utah. Journal of Wildlife Management, 48(1), pp.147-155.

Akhani, H., 2005. The illustrated flora of Golestan National Park, Iran vol. 1., Tehran: Tehran University Press.

Alves, J., Alves da Silva, A., Soares, A.M.V.M. \& Fonseca, C., 2013. Pellet group count methods to estimate red deer densities: precision, potential accuracy and efficiency. Mammalian Biology, 78(2), pp.134-141.

Amos, M., Baxter, G., Finch, N., Lisle, A. \& Murray, P., 2014. "I just want to count them! Considerations when choosing a deer population monitoring method." Wildlife Biology, 20(6), pp.362-370.

Andheria, a. P., Karanth, K.U. \& Kumar, N.S., 2007. Diet and prey profiles of three sympatric large carnivores in Bandipur Tiger Reserve, India. Journal of Zoology, 273(2), pp.169-175.

Anile, S., Ragni, B., Randi, E., Mattucci, F. \& Rovero, F., 2014. Wildcat population density on the Etna volcano, Italy: a comparison of density estimation methods. Journal of Zoology, 293(4), pp.252-261.

Ashayeri, S., 2014. 2nd phase of conservation of leopard project in Golestan National Park; social research, Persian Wildlife Heritage Foundation, Tehran, Iran.

Ashayeri, S. \& Newing, H., 2012. Meat, markets, pleasure and revenge: multiple motivations for hunting in Bamu National Park, Fars Province, Iran. Parks, 18(1), pp.125-133.

Athreya, V., Odden, M., Linnell, J.D.C., Krishnaswamy, J. \& Karanth, U., 2016. A cat among the dogs: leopard Panthera pardus diet in a human-dominated landscape in western Maharashtra, India. Oryx, 5(1), pp.156-162.

Averbeck, C., Plath, M., Wronski, T. \& Apio, A., 2012. Effect of human nuisance on the social organisation of large mammals: group sizes and compositions of seven ungulate species in Lake Mburo National Park and the adjacent Ankole Ranching Scheme. Wildlife Biology, 18(2), pp.180-193.

Bahrami, F., Arbabi, M., Shoushtari Vafaei, R. \& Kazemi, S., 2011. Mesostigmatic mites associated with Coleoptera and biodiversity calculation of these mites phoretic on dung beetles in Golestan Province (north of Iran). Middle-East Journal of Scientific Research, 9(3), pp.345-366.

Bailey, T.N., 1993. The African leopard: a study of the ecology and behavior of a solitary felid, New York, USA: Columbia University Press.

Balme, G. a., Lindsey, P. a., Swanepoel, L.H. \& Hunter, L.T.B., 2014. Failure of research to address the rangewide conservation needs of large carnivores: leopards in South Africa as a case study. Conservation Letters, 7(1), pp.3-11.

Balme, G., Hunter, L. \& Slotow, R., 2007. Feeding habitat selection by hunting leopards Panthera pardus in a woodland savanna: prey catchability versus abundance. Animal Behaviour, 74(3), pp.589-598.

Barton, K., 2009. MuMIn: multi-model inference. $R$ package, version 0.12.2.

Beyer, H.L., 2004. Hawth's analysis tool for ArcGIS.

Bolker, B.M., 2008. Ecological models and data in R, Princeton: Princeton University Press. 
Bothma, J. du P. \& le Riche, E.A.N., 1994. Scat analysis and aspects of defecation in northern Cape leopards. South African Journal of Wildlife Research, 24(1 \& 2), pp.21-25.

Buckland, S.T., Anderson, D.R., Burnham, K.P., Laake, J.L., Borchers, D. \& Thomas, L., 2001. Introduction to distance sampling estimating abundance of biological populations., Oxford: Oxford University Press.

Burnham, K.P. \& Anderson, D.R., 2002. Model selection and multimodel inference: $a$ practical information-theoretic approach 2nd ed., Oxford: Oxford University Press.

Burton, A.C., Neilson, E., Moreira, D., Ladle, A., Steenweg, R., Fisher, J.T., Bayne, E. \& Boutin, S., 2015. Wildlife camera trapping: a review and recommendations for linking surveys to ecological processes. Journal of Applied Ecology, 52(3), pp.675-685.

Campbell, D., Swanson, G.M. \& Sales, J., 2004. Comparing the precision and costeffectiveness of faecal pellet group count methods. Journal of Applied Ecology, 41(6), pp.1185-1196.

Campbell, G., Kuehl, H., Diarrassouba, a, N'goran, P.K. \& Boesch, C., 2011. Long-term research sites as refugia for threatened and over-harvested species. Biology letters, 7(5), pp.723-726.

Carbone, C., Pettorelli, N. \& Stephens, P.A., 2011. The bigger they come, the harder they fall: body size and prey abundance influence predator-prey ratios. Biology letters, 7(2), pp.312-5.

Caro, T.M. \& Stoner, C.J., 2003. The potential for interspecific competition among African carnivores. Biological Conservation, 110(1), pp.67-75.

Carranza, J., Hidalgo de Trucios, S.J., Medina, R., Valencia, J. \& Delgado, J., 1991. Space use by red deer in a Mediterranean ecosystem as determined by radiotracking. Applied Animal Behaviour Science, 30(3-4), pp.363-371.

Carter, N.H. \& Linnell, J.D.C., Co-Adaptation is key to coexisting with large carnivores. Trends in Ecology \& Evolution. Available at: http://dx.doi.org/10.1016/j.tree.2016.05.006.

Chakrabarti, S., Jhala, Y. V., Dutta, S., Qureshi, Q., Kadivar, R.F. \& Rana, V.J., 2016. Adding constraints to predation through allometric relation of scats to consumption. Journal of Animal Ecology, 85(3), pp.660-670.

Challender, D.W.S. \& MacMillan, D.C., 2014. Poaching is more than an Enforcement Problem. Conservation Letters, 7(5), pp.484-494.

Chapron, G. \& López-Bao, J.V., Coexistence with large carnivores informed by community ecology. Trends in Ecology \& Evolution. Available at: http://dx.doi.org/10.1016/j.tree.2016.06.003.

Chapron, G., Miquelle, D.G., Lambert, A., Goodrich, J.M., Legendre, S. \& Clobert, J., 2008. The impact on tigers of poaching versus prey depletion. Journal of Applied Ecology, 45, pp.1667-1674.

Chattha, S.A., Hussain, S.M., Javid, A., Abbas, M.N., Barq, M.G. \& Hussain, M., 2015. Seasonal diet composition of leopard (Panthera pardus) in Machiara National Park, Azad Jammu and Kashmir, Pakistan. Pakistan Journal of Zoology, 47(1), pp.201-207.

Ciucci, P., Tosoni, E. \& Boitani, L., 2004. Assessment of the point-frame method to quantify wolf Canis lupus diet by scat analysis. Wildlife Biology, 10(2), pp.149- 
153.

Clements, H.S., Tambling, C.J., Hayward, M.W. \& Kerley, G.I.H., 2014. An objective approach to determining the weight ranges of prey preferred by and accessible to the five large African carnivores. PLOS ONE, 9(7): e101054.

Colwell, R.K., 2013. EstimateS: Statistical estimation of species richness and shared species from samples.

Crawley, M.J., 2007. The R Book 1st ed., John Wiley \& Sons, Inc.

Crooks, K.R., Burdett, C.L., Theobald, D.M., Rondinini, C. \& Boitani, L., 2011. Global patterns of fragmentation and connectivity of mammalian carnivore habitat. Philosophical transactions of the Royal Society of London. Series B, Biological sciences, 366(1578), pp.2642-51.

Cusack, J.J., Dickman, A.J., Rowcliffe, J.M., Carbone, C., Macdonald, D.W. \& Coulson, T., 2015a. Random versus game trail-based camera trap placement strategy for monitoring terrestrial mammal communities. PLOS ONE, 10(5):e0126373.

Cusack, J.J., Swanson, A., Coulson, T., Packer, C., Carbone, C., Dickman, A.J., Kosmala, M., Lintott, C. \& Rowcliffe, J.M., 2015b. Applying a random encounter model to estimate lion density from camera traps in Serengeti National Park, Tanzania. The Journal of Wildlife Management, 79(6), pp.1014-1021.

Dajun, W., Sheng, L., McShea, W.J. \& Fu, L.M., 2006. Use of remote-trip cameras for wildlife surveys and evaluating the effectiveness of conservation activities at a nature reserve in Sichuan Province, China. Environmental management, 38(6), pp.942-51.

Darimont, C.T., Fox, C.H., Bryan, H.M. \& Reimchen, T.E., 2015. The unique ecology of human predators. Science (New York, N.Y.), 349(6250), pp.858-860.

Datta, A., Anand, M.O. \& Naniwadekar, R., 2008. Empty forests: large carnivore and prey abundance in Namdapha National Park, north-east India. Biological Conservation, 141(5), pp.1429-1435.

Decker, E. \& Kowalski, G.J., 1972. The behavior and ecology of the urial sheep, Ft. Collins, Colorado.

Duffy, R., John, F.A.V.S., Büscher, B. \& Brockington, D., 2016. Towards a new understanding of the links between poverty and illegal wildlife hunting. Conservation Biology, 30(1), pp.14-22.

Efron, B. \& Tibshirani, R.J., 1993. An introduction to the bootstrap, New York: Chapman and Hall/CRC.

Ehrlich, P.R. \& Pringle, R.M., 2008. Where does biodiversity go from here? a grim business-as-usual forecast and a hopeful portfolio of partial solutions. Proceedings of the National Academy of Sciences of the United States of America, 105 Suppl, pp.11579-11586.

Erisman, B.E., Allen, L.G., Claisse, J.T., Pondella II, D.J., Miller, E.F. \& Murray, J.H., 2011. The illusion of plenty: hyperstability masks collapses in two recreational fisheries that target fish spawning aggregations. Canadian Journal of Fisheries and Aquatic Sciences, 68, pp.1705-1716.

Fa, J.E., Currie, D. \& Meeuwig, J., 2003. Bushmeat and food security in the Congo basin: linkages between wildlife and people's future. Environmental Conservation, 30(1), pp.71-78.

Fa, J.E. \& Peres, C., 2001. Game vertebrate extraction in African and Neotropical forests: an intercontinental comparison. In J. D. Reynolds et al., eds. 
Conservation of Exploited Species. Cambridge: Cambridge University Press, pp. 203-241.

Farhadinia, M.S., Moqanaki, E.M. \& Hosseini-Zavarei, F., 2014. Predator-prey relationships in a middle Asian montane steppe: Persian leopard versus urial wild sheep in Northeastern Iran. European Journal of Wildlife Research, 60(2), pp.341-349.

Firouz, E., 2005. The complete fauna of Iran, London, UK: I.B.Tauris \& Co.

Floyd, T.J., Mech, L.D. \& Jordan, P.A., 1978. Relating wolf scat content to prey consumed. The Journal of Wildlife Management, 42(3), pp.528-532.

Foster, R.J. \& Harmsen, B.J., 2012. A critique of density estimation from camera-trap data. The Journal of Wildlife Management, 76(2), pp.224-236.

Foster, R.J., Harmsen, B.J., Macdonald, D.W., Collins, J., Urbina, Y., Garcia, R. \& Doncaster, C.P., 2016. Wild meat: a shared resource amongst people and predators. Oryx, 50(1), pp.63-75.

Garrott, R.A., Bruggeman, J.E., Becker, M.S., Kalinowski, S.T. \& White, P.J., 2007. Evaluating prey switching in wolf on ungulate systems. Ecological Applications, 17(6), pp.1588-1597.

Gavin, M.C., Solomon, J.N. \& Blank, S.G., 2010. Measuring and monitoring illegal use of natural resources. Conservation biology, 24(1), pp.89-100.

Gervasi, V., Nilsen, E.B., Odden, J., Bouyer, Y. \& Linnell, J.D.C., 2014. The spatiotemporal distribution of wild and domestic ungulates modulates lynx kill rates in a multi-use landscape. Journal of Zoology, 292, pp.175-183.

Ghoddousi, A., Hamidi, A.K., Ghadirian, T., Ashayeri, D. \& Khorozyan, I., 2010. The status of the Endangered Persian leopard Panthera pardus saxicolor in Bamu National Park, Iran. Oryx, 44(04), pp.551-557.

Ghoddousi, A., Kh Hamidi, A., Soofi, M., Khorozyan, I., H. Kiabi, B. \& Waltert, M., 2016a. Effects of ranger stations on predator and prey distribution and abundance in an Iranian steppe landscape. Animal Conservation, 19(3), pp.273280.

Ghoddousi, A., Soofi, M., Kh Hamidi, A., Ashayeri, S., Egli, L., Ghoddousi, S., Speicher, J., Khorozyan, I., Kiabi, B.H. \& Waltert, M., Decline in ungulate populations of Iran's oldest national park calls for urgent actions against poaching. Submitted to Oryx.

Ghoddousi, A., Soofi, M., Kh Hamidi, A., Lumetsberger, T., Egli, E., Khorozyan, I., H Kiabi, B. \& Waltert, M., 2016b. Assessing the role of livestock in big cat prey choice using spatiotemporal availability patterns. PLOS ONE, 11(4): e0153439.

Goshtasb, H., 2001. Investigation of habitat, food habits and reproduction of wild boar in Golestan National Park. PhD thesis Islamic Azad University Tehran.

Hamidi, A.K., Ghoddousi, A., Soufi, M., Ghadirian, T., Jowkar, H. \& Ashayeri, S., 2014. Camera trap study of Persian leopard in Golestan National Park, Iran. Cat News, 60, pp.12-14.

Harihar, A., Pandav, B. \& Goyal, S.P., 2011. Responses of leopard Panthera pardus to the recovery of a tiger Panthera tigris population. Journal of Applied Ecology, 48(3), pp.806-814.

Hay, T., Holmern, T., Mwakalebe, G., Stokke, S. \& Røskaft, E., 2007. How does human exploitation affect impala populations in protected and partially protected areas ? - A case study from the Serengeti Ecosystem, Tanzania. Biological 
Conservation, 136, pp.563-570.

Hayward, M.W., Hayward, G.J., Tambling, C.J. \& Kerley, G.I.H., 2011. Do lions Panthera leo actively select prey or do prey preferences simply reflect chance responses via evolutionary adaptations to optimal foraging? PLOS ONE, 6(9): e23607.

Hayward, M.W., Henschel, P., O'Brien, J., Hofmeyr, M., Balme, G. \& Kerley, G.I.H., 2006. Prey preferences of the leopard (Panthera pardus). Journal of Zoology (London), 270, pp.298-313.

Hayward, M.W. \& Kerley, G.I.H., 2008. Prey preferences and dietary overlap amongst Africa's large predators. South African Journal of Wildlife Research, 38(2), pp.93-108.

Hemami, M., Kaczensky, P., Lkhagvasuren, B., Pereladova, O. \& Bouskila, A., 2015. Equus hemionus ssp. onager. The IUCN Red List of Threatened Species 2015: e.T7966A3144941. Available at: http://dx.doi.org/10.2305/IUCN.UK.20154.RLTS.T7966A3144941.en [Accessed May 24, 2016].

Hemami, M.R. \& Dolman, P.M., 2005. The disappearance of muntjac (Muntiacus reevesi) and roe deer (Capreolus capreolus) pellet groups in a pine forest of lowland England. European Journal of Wildlife Research, 51(1), pp.19-24. Hemami, M.R., Watkinson, A.R., Gill, R.M.A. \& Dolman, P.M., 2007. Estimating abundance of introduced Chinese muntjac Muntiacus reevesi and native roe deer Capreolus capreolus using portable thermal imaging equipment. Mammal Review, 37(3), pp.246-254.

Henschel, P., Abernethy, K.A. \& White, L.J.T., 2005. Leopard food habits in the Lopé National Park, Central Africa. African Journal of Ecology, 43, pp.21-28.

Henschel, P., Hunter, L.T.B., Coad, L., Abernethy, K.A. \& Mühlenberg, M., 2011. Leopard prey choice in the Congo basin rainforest suggests exploitative competition with human bushmeat hunters. Journal of Zoology (London), 285(1), pp.11-20.

Hernández-SaintMartín, A.D., Rosas-Rosas, O.C., Palacio-Núñez, J., TarangoArambula, L.A., Clemente-Sánchez, F. \& Hoogesteijn, A.L., 2015. Food habits of jaguar and puma in a protected area and adjacent fragmented landscape of northeastern Mexico. Natural Areas Journal, 35(2), pp.308-317.

Hilborn, R., Arcese, P., Borner, M., Hando, J., Hopcraft, G., Loibooki, M., Mduma, S. \& Sinclair, A.R.E., 2006. Effective enforcement in a conservation area. Science (New York, N.Y.), 314(5803), p.1266.

Holmern, T., Muya, J. \& Røskaft, E., 2007. Local law enforcement and illegal bushmeat hunting outside the Serengeti National Park, Tanzania. Environmental Conservation, 34(1), p.55-63.

Hopcraft, J.G.C., Sinclair, A.R.E. \& Packer, C., 2005. Planning for success: Serengeti lions seek prey accessibility rather than abundance. Journal of Animal Ecology, 74, pp.559-566.

Hunter, M. \& Cresswell, W., 2015. Factors affecting the distribution and abundance of the Endangered volcano rabbit Romerolagus diazi on the Iztaccihuatl volcano, Mexico. Oryx, 49(2), pp.366-375.

Hutchinson, J.M.C. \& Waser, P.M., 2007. Use, misuse and extensions of "ideal gas" models of animal encounter. Biological Reviews, 82(3), pp.335-359.

Inskip, C. \& Zimmermann, A., 2009. Human-felid conflict: a review of patterns and 
priorities worldwide. Oryx, 43(1), pp.18-34.

lyengar, E. V., 2008. Kleptoparasitic interactions throughout the animal kingdom and a re-evaluation, based on participant mobility, of the conditions promoting the evolution of kleptoparasitism. Biological Journal of the Linnean Society, 93(4), pp.745-762.

Jachmann, H., 2008. Illegal wildlife use and protected area management in Ghana. Biological Conservation, 141(7), pp.1906-1918.

Jachmann, H. \& Billiouw, M., 1997. Elephant poaching and law enforcement in the central Luangwa Valley, Zambia. Journal of Applied Ecology, 34(1), pp.233-244.

Jacobs, J., 1974. Quantitative measurement of food selection; a modification of the forage ratio and Ivlev's electivity index. Oecologia, 14, pp.413-417.

Jacobson, A.P., Gerngross, P., Lemeris Jr., J.R., Schoonover, R.F., Anco, C., Breitenmoser-Würsten, C., Durant, S.M., Farhadinia, M.S., Henschel, P., Kamler, J.F., Laguardia, A., Rostro-García, S., Stein, A.B. \& Dollar, L., 2016. Leopard (Panthera pardus) status, distribution, and the research efforts across its range. PeerJ, 4: e1974.

Jenks, K.E., Howard, J. \& Leimgruber, P., 2012. Do ranger stations deter poaching activity in national parks in Thailand? Biotropica, 44(6), pp.826-833.

Jethva, B.D. \& Jhala, Y. V., 2004. Computing biomass consumption from prey occurrences in Indian wolf scats. Zoo Biology, 23(6), pp.513-520.

Johansson, Ö., Mccarthy, T., Samelius, G., Andrén, H., Tumursukh, L. \& Mishra, C., 2015. Snow leopard predation in a livestock dominated landscape in Mongolia. Biological Conservation, 184, pp.251-258.

Jorgensen, B., 1987. Exponentional dispersion models (with discussion). Journal of Royal Statistical Society: Series B (Statistical Methodology), 49, pp.127-162.

Jumabay-Uulu, K., Wegge, P., Mishra, C. \& Sharma, K., 2014. Large carnivores and low diversity of optimal prey: a comparison of the diets of snow leopards Panthera uncia and wolves Canis lupus in Sarychat-Ertash Reserve in Kyrgyzstan. Oryx, 48(4), pp.529-535.

Kabir, M., Ghoddousi, A., Awan, M.S. \& Awan, M.N., 2014. Assessment of humanleopard conflict in Machiara National Park, Azad Jammu and Kashmir, Pakistan. European Journal of Wildlife Research, 60(2), pp.291-296.

Kaffashi, S., Shamsudin, M.N., Radam, A., Yacob, M.R., Rahim, K.A. \& Yazid, M., 2012. Economic valuation and conservation: Do people vote for better preservation of Shadegan International Wetland? Biological Conservation, 150(1), pp.150-158.

Karami, M., Hemami, M.R. \& Groves, C.P., 2002. Taxonomic, distribution and ecological data on gazelles in Iran. Zoology in the Middle East, 26, pp.29-36.

Karanth, K.U., Nichols, J.D., Kumar, N.S., Link, W.A. \& Hines, J.E., 2004. Tigers and their prey: predicting carnivore densities from prey abundance. Proceedings of the National Academy of Sciences, 101(14), pp.4854-4858.

Karanth, K.U. \& Sunquist, M.E., 2000. Behavioural correlates of predation by tiger (Panthera tigris), leopard (Panthera pardus) and dhole (Cuon alpinus) in Nagarahole, India. Journal of Zoology (London), 250, pp.255-265.

Karanth, K.U. \& Sunquist, M.E., 1995. Prey selection by tiger, leopard and dhole in tropical forests. Journal of Animal Ecology, 64, pp.439-450.

Keane, A., Jones, J.P.G. \& Milner-Gulland, E.J., 2011. Encounter data in resource management and ecology: pitfalls and possibilities. Journal of Applied Ecology, 
48(5), pp.1164-1173.

Khorozyan, I., 2008. Panthera pardus saxicolor. IUCN Red List of Threatened Species. Version 2012.2. Available at: www.iucnredlist.org [Accessed May 12, 2014].

Khorozyan, I., Ghoddousi, A., Soofi, M. \& Waltert, M., 2015a. Big cats kill more livestock when wild prey reaches a minimum threshold. Biological Conservation, 192, pp.268-275.

Khorozyan, I. \& Malkhasyan, A., 2002. Ecology of the leopard (Panthera pardus) in Khosrov Reserve, Armenia: Implications for conservation. Scientific Reports La Torbiera Zoological Society, 6, pp.1-40.

Khorozyan, I., Soofi, M., Hamidi, A.K., Ghoddousi, A. \& Waltert, M., 2015b. Dissatisfaction with veterinary services is associated with leopard (Panthera pardus) predation on domestic animals. PLOS ONE, 10(6): e0129221.

Kiabi, B.H., 1978. Ecology and management of Maral (Cervus elaphus maral) in northeastern Iran, 1976-1978. PhD thesis Michigan State University.

Kiabi, B.H., Dareshouri, B.F., Ghaemi, R. a \& Jahanshahi, M., 2002. Population status of the Persian leopard (Panthera pardus saxicolor Podock, 1927) in Iran. Zoology in the Middle East, 26, pp.41-47.

Kiabi, B.H., Ghaemi, R.A., Jahanshahi, M. \& Sassani, A., 2004. Population status, biology and ecology of the Maral, Cervus elaphus maral, in Golestan National Park, Iran. Zoology in the Middle East, 33, pp.125-138.

Kilgo, J.C., Labisky, R.F. \& Fritzen, D.E., 1998. Influences of hunting on the behavior of white-tailed deer: implications for conservation of the Florida panther. Conservation Biology, 12(6), pp.1359-1364.

Kissui, B.M., 2008. Livestock predation by lions, leopards, spotted hyenas, and their vulnerability to retaliatory killing in the Maasai steppe, Tanzania. Animal Conservation, 11(5), pp.422-432.

Klare, U., Kamler, J.F. \& MacDonald, D.W., 2011. A comparison and critique of different scat-analysis methods for determining carnivore diet. Mammal Review, 41(4), pp.294-312.

Kolahi, M., Sakai, T., Moriya, K. \& Makhdoum, M.F., 2012. Challenges to the future development of Iran's protected areas system. Environmental Management, 50(4), pp.750-765.

Kolahi, M., Sakai, T., Moriya, K., Makhdoum, M.F. \& Koyama, L., 2013. Assessment of the effectiveness of protected areas management in iran: case study in Khojir National Park. Environmental Management, 52(2), pp.514-530.

Kuiper, T.R., Loveridge, A.J., Parker, D.M., Johnson, P.J., Hunt, J.E., Stapelkamp, B., Sibanda, L. \& Macdonald, D.W., 2015. Seasonal herding practices in fluence predation on domestic stock by African lions along a protected area boundary. Biological Conservation, 191, pp.546-554.

Kutner, M.H., Nachtsheim, C.J. \& Neter, J., 2004. Applied linear regression models 4th ed., Irwin: McGraw-Hill.

Laing, S.E., Buckland, S.T., Burn, R.W., Lambie, D. \& Amphlett, A., 2003. Dung and nest surveys: estimating decay rates. Journal of Applied Ecology, 40, pp.11021111.

Levins, R., 1968. Evolution in changing environments, Princton: Princton University Press.

Lindsey, P.A. et al., 2013. The bushmeat trade in African savannas: impacts, drivers, 
and possible solutions. Biological Conservation, 160, pp.80-96.

Linkie, M., Martyr, D.J., Harihar, A., Risdianto, D., Nugraha, R.T., Maryati, M., LeaderWilliams, N. \& Wong, W.-M., 2015. Safeguarding Sumatran tigers: evaluating effectiveness of law enforcement patrols and local informant networks. Journal of Applied Ecology, 52(4), pp.851-860.

Linnell, J.D.C., Odden, J., Smith, M.E., Aanes, R. \& Swenson, J.E., 1999. Large carnivores that kill livestock: Do "problem individuals" really exist ? Wildlife Society Bulletin, 27(3), pp.698-7-5.

Lockie, J.D. (1959). The estimation of the food of foxes. J. Wildl. Manage. 23, 224227.

Logan, M., 2010. Biostatistical design and analysis using R: a practical guide, Chichester: Wiley-Blackwell.

Lovari, S., Minder, I., Ferretti, F., Mucci, N., Randi, E. \& Pellizzi, B., 2013. Common and snow leopards share prey, but not habitats: competition avoidance by large predators? Journal of Zoology (London), 291(2), pp.127-135.

Loveridge, A.J., Wang, S.W., Frank, L.G. \& Seidensticker, J., 2010. People and wild felids: conservation of cats and management of conflicts. In Biology and conservation of wild felids. Oxford: Oxford University Press, pp. 161-195.

Lumetsberger, T., 2014. Diet of the Persian leopard (Panthera pardus saxicolor) in Golestan National Park, Iran; using scat analysis and biomass regression models. MSc. thesis Georg-August-Universität Göttingen.

Lyngdoh, S., Shrotriya, S., Goyal, S.P., Clements, H., Hayward, M.W. \& Habib, B., 2014. Prey preferences of the snow leopard (Panthera uncia): regional diet specificity holds global significance for conservation. PLOS ONE, 9(2): e88349.

Lyons, S.K. et al., 2016. Holocene shifts in the assembly of plant and animal communities implicate human impacts. Nature, 529(7584), pp.80-83.

Mallon, D.P., 2008. Gazella subgutturosa. The IUCN Red List of Threatened Species 2008: e.T8976A12945246. Available at: http://dx.doi.org/10.2305/IUCN.UK.2008.RLTS.T8976A12945246.en [Accessed May 24, 2016].

Manel, S., Williams, H.C. \& Ormerod, S.J., 2001. Evaluating presence-absence models in ecology: the need to account for prevalence. Journal of Applied Ecology, 38(5), pp.921-931.

Manor, R. \& Saltz, D., 2003. Impact of human nuisance disturbance on vigilance and group size of a social ungulate. Ecological Applications, 13(6), pp.1830-1834.

De Marinis, A.M. \& Aspea, A., 2006. Hair identification key of wild and domestic ungulates from southern Europe. Wildlife Biology, 12, pp.305-320.

Marker, L.L., Muntifering, J.R., Dickman, A.J., Mills, M.G.L. \& Macdonald, D.W., 2003. Quantifying prey preferences of free-ranging Namibian cheetahs. South African Journal of Wildlife Research, 33(1), pp.43-53.

Marques, F.F.C., Buckland, S.T., Goffin, D., Dixon, C.E., Borchers, D.L., Mayle, B.A. \& Peace, A.J., 2001. Estimating deer abundance from line transect surveys of dung: Sika deer in southern Scotland. Journal of Applied Ecology, 38(2), pp.349363.

Martin, A., Caro, T. \& Kiffner, C., 2012. Prey preferences of bushmeat hunters in an East African savannah ecosystem. European Journal of Wildlife Research, 59(2), pp.137-145. 
Metzger, K.L., Sinclair, a. R.E., Hilborn, R., Hopcraft, J.G.C. \& Mduma, S. a. R., 2010. Evaluating the protection of wildlife in parks: the case of African buffalo in Serengeti. Biodiversity and Conservation, 19(12), pp.3431-3444.

Miller, J.R.B., 2015. Mapping attack hotspots to mitigate human-carnivore conflict: approaches and applications of spatial predation risk modeling. Biodiversity and Conservation, 24:2887-2911.

Milner-Gulland, E.J., Bennett, E.L. \& the SCB 2002 Annual Meeting Wild Meat Group, 2003. Wild meat: the bigger picture. Trends in Ecology \& Evolution, 18(7), pp.351-357.

Milner-Gulland, E.J. \& Leader-Williams, N., 1992. A model of incentives for the illegal exploitation of black rhinos and elephants: poaching pays in Luangwa Valley, Zambia. Journal of Applied Ecology, 29, pp.388-401.

Milner-Gulland, E.J., Mcgregor, J. a., Agarwala, M., Atkinson, G., Bevan, P., Clements, T., Daw, T., Homewood, K., Kumpel, N., Lewis, J., Mourato, S., Palmer Fry, B., Redshaw, M., Rowcliffe, J.M., Suon, S., Wallace, G., Washington, H. \& Wilkie, D., 2014. Accounting for the impact of conservation on human well-being. Conservation Biology, 28(5), pp.1160-1166.

Milner-Gulland, E.J. \& Rowcliffe, J.M., 2007. Conservation and Sustainable Use: a handbook of techniques,

Minnie, L., Boshoff, A.F. \& Kerley, G.I.H., 2015. Vegetation type influences livestock predation by leopards: implications for conservation in agro-ecosystems. African Journal of Wildlife Research, 45(2), pp.204-214.

Moa, P.F., Herfindal, I., Linnell, J.D.C., Overskaug, K., Kvam, T. \& Andersen, R., 2006. Does the spatiotemporal distribution of livestock influence forage patch selection in Eurasian lynx lynx lynx? Wildlife Biology, 12(1), pp.63-69.

Mondal, K., Gupta, S., Bhattacharjee, S., Qureshi, Q. \& Sankar, K., 2012. Prey selection, food habits and dietary overlap between leopard Panthera pardus (Mammalia: Carnivora) and reintroduced tiger Panthera tigris (Mammalia: Carnivora) in a semi-arid forest of Sariska Tiger Reserve, Western India. Italian Journal of Zoology, 79(4), pp.607-616.

Mondal, K., Gupta, S., Qureshi, Q. \& Sankar, K., 2011. Prey selection and food habits of leopard (Panthera pardus fusca) in Sariska Tiger Reserve, Rajasthan, India. Mammalia, 75, pp.201-205.

Moore, P.D., 1976. Conservation in Iran. Nature, 260, pp.359-360.

Muchaal, P.I.A.K. \& Ngandjui, G., 1999. Impact of village hunting on wildlife populations in the Western Dja Reserve, Cameroon. Conservation Biology, 13(2), pp.385-396.

Mukherjee, S. \& Heithaus, M.R., 2013. Dangerous prey and daring predators: a review. Biological Reviews, 88, pp.550-563.

N'Goran, P.K., Boesch, C., Mundry, R., N'Goran, E.K., Herbinger, I., Yapi, F. a \& Kühl, H.S., 2012. Hunting, law enforcement, and African primate conservation. Conservation Biology, 26(3), pp.565-571.

Neff, D.J., 1968. The pellet-group count technique for big game trend, census, and distribution: a review. The Journal of Wildlife Management, 32(3), pp.597-614.

Nellemann, C., Henriksen, R., Kreilhuber, A., Stewart, D., Kotsovou, M., Raxter, P., Mrema, E. \& Barrat, S., 2016. The rise of environmental crime - a growing threat to natural resources peace, development and security, Available at: 
www.rhipto.org.

Newing, H., 2011. Conducting research in conservation: a social science perspective, London \& New York: Routledge Taylor \& Francis Group.

Nichols, J., Hines, J., Sauer, J., Fallon, F., Fallon, J. \& Heglund, P., 2000. A doubleobserver approach for estimating detection probability and abundance from point counts. The Auk, 117(2), pp.393-408.

Nilsen, E.B., Christianson, D., Gaillard, J.-M., Halley, D., Linnell, J.D.C., Odden, M., Panzacchi, M., Toigo, C. \& Zimmermann, B., 2012. Describing food habits and predation: field methods and statistical considerations. In L. Boitani \& R. A. Powell, eds. Carnivore Ecology and Conservation: A handbook of techniques. Oxford University Press, pp. 256-272.

Nuno, A., Bunnefeld, N., Naiman, L.C. \& Milner-Gulland, E.J., 2013. A novel approach to assessing the prevalence and drivers of illegal bushmeat hunting in the serengeti. Conservation biology, 27(6), pp.1355-1365.

Nuno, A. \& St John, F. a V, 2015. How to ask sensitive questions in conservation: a review of specialised questioning techniques. Biological Conservation, 189(Conservation Crime), pp.5-15.

Odden, J., Herfindal, I., Linnell, J.D.C. \& Andersen, R., 2008. Vulnerability of domestic sheep to lynx depredation in relation to roe deer density. Journal of Wildlife Management, 72(1), pp.276-282.

Odden, M. \& Wegge, P., 2009. Kill rates and food consumption of leopards in Bardia National Park, Nepal. Acta Theriologica, 54(1), pp.23-30.

Odden, M., Wegge, P. \& Fredriksen, T., 2010. Do tigers displace leopards? If so, why? Ecological Research, 25(4), pp.875-881.

Oli, M.K., 1993. A key for the identification of the hair of mammals of a snow leopard (Panthera uncia) habitat in Nepal. Journal of Zoology (London), 231, pp.71-93.

Ott, T., Kerley, G.I.H. \& Boshoff, A.F., 2007. Preliminary observations on the diet of leopards (Panthera pardus) from a conservation area and adjacent rangelands in the Baviaanskloof region, South Africa. African Zoology, 42(1), pp.31-37.

Pahlevani, A., 2004. Urial sheep habitat assessment in Golestan National Park. Mohitshenasi, 35, pp.1-8 (in Farsi).

Pépin, D., Adrados, C., Janeau, G., Joachim, J. \& Mann, C., 2008. Individual variation in migratory and exploratory movements and habitat use by adult red deer (Cervus elaphus L.) in a mountainous temperate forest. Ecological Research, 23(6), pp.1005-1013.

Pépin, D., Adrados, C., Mann, C. \& Janeau, G., 2004. Assessing real daily distance traveled by ungulates using differential GPS locations. Journal of Mammalogy, 85(4), pp.774-780.

Pépin, D., Morellet, N. \& Goulard, M., 2009. Seasonal and daily walking activity patterns of free-ranging adult red deer (Cervus elaphus) at the individual level. European Journal of Wildlife Research, 55(5), pp.479-486.

Pianka, E.R., 1973. The structure of lizard communities. Annual Review of Ecology, Evolution, and Systematics, 4, pp.53-74.

Pinheiro, J., Bates, D., DebRoy, S., Sarkar, D. \& R Development Core Team, 2012. nlme: Linear and nonlinear mixed effects models. R package version 3.1-103.

Pitman, R.T., Kilian, P.J., Ramsay, P.M. \& Swanepoel, L.H., 2013. Foraging and habitat specialization by female leopards (Panthera pardus) in the Waterberg 
Mountains of South Africa. South African Journal of Wildlife Research, 43(2), pp.167-176.

Pitman, R.T., Mulvaney, J., Ramsay, P.M., Jooste, E. \& Swanepoel, L.H., 2014. Global Positioning System-located kills and faecal samples: A comparison of leopard dietary estimates. Journal of Zoology, 292, pp.18-24.

Plumptre, A.J., 2000. Monitoring mammal populations with line transect techniques in African forests. Journal of Applied Ecology, 37(2), pp.356-368.

Plumptre, A.J., Fuller, R. a., Rwetsiba, A., Wanyama, F., Kujirakwinja, D., Driciru, M., Nangendo, G., Watson, J.E.M. \& Possingham, H.P., 2014. Efficiently targeting resources to deter illegal activities in protected areas. Journal of Applied Ecology, 51, pp.714-725.

Podgórski, T., Ba, G., Jedrzejewska, B., Sönnichsen, L., Sniezko, S., Jedrzejewski, W. \& Okarma, H., 2013. Spatiotemporal behavioral plasticity of wild boar (Sus scrofa) under contrasting conditions of human pressure: primeval forest and metropolitan area. Journal of Mammalogy, 94(1), pp.109-119.

Qi, J., Shi, Q., Wang, G., Li, Z., Sun, Q., Hua, Y. \& Jiang, G., 2015. Spatial distribution drivers of Amur leopard density in northeast China. Biological Conservation, 191, pp.258-265.

R Development Core Team, 2012. R: A language and environment for statistical computing, Vienna: R Foundation for Statistical Computing.

Ramesh, T., Snehalatha, V., Sankar, K. \& Qureshi, Q., 2009. Food habits and prey selection of tiger and leopard in Mudumalai Tiger Reserve, Tamil Nadu, India. Journal of Science Transaction Environment and Technovation, 2(3), pp.170181.

Randrianandrianina, F.H., Racey, P.A. \& Jenkins, R.K.B., 2010. Hunting and consumption of mammals and birds by people in urban areas of western Madagascar. Oryx, 44(3), pp.411-415.

Ransom, J.I., Kaczensky, P., Lubow, B.C., Ganbaatar, O. \& Altansukh, N., 2012. A collaborative approach for estimating terrestrial wildlife abundance. Biological Conservation, 153, pp.219-226.

Reiczigel, J., Lang, Z., Rozsa, L. \& Tothmeresz, B., 2008. Measures of sociality: two different views of group size. Animal Behaviour, 75(2), pp.715-721.

Rezaei, H.R., Naderi, S., Chintauan-Marquier, I.C., Taberlet, P., Virk, A.T., Naghash, H.R., Rioux, D., Kaboli, M. \& Pompanon, F., 2010. Evolution and taxonomy of the wild species of the genus Ovis (Mammalia, Artiodactyla, Bovidae). Molecular phylogenetics and evolution, 54(2), pp.315-26.

Ripple, W.J., Estes, J. a, Beschta, R.L., Wilmers, C.C., Ritchie, E.G., Hebblewhite, M., Berger, J., Elmhagen, B., Letnic, M., Nelson, M.P., Schmitz, O.J., Smith, D.W., Wallach, A.D. \& Wirsing, A.J., 2014. Status and ecological effects of the world's largest carnivores. Science (New York, N.Y.), 343, p.1241484.

Robinson, J.G. \& Bennett, E.L., 2002. Will alleviating poverty solve the bushmeat crisis? Oryx, 36(04), p.332.

Rodgers, T.W. \& Janečka, J.E., 2013. Applications and techniques for non-invasive faecal genetics research in felid conservation. European Journal of Wildlife Research, 59(1), pp.1-16.

Rosenblatt, E., Creel, S., Becker, M.S., Merkle, J., Mwape, H., Schuette, P. \& Simpamba, T., 2016. Effects of a protection gradient on carnivore density and 
survival: an example with leopards in the Luangwa valley, Zambia. Ecology and Evolution, 6(11), pp.3772-3785.

Rovero, F., Marshall, A.R., Tridentino, M., Calepina, V., Ecological, U., Centre, M., Mountains, U., Park, N. \& Box, P.O., 2009. Camera trapping photographic rate as an index of density in forest ungulates. Journal of Applied Ecology, pp.10111017.

Rowcliffe, J.M., Carbone, C., Jansen, P.A., Kays, R. \& Kranstauber, B., 2011. Quantifying the sensitivity of camera traps: an adapted distance sampling approach. Methods in Ecology and Evolution, 2(5), pp.464-476.

Rowcliffe, J.M., Cowlishaw, G. \& Long, J., 2003. A model of human hunting impacts in multi-prey communities. Journal of Applied Ecology, 40(5), pp.872-889.

Rowcliffe, J.M., Field, J., Turvey, S.T. \& Carbone, C., 2008. Estimating animal density using camera traps without the need for individual recognition. Journal of Applied Ecology, 45, pp.1228-1236.

Rowcliffe, J.M., Kays, R., Carbone, C. \& Jansen, P.A., 2013. Clarifying assumptions behind the estimation of animal density from camera trap rates. The Journal of Wildlife Management, 77(5), p.876.

Rowcliffe, J.M., de Merode, E. \& Cowlishaw, G., 2004. Do wildlife laws work? species protection and the application of a prey choice model to poaching decisions. Proceedings. Biological sciences / The Royal Society, 271(1557), pp.2631-2636.

Rühe, F., Burmester, T. \& Ksinsik, M., 2007. Data for estimating eaten prey masses from Eurasian lynx Lynx lynx scats in Central and East Europe. Acta Theriologica, 52(3), pp.317-322.

Rühe, F., Ksinsik, M. \& Kiffner, C., 2008. Conversion factors in carnivore scat analysis: sources of bias. Wildlife Biology, 14(4), pp.500-506.

Sangay, T. \& Vernes, K., 2008. Human-wildlife conflict in the Kingdom of Bhutan: patterns of livestock predation by large mammalian carnivores. Biological Conservation, 141, pp.1272-1282.

Santos, J.L., Paschoal, A.M.O., Massara, R.L. \& Chiarello, A.G., 2014. High consumption of primates by pumas and ocelots in a remnant of the Brazilian Atlantic Forest. Brazilian Journal of Biology, 74(3), pp.632-641.

Sappington, J.M., Longshore, K.M. \& Thomson, D.B., 2005. Quantifying landscape ruggedness for animal habitat analysis: a case study using bighorn sheep in the Mojave Desert. Journal of Wildlife Management, 71(5), pp.1419-1426.

Schmidt, K., 2008. Behavioural and spatial adaptation of the Eurasian lynx to a decline in prey availability. Acta Theriologica, 53(1), pp.1-16.

Selvan, K.M., Veeraswami, G.G., Lyngdoh, S., Habib, B. \& Hussain, S.A., 2013. Prey selection and food habits of three sympatric large carnivores in a tropical lowland forest of the eastern Himalayan biodiversity hotspot. Mammalian Biology, 78, pp.296-303.

Sergio, F., Caro, T., Brown, D., Clucas, B., Hunter, J., Ketchum, J., McHugh, K. \& Hiraldo, F., 2008. Top predators as conservation tools: ecological rationale, assumptions, and efficacy. Annual Review of Ecology, Evolution, and Systematics, 39(1), pp.1-19.

Shams Esfandabad, B., Karami, M., Hemami, M.R., Riazi, B. \& Sadough, M.B., 2010. Habitat associations of wild goat in central Iran: Implications for conservation. European Journal of Wildlife Research, 56(6), pp.883-894. 
Sharbafi, E., 2011. Persian leopard (Panthera pardus saxicolor) diet assessment in Golestan National Park habitats. Islamic Azad University.

Shehzad, W., Nawaz, M.A., Pompanon, F., Coissac, E., Riaz, T., Shah, S.A. \& Taberlet, P., 2014. Forest without prey: livestock sustain a leopard Panthera pardus population in Pakistan. Oryx, 49(2), pp.248-253.

Shehzad, W., Riaz, T., Nawaz, M.A., Miquel, C., Poillot, C., Shah, S.A., Pompanon, F., Coissac, E. \& Taberlet, P., 2012. Carnivore diet analysis based on nextgeneration sequencing: Application to the leopard cat (Prionailurus bengalensis) in Pakistan. Molecular Ecology, 21, pp.1951-1965.

Sidhu, S., Raman, T.R.S. \& Mudappa, D., 2015. Prey abundance and leopard diet in a plantation and rainforest landscape, Anamalai Hills, Western Ghats. Current Science, 109(2), pp.323-330.

Sinclair, A.R.E., Fryxell, J.M. \& Caughley, G., 2006. Wildlife ecology, conservation and management 2nd edn, ed., Oxford: Blackwell Publishing Inc.

Singh, N.J. \& Milner-Gulland, E.J., 2011. Monitoring ungulates in Central Asia: current constraints and future potential. Oryx, 45(1), pp.38-49.

Smart, J.C.R., Ward, A.I. \& White, P.C.L., 2004. Monitoring woodland deer populations in the UK: An imprecise science. Mammal Review, 34(1), pp.99114.

Soofi, M., Ghoddousi, A., Hamidi, A.K., Ghasemi, B., Egli, L., Voinopol-Sassu, A.-J., Kiabi, B.H., Balkenhol, N., Khorozyan, I. \& Waltert, M., 2016. Precision and reliability of indirect population assessments for the Caspian red deer (Cervus elaphus maral). Submitted to Wildlife Biology.

South, N. \& Wyatt, T., 2011. Comparing illicit trades in wildlife and drugs: an exploratory study. Deviant Behavior, 32(6), pp.538-561.

Speicher, J., 2013. Population status and habitat use of the wild goat (Capra aegagrus) in Golestan National Park, Iran. MSc thesis Georg-August-University Göttingen.

Stander, P.E., Haden, P.J., Kaqece \& Ghau, 1997. The ecology of asociality in Namibian leopards. Journal of Zoology, 242, pp.343-364.

Stein, A.B., Athreya, V., Gerngross, P., Balme, G., Henschel, P., Karanth, U., Miquelle, D., Rostro, S., Kamler, J.F. \& Laguardia, A., 2016. Panthera pardus. The IUCN Red List of Threatened Species 2016: e.T15954A50659089. Available at: http://www.iucnredlist.org/details/15954/0 [Accessed July 7, 2016].

Stein, A.B., Bourquin, S.L. \& McNutt, J.W., 2015. Avoiding intraguild competition: leopard feeding ecology and prey caching in northern Botswana. African Journal of Wildlife Research, 45(2), pp.247-257.

Steinmetz, R., Srirattanaporn, S., Mor-Tip, J. \& Seuaturien, N., 2014. Can community outreach alleviate poaching pressure and recover wildlife in South-East Asian protected areas? Journal of Applied Ecology, 51(6), pp.1469-1478.

Stephanie, M. et al. 2001. Evaluating presence-absence models in ecology: the need to account for prevalence. - J. Appl. Ecol. 38: 921-931.

Stephens, D.W. \& Krebs, J.R., 1986. Foraging theory, Princton, New Jersey: Princton University Press.

Stone, R., 2015. Fragile ecosystems under pressure. Science (New York, N. Y.), 349(6252), pp.1046-1047.

Sunquist, M. \& Sunquist, F., 2009. Family Felidae. In D. E. Wilson \& R. A. Mittermeier, 
eds. Handbook of the Mammals of the World. Barcelona: Lynx Edicions, pp. 54168.

Suryawanshi, K.R., Veer Bhatnagar, Y. \& Mishra, C., 2012. Standardizing the doubleobserver survey method for estimating mountain ungulate prey of the endangered snow leopard. Oecologia, 169, pp.581-590.

Sutherland, W.J., 2006. Ecological census techniques: A handbook 2nd ed., Cambridge: Cambridge University Press.

Sutherland, W.J., 2000. The conservation handbook: research, management and policy, Oxford: Blackwell Publishing Inc.

Swallow, B., Buckland, S.T., King, R. \& Toms, M.P., 2016. Bayesian hierarchical modelling of continuous non-negative longitudinal data with a spike at zero: An application to a study of birds visiting gardens in winter. Biometrical Journal, 58(2), pp.357-371.

Taghdisi, M., Mohammadi, A., Nourani, E., Shokri, S., Rezaei, A. \& Kaboli, M., 2013. Diet and habitat use of the endangered Persian leopard (Panthera pardus saxicolor) in northeastern Iran. Turkish Journal of Zoology, 37, pp.554-561.

Tajbakhsh, H. \& Jamali, S., 1995. Nakhjeeran, Tehran, Iran: The Museum of Natural History and Wildlife of Iran (in Farsi).

Tatin, L., Darreh-Shoori, B.F., Tourenq, C., Tatin, D. \& Azmayesh, B., 2003. The last populations of the critically endangered onager Equus hemionus onager in Iran: urgent requirements for protection and study. Oryx, 37(04), pp.488-491.

Thomas, L., Buckland, S.T., Rexstad, E.A., Laake, J.L., Strindberg, S., Hedley, S.L., Bishop, J.R.B., Marques, T.A. \& Burnham, K.P., 2010. Distance software: design and analysis of distance sampling surveys for estimating population size. Journal of Applied Ecology, 47, pp.5-14.

Tortato, F.R., Layme, V.M.G., Crawshaw Jr., P.G. \& Izzo, T.J., 2015. The impact of herd composition and foraging area on livestock predation by big cats in the Pantanal of Brazil. Animal Conservation, 18, pp.539-547.

Treves, A. \& Naughton-Treves, L., 1999. Risk and opportunity for humans coexisting with large carnivores. Journal of Human Evolution, 36, pp.275-282.

Tsaparis, D., Katsanevakis, S., Ntolka, E. \& Legakis, A., 2009. Estimating dung decay rates of roe deer (Capreolus capreolus) in different habitat types of a Mediterranean ecosystem: an information theory approach. European Journal of Wildlife Research, 55(2), pp.167-172.

Urquiza-Hass, T., Peres, C.A. \& Dolman, P.M., 2011. Large vertebrate responses to forest cover and hunting pressure in communal landholdings and protected areas of the Yucatan Peninsula, Mexico. Animal Conservation, 14, pp.271-282.

Valdez, R., 2008. Ovis orientalis. IUCN Red List of Threatened Species 2008: e.T15739A5076068. Available at: http://dx.doi.org/10.2305/IUCN.UK.2008.RLTS.T15739A5076068.en [Accessed May 24, 2016].

Valipour, A., Plieninger, T., Shakeri, Z., Ghazanfari, H., Namiranian, M. \& Lexer, M.J., 2014. Traditional silvopastoral management and its effects on forest stand structure in northern Zagros, Iran. Forest Ecology and Management, 327, pp.221-230.

Vanthomme, H., Kolowski, J., Korte, L. \& Alonso, A., 2013. Distribution of a community of mammals in relation to roads and other human disturbances in 
Gabon, central Africa. Conservation Biology, 27(2), pp.281-291.

Vucetich, J.A., Vucetich, L.M. \& Peterson, R.O., 2012. The causes and consequences of partial prey consumption by wolves preying on moose. Behavioral Ecology and Sociobiology, 66(2), pp.295-303.

Wachter, B., Blanc, A.-S., Melzheimer, J., Höner, O.P., Jago, M. \& Hofer, H., 2012. An advanced method to assess the diet of free-ranging large carnivores based on scats. PLOS ONE, 7(6): e38066.

Waltert, M., Meyer, B., Shanyangi, M.W., Balozi, J.J., Qolli, S., Krischke, H. \& Mühlenberg, M., 2008. Foot surveys of large mammals in woodlands of western Tanzania. Journal of Wildlife Management, 72(3), pp.603-610.

Wang, S.W. \& Macdonald, D.W., 2009. Feeding habits and niche partitioning in a predator guild composed of tigers, leopards and dholes in a temperate ecosystem in central Bhutan. Journal of Zoology, 277(4), pp.275-283.

Wang, S.W. \& Macdonald, D.W., 2006. Livestock predation by carnivores in Jigme Singye Wangchuck National Park, Bhutan. Biological Conservation, 129(4), pp.558-565.

Watson, J.E.M., Dudley, N., Segan, D.B. \& Hockings, M., 2014. The performance and potential of protected areas. Nature, 515(7525), pp.67-73.

Waylen, K. a., McGowan, P.J.K. \& Milner-Gulland, E.J., 2009. Ecotourism positively affects awareness and attitudes but not conservation behaviours: a case study at Grande Riviere, Trinidad. Oryx, 43(3), pp.343-351.

Webbon, C.C., Baker, P.J., Cole, N.C. \& Harris, S., 2006. Macroscopic prey remains in the winter diet of foxes Vulpes vulpes in rural Britain. Mammal Review, 36(1), pp.85-97.

Weinberg, P., Jdeidi, T., Masseti, M., Nader, I., de Smet, K. \& Cuzin, F., 2008. Capra aegagrus. IUCN Red List of Threatened Species 2008: e.T3786A10076632.

Available at: http://dx.doi.org/10.2305/IUCN.UK.2008.RLTS.T3786A10076632.en [Accessed May 24, 2016].

Werner, Y.L., Rabiei, A., Saltz, D., Daujat, J. \& Baker, K., 2015. Dama mesopotamica. The IUCN Red List of Threatened Species 2015: e.T6232A22164332. Available at: http://dx.doi.org/10.2305/IUCN.UK.2015-4.RLTS.T6232A22164332.en [Accessed May 24, 2016].

Winkler, R., 2011. Why do ICDPs fail? The relationship between agriculture, hunting and ecotourism in wildlife conservation. Resource and Energy Economics, 33(1), pp.55-78.

Woodroffe, R., Frank, L.G., Lindsey, P.A., ole Ranah, S.M.K. \& Romañach, S., 2007. Livestock husbandry as a tool for carnivore conservation in Africa's community rangelands: a case-control study. Biodiversity and Conservation, 16, pp.12451260.

Woodroffe, R. \& Ginsberg, J., 1998. Edge effects and the extinction of populations inside protected areas. Science (New York, N.Y.), 280(5372), pp.2126-8.

Yoccoz, N.G., Nichols, J.D. \& Boulinier, T., 2001. Monitoring of biological diversity in space and time. Trends in Ecology and Evolution, 16(8), pp.446-453.

Zehzad, B., Kiabi, B.H. \& Madjnoonian, H., 2002. The natural areas and landscape of Iran: an overview. Zoology in the Middle East, 26(1), pp.7-10.

Zendehdel, K., Rademaker, M., De Baets, B. \& Van Huylenbroeck, G., 2010. 
Environmental decision making with conflicting social groups: A case study of the Lar rangeland in Iran. Journal of Arid Environments, 74(3), pp.394-402.

Zero, V.H., Sundaresan, S.R., O’Brien, T.G. \& Kinnaird, M.F., 2013. Monitoring an endangered savannah ungulate, Grevy's zebra Equus grevyi: choosing a method for estimating population densities. Oryx, 47(3), pp.410-419.

Zohary, M., 1973. Geobotanical foundations of the Middle East Vols. 1 \&., Stuttgart, Germany: Fischer. 


\section{Acknowledgements}

Firstly, I would like to thank to my supervisor Matthias Waltert for giving me the opportunity to do my PhD in Germany. I appreciate all the advice and support throughout the last four years. I have learnt a lot and have had great experiences and opportunities. I appreciate the support from my other supervisors Michael Mühlenberg and Niko Balkenhol as well.

I would also like to acknowledge and thank Igor Khorozyan and Bahram H. Kiabi for all their supports, feedbacks and advices on every stage of my PhD. Mahmood Soofi you have been immensely helpful both during the fieldwork in Iran and also in the last half of my PhD with analysis and writing, thank you! Tanja Lumetsberger, Julian Speicher and Lukas Egli, this project benefitted a lot from your sincere work in the best possible way. Christian Kiffner assisted with developing ideas and preparation of the proposal related to this project. I appreciate Lisa Denmead's help in reviewing chapters of my dissertation.

This project would have not been possible without a huge amount of help from the colleagues in Iran. Amirhossein Kh. Hamidi, thanks for all the days in the field and advices on the study design and interpretation of the results. A great number of volunteers and friends $(n=36$ !) made fieldwork of this project some of the best days of my life. I would like to thank them all, especially Amin, Siavash, Yasaman, Khashayar, Mehdi, Alborz, Ali F. and Azar, as well as, Ali Q., Ashkan, Bahman, Edris, Hamed, Jeiran, Kamran, Mobin, Niloufar and Taher. Being a part of such a large team has only been possible through everyone being so great!

R. Rostaghi and J. Selyari former managers of Golestan National Park kindly assisted with administration of the fieldwork. Also, more than 16 rangers helped me with conduction of around 10 months of field surveys. I thank them all, especially J. Hassanzadeh, who has been always so enthusiastic in contributing to this work. Also, nine local guides helped me during the fieldwork. Your ecological knowledge about the park is invaluable and I learnt a lot from you. 
This research was possible due to financial support from German Academic Exchange Service (DAAD) and Panthera's Kaplan Graduate Award. Iranian Department of Environment and its Golestan provincial office administrated the required permits related to this work.

Michelle, thanks for being there and supporting me during the months of my PhD. Most importantly, my family (Feraidoon, Neshat and Siavash), I am super lucky to have you around me. Your unconditional support and encouragement helped me throughout the PhD and everything before. I am and will always be grateful! Finally, grandma and Ali, thanks for always being so kind and supportive with my life. It means a lot to me! 


\section{Declaration}

Specific chapter contributions

I am the first author of the manuscripts included as chapter three, five, six and seven of this thesis in which I took part in all aspects of study design, data collection and statistical analysis and wrote the majority of the manuscript. I personally contributed to the study design, data collection, statistical analyses, and a significant amount of writing and editing of chapters two and four. I helped supervise the MSc research, which was the basis for chapter two.

I, Arash Ghoddousi, hereby declare that I am the author of this dissertation entitled 'Prey preferences of the Persian leopard and trophic competition with human hunters in Iran'. All references and data sources that were used in this dissertation have been appropriately acknowledged. Furthermore, I declare that this work has not been submitted elsewhere in any form as part of another dissertation procedure.

Göttingen, $14^{\text {th }}$ July, 2016

(Arash Ghoddousi) 
